\title{
ASOCIACIÓN DE UNA RESPUESTA INFLAMATORIA CON LA DINÁMICA DE LAS FLUCTUACIONES DE LA FRECUENCIA CARDIACA DURANTE EL TRABAJO DE PARTO A TÉRMINO Y DE BAJO RIESGO
}

\author{
Tesis que presenta \\ M. en C. José Javier Reyes Lagos \\ Para obtener el grado de \\ Doctor en Ciencias (Ingeniería Biomédica)
}

\author{
Asesores: Dr. Miguel Ángel Peña Castillo \\ Dr. Gustavo Pacheco López \\ Jurado calificador: \\ Presidente Dr. Lenin Pavón Romero \\ Secretaria Dra. Mercedes Jatziri Gaitán González \\ Vocal Dr. Benjamín Domínguez Trejo \\ Vocal Dr. Miguel Ángel Peña Castillo \\ Vocal Dra. Claudia Lerma González
}

Ciudad de México a 20 de julio del 2017 


\title{
DEDICATORIA Y AGRADECIMIENTOS
}

\author{
Para mi mamá Luz Mireya Reyes Lagos, por su apoyo incondicional y \\ amor a lo largo de toda mi vida
}

En primer lugar, me gustaría agradecer a mi coasesor de tesis, el Dr. Gustavo Pacheco López, por haber enriquecido ampliamente esta investigación con sus conocimientos, experiencia y orientación en el área de neurociencias y por haber sido la persona que me motivó a realizar una estancia de investigación en el extranjero. De igual manera, agradezco el apoyo incondicional y amistad de mí asesor, el Dr. Miguel Ángel Peña Castillo, que desde la licenciatura ha depositado su confianza en mí, y de igual manera me ha orientado con su vasto conocimiento en el área de la ingeniería biomédica.

Quiero también agradecer al Dr. Juan Carlos Echeverría Arjonilla por haber estado al pendiente de esta investigación desde un inicio hasta el final. Así como sus excelentes ideas para la constante mejora del proyecto y la motivación brindada.

Agradezco al personal adscrito al Laboratorio de Psicoinmunología del Instituto Nacional de Psiquiatría por haber contribuido en esta investigación. También me encuentro muy agradecido con el personal de la Universidad de Essen, Alemania quienes amablemente me acogieron a mi llegada y me proporcionaron todos los materiales y recursos para realizar mi investigación, así como también con el personal médico, de enfermería y de laboratorio clínico del Centro de Investigación Materno Infantil del Grupo de estudios al nacimiento (CIMIGen) por su tan buena disposición y apoyo hacia este proyecto.

Agradezco el apoyo y cariño de mis tías Marisa Reyes, Consuelo Figueroa y Arcelia Reyes, así como el de mis amigos Eric Abarca, Alberto Gallo, Irvin Aguilar y Lizeth Ávila. Finalmente, agradezco al Consejo Nacional de Ciencia y Tecnología (CONACYT), por la beca de estudios de posgrado que me fue otorgada (CVU/Número de beca 381983/253449). 


\section{RESUMEN}

Los mecanismos precisos del inicio del trabajo de parto a término aún no son conocidos en su totalidad; sin embargo, algunos estudios en humanos han revelado el papel que juegan las citoquinas en el inicio y mantenimiento del mismo, vinculándolo como un proceso inflamatorio que parece coincidir con el retiro funcional de la progesterona al final del embarazo. Hallazgos previos sugieren una posible relación entre la actividad del sistema nervioso autónomo y una respuesta inflamatoria durante el trabajo de parto. Un método no invasivo para evaluar indirectamente la actividad del sistema nervioso autónomo es por medio del análisis de las fluctuaciones de la frecuencia cardiaca (FFC), que incluso ha sido considerado como una importante "ventana" para entender las interacciones neuroinmunes que involucran al nervio vago. Durante mi trabajo previo de maestría encontré evidencia que sugiere una posible relación entre la actividad autonómica y una respuesta antiinflamatoria durante el trabajo de parto. Esto se identificó a través de los exponentes de escalamiento fractal del corto plazo $\alpha_{1}, \alpha_{1 \text { (MAG) }}$ (de magnitud) y $\alpha_{1 \text { (SIGN) }}$ (de signo) por el método de análisis de fluctuaciones sin tendencia (DFA, por sus siglas en inglés).

Considerando que el trabajo de parto a término es un estado proinflamatorio desencadenado por un estímulo estéril, y que a su vez éste involucra una intensa actividad muscular, gasto energético y daño tisular, entonces hipoteticé que, en esta etapa, el análisis de las FFC reflejará una respuesta autonómica cardiaca con participación colinérgica como mecanismo homeostático.

Con este marco de referencia, el objetivo de la presente investigación fue asociar una respuesta inmune con la dinámica de las FFC durante el trabajo de parto a término y de bajo riesgo, involucrando la acción de una ruta colinérgica y la cuantificación de citoquinas proinflamatorias/antiinflamatorias. Para lograr este objetivo, en primer lugar, se validó en un modelo experimental en roedores si los parámetros no lineales de las FFC son sensibles para identificar un proceso de inflamación sistémico (endotoxemia). Posteriormente, se exploró en dicho modelo los posibles efectos antiinflamatorios de la oxitocina, una hormona relevante durante el trabajo de parto, a través del análisis de las FFC y la respiración derivada del electrocardiograma. Por otra parte, y en un contexto clínico, se analizaron longitudinalmente las citoquinas proinflamatorias/antiinflamatorias en un grupo de mujeres en tercer trimestre de gestación y posteriormente en el trabajo de parto activo. Finalmente se buscaron correlaciones entre parámetros de las FFC y los 
marcadores inmunológicos, así como también se implementaron herramientas de reconocimiento de patrones para futuras aplicaciones diagnósticas.

De un modelo animal desarrollado durante el presente trabajo puedo resumir lo siguiente a partir de mis hallazgos: se encontró que la endotoxemia inducida por la administración intraperitoneal de lipopolisacárido (LPS) produjo que las FFC en el largo plazo se tornaran más anticorrelacionadas (como es indicado por valores de $\alpha_{1(\mathrm{SIGN})}$ más cercanos a 0). Además, la endotoxemia estuvo acompañada de taquicardia, taquipnea, pérdida de la dinámica fractal del ritmo cardiaco, disminución en parámetros espectrales de las FFC, baja variabilidad cardiaca, cambios en la temperatura periférica, y conducta letárgica. En contraste, la mayoría de los cambios en estos parámetros fueron amortiguados en las ratas a las que se les administró oxitocina subcutánea, posiblemente como resultado de un acoplamiento autonómico cardiorrespiratorio con influencias colinérgicas debido a la administración concomitante de oxitocina exógena durante la endotoxemia inducida por LPS.

Mis resultados en la investigación en mujeres embarazadas sugieren que el trabajo de parto es un proceso inflamatorio caracterizado por la disminución de varios miembros de la familia de citoquinas IL-10. Además, la menor anticorrelación en las FFC (indicado por valores de $\alpha_{1 \text { (SIGN) }}$ cercanos a 0.5 ) y mayor variabilidad total en las FFC (indicado por valores elevados del SDNN) en el trabajo de parto parecen reflejar una interacción distinta entre las ramas simpática y parasimpática del control autonómico cardiaco en comparación con el tercer trimestre de embarazo.

De manera general con todos estos hallazgos concluyo que el trabajo de parto es un proceso inflamatorio acompañado de una posible influencia concomitante de las ramas simpática y parasimpática del control autonómico, dicho mecanismo podría perdurar hasta resolver el proceso inflamatorio, es decir posterior al nacimiento. Por último, el hallazgo de que diversas citoquinas, principalmente el SCD30 y los miembros de la familia de la IL-10 estén correlacionadas con parámetros vagales de la FFC, sugiere un vínculo funcional entre una inflamación sistémica y la regulación autonómica en el trabajo de parto. 


\section{LISTA DE ABREVIATURAS}

$\alpha_{1}$

$\alpha_{1 \text { (SIGN) }}$

$\alpha_{1(\mathrm{MAG})}$

$\alpha_{2}$

$\alpha 7 n A C H R$

ACh

ApEn

APRIL / TNFSF13

ASR

ATP

AUC

BAFF / TNFSF13B

Chitinase-3-like 1

CIMIGen

CRP

CTL

DFA

EDR

ELISA

FFC
Exponente de escalamiento fractal de corto plazo (alfa uno)

Exponente de escalamiento fractal de signo (alfa uno de signo)

Exponente de escalamiento fractal de magnitud (alfa uno de magnitud)

Exponente de escalamiento fractal de largo plazo (alfa dos)

Receptor nicotínico de acetilcolina alfa siete

Acetilcolina

Entropía aproximada (Approximate entropy)

Miembro 13 de la superfamilia de ligandos de factores de necrosis tumoral

Arritmia sinusal respiratoria

Adenosina trifosfato

Área bajo la curva (Area under curve)

Miembro 13b de la superfamilia de ligandos de factores de necrosis tumoral

Quitinasa tipo 3-1

Centro de Investigación Materno Infantil del grupo de estudios al nacimiento

Proteína $\mathrm{C}$ reactiva ( $C$-reactive protein)

Células T citotóxicas (Cytotoxic T cells)

Análisis de fluctuaciones sin tendencia (Detrended fluctuation analysis)

Respiración derivada del electrocardiograma (ECGderived respiration)

Ensayo por inmunoadsorción ligado a enzimas (Enzyme-Linked ImmunoSorbent Assay)

Fluctuaciones de la frecuencia cardiaca 
FUM

G-CSF

GM-CSF

gp130 / slL-6R $\beta$

HF

HF/LF

$\mathrm{HHA}$

IFN- $\alpha 2$

IFN- $\beta$

IFN-Y

IL-XX

LF

LIGHT / TNFSF14

LPS

MCP-1

MHR

MIP-1

MMP-

MSA

$N F-\kappa \beta$

NMDV

NTS

Ox

PG
Fecha de última menstruación

Factor estimulante de colonias de granulocitos (Granulocyte colony-stimulating factor)

Factor estimulante de colonias de granulocitos y monocitos (Granulocyte Macrophage ColonyStimulating Factor)

Receptor soluble de IL-6 $\beta$

Altas frecuencias (High frequency)

Razón entre bajas y altas frecuencias

Eje hipotalámico-hipofisario-adrenal

Interferón alfa2

Interferón beta

Interferón gamma

Interleucina -XX (Ejemplo IL-10, Interleucina-10, etc.)

Bajas frecuencias (Low frequency)

Miembro 14 de la superfamilia de ligandos de factores de necrosis tumoral

Lipopolisacárido

Proteína quimioatrayente de monocitos 1 (Monocyte Chemoattractant Protein-1)

Frecuencia cardiaca media (Mean heart rate)

Proteína inflamatoria de macrófagos (Macrophage Inflammatory Proteins)

Metaloproteinasas de la matriz extracelular

Análisis de magnitud y signo (Magnitude and sign analysis)

Factor nuclear potenciador de las cadenas ligeras kappa de las células beta activadas (nuclear factorkарра $\beta$ )

Núcleo motor dorsal del vago

Núcleo del tracto solitario

Oxitocina

Prostaglandinas 
PNN50

PSD

RCA

$\mathrm{R}-\mathrm{R}$

RMS

RMSSD

SampEn

sCD30 / TNFRSF8

sCD163

SDNN/SDRR

sIL-6Ra

SNA

SNC

sTNF-R1

sTNF-R2

Th1

Th2

TNF- $\alpha$

TSLP

TWEAK / TNFSF12

VLF
Porcentaje de intervalos R-R consecutivos que se diferencian en más de cincuenta milisegundos

Densidad de potencia espectral (Power spectral density)

Respuesta colinérgica antinflamatoria

Distancia entre un pico $R$ a otro pico $R$

Valor cuadrático medio (root mean square)

Raíz cuadrada del promedio de la suma de las diferencias cuadráticas entre intervalos R-R adyacentes

Entropía muestra (Sample entropy)

Miembro 8 de la superfamilia de ligandos de factores de necrosis tumoral

Miembro de la familia de receptores scavenger rico en cisteína (Forma soluble)

Desviación estándar de los valores NN o R-R

Receptor soluble de IL-6a

Sistema nervioso autónomo

Sistema nervioso central

Receptor soluble de factor de necrosis tumoral R1

Receptor soluble de factor de necrosis tumoral R2

Linfocitos T helper uno

Linfocitos T helper dos

Factor de necrosis tumoral alfa (Tumor necrosis factor alpha)

Linfopoyetina estromal tímica

Miembro 12 de la superfamilia de ligandos de factores de necrosis tumoral

Muy bajas frecuencias (Very low frequency) 


\section{ÍNDICE}

Prólogo

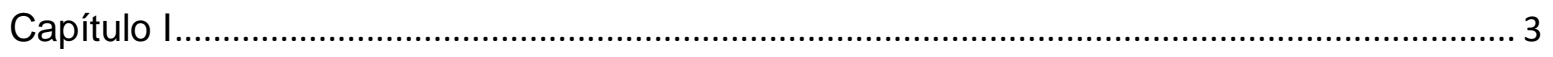

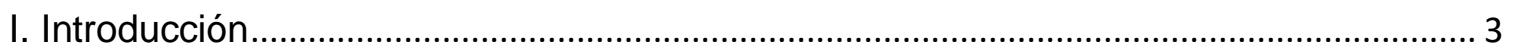

1.1 El trabajo de parto y su desencadenamiento: una perspectiva endocrinológica e inmunológica ............................................................................................................. 3

1.2 La homeostasis energética durante el trabajo de parto............................................. 10

1.3 La respuesta colinérgica antiinflamatoria (RCA) durante el trabajo de parto.......... 13

$1.4 \mathrm{El}$ análisis de las fluctuaciones de la frecuencia cardiaca (FFC) ............................ 18

$1.5 \mathrm{El}$ análisis de las FFC y su vinculación con procesos inflamatorios........................ 19

1.6 La oxitocina como agente antiinflamatorio............................................................... 25

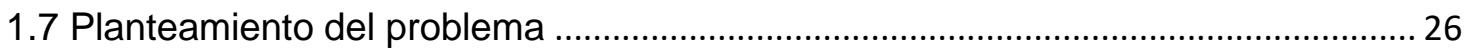

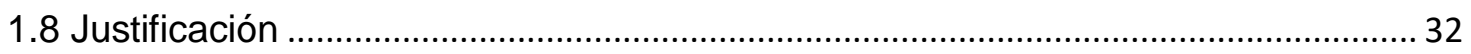

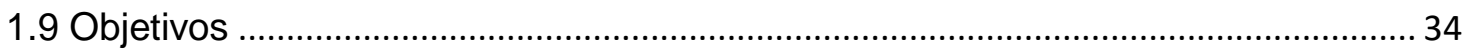

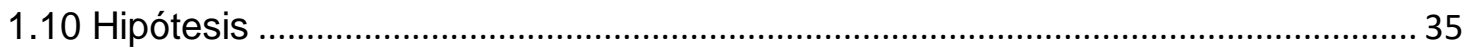

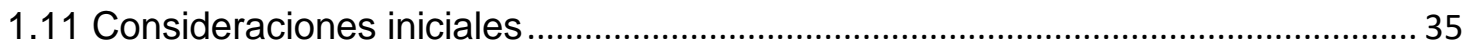

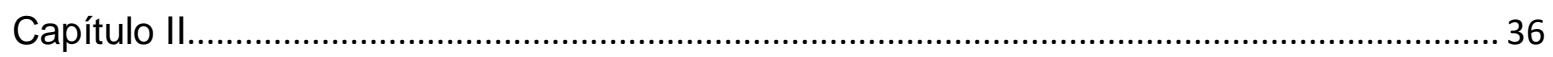

2. Técnicas de análisis lineal y no lineal de las FFC y sistemas de adquisición...............36

2.1. Preprocesamiento del ECG y detección de la onda $R$........................................... 36

2.2. Técnicas lineales del análisis de las FFC ............................................................ 40

2.3 Técnicas no lineales del análisis de las FFC......................................................... 42

2.4. Respiración derivada del electrocardiograma (EDR) ............................................. 54

2.5. Sistema de adquisición radiotelemétrico de datos fisiológicos................................. 56

2.6. Sistema de adquisición de señales fisiológicas materno-fetal portátil .....................58

2.7. Sistema de inmunoensayos múltiples por bioluminicencia acoplada a citometría de

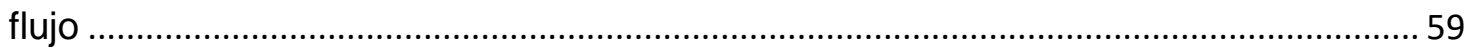

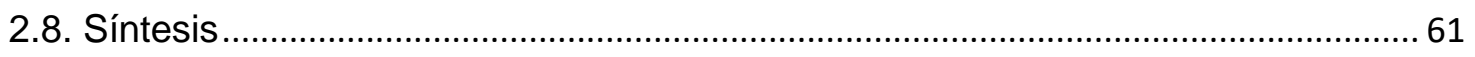

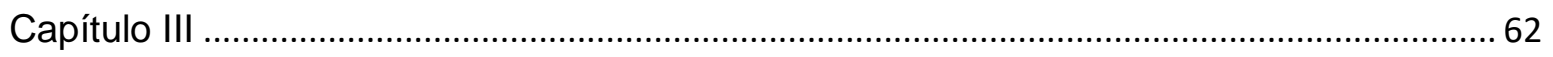

3. Estudio I: Efecto de la oxitocina exógena en la dinámica cardiaca de ratas endotoxémicas ............................................................................................................ 62

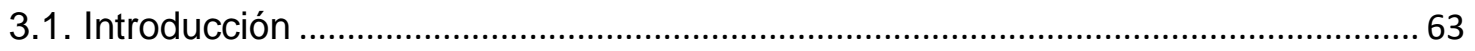




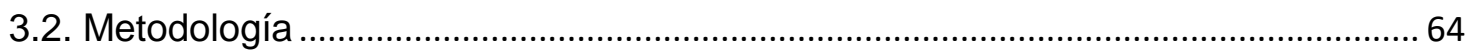

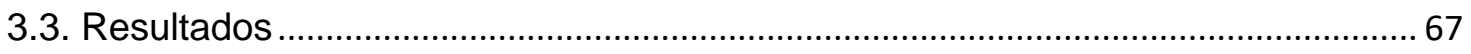

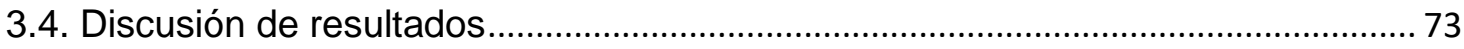

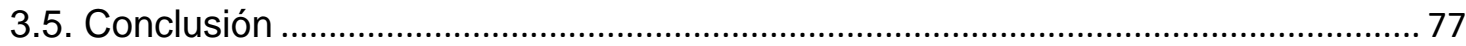

4. Estudio II: El rol de la oxitocina en la actividad cardiorrespiratoria de ratas

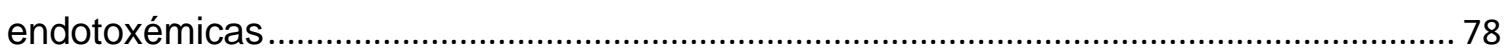

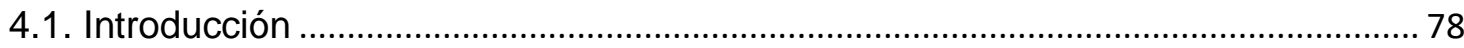

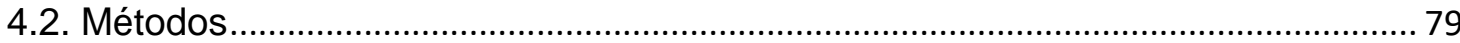

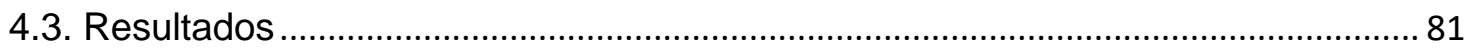

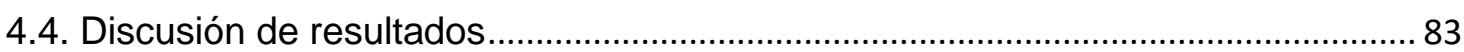

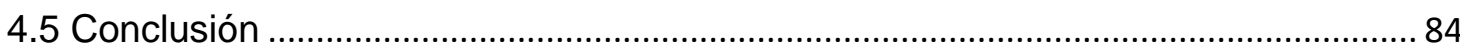

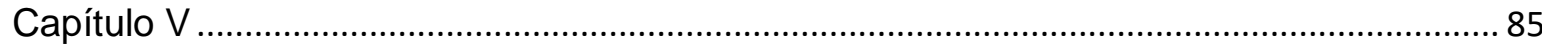

5. Estudio III: Reducción de las concentraciones séricas maternas de la familia de las citoquinas IL-10 en el trabajo de parto activo ....................................................................... 85

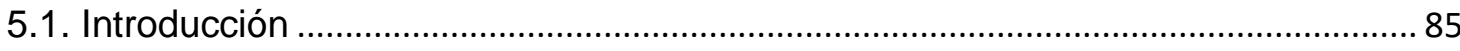

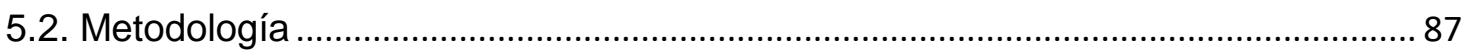

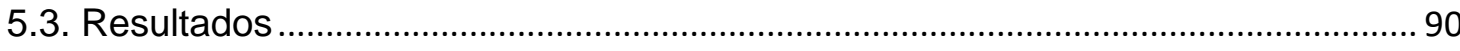

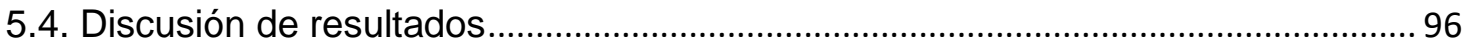

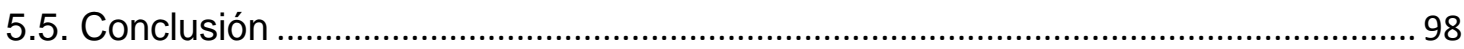

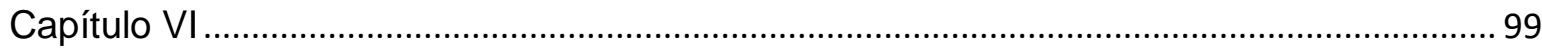

6. Estudio VI: Análisis de la dinámica cardiaca y su correlación con marcadores inflamatorios en el trabajo de parto activo ............................................................................. 99

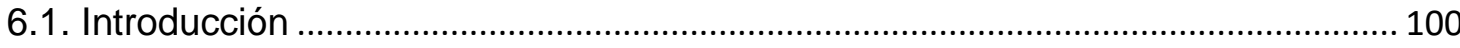

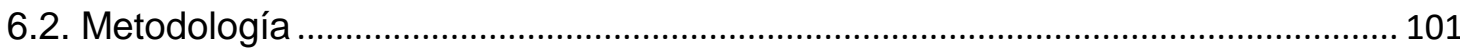

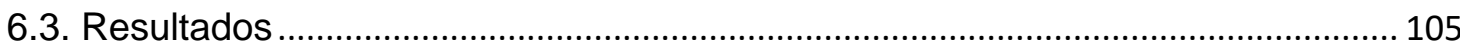

6.4. Discusión de resultados....................................................................................... 117

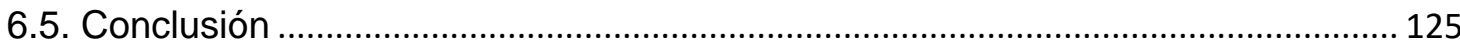

Conclusiones generales ......................................................................................... 126

Apéndice A. Implantación dorsal de los transmisores telemétricos. .................................... 131

Apéndice B. Carta de consentimiento informado ............................................................... 138

Apéndice C. Toma de muestra sanguínea, centrifugación y conservación de las muestras 
Apéndice D. Análisis estadísticos complementarios......................................................... 142

Apéndice E. Publicaciones y presentaciones en eventos académicos relacionadas........ 146

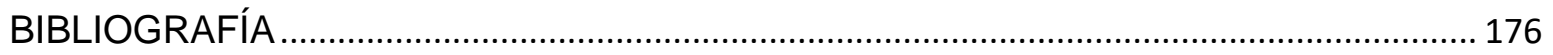




\section{Prólogo}

Esta tesis la estructuré de la siguiente manera: el capítulo I "Introducción" proporciona al lector el estado del arte de la aplicación del análisis de las fluctuaciones de la frecuencia cardiaca en diversos procesos inflamatorios (como por ejemplo la endotoxemia), así como los fundamentos fisiológicos, endocrinológicos e inmunológicos del trabajo de parto necesarios para concebirlo como un proceso complejo. En el capítulo II "Técnicas de análisis lineal y no lineal de las FFC y sistemas de adquisición" se describen aspectos relevantes de la tesis desde un punto de vista técnico y matemático, que involucra la detección de picos $\mathrm{R}$ del electrocardiograma, el preprocesamiento de las series de tiempo $R-R$, la descripción del análisis lineal y no lineal de las fluctuaciones cardiacas, también se incluye una breve descripción de los sistemas de adquisición de biopotenciales y la técnica de cuantificación de marcadores inflamatorios.

Consecutivamente, desde el capítulo III al capítulo VI presento los estudios realizados a largo de mi trabajo de tesis doctoral, en donde utilicé el análisis lineal y no lineal de las fluctuaciones de la frecuencia cardiaca para extraer información sobre la regulación cardiovascular en un contexto experimental preclínico y otro clínico exploratorio. En estos términos, cada uno de estos capítulos funge como un estudio individual; sin embargo, éstos se encuentran interrelacionados con el propósito de cumplir el objetivo general de esta investigación. La estructura de la tesis se encuentra resumida en el diagrama de flujo de la Figura 0.

Los estudios citados en el capítulo III titulado "Efecto de la oxitocina exógena en la dinámica cardiaca de ratas endotoxémicas" y IV "EI rol de la oxitocina en la actividad cardiorrespiratoria de ratas endotoxémicas" fueron desarrollados en su totalidad en el Instituto de Psicología Médica e Inmunobiología del Comportamiento de la Universidad Duisburg-Essen, Essen, Alemania. Para estos estudios utilicé un modelo animal en ratas, con el propósito de validar si diversos parámetros de las fluctuaciones de la frecuencia cardiaca eran sensibles para identificar una respuesta inflamatoria prototípica, provocada por un cuadro de inflamación inducida por la aplicación de un lipopolisacárido (LPS). Así mismo, al ser la oxitocina una hormona de suma relevancia durante el trabajo de parto, se exploró el efecto de la oxitocina sobre la dinámica de las fluctuaciones cardiacas y la respiración derivada del electrocardiograma durante la endotoxemia, es importante 
subrayar que la oxitocina ha sido considerada por algunos autores como un potencial agente antiinflamatorio y modulador colinérgico [1], [2].

Los estudios vinculados al capítulo $V$ titulado "Reducción de concentraciones séricas maternas de la familia de la IL-10 en el trabajo de parto activo" y VI "Análisis de la dinámica cardiaca y su correlación con marcadores inflamatorios en el trabajo de parto activo" fueron desarrollados totalmente en la CDMX, México, en colaboración con el Centro de Investigación Materno Infantil del Grupo de estudios al nacimiento (CIMIGen) y el Laboratorio de Psicoinmunología del Instituto Nacional de Psiquiatría "Ramón de la Fuente Muñiz". En estos capítulos realicé un estudio longitudinal en mujeres en el tercer trimestre de embarazo y consecuentemente en el trabajo de parto activo; se cuantificaron diversos perfiles de citoquinas y se estimaron parámetros de las fluctuaciones de la frecuencia cardiaca. Posteriormente busqué correlaciones lineales a través de análisis univariado y multivariado y se aplicaron técnicas de reconocimiento de patrones para futuras aplicaciones diagnósticas. Por último, en el capítulo VII muestro las conclusiones generales de todo el trabajo de tesis doctoral en conjunto y finalmente procedo a plantear perspectivas a futuro del trabajo de investigación.

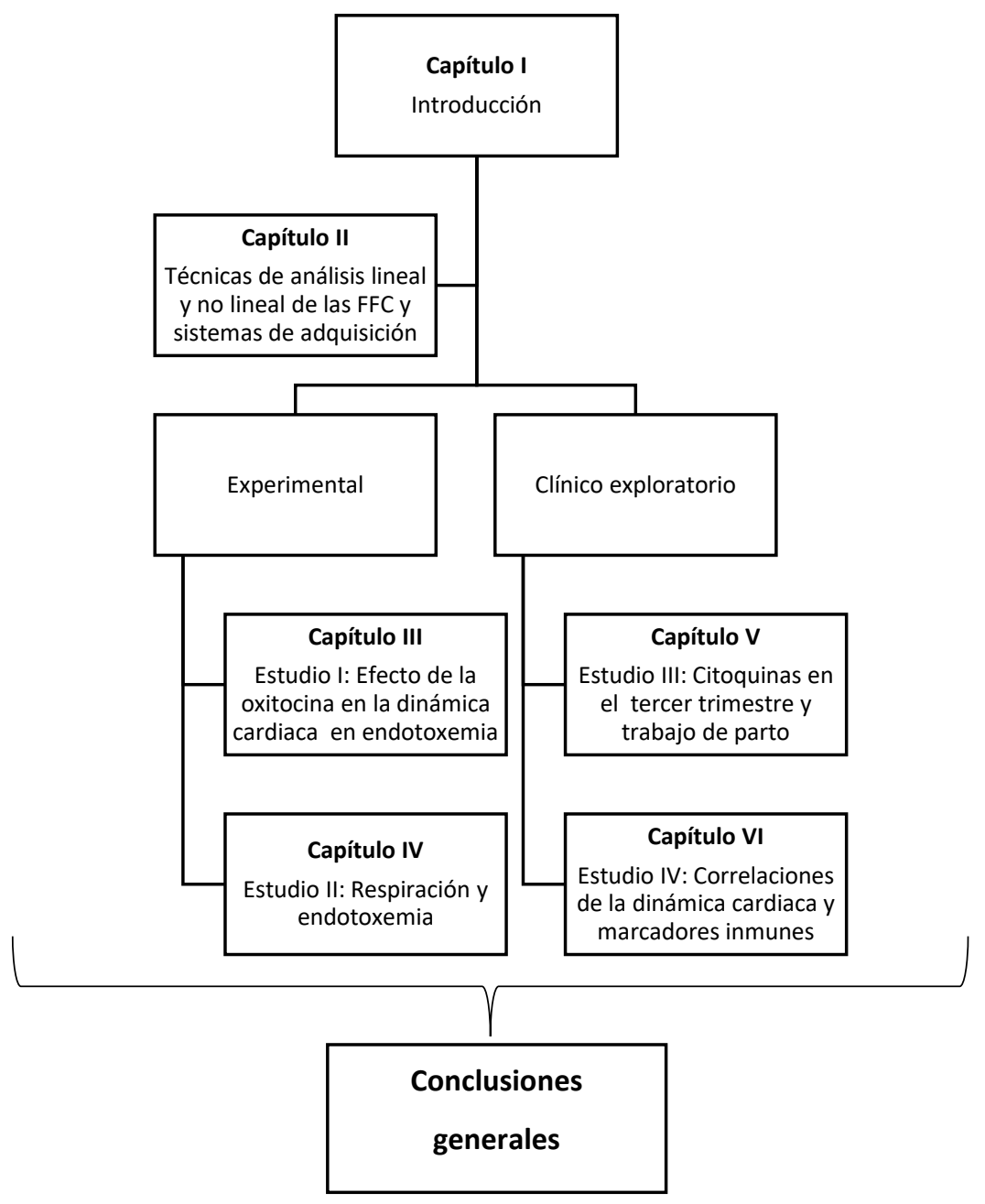

Figura 0. Estructura de la tesis en capítulos. 


\section{Capítulo I}

\section{Introducción}

Resumen: Este capítulo pretende introducir al lector a entender el proceso de inicio del trabajo de parto desde una perspectiva fisiológica, endocrinológica e inmunológica, así como también a comprender la vinculación del análisis de las fluctuaciones de la frecuencia cardiaca (FFC) con procesos inflamatorios sistémicos. También aporta evidencia de la regulación autonómica cardiaca que se podría manifestar en el trabajo de parto a través de la llamada vía o respuesta colinérgica antiinflamatoria.

Primero, la sección 1.1 presenta la definición fisiológica del trabajo de parto y las aproximaciones endocrinológicas e inmunológicas que explican su desencadenamiento. Posteriormente la sección 1.2 aborda la homeostasis energética del trabajo de parto, en la sección 1.3 se discute acerca de la potencial participación de la vía colinérgica antiinflamatoria durante el trabajo de parto, la sección 1.4 introduce al lector de una manera general al análisis de las FFC y conjuntamente en la sección 1.5 se hace una revisión de la vinculación de los algunos índices de las FFC con procesos inflamatorios sistémicos. Debido a la importancia de la oxitocina durante el trabajo de parto, en la sección 1.6 se indaga su rol como potencial agente antiinflamatorio. Además, el planteamiento del problema, la justificación, los objetivos generales, específicos y la hipótesis de la tesis se definen en las secciones 1.7 a 1.10 respectivamente. Finalmente, el presente capítulo cierra con algunas consideraciones iniciales a manera de síntesis en la sección 1.11.

Es pertinente mencionar que parte de este desarrollo teórico ha sido publicado como: Reyes-Lagos JJ, Echeverría JC, Peña-Castillo MA, Montiel-Castro A, Pacheco-López G. Physiological, Immunological and Evolutionary Perspectives of Labor as an Inflammatory Process. Advances in Neuroimmune Biology, 2014; 5(2), 75-89. doi: 10.3233/NIB-140085. Una copia de dicho artículo se encuentra en el Apéndice $E$.

\subsection{El trabajo de parto y su desencadenamiento: una perspectiva endocrinológica e inmunológica}

El trabajo de parto es un proceso fisiológico por el cual el feto es expulsado del útero hacia el mundo externo. Éste se define como un aumento en la actividad miometrial o, más precisamente, un cambio en el patrón de contractilidad miometrial de contracciones irregulares (de poca duración, de baja frecuencia y poca intensidad) a contracciones regulares (de mayor duración, alta frecuencia, mayor intensidad), dando como resultado el borramiento y la dilatación del cuello uterino [3]. En el parto normal parece existir una relación temporal dependiente entre los cambios bioquímicos en el tejido conectivo del cuello uterino, que usualmente precede a las contracciones uterinas y la dilatación cervical. Todos estos eventos suelen ocurrir antes de la ruptura espontánea de las membranas [4]. 
La duración media del embarazo humano es de 280 días (40 semanas) a partir del primer día posterior a la fecha de última menstruación (FUM). El trabajo de parto a término se produce entre las 37.0 a 42.0 semanas de gestación [5]. En este sentido, el trabajo de parto a término es considerado fisiológicamente como la liberación natural y espontánea de los efectos inhibitorios presentes en el embarazo sobre el miometrio [6]. De hecho, se sabe que tejido miometrial quiescente de úteros a término en solución isotónica, presentan efectos contráctiles vigorosos y espontáneos sin necesidad de estímulos adicionales [6], [7]. In vivo, sin embargo, es probable que ambos mecanismos sean importantes.

La regulación de la actividad uterina durante el embarazo y el trabajo de parto puede dividirse en cuatro fases fisiológicas distintas [8]. Durante el embarazo, el útero se mantiene en estado de quiescencia funcional (fase 0) a través de la acción de varios inhibidores, incluyendo la progesterona, la prostaciclina, la relaxina, el óxido nítrico, el péptido relacionado con la hormona paratiroidea, la hormona liberadora de corticotropina, el lactógeno placentario humano, el péptido relacionado con el gen de la calcitonina, la adrenomedulina y el péptido intestinal vasoactivo. Antes del término, el útero sufre una activación (fase 1) y una estimulación (fase 2). La activación se produce en respuesta a las uterotropinas, incluyendo el estrógeno, y se caracteriza por el aumento de la expresión de una serie de contracciones asociadas a proteínas (incluyendo los receptores miometriales para las prostaglandinas y la oxitocina), la activación de ciertos canales iónicos y un aumento de la conexina 43 (un componente clave de las uniones intercelulares gap). Un aumento de las uniones gap entre las células miometriales adyacentes resulta en la sincronía eléctrica del miometrio y permite la coordinación eficaz de las contracciones uterinas. Una vez activado, el útero puede ser estimulado al contraerse por la acción de las uterotoninas tales como la oxitocina y las prostaglandinas. La involución del útero después del parto ocurre en la fase 3 y está mediada principalmente por la oxitocina [9].

Complementariamente a este conocimiento, algunos estudios en animales han sugerido la importancia del feto en el control y desencadenamiento del trabajo de parto [10], [11]. Éstos revelan que la activación del eje hipotalámico-hipofisario-adrenal (HHA) fetal produce un aumento en la producción del cortisol suprarrenal. De esta manera, el cortisol fetal estimula la actividad de la enzima 17 a-hidroxilasa / 17, 20-liasa (CYP) placentaria, que a su vez cataliza la conversión de pregnenolona en estradiol (Figura 1.1). 
La disminución de los niveles de progesterona acompañada del aumento de los estrógenos al final del embarazo, modifican la síntesis de las prostaglandinas (PG) uterinas y por ende favorece al desencadenamiento del trabajo de parto [5].

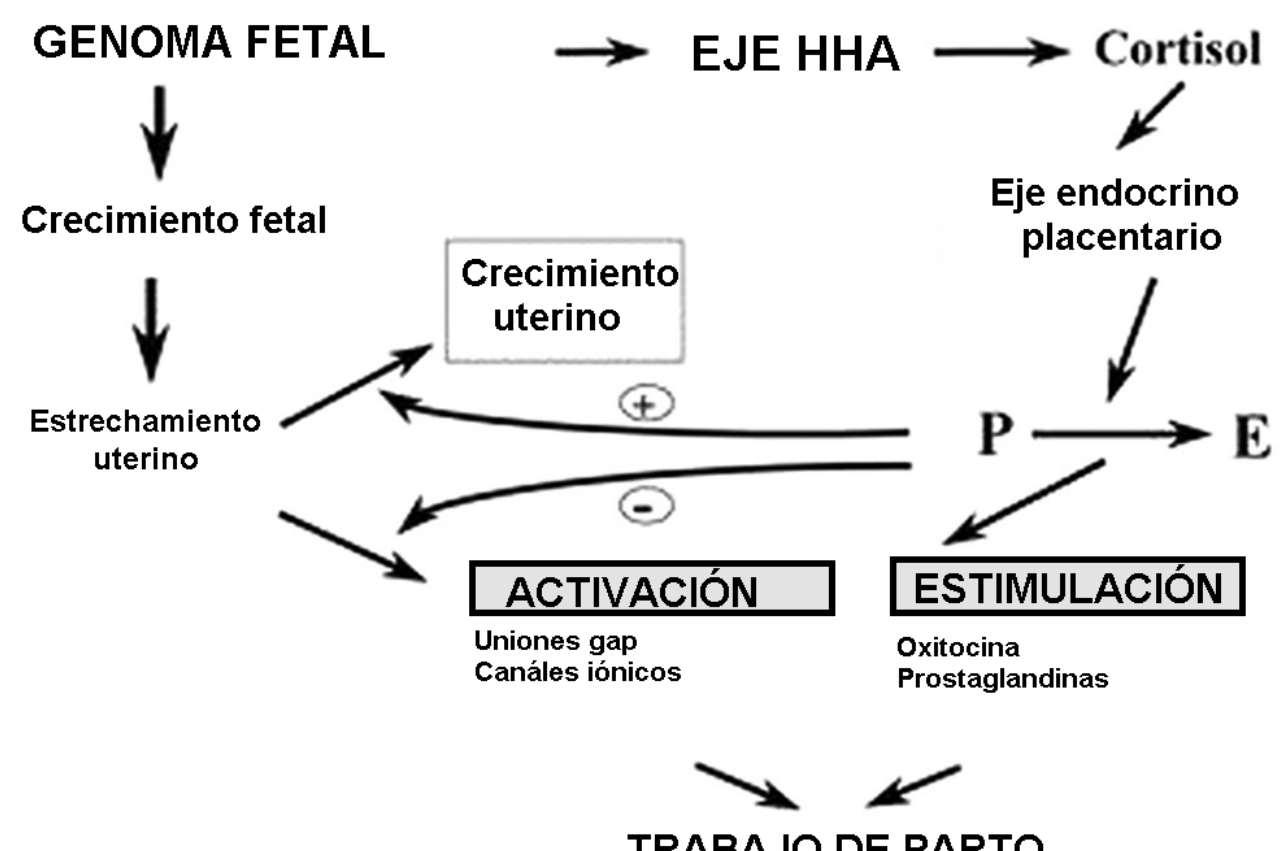

Figura 1.1. Doble vía por la cual el desarrollo fetal controla el inicio del trabajo de parto mediante señales endocrinas y mecánicas. Eje hipotalámico-hipofisario-adrenal (HHA) fetal, P-progesterona, E-estrógenos. El desencadenante del inicio del trabajo de parto comprende una cascada endocrina fetal que involucra al eje HHA, que, en la mayoría de las especies, conduce a un aumento del estrógeno y a una disminución de la progesterona en el plasma materno. Esta cascada endocrina conlleva tanto a la activación como a la estimulación del miometrio a través del aumento de la producción de agonistas uterotónicos como la oxitocina y las prostaglandinas. Imagen adaptada de [5].

En general, podemos considerar que el proceso fisiológico del inicio del trabajo de parto es un evento dicotómico, es decir, no se dispara y se mantiene el embarazo, o por el contrario dicho proceso se desencadena. Si se inicia el trabajo de parto, el tejido conectivo cervical y el músculo liso deben ser capaces de dilatarse para permitir el paso del feto desde el útero. En síntesis, los procesos endocrinos que involucran el inicio del trabajo de parto son: 1) un cambio de la progesterona hacia la dominancia de los estrógenos; 2) un aumento de la respuesta a la oxitocina mediante la regulación de la expresión de los receptores de oxitocina miometriales; 3) un incremento en la síntesis de prostaglandinas en el útero; 4) un decremento de la actividad del óxido nítrico; 5) una elevación del flujo de calcio a los miocitos [12], [13] con la adenosina trifosfato (ATP) dependiente de la unión de la miosina a la actina [5] y 6) un aumento de la endotelina que produce mayor flujo sanguíneo uterino y actividad miometrial [14] (Figura 1.2). 


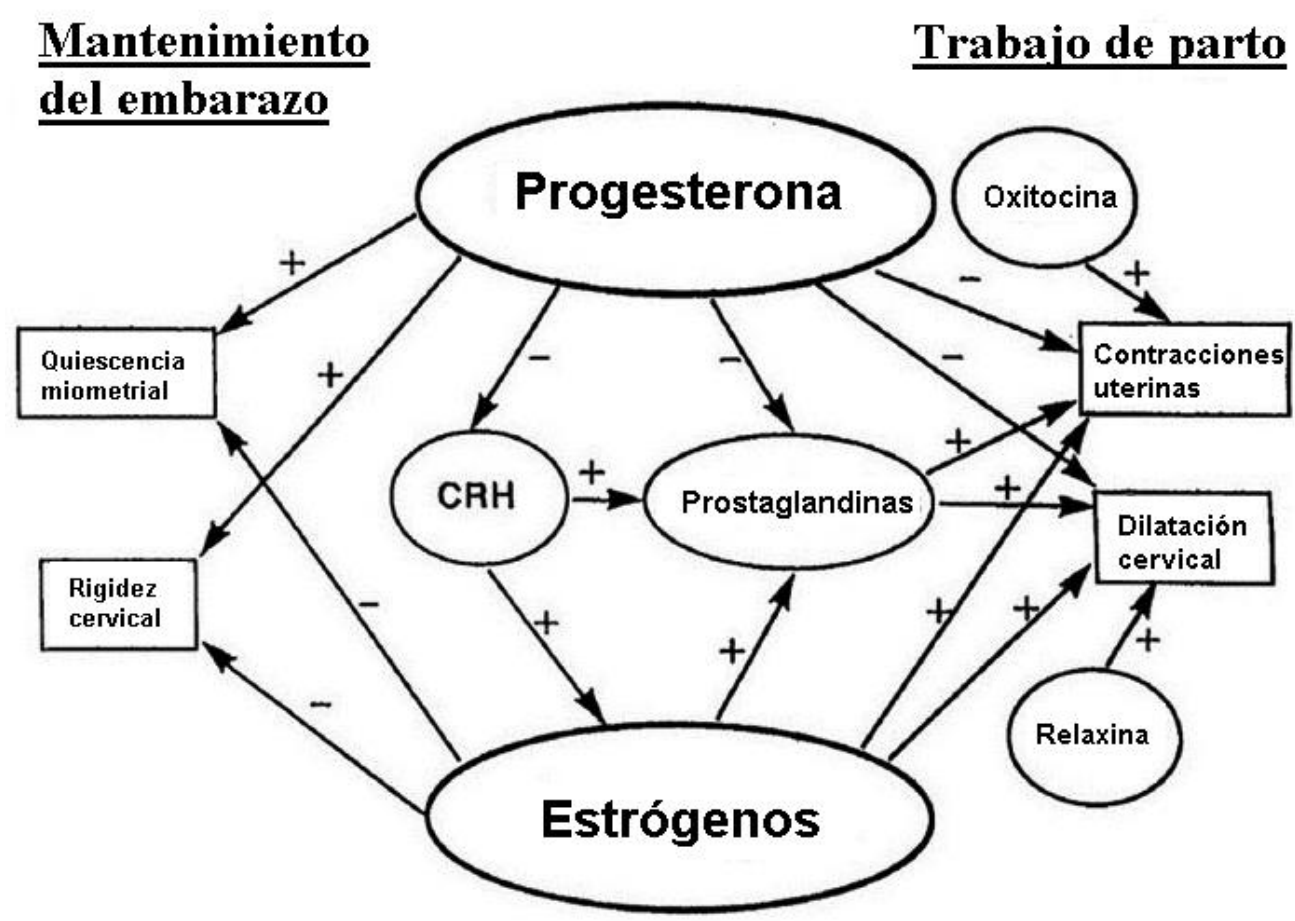

Figura 1.2. Control endocrinológico del embarazo y el trabajo de parto en mujeres. El equilibrio entre los efectos del estrógeno y la progesterona es fundamental para el mantenimiento del embarazo y el inicio del trabajo de parto. Otros factores hormonales importantes que modulan este equilibrio también se muestran en el esquema. El término $\mathrm{CRH}$ es la abreviatura de la hormona liberadora de corticotropina por sus siglas en inglés corticotropin releasing hormone. Imagen adaptada de [5].

Otras aproximaciones han considerado que durante el embarazo el feto debe ser inmunológicamente tolerado por la madre para permitir que se desarrolle y alimente [15]. Dado que el trabajo de parto puede ser un evento fisiológico mediado por citoquinas proinflamatorias, al exhibir características de inflamación, algunos autores han considerado que los privilegios inmunológicos que la interfaz feto-placentaria disfruta durante el embarazo son revocados en el momento de inicio del trabajo de parto [16]. En ese sentido, diversos estudios apoyan la hipótesis de que el trabajo de parto involucra un evento inflamatorio [17]-[23].

El sistema inmunitario generalmente se puede clasificar en el sistema inmunitario innato y el sistema inmunitario adaptativo. El primero es un sistema inespecífico que proporciona una defensa inmediata contra patógenos, mientras que el segundo es más específico, caracterizado por los linfocitos T y B. Aunque existe un vínculo entre estos linfocitos, las células B y sus anticuerpos dan lugar principalmente a la inmunidad humoral, mientras que las células $\mathrm{T}$ proporcionan principalmente inmunidad mediada por células [24]. Las células $\mathrm{T}$ auxiliares (CD4+) forman un subconjunto de células $\mathrm{T}$ y pueden subdividirse en células T auxiliar 1 (Th1) y células T auxiliar 2 (Th2) dependiendo de su 
patrón de producción de citoquinas. Las células Th1 segregan citoquinas proinflamatorias tales como la interleucina (IL)-1, IL-2, IL-12, IL-15, IL-18, el interferón gamma (IFN- $\mathrm{Y}$ ) y el factor de necrosis tumoral alfa (TNF- $\alpha$ ), mientras que las células Th2 secretan citoquinas antiinflamatorias como la IL-4, IL-5, IL-6, IL-10, IL-13, el factor estimulante de colonias de granulocitos y monocitos o (GM-CSF), [25] (Figura 1.3).

En condiciones normales estas citoquinas se hallan en equilibrio, pero, dependiendo del tipo de estímulo, se promoverá una u otra respuesta. Ambos grupos de citoquinas son inhibitorias entre sí; por ejemplo, las Th1 inhibirán mediante la liberación IFN-y la vía Th2, y, a la inversa, los linfocitos Th2 mediante la liberación de IL-10 pueden inhibir la vía Th1[26].

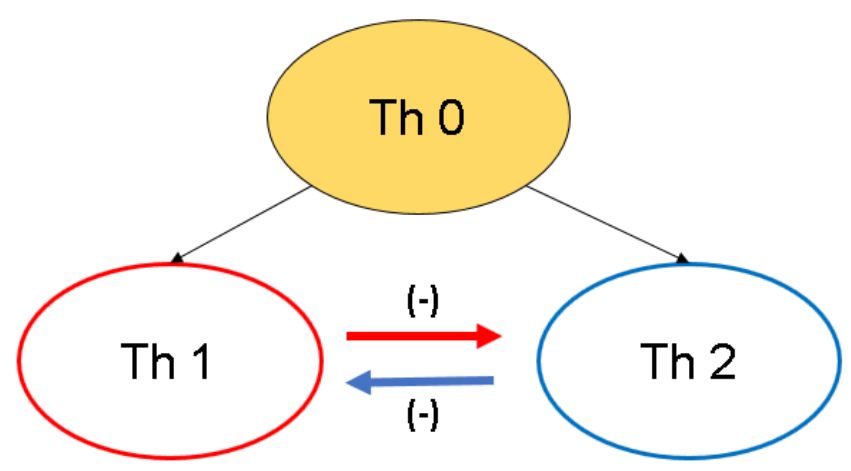

\begin{tabular}{c} 
IL-1, IL-2, IL-15, IL-15, IL-18, \\
IFN- $\gamma$, TNF-a \\
Citocinas proinflamatorias \\
Dominancia respuesta \\
INFLAMATORIA \\
$\begin{array}{c}\text { Mediada por células, linfocitos T (Th y } \\
\text { Tc) activados y sus citocinas } \\
\text { Inmunidad específica mediada por } \\
\text { fagocitos }\end{array}$ \\
\hline
\end{tabular}

IL-4, IL-5, IL-6, IL-10, IL-13,
TGF- $\beta$, GM-CSF
Citocinas antiinflamatorias
Dominancia respuesta
ANTIINFLAMATORIA
Mediada por anticuerpos producidos
por células plasmáticas derivadas de
linfocitos B

Figura 1.3. Células y citoquinas Th1 y Th2. Las citoquinas tipo Th1 inducen una respuesta inmune inflamatoria mientras que las citoquinas tipo Th2 favorecen la respuesta antiinflamatoria. Ambos tipos de citoquinas se interregulan. Diagrama tomado de [26].

Wegmann et al. desarrollaron por primera vez la hipótesis de que durante el embarazo hay un cambio de una respuesta Th1 a una Th2 que induce funcionalmente la tolerancia materna e inmunomodulación [27]. De acuerdo con esta noción, la administración de interleucinas Th1 como el IFN-y [28] e IL-2 [29] conduce a abortos y trabajos de parto prematuros en ratones. Del mismo modo, ratones $\mathrm{CBA} \times \mathrm{DBA} / 2$ que tienen placentas 
deficientes en IL-4 e IL-10 son propensos a la reabsorción fetal. Sin embargo, el tratamiento con IL-10 intraperitoneal protege a los fetos de ser reabsorbidos [30].

Durante el embarazo, las células $T$ participan en el mantenimiento de la tolerancia periférica materno-fetal. Colectivamente, estas células crean un microambiente antiinflamatorio que mantendrá el embarazo. De acuerdo con Gomez-Lopez et al. se sugiere que los siguientes eventos inmunológicos podrían desencadenar el trabajo de parto [31]: (1) la activación de las células inmunes innatas y adaptativas aumenta su capacidad migratoria; (2) los tejidos reproductivos y la interfaz materno-fetal reclutan las células activadas a través de la liberación de quimiocinas tales como CXCL10, CXCL8, CCL2 y CCL5; (3) los leucocitos infiltrados amplifican el microambiente proinflamatorio en la interfaz materno fetal que conlleva al trabajo de parto. Un estímulo desencadenador (por ejemplo, infección/inflamación, estrés, etc.) podría provocar la activación prematura de esta vía, produciendo un cambio de un microambiente antiinflamatorio a un microambiente proinflamatorio y consecuentemente al trabajo de parto prematuro (Figura 1.4). En la Figura 1.5 se muestra una visión general de las células inmunes innatas y adaptativas en los tejidos reproductivos y en la interfaz materno-fetal. Los neutrófilos están presentes en el cuello uterino, miometrio, membranas fetales y decidua a término; sin embargo, su densidad aumenta en el miometrio y la decidua debido al trabajo de parto. Los macrófagos están presentes en el cuello uterino, miometrio, membranas fetales y decidua a término y su densidad aumenta en todos estos tejidos, excepto en el cuello uterino durante el parto prematuro y a término. Los macrófagos cervicales también parecen participar en los procesos de recuperación postparto. Los mastocitos se encuentran en los tejidos cervicales y miometriales durante la gestación; sin embargo, sus roles durante el trabajo a término y prematuro no están claros. Las células T efectoras CD4+ están presentes en los tejidos deciduales durante el trabajo de parto a término. Las células T citotóxicas (CTL) se encuentran en el embarazo a término y en los tejidos placentarios en casos de enfermedades placentarias como la villitis de etiología desconocida; sin embargo, su papel durante el trabajo de parto es desconocido. Las membranas fetales muestran reclutamiento de células $B$ durante el parto a término, también estas células se encuentran en los tejidos deciduales y el cordón umbilical [31]. 


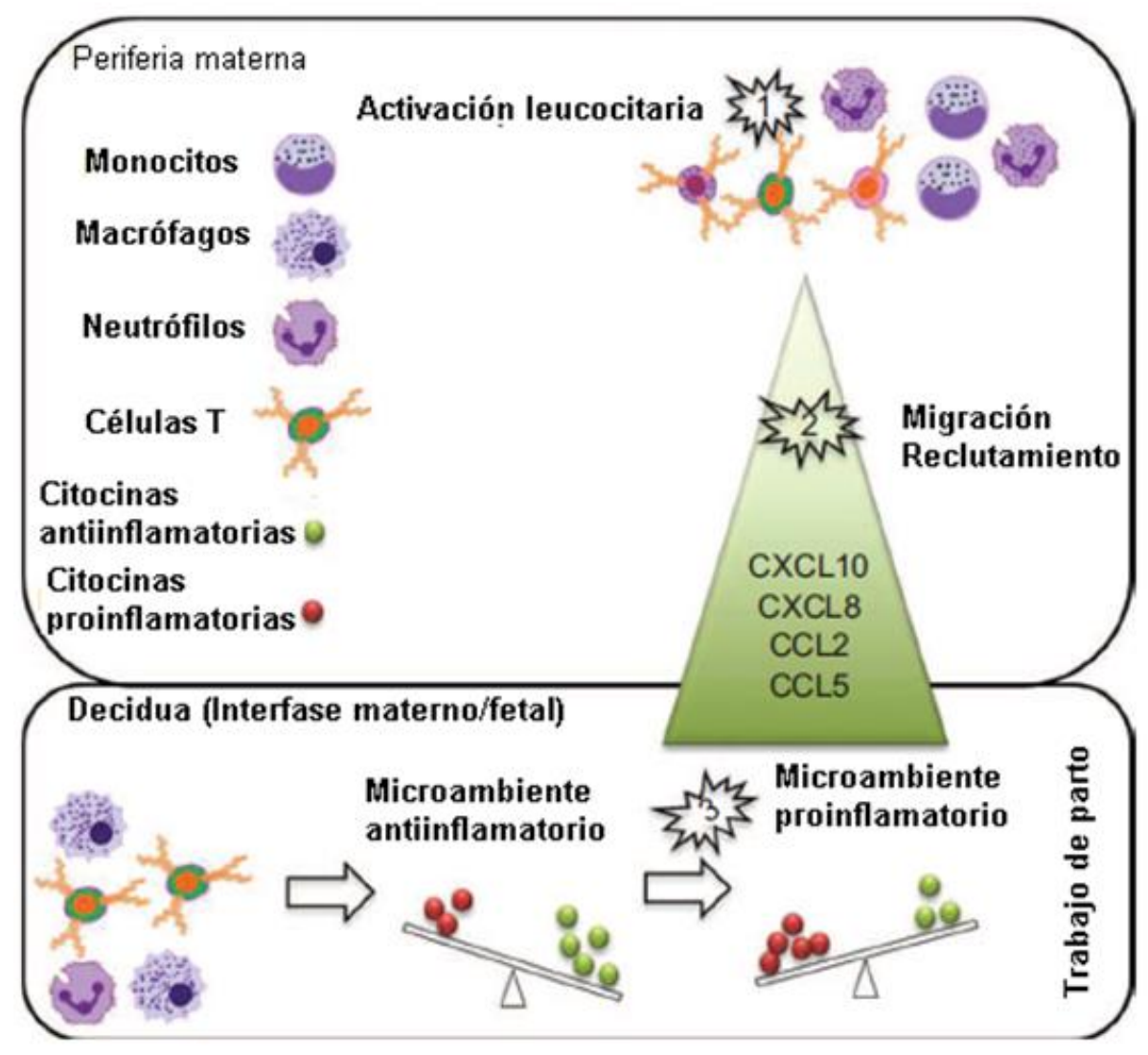

Figura 1.4. Vía sugerida que conduce al trabajo de parto a término o prematuro: (1) la activación de las células inmunes innatas y adaptativas aumenta su capacidad migratoria; (2) la interfaz materno fetal recluta las células activadas mediante la liberación de quimiocinas tales como CXCL10, CXCL8, CCL2 y CCL5; (3) los leucocitos infiltrados amplifican el microambiente proinflamatorio en la interfaz materno-fetal que llevan al parto. Un estímulo desencadenador (por ejemplo, infección / inflamación, inflamación estéril, estrés, etc.) podría provocar la activación prematura de esta vía, resultando en un cambio de un microambiente antiinflamatorio a un microambiente proinflamatorio y consecuentemente a un trabajo de parto prematuro. Imagen tomada de [31].

En resumen, la paradoja inmunológica del embarazo se basa en un equilibrio tanto de la tolerancia inmune como de la inmunosupresión [32]. De esta manera, la colaboración entre la respuesta innata y adaptativa del sistema inmunitario es necesaria para mantener el embarazo hasta el término. Una interrupción de cualquiera de las respuestas podría resultar en un parto prematuro. Por ello, la investigación dirigida a las células inmunitarias involucradas en el proceso de trabajo de parto podría revelar nuevas estrategias para prevenir el parto prematuro. 


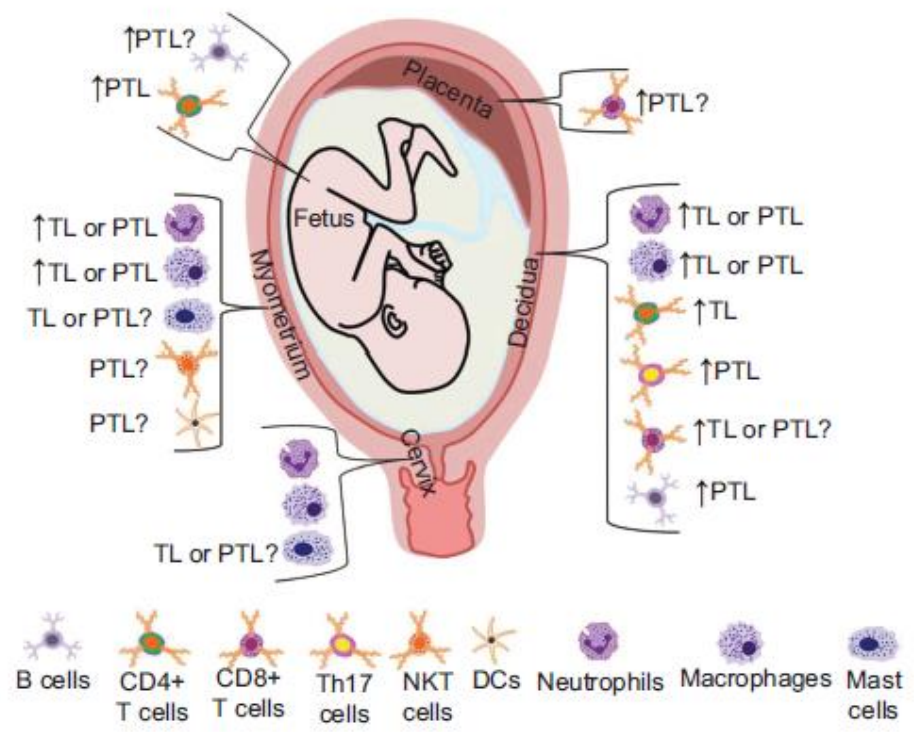

Figura 1.5. Células inmunológicas en trabajo de parto a término (TL) y pretérmino (PTL). Representación esquemática de las células inmunes innatas y adaptativas en los tejidos reproductivos y en la interfaz materno fetal. Imagen tomada de [31].

Puesto que el trabajo de parto implica un trabajo muscular intenso y por consiguiente, una actividad metabólica importante [33], se debe considerar también que una regulación energética rigurosa deberá ser alcanzada por los procesos fisiológicos homeostáticos durante esta etapa final del embarazo, donde se están produciendo dos procesos fisiológicos altamente demandantes de energía. Estas consideraciones se presentarán en la siguiente sección.

\subsection{La homeostasis energética durante el trabajo de parto}

Durante el embarazo, el feto requiere de glucosa y aminoácidos para su desarrollo y crecimiento, lo cual coloca a la mujer embarazada en un estado continuo de demanda energética. Estudios del metabolismo energético han demostrado la necesidad de regular el uso de nutrientes [34], [35]. Llama la atención que los estudios sobre el balance energético durante el embarazo se han limitado a una estimación de las reservas acumuladas por la madre, estimando que al final de la gestación se acumula una reserva energética de aproximadamente 30,000 Kcal [34] en la grasa depositada. Por supuesto, esta reserva es importante para satisfacer las demandas del feto, pero posiblemente, también, para hacer frente a un período importante de gasto energético causado principalmente por un aumento de la actividad contráctil en el miometrio durante el trabajo de parto. De hecho, la frecuencia cardíaca materna durante la expulsión aumenta hasta 
niveles comparables con el ejercicio moderado o intenso [36], proporcionando así un punto de partida para comprender las demandas energéticas de este fenómeno fisiológico.

Los mecanismos moleculares implicados en la quiescencia uterina durante la gestación y la inducción del trabajo de parto no son entendidos por completo, aunque se ha demostrado que el metabolismo energético del músculo uterino es diferente entre el embarazo y el trabajo de parto [37]. La glucosa representa el reservorio de energía primario materno durante la primera etapa de dicho proceso (cuando se inician las contracciones uterinas) y segunda etapa (cuando se alcanza una dilatación completa del cérvix) [35]; por lo que si el trabajo de parto se prolonga y si la fuente de glucosa es limitada, la gluconeogénesis puede llegar a ser insuficiente. Durante el trabajo de parto normal, la concentración de ácidos grasos libres y cuerpos cetónicos aumenta, lo que lleva a la producción de sustratos distintos a la glucosa y a una reducción relativa de carbohidratos [38], [39]. Por lo tanto, los esfuerzos producidos en el trabajo de parto disminuyen rápidamente la disponibilidad de carbohidratos, lo que lleva a que el cuerpo de la mujer metabolice grasa para obtener energía. En consecuencia, la disponibilidad de aminoácidos en el torrente sanguíneo materno y fetal se reducen, mientras que los ácidos grasos y las cetonas aumentan [40]. Además, Scheepers et al. sugirieron que la hiperglucemia materna ocurre durante el trabajo de parto, lo que lleva a incrementos en la producción de lactato materno y fetal, resultando en acidosis metabólica [35].

Es bien sabido que, durante la actividad física, el consumo de energía está vinculado a la duración real de esta actividad [41]. Pero, dado que el trabajo de parto se puede extender durante varias horas (el tiempo promedio del trabajo de parto para una mujer primípara es alrededor de 16 a 17 horas) [42], éste se convierte en un proceso de alta demanda energética similar a la del ejercicio moderado a pesado de acuerdo a Söhnchen et al. [36]. Por ejemplo, el gasto energético para una mujer de $55 \mathrm{~kg}$ durante el ejercicio moderado a pesado es de entre 3.5 a $7.7 \mathrm{kcal} / \mathrm{min}$ [43], por lo que se podría estimar un consumo energético de entre $3400-7900 \mathrm{kcal}$ para una mujer durante 16 a 17 horas en trabajo de parto. En este contexto existe poca evidencia empírica sobre el gasto energético durante el trabajo de parto. Algunos autores han reportado un consumo bajo como 50 a 100 kcal por hora de [44] y tan alto como 300 a $520 \mathrm{kcal}$ [45]. Esta variación puede estar relacionada con las diferencias en el gasto energético entre la primera y segunda etapa del trabajo de parto [46]. Katz et al. plantearon que debido al carácter intermitente de las contracciones uterinas, un trabajo de parto normal no impone altas demandas energéticas en la parturienta, pero que un trabajo de parto prolongado puede ocasionar alteraciones 
metabólicas maternas [47]. Por lo tanto, estas consideraciones proporcionan oportunidades para la realización de futuras investigaciones sobre el balance energético durante el trabajo de parto.

Steingrímsdóttir et al. indicaron que en lugar de los lípidos, el músculo liso uterino de la mujer embarazada usa glucosa como su principal metabolito nutritivo y que en comparación con el músculo estriado, la ruta anaeróbica del metabolismo de la glucosa es más activa en el miometrio [48]. También, se ha sugerido que la glucosa tiene un papel crítico como combustible principal para la formación de ATP, además de que el adenilato quinasa y las reacciones de 5' nucleotidasa están involucradas en eventos vinculados a la escasez de glucosa [48]. Chew y Rinard, sugirieron que el glucógeno es un metabolito importante, ya que se encontró que el contenido de glucógeno miometrial en ratas embarazadas aumentó justo antes del parto [49]. Sakamoto et al. reportaron que durante la última etapa de gestación en ratas preñadas hay un aumento gradual en los receptores de insulina, con picos en el día del parto [50]. Otros hallazgos sugieren la eficacia de la insulina en el útero de ratas embarazadas, mostrando que su comportamiento en el miometrio fue similar al observado en el músculo esquelético [51]. Por lo tanto, la inflamación miometrial por medio de la resistencia a la insulina podría ser requerida para mantener el flujo de energía que sostiene las contracciones uterinas, esto es sustentado con el hecho que algunos estudios reportan efectos antiinflamatorios de la insulina [52].

Desde un punto de vista inmunológico y como ya se ha mencionado previamente, el trabajo de parto es considerado como un evento inflamatorio. Desde esta perspectiva, la regulación de la homeostasis energética y la respuesta inmune son cruciales para la supervivencia de un organismo [53]. Por ejemplo, en las enfermedades inflamatorias crónicas, el balance energético se ve alterado en gran medida debido al consumo excesivo de un sistema inmunitario activado [53]. A su vez, este proceso debe estar ocurriendo durante el trabajo de parto para cumplir con el consumo energético de la madre y el feto. Por lo tanto, la respuesta inmune de la madre y la regulación metabólica deben estar integradas y la función de cada una debe ser altamente dependiente de la otra. Según Hotamisligil et al., esta interrelación se puede ver como un mecanismo homeostático [54]. Es bien conocido que una respuesta inmune implica una inversión sustancial de energía [55]-[57]; por lo tanto, la inmunidad es dependiente de un compromiso entre otros procesos de energía altamente exigentes [58]. El trabajo de parto es un proceso de consumo energético en el cual la interacción inmune y energética entre la madre y el feto todavía no está completamente entendida. Desde este punto de vista, el trabajo de parto puede ser 
considerado como una "reacción de demanda energética", provocado por la actividad del sistema inmunitario, la movilización de las reservas energéticas (lipólisis/glucogenólisis), y la inducción de resistencia a la insulina en el hígado, tejido adiposo y músculo esquelético, con el resultado general de la asignación apropiada de sustrato energético a las células inmunes activadas [53] y, claro, también al miometrio. A medida que el sistema inmunitario necesita muchos suministros ricos en energía [59], la inflamación del tejido local debe ser mantenida por suministros energéticos en sitios locales o sistémicos. Por lo tanto, la participación de una respuesta antiinflamatoria por el sistema inmunitario es vital para restringir la inflamación [60] y para limitar el aumento progresivo de las demandas energéticas durante el trabajo de parto.

\subsection{La respuesta colinérgica antiinflamatoria (RCA) durante el trabajo de parto}

El nervio vago es el nervio principal de la división parasimpática del sistema nervioso autónomo (SNA), regula la función de los órganos, incluyendo la frecuencia cardíaca, la motilidad intestinal y la constricción bronquial a través de fibras motoras eferentes [61]. Aproximadamente el $80 \%$ de las fibras del nervio vago son fibras sensoriales que recogen información de las vías respiratorias, el corazón, el hígado y el tracto gástrico a través de receptores que responden a la presión y la temperatura [62]. La evidencia experimental sugiere que el componente aferente del nervio vago también transmite información al cerebro sobre los procesos inflamatorios que ocurren en la periferia. Por ejemplo, la administración intraperitoneal de la citoquina proinflamatoria IL-1 $\beta$ induce la expresión del marcador de activación neural c-Fos en las neuronas aferentes del nervio vago [63], que expresan los receptores IL-1 $\beta$ [64]. La vagotomía abroga el comportamiento de enfermedad o sickness behavior originado en el sistema nervioso central (SNC) en respuesta a inyecciones intraperitoneales de IL-1 $\beta$ o lipopolisacárido (LPS). De esta manera el sistema inmunitario "recoge" la información generada en la periferia y sirve como un órgano sensorial que informa al cerebro de estímulos nocivos [65]. Las fibras aferentes del nervio vago alcanzan el bulbo raquídeo y terminan en el núcleo del tracto solitario (NTS), donde la liberación de glutamato se incrementa en respuesta a la administración periférica de LPS o IL-1ß. La información que llega al NTS es llevada al núcleo motor dorsal del vago (NMDV), que es el origen de las neuronas preganglionares cuyos axones encarnan el componente eferente del nervio vago. La conexión entre el NTS y el NMDV coordina las señales 
aferentes vagales y las respuestas eferentes vagales. EI SNA, a través de esta estructura anatómica, "recoge" la información de las respuestas inflamatorias periféricas y responde en tiempo real a través de las fibras eferentes del nervio vago que mantienen la homeostasis, un mecanismo conocido como el reflejo antiinflamatorio [66] (Figura 1.6).

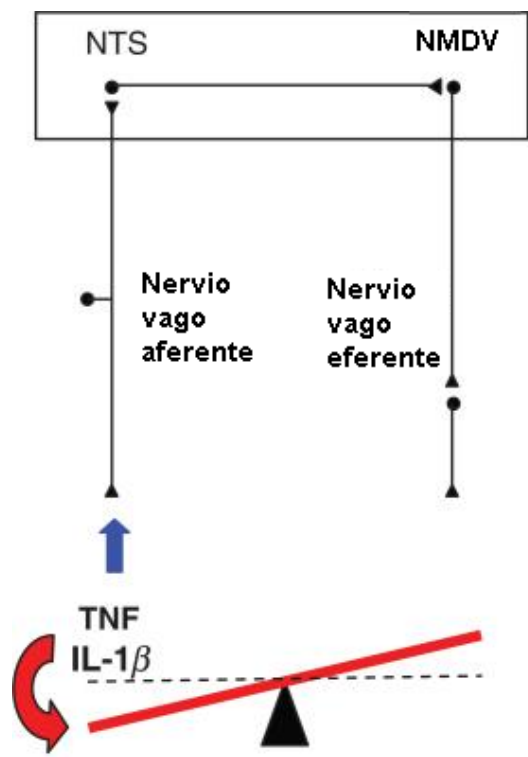

Inflamación

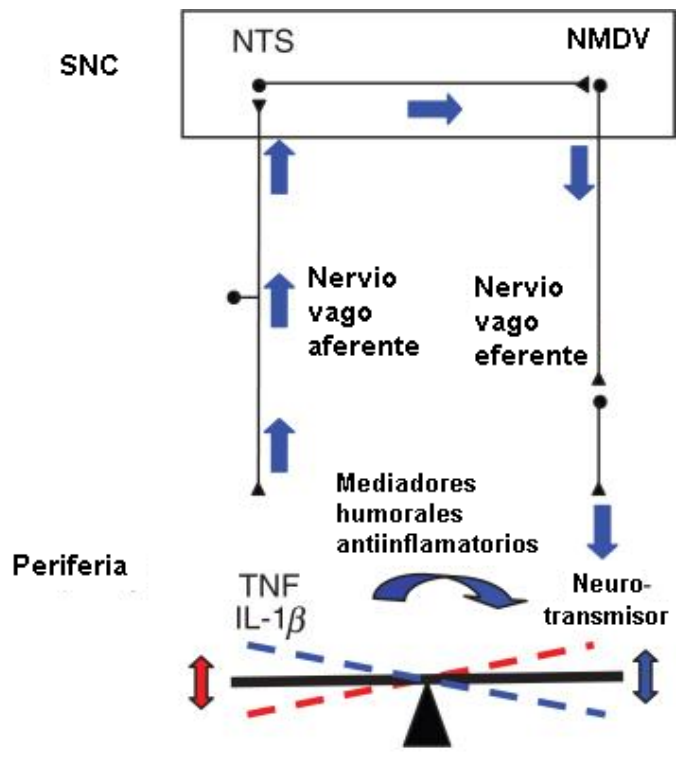

Homeostasis

Figura 1.6. Reflejo antiinflamatorio. Los patógenos y el daño tisular inducen la liberación de citoquinas que sirven para limitar la extensión de la infección y promover la reparación tisular. Las vías reguladoras humorales y neurales regulan la magnitud de la respuesta inflamatoria. Las citoquinas liberadas en el sitio inflamatorio activan las vías aferentes del nervio vago y llegan al núcleo del tracto solitario (NTS) y posteriormente al núcleo motor dorsal del vago (NMDV), proporcionando así la información del sistema nervioso autónomo con respecto al estado inflamatorio periférico. Las señales compensatorias son transportadas por el nervio vago eferente y alcanzan el sitio de la inflamación donde los neurotransmisores actúan sobre los macrófagos y otras células del sistema inmunitario para atenuar la respuesta inflamatoria. Imagen adaptada de [67].

Como se describió anteriormente, el trabajo de parto se puede concebir como un proceso inflamatorio asociado con el incremento de citoquinas proinflamatorias [15], [68][70]. Por lo anterior es plausible proponer que durante el parto un proceso homeostático antiinflamatorio debería de existir para contener la liberación de citoquinas proinflamatorias y moderar, entre otros factores, el consumo energético. En este sentido el reflejo antiinflamatorio a través de la vía vagal propuesto por Tracey es una opción pertinente. Adicionalmente, en algunas condiciones, puede existir una coactivación o sinergia de los sistemas simpático/parasimpático que se manifiesta a través de la liberación de adrenalina/noradrenalina y acetilcolina (ACh), respectivamente [66]. Debido a que los reflejos de dolor y lucha se manifiestan probablemente durante el trabajo de parto, una participación simpática también podría estar implicada. Por lo tanto, ambos sistemas probablemente actúan para regular la inflamación. Esto es apoyado por el hecho de que 
algunos autores han mencionado que los sistemas simpático y parasimpático modulan el flujo de sangre uterino que producen las contracciones; documentado experimentalmente en ratas [71]. Ahora, teniendo en cuenta el papel de las mioquinas, que son aquellas citoquinas $u$ otros péptidos que son producidos, expresados o liberados por las fibras musculares esqueléticas, [72], se reconoce que los músculos esqueléticos expresan y liberan mioquinas en el torrente sanguíneo en respuesta a la contracción muscular por la actividad física. Dado que las fibras musculares expresan la mioquina IL-6, algunos estudios apoyan la relación entre un efecto antiinflamatorio del ejercicio y la IL-6, debido a que estas mioquinas estimulan la producción de las citoquinas antiinflamatorias clásicas como la IL1ra [73], [74]. Incluso se ha reportado una vinculación entre los tres principales fenotipos del miometrio (es decir, proliferativo, sintético y contráctil), y las tres fases de la transformación inmunológica (es decir, la iniciación, la tolerancia y la activación) [75]. Sin embargo, esto lleva a preguntarse: ¿cuál es la participación de las mioquinas del miometrio durante el trabajo de parto? Algunos reportes sugieren que el estiramiento de los miocitos uterinos aumentan la expresión de RNAm de IL-8 durante el inicio del trabajo de parto [76]. Por otra parte, se ha visto que las citoquinas IL-1 $\beta$, IL-6 e IL-8 presentaron niveles más altos en el suero materno durante el inicio del trabajo de parto, en comparación a mujeres sin evidencia de estar en él [77]. Al hacer una analogía entre el ejercicio y el trabajo de parto, podríamos hipotetizar que la fuerte actividad uterina contribuye a inducir una condición de inflamación por medio de una producción mioquinas. Sin embargo, esto aún no ha sido empíricamente comprobado. Por otra parte uno de los principales factores desencadenantes de la inflamación es la infección, siendo ciertas moléculas de microorganismos invasores el estímulo inicial desencadenante [78]-[80].

En este contexto y considerando que el trabajo de parto debe iniciarse espontáneamente y en condiciones libre de microbios [81], el trabajo de parto de bajo riesgo y a término podría ser conceptualizado como un "evento inflamatorio estéril". La evidencia clínica apoya esta propuesta, con algunos resultados mostrando que la vía de IL-1 juega un papel clave en la inflamación neutrofílica a diversos estímulos estériles, incluyendo una variedad de partículas irritantes y células muertas [82]; y esta misma citoquina ha sido implicada en el mecanismo del parto humano, ya que se ha reportado que mujeres embarazadas sin evidencia de encontrase en trabajo de parto tuvieron concentraciones indetectables de IL-1 $1 \alpha$ en comparación con un grupo de mujeres en trabajo de parto con niveles altos de IL-1 circulante [83]. 
Una de las citoquinas que podría ser clave para el mantenimiento del embarazo es la IL-10, o incluso la familia de la IL-10. De hecho, la regulación de esta citoquina antiinflamatoria conduce a la supresión de las células natural killer (NK) y los linfocitos T frente a los aloantígenos fetales. Los factores que alteran la expresión de la IL-10, incluyendo infecciones y variaciones genéticas dentro del gen de IL-10, podrían determinar el resultado del embarazo. Además, la alteración en la expresión de la IL-10 también está asociada con la incidencia en partos prematuros. Por otro lado, la administración exógena de IL-10 puede disminuir los efectos patológicos de la inflamación que es frecuente en el parto prematuro [84].

En la Figura 1.7 se presenta un esquema que sugiere los procesos que desencadenan el trabajo de parto a término y su vinculación con el SNA: un estímulo estéril es censado por los receptores del tipo Toll (TL), produciendo un aumento en la producción de citoquinas proinflamatorias: IL-1, TNF- $\alpha, \quad$ IL-8, IL-6, y proteína quimiotáctica de monocitos 1 (MCP-1), entre otras. Estas citoquinas y quimiocinas podrían aumentar entre sí para facilitar su producción, así como para reclutar neutrófilos y macrófagos a la interfaz materno-fetal e incrementar la producción de mediadores de inflamación (entre los más importantes parecen estar las prostaglandinas y las metaloproteinasas de la matriz). Estos distintos mediadores tienen una variedad de efectos en distintos tejidos; produciendo así contracciones uterinas, dilatación y borramiento del cérvix y estimulando la producción de mioquinas. Sin embargo; el reflejo colinérgico antiinflamatorio se activaría para restringir la inflamación, produciendo la inhibición de síntesis de citoquinas proinflamatorias y el incremento de receptores de citoquinas antiinflamatorias [66]. 

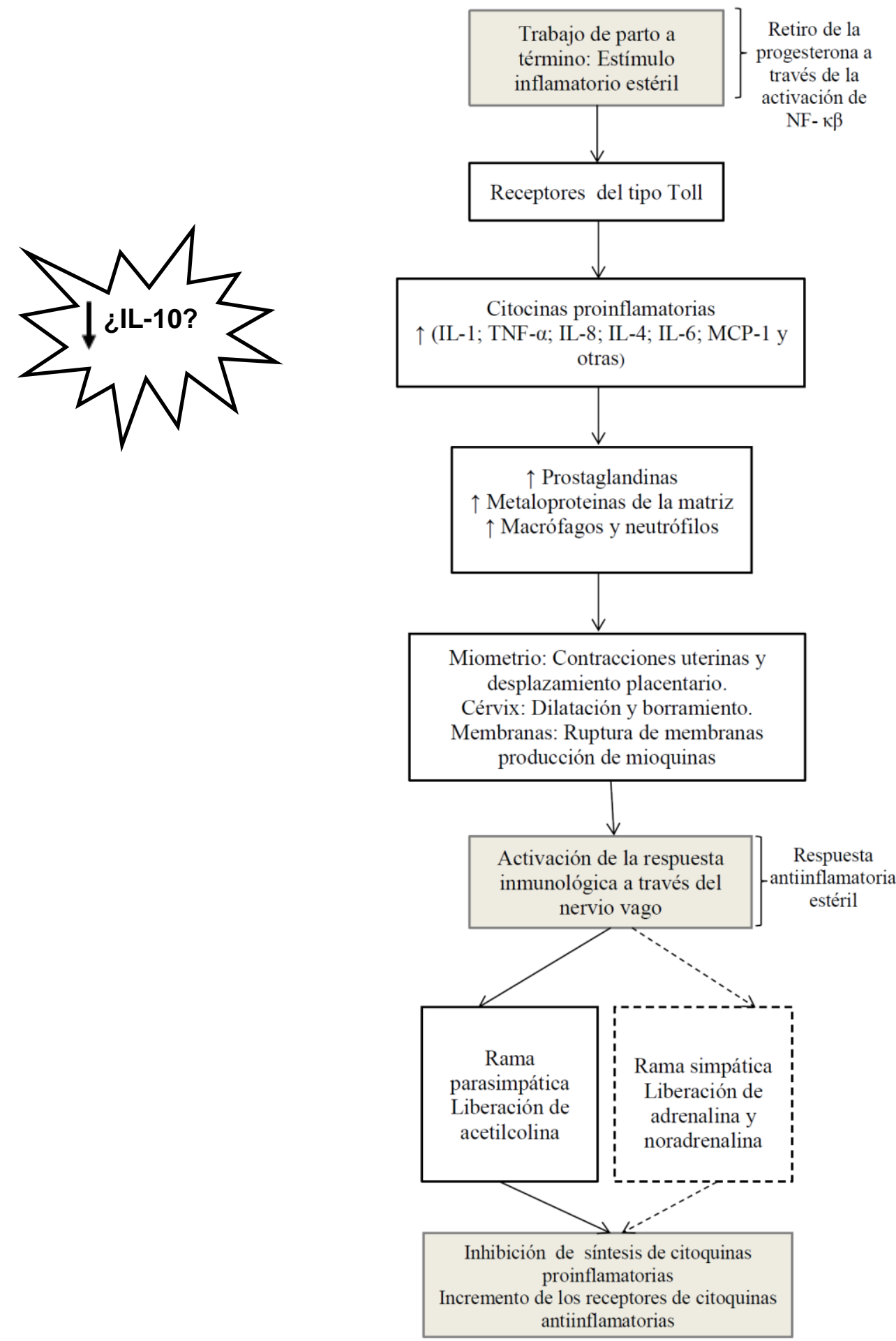

Figura 1.7. Diagrama del proceso inflamatorio durante el trabajo de parto y su posible relación con una respuesta estéril antiinflamatoria. De acuerdo con Tracey, 2002, esta respuesta a veces presenta una coactivación de los sistemas simpático y parasimpático para contender con la inflamación. La citoquina IL-10 también podría estar involucrada (ver texto). Imagen tomada de [85]. 


\subsection{El análisis de las fluctuaciones de la frecuencia cardiaca (FFC)}

Un método no invasivo para evaluar indirectamente la actividad del SNA es el análisis de las fluctuaciones o variabilidad de la frecuencia cardiaca (FFC). El análisis de las FFC tiene como objetivo separar y cuantificar la respuesta cardiaca autónoma en simpática (adrenérgica) y parasimpática (colinérgica). Las ramas simpática y parasimpática del SNA y sus influencias en la frecuencia cardíaca (FC) y en las FFC están bien establecidas. La actividad simpática tiende a aumentar la FC y reducir las FFC, mientras que la parasimpática tiende a disminuir la FC y aumentar las FFC [86]. Los intervalos de tiempo entre latidos cardiacos consecutivos se miden en el electrocardiograma (ECG) desde el máximo de la onda $R$ hasta la siguiente onda $R$. Se denominan convencionalmente intervalos R-R (Figura 1.8). Por lo tanto, las FFC se definen como la variación temporal de intervalos R-R consecutivos, esta variación depende del control autonómico del corazón. Las variaciones en los periodos cardiacos consecutivos pueden ser evaluadas por varios métodos matemáticos, ya sean métodos en el dominio del tiempo, métodos en el dominio de la frecuencia, métodos no lineales, entre otros [86].

Un grupo de investigadores inició en 2006 una serie de debates sobre el papel de las FFC como un índice de control autonómico, concluyendo que las diferentes técnicas de análisis de las FFC mostraron índices asociados con el control autonómico del corazón [87]. De hecho, varios estudios han relacionado específicamente la actividad antiinflamatoria colinérgica con los cambios en algunos de los índices de las FFC; por lo tanto, son considerados como parámetros útiles para la exploración de la actividad de dicha vía [88]. En particular, dado que la raíz cuadrada del promedio de la suma de las diferencias cuadráticas entre intervalos R-R adyacentes (Root Mean Square of the Successive Differences, por sus siglas en inglés RMSSD) es comúnmente usada como un índice autonómico vinculado al control cardiaco vagal, y que está estrechamente ligada a la respiración a través de la arritmia sinusal respiratoria [89], se ha propuesto a este parámetro como una de las herramientas del domino temporal que puede vincularse al reflejo colinérgico antiinflamatorio [90]. La actividad parasimpática también se puede cuantificar mediante el análisis espectral de las FFC, proporcionando el índice de alta frecuencia (High frequency, en sus siglas en inglés HF) en la banda de 0.15-0.4 Hz.

Todas estas técnicas de análisis se describen con más detalle en el capítulo II secciones 2.2 y 2.3 de la presente tesis. 

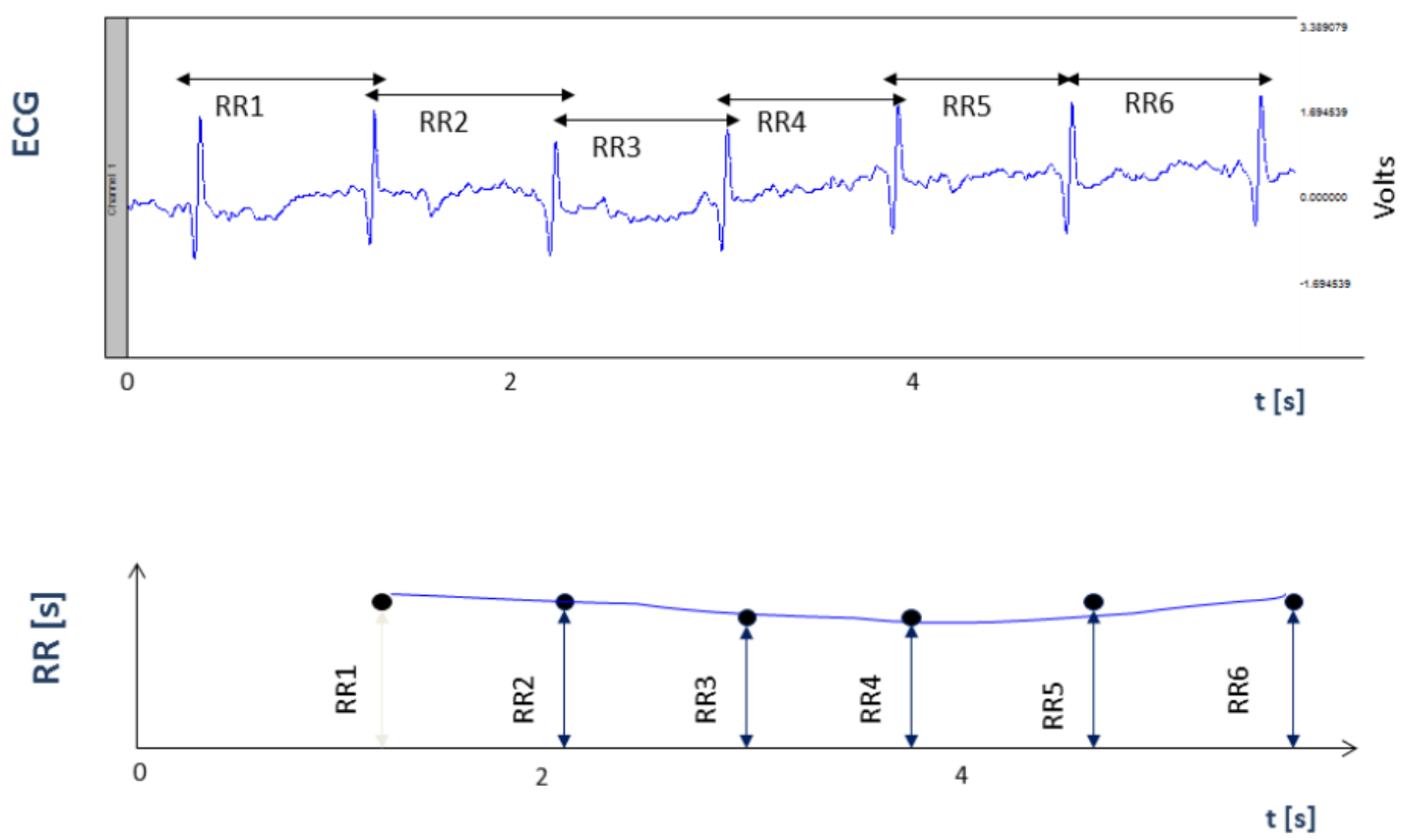

Figura 1.8. Un intervalo R-R es el tiempo transcurrido entre dos ondas $R$ sucesivas del ECG. Los intervalos R$R$ muestran la variación entre latidos consecutivos.

\subsection{El análisis de las FFC y su vinculación con procesos inflamatorios}

Algunos autores han reportado que diversos procesos inflamatorios pueden modificar parámetros de la FFC. Por ejemplo, las enfermedades atópicas, tales como la dermatitis, se han vinculado con cambios en la modulación autonómica hacia una mayor actividad parasimpática. Los pacientes con dermatitis presentaron valores elevados de los parámetros vagales (por ejemplo, una RMSSD aumentada) con respecto a los controles. Con base en estos resultados, Boettger et al. llegaron a la conclusión de que los ajustes autonómicos son causados por la respuesta colinérgica antinflamatoria (RCA) para aliviar los síntomas de la dermatitis atópica [91]. Es importante mencionar que otros estudios refuerzan la consideración de que la actividad cardiovagal, cuantificada por el análisis de las FFC, podría proporcionar indicios para comprender el reflejo colinérgico antiinflamatorio [92].

Existen estudios que han vinculado diversos marcadores inflamatorios en personas sanas, como el factor de necrosis tumoral TNF- $\alpha$, las citoquinas IL-8 e IL-6, el fibrinógeno, el receptor activador de plasminógeno uroquinasa (SuPAR), la proteína $C$ reactiva (CRP) y el número de leucocitos con parámetros de las FFC [93], [94]. En estos trabajos se concluyó 
que existe una asociación inversa entre algunos marcadores inflamatorios con los parámetros extraídos de las FFC, además de que se presenta una disminución de actividad vagal que promueve la producción de citoquinas proinflamatorias. Además de esto, se han estudiado escenarios que conllevan a procesos inflamatorios específicos, donde se observó un cambio en los índices de las FFC: como la exposición a partículas ambientales como el sulfato de níquel (NiSO4). En dicho trabajo se reportaron valores del logaritmo natural de RMSSD y de la desviación estándar de los valores NN (standard deviation of all normal $R$ $R$ intervals por sus siglas en inglés, SDNN) aumentados en ratas durante $72 \mathrm{~h}$ después de la exposición a NiSO4, lo que se atribuye a un desequilibrio autonómico cardiaco debido a estrés oxidativo e inflamación [95].

Otro escenario inflamatorio sistémico es el de endotoxemia inducida por LPS, éste se ha estudiado tanto en humanos como en modelos animales. Huang et al., demostraron en el 2010 que las descargas de los nervios vagales aferentes y eferentes en ratas aumentaron después de la inyección de LPS, así como el número de descargas en el NTS [96]. Los parámetros de las FFC como las altas frecuencias (High frequency, por sus siglas en inglés HF), las bajas frecuencias (Low frequency, por sus siglas en inglés LF), la razón entre bajas y altas frecuencias (Ratio between low and high frequency components, LF/HF por sus siglas en inglés) y las muy bajas frecuencias (Very Low frequency, por sus siglas en inglés VLF) se incrementaron después de la inyección de LPS. Este estudio concluyó que tanto el sistema simpático como el parasimpático están aumentados debido a la endotoxemia para activar la protección en contra de la inflamación (Figura 1.9). Pero Godin et al. mostraron que la endotoxemia inducida por LPS causa la disminución de las FFC, como también causa el incremento de la regularidad en las FFC al ser medido por la entropía aproximada (ApEn). Dicho estudio indica que dicha pérdida de complejidad es consistente con un modelo de patogénesis por falla orgánica múltiple, en el cual existe un desacoplo fisiológico entre los sistemas de regulación [97]. 


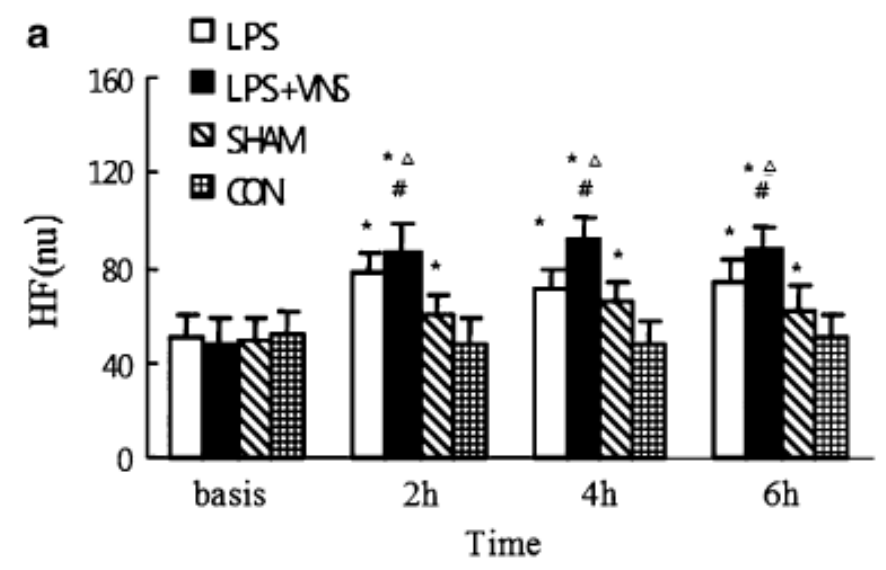

Figura 1.9. Efecto sobre el parámetro espectral HF de las fluctuaciones de la frecuencia cardiaca en ratas, por un periodo 0 (basal), 2, 4 y 6 horas después de una inyección de lipopolisacárido (LPS) en distintos grupos. LPS=Grupo inyectado con $5 \mathrm{mg} / \mathrm{kg}$ de LPS; LPS+VNS = Grupo inyectado con $5 \mathrm{mg} / \mathrm{kg}$ de lipopolisacárido y con estimulación del nervio vago; SHAM= Grupo con únicamente estimulación del nervio vago; CON= Grupo control. Imagen extraída de [96]. Los diversos símbolos indicaron diferencias significativas: * $p<0.05$ vs periodo basal (basis) y el grupo control (CON); \# $p<0.05$ vs LPS y $\Delta p<0.05$ vs el grupo SHAM.

Así mismo, Fairchild et al. experimentaron al aplicar diversas dosis intraperitoneales de LPS (altas de $10 \mathrm{mg} / \mathrm{kg}$ y bajas de $0.01 \mathrm{mg} / \mathrm{kg}$ ) en ratones C57BL/6, encontrando que las dosis altas de LPS provocaron en los ratones machos una disminución de la temperatura y frecuencia cardiaca una hora posterior a la inyección de LPS, seguida de un largo periodo de disminución de las FFC (Figura 1.10) [98]. Por otro lado, el descenso en la temperatura y en la frecuencia cardiaca coincidió con el pico de liberación de TNF- $\alpha$ una hora post-LPS, y la máxima disminución de las FFC coincidió con el pico en los niveles de múltiples citoquinas post LPS como, por ejemplo: IL-10, IL-6 y MCP-1. Así mismo, estos autores encontraron una relación dependiente entre dosis de LPS y parámetros de las FFC (SDNN, en particular) asociados con la inflamación, además hallaron una dosis mínima $(0.01 \mathrm{mg} / \mathrm{kg})$ para producir modificaciones en las FFC debido a la inflamación. 


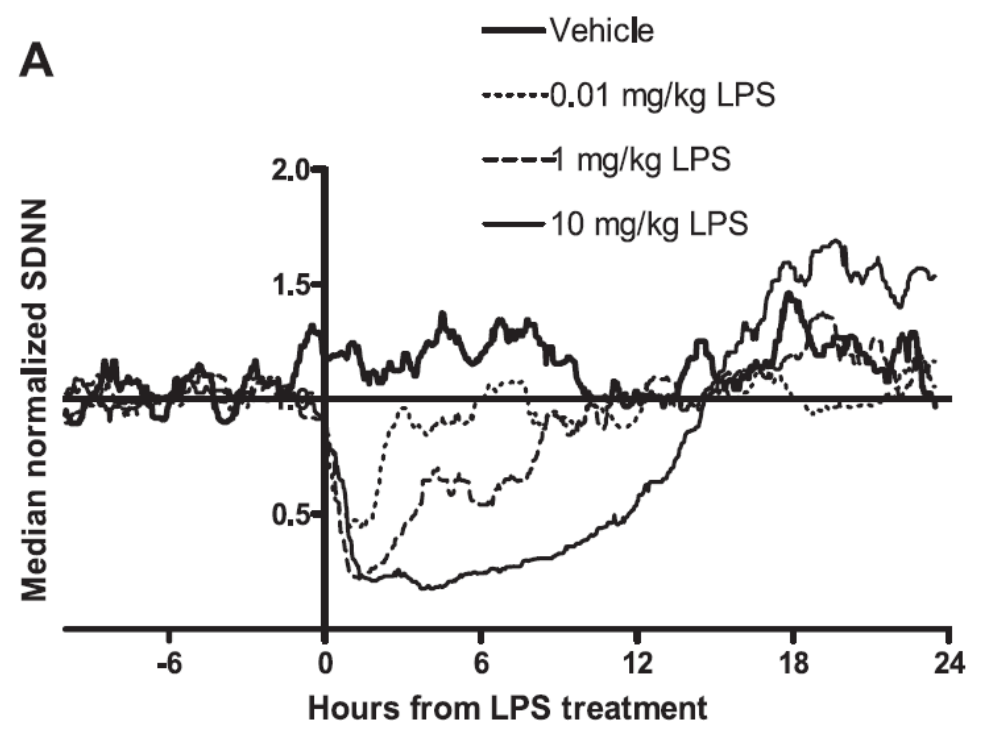

Figura 1.10. Efecto sobre el parámetro temporal de las fluctuaciones de la frecuencia cardiaca (SDNN, indicador de variabilidad total) en ratones C57BL/6. Los distintos tipos de líneas indican las cantidades de lipopolisacárido (LPS) suministradas a los ratones. Se observa que el efecto sobre el SDNN es dependiente de la dosis de LPS administrada [98].

Gholami et al. experimentaron en ratas Sprague-Dawley machos, aplicando una dosis intraperitoneal de LPS (1 mg/kg). Ellos observaron nuevamente una disminución en las FFC en las ratas en endotoxemia y además lo asociaron con una respuesta disminuida del atrio aislado a la estimulación colinérgica [99]. Estos resultados sugieren que la endotoxemia sistémica podría provocar un desacoplamiento parcial del marcapasos del corazón y el SNA. Así, la reducción en las FFC podría no ser concordante con la hipótesis de que una respuesta colinérgica está presentándose durante la endotoxemia; sin embargo, los autores discuten acerca de la posible participación de la respuesta antiinflamatoria colinérgica, sugiriendo que podría tener un papel relevante en sus resultados, ya que se encontraron patrones bifásicos en las aceleraciones y desaceleraciones de la frecuencia cardiaca post LPS. Además, dichos autores hacen hincapié en que se necesitan más estudios para entender si los cambios en los parámetros de las FFC están vinculados a una respuesta colinérgica antiinflamatoria.

En otro estudio realizado por Fairchild et al., se encontró que algunas citoquinas como la IL-6, IL-10, TNF- $\alpha$, IFN- $y$, G-CSF (factor estimulante de colonias de granulocitos), KC, y proteínas inflamatorias de macrófagos beta (MIP-1 $\beta$ ) se correlacionaron inversamente con el SDNN (Figura 1.11) [100]. 

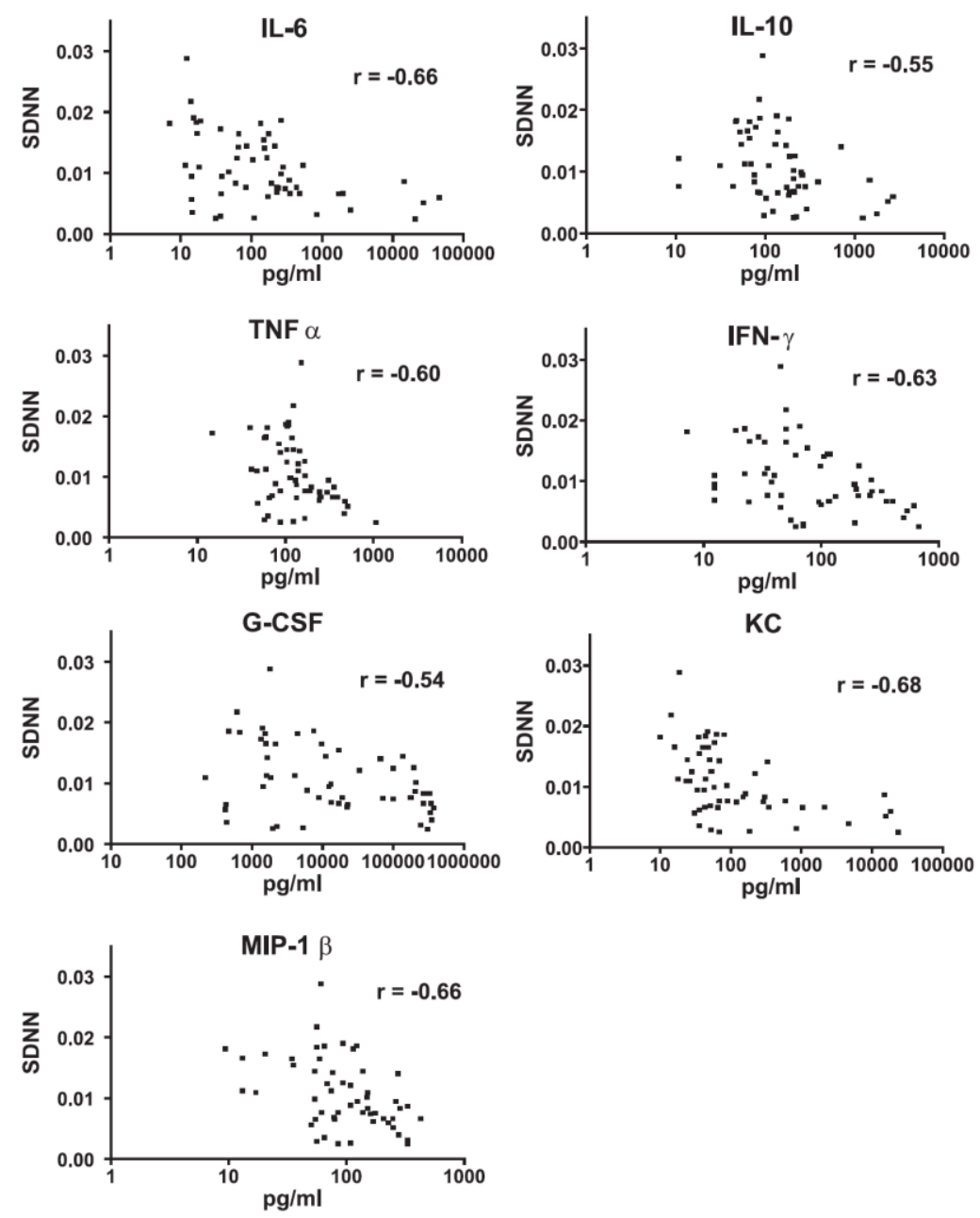

Figura 1.11. En el estudio de Fairchild et al., 2011; siete citoquinas se correlacionaron inversamente con el parámetro SDNN de las FFC. Éstas se midieron en el plasma $18 \mathrm{~h}$ y $42 \mathrm{~h}$ después de la inyección de solución salina, o Klebsiella pneumoniae, Staphylococcus aureus o Candida albicans. Se reportó el coeficiente de correlación de Spearman "r", que osciló entre 0.54 a 0.68, como se indica en lafFigura. Imagen tomada de [100].

Mazloom et al. estudiaron el receptor nicotínico de acetilcolina alfa siete ( $\alpha 7 \mathrm{nACHR})$ a través de las FFC en ratas que se les indujo un estado de endotoxemia. Ellos supusieron que dichos receptores pueden modular la disminución de las FFC en ese escenario, puesto que los $\alpha 7 \mathrm{nACHR}$ juegan un papel importante en la activación de respuesta antiinflamatoria colinérgica vagal [101]. En ese estudio se experimentó con ratas Sprague-Dawley machos y se aplicaron dosis de LPS de $0.1 \mathrm{mg} / \mathrm{kg}$ y $1 \mathrm{mg} / \mathrm{kg}$, así como agonistas y antagonistas del $\alpha 7 n A C H R$. Se llegó a la conclusión de que el bloqueo de $\alpha 7 n A C H R$ podría reducir aún más las FFC y provocar una respuesta febril en ratas endotoxémicas. Por otro lado, el agonista de los $\alpha 7 \mathrm{nACHR}$ fue incapaz de modular la frecuencia cardiaca en ratas endotoxémicas, pero pudo prevenir el efecto de la endotoxina en la temperatura. Los autores sugieren un 
papel relevante para los receptores nicotínicos de la ACh en la modulación de la dinámica de la frecuencia cardíaca durante la inflamación sistémica.

Por su parte en humanos, Lehrer et al. encontraron que gracias a la biorretroalimentación (técnica para poder controlar conscientemente variables fisiológicas autonómicas) de las FFC disminuyó la disfunción autonómica en un grupo de personas expuesto a LPS en comparación de uno que no uso la biorretroalimentación [102]. Dicha técnica disminuyó los síntomas de dolor de cabeza y sensibilidad a la luz, pero no afectó el nivel de citoquinas proinflamatorias. Jan et al., estudiaron el efecto de la epinefrina en sujetos con endotoxemia inducida por LPS [103]. Estos autores reportaron cambios en la mayoría de los parámetros temporales y espectrales de las FFC $(p<0.01)$ debido a la inflamación, así mismo notaron que una infusión de epinefrina disminuye la liberación de citoquinas proinflamatorias como el TNF- $\alpha$, la IL-6 e IL-8 ( $p<0.01)$, llegando a la conclusión de que la aplicación de epinefrina tiene efectos protectores contra la inflamación; sin embargo, ésta reduce la actividad vagal. En un estudio posterior Jan et al., no encontraron diferencias de género en los parámetros de las FFC al inducir la endotoxemia por LPS entre hombres y mujeres [104] (Figura 1.12), adicionalmente encontraron una correlación del porcentaje de intervalos R-R consecutivos que difieren en más de 50 ms (o pNN50) y el componente HF con el TNF- $\alpha$.

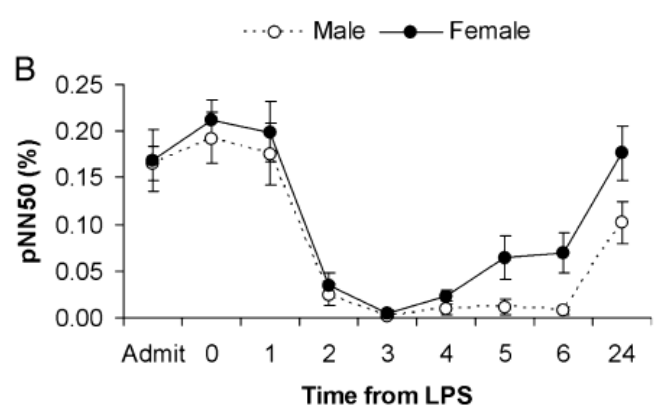

Figura 1.12. Análisis del parámetro temporal de las FFC (pNN50) posterior a la aplicación de lipopolisacárido (LPS) (tiempo 0). Los círculos sólidos representan al grupo de mujeres estudiadas $(n=14)$ y los círculos blancos al grupo hombres $(n=16)$. En los resultados se muestra el promedio y su desviación estándar. No se reportan diferencias estadísticas entre los grupos. Imagen extraída de [104].

Kox et al. llegaron a la conclusión que distintos patrones de respiración (como la hiperventilación o la respiración pausada) no afectan los índices de las FFC durante endotoxemia por LPS, además de que los parámetros temporales (SDNN, RMSSD) y espectrales (HF, LF) de las FFC mostraron una disminución después de la aplicación de LPS [105]. Otra situación que está vinculada con un proceso inflamatorio es la depresión, 
ya que de acuerdo al estudio de Kop et al. en el cual se estudiaron 907 personas mayores a 65 años, se hallaron valores elevados de marcadores inflamatorios en personas deprimidas, así mismo se calcularon índices de las FFC en el tiempo, frecuencia y no lineales y se encontró asociaciones entre los parámetros de las FFC y los parámetros inflamatorios [106]. En este estudio se concluyó que la disfunción autonómica e inflamación puede contribuir a incrementar la muerte por riesgo cardiovascular asociado con la depresión.

Celik et al., consideraron que la inflamación juega un papel importante en los mecanismos que provocan la hipertensión arterial [107]. El objetivo de su trabajo fue evaluar la relación de inflamación y la respuesta autonómica cardiaca en pacientes con hipertensión. Dicho estudio demostró que existe una disminución en los parámetros de las FFC (RMSSD y SDNN y análisis de turbulencia) en los sujetos con hipertensión; así como la CRP se vio incrementada en este grupo a diferencia del grupo control. Se encontró una correlación entre los parámetros de las FFC con la CRP. Este estudio concluyó que existe un proceso inflamatorio que en pacientes con hipertensión y que es asociado a una función autonómica cardiaca alterada [107].

\subsection{La oxitocina como agente antiinflamatorio}

Como ya se ha mencionado anteriormente, la oxitocina es una hormona importante durante el trabajo de parto, y hay algunos estudios que también la han relacionado con parámetros de las FFC. Por ejemplo, se ha encontrado que al aplicar oxitocina intranasal en personas, tanto hombres como mujeres, se presenta un incremento en la actividad autonómica cardiaca, principalmente en la banda de alta frecuencia (HF) [108] que revela información acerca del control parasimpático. Adicionalmente, se ha reportado que esta hormona funciona como péptido de regulación cardiovascular [109] y como modulador autonómico [108]. En un estudio se analizó el efecto de la oxitocina en 21 hombres, se encontró que en los parámetros HF del análisis espectral y el exponente $\alpha_{1}$ de escalamiento fractal del método de análisis de fluctuaciones sin tendencia (Detrended fluctuation analysis, por sus siglas en inglés DFA) presentaron cambios en la presencia o ausencia de oxitocina [110]. Los resultados sugieren que la administración aguda de oxitocina puede facilitar lo que se considera una característica psicofisiológica fundamental de la conducta social, el aumento de la capacidad para relacionase y así establecer un compromiso social. 


\subsection{Planteamiento del problema}

Puesto que tanto los partos espontáneos a término como los prematuros están mediados por la inflamación en el cuello del útero, las membranas y el miometrio [16], la participación de una respuesta colinérgica antiinflamatoria (RCA) se plantea como crucial para limitar un escenario de inflamación (Figura 1.13). Así, las preguntas de investigación que se plantearon son:

1. ¿Existe la participación de una RCA en mujeres durante el trabajo de parto a término y de bajo riesgo?

Esta pregunta fue posible abordarla en el momento en el que se consideró al trabajo de parto a término como un proceso de inflamación, en donde el organismo de la mujer debe contender ante la inflamación, y podría ser considerado estéril debido a que el estímulo inmune tiene un origen no infeccioso. De hecho las citoquinas proinflamatorias, como la IL-1, la IL-6, el factor de necrosis tumoral TNF- $\alpha$, la IL-8, la IL-16, la MCP-1, las proteínas inflamatorias de macrófagos alfa (MIP-1 $\alpha$ ), la quimiocina CCL5, entre otras más están involucradas con los mecanismos responsables del trabajo de parto prematuro [69]. Así mismo, estudios han reportado que las citoquinas están presentes en altas concentraciones en el líquido amniótico de pacientes con infección o inflamación, estimulando la contractilidad uterina por la inducción de prostaglandinas, y con ello induciendo el trabajo de parto prematuro y el nacimiento. Se ha demostrado que el factor nuclear potenciador de las cadenas ligeras kappa de las células B activadas (NF-k $\beta$ ) en el miometrio humano es capaz de regular isoformas inhibitorias de progesterona [111]. Algunos estudios han encontrado que el NF-k $\beta$ es un inmunomodulador importante y actúa regulando la expresión de prostaglandinas, quimiocinas y citoquinas proinflamatorias involucradas tanto en trabajo de parto a término y prematuro [15], [112]. Así, cambios en la inmunomodulación y las influencias quiescentes de la progesterona a través de su retiro funcional, podría ser iniciado por medio de la activación del NF-k $\beta$. Cabe mencionar nuevamente que al parecer la citoquina antiinflamatoria IL-10 tiene un rol importante en la regulación de la respuesta inmune durante el trabajo de parto, puesto que se ha visto que aumenta su concentración en el líquido amniótico tanto en partos a término y prematuros [69].

Además de esto, son bien conocidos los efectos de la oxitocina sobre la contractilidad uterina; sin embargo, algunos autores han discutido su posible efecto antiinflamatorio. Por ejemplo, Clodi et al. estudiaron a hombres sanos que se les administró 
LPS ( $2 \mathrm{ng} / \mathrm{kg}$ ) y oxitocina ( $\left.1 \mathrm{pmol} \cdot \mathrm{kg}^{-1} \mathrm{~min}^{-1}\right)$ y una combinación de ambos. Ellos encontraron que hubo una disminución en la concentración de diversas citoquinas inflamatorias como: TNF- $\alpha$, IL-1ra, IL-4, IL-6, MIP-1 $\alpha$, MIP-1 $\beta$, MCP-1 y la proteína inducible por interferón 10 (IP-10) en los hombres en donde la oxitocina fue administrada, y concluyeron que dicha hormona restringe la producción de citoquinas inflamatorias debido a su probable vínculo con la RCA [113]. Es importante mencionar, que los receptores de oxitocina en la mujer durante el trabajo de parto se incrementan hasta 150 veces en comparación con el embarazo [114], por lo que probablemente la oxitocina también está jugando un papel importante como agente antiinflamatorio durante el trabajo de parto.

2. ¿Cómo se vinculan los marcadores de inflamación, la RCA y las FFC durante el trabajo de parto?

Antes de contestar esta pregunta, se debía entender los mecanismos fisiológicos involucrados en la generación de la RCA y si ésta aparece en el momento que se produce un evento inflamatorio, ya sea agudo o crónico.

Este mecanismo está mediado por la vía colinérgica antiinflamatoria, debido a que la ACh es el neurotransmisor parasimpático principal. Se ha documentado que los macrófagos que están expuestos a la ACh se inactivan. El nervio vago inerva los órganos principales, incluyendo aquellos que contienen el sistema retículo-endotelial (hígado, pulmón, bazo, riñones y el tracto gastrointestinal) [60].

Como ya se mencionó previamente, un método no invasivo para evaluar indirectamente el SNA es por medio del análisis de las FFC. En particular, la RMSSD es un parámetro de las FFC que es usado para estimar la actividad parasimpática [86]. Thayer en el 2009, encontró una asociación inversa entre la RMSSD y a la CRP, que ha sido identificada como un predictor de muerte cardiovascular [90]. El autor puntualiza que existe un importante control vagal (a través de una RCA) para mediar la inflamación.

Hay un interés creciente en tratar de caracterizar a la RCA a través de las FFC, la Figura 1.13 incorpora la posible vinculación de las FFC con la RCA y el SNA. Existen trabajos como los de Gholami et al. y Fairchild et al. [98], [99]; en donde fue encontrada una respuesta bifásica en la frecuencia cardiaca en roedores después de la inyección de LPS. Estos trabajos se centran en señalar que las aceleraciones y desaceleraciones encontradas podrían vincularse a una respuesta antiinflamatoria. Así mismo, existen diversos estudios en donde se ha estudiado el efecto de la endotoxemia por lipopolisacárido (LPS) tanto en humanos como en roedores [96], [97], [102]-[104], [115]. No obstante, algunos de estos 
estudios parecen no ser concordantes, y nuevamente están limitados a la identificación de una respuesta inflamatoria en las FFC.

Una de las referencias más importantes para esta investigación fue mi trabajo de maestría [116]. Mis resultados sugirieron que la causa fisiológica de encontrar una menor anticorrelación en las FFC durante el trabajo de parto parece asociarse a un menor antagonismo autonómico en la direccionalidad de las FFC, que posiblemente podría también vincularse, a una respuesta antiinflamatoria como resultado de la inflamación exacerbada durante el trabajo de parto. Esta probable respuesta antiinflamatoria se vio reflejada en el exponente de escalamiento fractal de signo $\alpha_{1(\mathrm{SIGN})}$ y la RMSSD, al encontrarse valores elevados de ambos parámetros en trabajo de parto con respecto a un grupo en tercer trimestre de embarazo estudiado previamente [116]. Cabe mencionarse que mi investigación de maestría presentó las siguientes limitaciones: 1) fue un estudio transversal; 2) no se midieron citoquinas de ningún tipo y 3) todas las mujeres estudiadas se les condujo con oxitocina exógena. En este sentido, la oxitocina exógena pudo haber modificado nuestros resultados al ser un potencial agente antiinflamatorio.

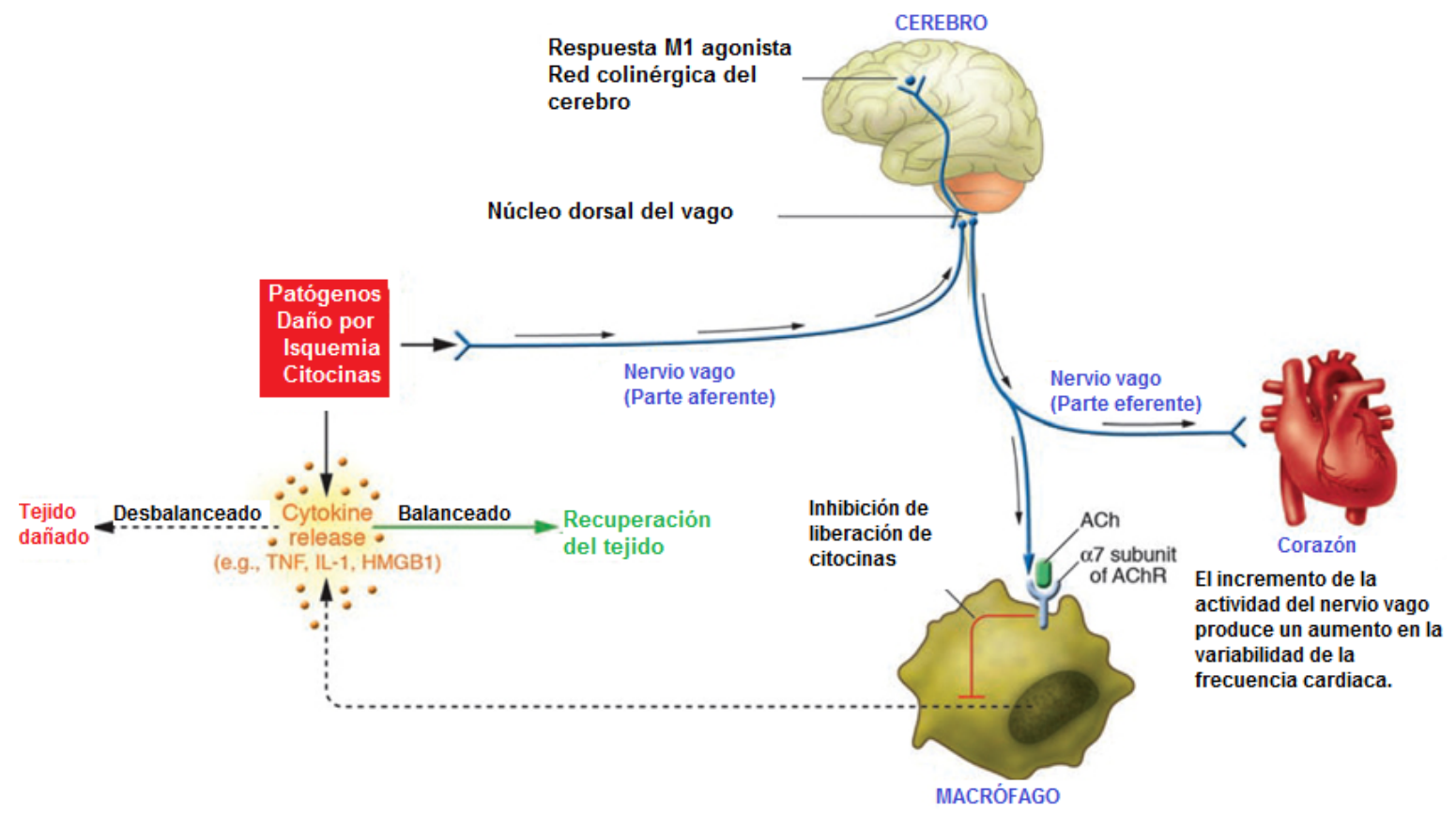

Figura 1.13. Respuesta colinérgica antiinflamatoria y su vinculación con las FFC. Los agentes patógenos, así como la isquemia y otras formas de lesión, activan la producción de citoquinas lo cual normalmente restaura la salud. Pero si la respuesta de citoquinas es excesiva, estos mismos mediadores podrían causar alguna enfermedad. Las señales eferentes del nervio vago inhiben la producción de citoquinas a través de vías que dependen del Receptor Nicotínico de Acetilcolina a7 ( $\alpha 7 \mathrm{nACHR}$ ) en los macrófagos y otras células. La actividad del nervio vago eferente también aumenta la variabilidad de la frecuencia cardiaca. Existe una red cerebral colinérgica que es sensible a los agonistas M1 y que aumenta la actividad de ruta colinérgica antinflamatoria y también aumenta de forma instantánea la variabilidad de la frecuencia cardiaca. Las señales aferentes llevadas hacia el nervio vago activan una respuesta eferente que inhibe la liberación de citoquinas, denominado el reflejo antiinflamatorio. Imagen adaptada de [117]. 


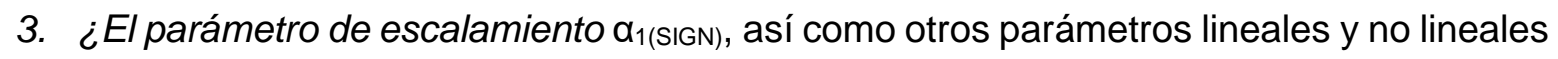
del análisis de las FFC serán sensibles a procesos inflamatorios sistémicos?

Diversos parámetros temporales de las FFC se han vinculado a procesos inflamatorios, entre ellos la RMSSD (Sección 1.5). Sin embargo, no existe información en la literatura consultada acerca del exponente de escalamiento de signo de corto plazo $\alpha_{1(\text { SIGN) }}$ y su vinculación con algún proceso inflamatorio. Así, la única evidencia que se tiene hasta ahora, son los cambios significativos que el parámetro mostró durante mi trabajo de maestría en un grupo de mujeres en trabajo de parto y otro grupo de mujeres en tercer trimestre de gestación [116]. Dicho parámetro se ha asociado a cambios en diversos contextos fisiológicos. Por ejemplo, en un estudio se comparó a un grupo de sujetos con insuficiencia cardiaca contra un grupo de sujetos sanos, y se identificó que este parámetro fue menor (es decir, presentó una fuerte anticorrelación), de manera significativa, en los pacientes con insuficiencia cardiaca. Los autores lo relacionaron con una perturbación del control vagal [118].

También se han implementado el uso de los exponentes de magnitud de signo en otros estudios de caracterización de las fases del sueño, en donde se encontró una fuerte anticorrelación en la direccionalidad de las fluctuaciones de la frecuencia cardiaca en el sueño profundo, menor en el sueño ligero y aún menor en el sueño REM. Sus resultados sugieren que las propiedades no lineales de la dinámica de las FFC se ven incrementadas durante el sueño REM y que es posible a partir de los exponentes de magnitud y signo distinguir entre las diferentes etapas del sueño [119]. Schmitt et al. realizaron también un estudio durante las etapas del sueño, en el que compararon los exponentes de escalamiento de sujetos jóvenes con adultos mayores sanos [120]. El patrón de comportamiento de los exponentes de escalamiento es muy similar al encontrado por Ivanov et al., lo que indicó que la influencia de la regulación del sueño sobre la actividad

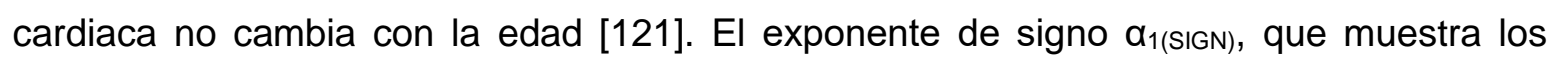
cambios más significativos entre etapas, fue más alto (es decir, menos anticorrelacionado) para los jóvenes en vigilia, y sueño REM ligero, siendo casi iguales en sueño profundo[119], [122] . En un experimento realizado por Ashkenazy et al., se encontró que sujetos sanos bajo la influencia de un $\beta$-bloqueador, presentaron un aumento en la alta frecuencia de la señal R-R en comparación a sujetos que recibieron un placebo (Figura 1.14) [123]. Estas alteraciones sugieren que se presenta un comportamiento fuertemente anticorrelacionado en las FFC debido a la aplicación de dicha droga. Así, estos resultados parecen exhibir que 
la interacción entre los sistemas parasimpático y simpático es reflejada por el análisis de signo de las FFC.
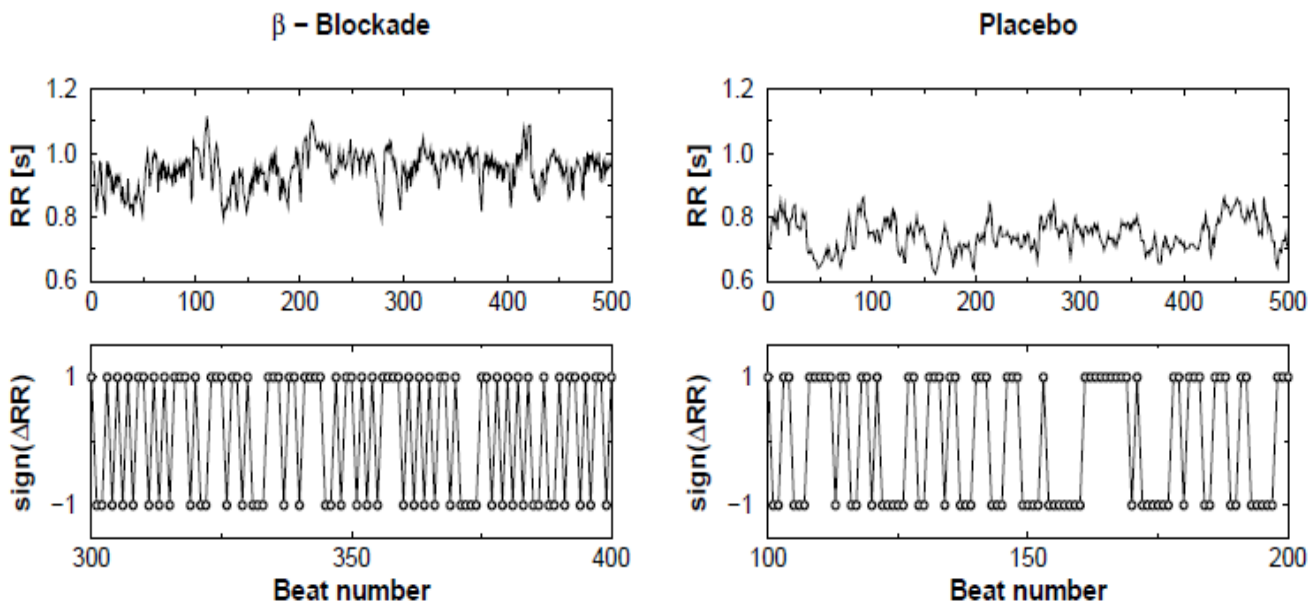

Figura 1.14. Ejemplos de la señal de fluctuaciones R-R después de la administración de un $\beta$-bloqueador (metoprolol, $120 \mathrm{mg}$; Figura izquierda) y en condiciones normales (placebo, Figura derecha) en un sujeto sano adulto. Así, el análisis de signo reveló un comportamiento más anticorrelacionado (valor de $\boldsymbol{\alpha}_{1(\mathrm{SIGN})}$ cercano a 0 ) en comparación con las condiciones de placebo. En esa imagen se puede observar un atractor dominante durante el $\beta$-bloqueador (simpático) en comparación con el Placebo. Imagen extraída de [123].

4. ¿Cómo se podrían evaluar experimentalmente la relación de la dinámica de las FFC con una RCA?

Una de las posibles formas para evaluar la capacidad de los índices de las FFC para identificar una RCA, en especial $\alpha_{1(\text { SIGN) }}$ que no ha sido estudiado previamente, es a través de la inducción de una inflamación aguda por lipopolisacárido (LPS), puesto que dicho modelo es ya conocido tanto en animales como en humanos [124]. Por lo que se esperaría que los parámetros lineales y no lineales de las FFC sean sensibles a la presencia de una respuesta antiinflamatoria subsecuente a la inflamación.

De acuerdo con una revisión efectuada por Rowan et al., existe suficiente evidencia para sustentar que las FFC en el roedor (especialmente de ratones y ratas) reflejan de manera similar el comportamiento de la regulación cardiovascular y control autonómico al que se produce en los seres humanos [125]. Por este motivo, ha surgido un reciente interés en el análisis de las FFC en estudios toxicológicos, en donde los roedores son comúnmente estudiados. Cabe mencionar que los individuos masculinos en varias especies también son sensibles a la oxitocina como agente antiinflamatorio, esto se ha visto en experimentos en hombres [113] y en ratas machos [126]. En este último estudio la oxitocina se administró a los roedores y se observó su efecto como agente antiinflamatorio en patologías cardiacas [126]. 
Por otro lado, es sabido que las infecciones intrauterinas o la inflamación sistémica juegan un rol importante en la patogénesis de los trabajos de parto y nacimientos prematuros [127]. Así mismo, estudios revelan que la inflamación inducida por LPS provoca trabajos de parto prematuros en ratones gestantes, y que incluso logra incrementar los niveles de citoquinas inflamatorias como: IL-6, 1L-8, IL-1 [128]. Es importante mencionar que estudios recientes utilizan el modelo con LPS para inducir nacimientos prematuros en ratones debido a infecciones [129], además se ha reportado que el LPS es capaz de inhibir las producción de las células marcapasos del corazón [130].

Aunado al escenario particular del trabajo de parto, es de importancia relacionar los parámetros de las FFC con marcadores inflamatorios que podrían indicar y confirmar la presencia de una respuesta antiinflamatoria durante el trabajo de parto [85], [116]. Como ya se ha mencionado, la IL-10 sería importante considerarla en este nuevo estudio. En el contexto experimental, un modelo de endotoxemia por LPS apoyaría a la comprensión de las observaciones de la parte clínica, es decir, ayudaría a comprender los resultados previos. 


\subsection{Justificación}

Si bien aún hay muchas preguntas entorno al trabajo de parto, existen serios problemas en materia de salud pública que son una realidad tanto en América Latina como en el resto del mundo. Por ejemplo, algunos de estos datos revelan que un número importante de mujeres mueren por complicaciones que se producen durante el embarazo y el parto o después de ellos [131]. La mayoría de esas complicaciones aparecen durante la gestación; otras pueden estar presentes desde antes del embarazo, pero se agravan con la gestación. Las principales complicaciones [131], causantes del $80 \%$ de las muertes maternas, son:

- las hemorragias graves (en su mayoría después del parto)

- las infecciones (generalmente después del parto)

- la hipertensión gestacional (preeclampsia y eclampsia)

- los abortos peligrosos.

En concordancia con lo reportado por la Organización Mundial de la Salud (OMS), en un estudio epidemiológico a largo plazo (1990 a 2010) realizado por Lozano et al., en donde se estudiaron 235 causas de muerte en 20 grupos de distintas edades y de diferentes países, se encontró que en el rubro de enfermedades maternas, las principales causas de muerte fueron en primer lugar las hemorragias, seguidas por la hipertensión y el aborto, y finalmente los procesos infecciosos [132].

Una de las complicaciones importantes durante la gestación, son los nacimientos prematuros. Estos se deben principalmente (en $50 \%$ de las ocasiones) a trabajos de partos desencadenados antes de la semana 37 de gestación [133]. El parto prematuro es la principal causa de mortalidad neonatal y morbilidad neurológica a corto y largo plazo. Este problema de salud tiene un impacto social (principalmente debido a la repercusión que tiene sobre la familia) y costo económico. Su frecuencia varía entre 5 y $12 \%$ en las regiones desarrolladas del mundo, pero puede ser de hasta $40 \%$ en las regiones más pobres (Villanueva et al., 2008). Así, al analizar los datos epidemiológicos se genera la necesidad de conocer nuevas herramientas de diagnóstico, así como conocimiento básico, para entender los mecanismos fisiológicos subyacentes durante las últimas fases del embarazo y el trabajo de parto.

Se conoce en realidad poco acerca de cómo se desencadena el trabajo de parto en la mujer, es por ello por lo que se propone el uso de parámetros de la FFC como herramientas de diagnóstico, al ser un método no invasivo para investigar la actividad del 
SNA. Con éste, se indagará acerca de los mecanismos homeostáticos involucrados en el trabajo de parto. En particular, se consideró que aportaría evidencia de la participación de una posible RCA en la mujer, con el fin de contender ante un escenario de inflamación exacerbada. Si bien existe evidencia que algunos de los parámetros de las FFC (como por ejemplo el SDNN, RMSSD, PNN50, HF, LF, HF/LF), se han correlacionado con procesos proinflamatorios/antiinflamatorios (sección 1.5), surge la necesidad de buscar otros medios que pudieran confirmar la existencia de una respuesta antiinflamatoria.

Así, la búsqueda de las interacciones entre las FFC y los marcadores proinflamatorios/antiinflamatorios, pueden dar una idea de la interacción de los mecanismos fisiológicos neuroinmunes involucrados para desencadenar el trabajo de parto. 


\subsection{Objetivos}

\section{Objetivo general}

Asociar una respuesta inmune con la dinámica de las fluctuaciones de la frecuencia cardiaca durante el trabajo de parto a término y de bajo riesgo, involucrando la acción de una ruta colinérgica y la cuantificación de citoquinas proinflamatorias y antiinflamatorias.

\section{Objetivos particulares}

- Validar si los parámetros no lineales de las FFC son sensibles a un proceso de inflamación sistémico (endotoxemia) a través de un montaje de un modelo experimental en roedores.

- Examinar los posibles efectos antiinflamatorios de la oxitocina en un modelo experimental en ratas a través del análisis de las FFC y la respiración derivada del ECG usando registros telemétricos de datos fisiológicos.

- Analizar longitudinalmente las citoquinas proinflamatorias y antiinflamatorias en un grupo de mujeres en tercer trimestre de gestación y posteriormente en el trabajo de parto.

- Buscar correlaciones entre parámetros de las FFC y las citoquinas proinflamatorias y antiinflamatorias, así como usar herramientas de reconocimiento de patrones para futuras aplicaciones diagnósticas. 


\subsection{Hipótesis}

Considerando que el trabajo de parto a término es un estado inflamatorio desencadenado por un estímulo estéril, y que a su vez éste involucra una intensa actividad muscular, gasto energético y daño tisular, entonces las FFC reflejarán una respuesta autonómica cardiaca con participación colinérgica como un mecanismo homeostático en el trabajo de parto.

\subsection{Consideraciones iniciales}

Con base en los antecedes, es posible considerar al trabajo de parto a término como un evento inflamatorio estéril, en donde la madre y el feto tienen un rol modulador endocrino e inmunológico importante (Figura 1.15). En este sentido, el análisis de las FFC maternas podría proveer evidencia acerca de los mecanismos involucrados en la generación de una RCA potencial, asumiendo que la participación de esta vía se manifestará como un mecanismo homeostático para contender ante el proceso de alta demanda energética derivado de un proceso inflamatorio exacerbado, como lo es el trabajo de parto. Las FFC fetales también podrían representar un marcador importante para entender más acerca del proceso inflamatorio durante el trabajo de parto; sin embargo, esta investigación sólo se enfocará a estudiar a la madre.

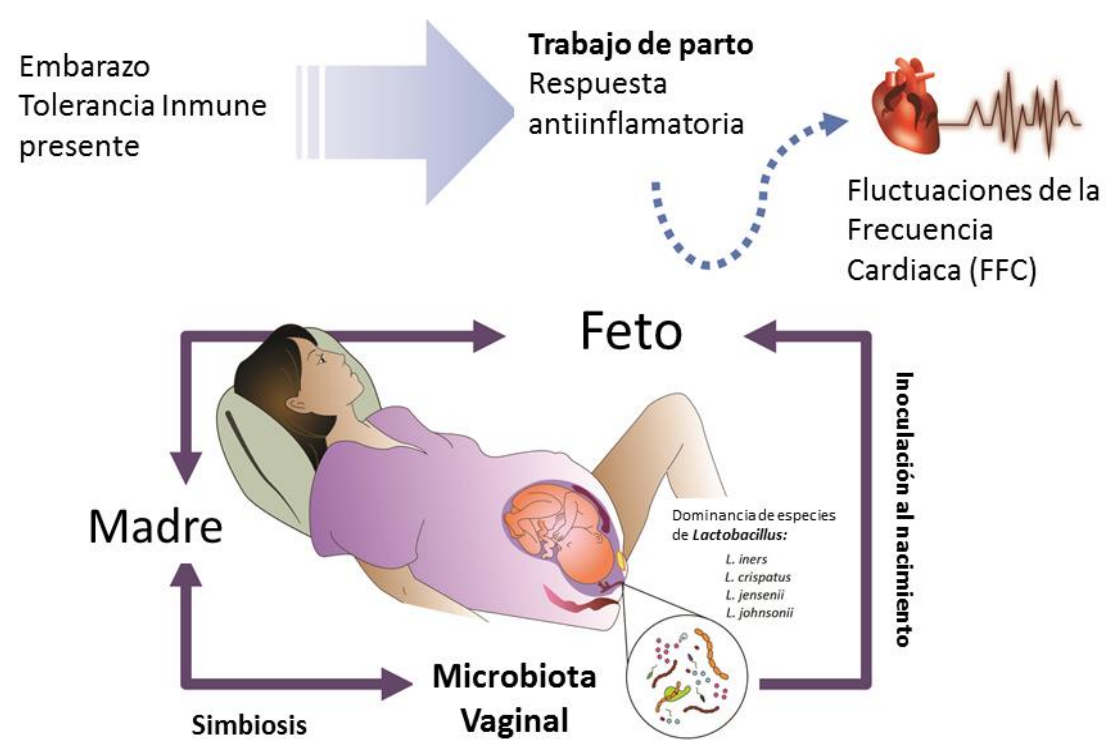

Figura 1.15. Interacción sugerida entre la madre, el feto e incluso con la microbiota vaginal. Se manifiesta una posible respuesta antiinflamatoria estéril durante el trabajo de bajo riesgo a término, ya sea por la acción de una vía colinérgica, mioquinas de tipo uterino o el microbioma vaginal. Imagen tomada de [85]. 


\section{Capítulo II}

\section{Técnicas de análisis lineal y no lineal de las FFC y sistemas de adquisición}

Resumen: El capítulo II introduce a los métodos matemáticos y las técnicas de análisis de las FFC con un especial énfasis en las técnicas no lineales, así como también al material utilizado, que incluyen los sistemas de adquisición de biopotenciales por telemetría y la tecnología para la cuantificación de marcadores inflamatorios. Esta información es necesaria para un buen entendimiento de la tesis. En primer lugar, el algoritmo de detección de pico y el preprocesamiento que las señales fisiológicas se describe en la Sección 2.1. La Sección 2.2 describe los métodos del análisis de las FFC en el dominio del tiempo y dominio de la frecuencia. La sección 2.3 ofrece una visión general de algunas técnicas no lineales que evalúan la complejidad y comportamiento caótico en las FFC. Adicionalmente una aplicación como lo es la respiración derivada del ECG (EDR) es explicada en la sección 2.4. Por último, de las secciones 2.5 a 2.7 se detallan las características de los equipos de adquisición de datos fisiológicos e inmunológicos utilizados, y finalmente en la sección 2.8 se sintetizan de manera general los aportes de este capítulo a la tesis.

\subsection{Preprocesamiento del ECG y detección de la onda $\mathbf{R}$}

El análisis de las FFC se basa en las fluctuaciones en los intervalos R-R. Esto significa que el primer paso en el procesamiento del ECG es determinar la ubicación de los picos R de los complejos QRS. El algoritmo de detección Pan-Tompkins para QRS en tiempo real está basado en el análisis de la pendiente, la amplitud y el ancho de los complejos QRS [134]. El algoritmo incluye una serie de filtros y métodos que involucran un filtro paso bajo, un filtro paso alto, derivación, elevación al cuadrado, integración, umbrales adaptativos y procedimientos de búsqueda como es ilustrado esquemáticamente en la Figura 2.1.

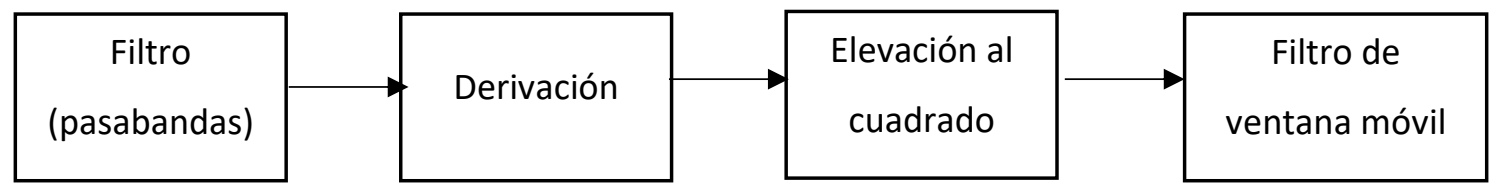

Figura 2.1. Diagrama de bloques del algoritmo Pan-Tompkins para la detección de picos QRS.

En la Figura 2.2 se muestra un segmento de un ECG en donde se aplicó el algoritmo de Pan-Tompkins para localizar los picos $R$ en MATLAB® (The Math-Works Inc., 
Massachusetts, U.S.A). Una vez que ya se tienen localizados los picos $R$, se calcula la distancia entre $R$ y $R$ adyacentes, a esto se le conoce como el intervalo $R-R$ y finalmente todos los intervalos R-R se convierten en una nueva señal, llamada señal de fluctuaciones $\mathrm{R}-\mathrm{R}$ o cardiotacograma, donde los intervalos $\mathrm{R}-\mathrm{R}(\mathrm{ms})$ son representados en el eje $Y$ vs. tiempo el cual es graficado en el eje $X$ (esto fue explicado brevemente en la Figura 1.8, capítulo I de manera general).

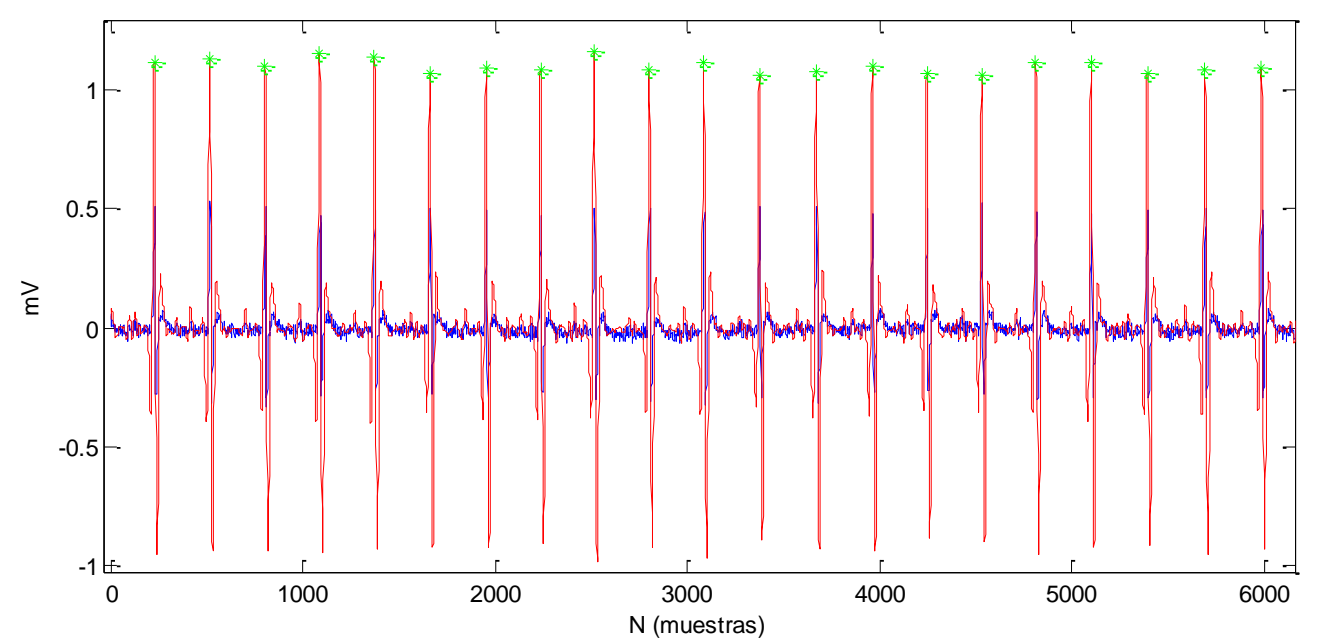

Figura 2.2. Ejemplo de detecciones de los picos $R$ del ECG de una rata por el algoritmo Pan-Tompkins.

Este algoritmo puede presentar errores en la detección de los picos $\mathrm{R}$, es decir, detecciones de picos erróneos o falta de detección de picos. La Figura 2.3 muestra una señal de fluctuaciones $R-R$ en donde el algoritmo falló en la detección de algunos picos $R$, originando artefactos que se ven reflejados en la señal como amplitudes muy grandes del R-R.

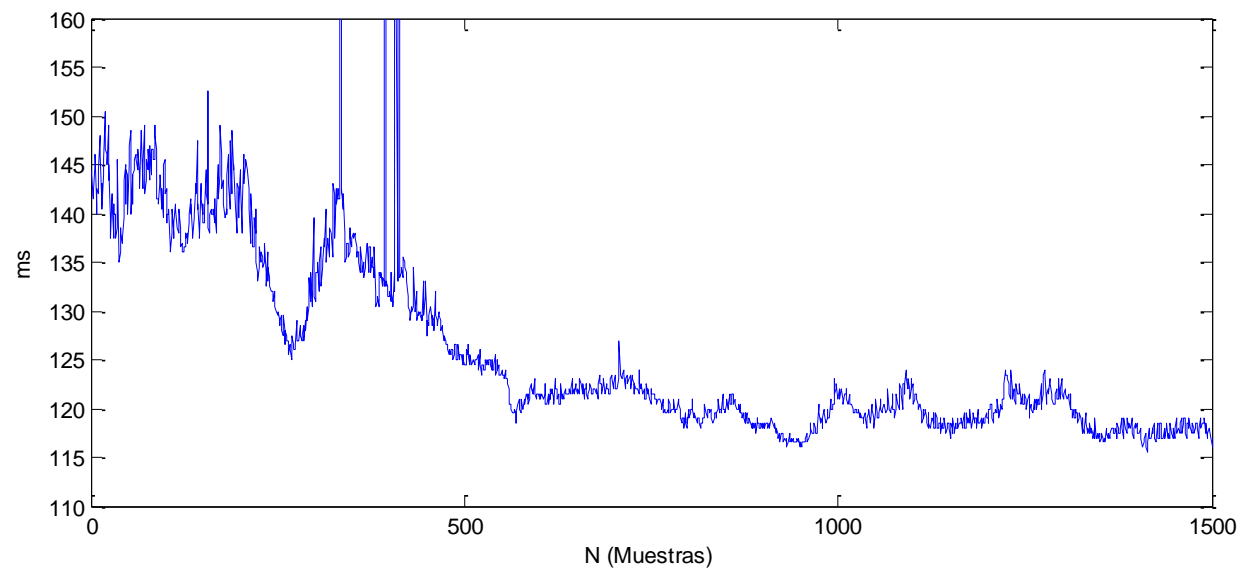

Figura 2.3. Señal de intervalos $R-R$ de una rata, se observan artefactos debido a la falta adecuada de detección de los picos $R$ (amplitud de R-R grande). 
Con el propósito de remover artefactos, se implementó la metodología propuesta por Wessel et al. que consiste en un algoritmo de filtrado adaptativo validado previamente para eliminar latidos ectópicos y errores en la detección de latidos [135]. Este algoritmo fue desarrollado basado en el valor promedio adaptativo $\mu_{a}$ y la desviación estándar adaptativa $\sigma_{a}$. Primeramente, para estimar la variabilidad básica en las series, una serie binomial de orden siete es calculada. Dada la señal de fluctuaciones $\mathrm{R}-\mathrm{R} x_{1}, x_{2}, \ldots, X_{n}$, la serie binomial filtrada está dada por:

$$
t_{n}=\frac{x_{n-3}+6 x_{n-2}+15 x_{n-1}+20 x_{n}+15 x_{n+1}+6 x_{n+2}+x_{n+3}}{64}
$$

La serie filtrada $t_{1}, t_{2}, \ldots, t_{n}$ refleja el comportamiento global del nodo sinoauricular sin la influencia de artefactos y complejos ventriculares prematuros. El valor promedio adaptativo $\mu_{a}$ y la desviación estándar adaptativa $\sigma_{a}$ de la serie binomial filtrada $t_{1}, t_{2}, \ldots, t_{n}$ está definida como:

$$
\begin{aligned}
\mu_{a}(n) & =\mu_{a}(n-1)-c\left(\mu_{a}(n-1)-t_{n-1}\right) \\
\sigma_{a}(n) & =\sqrt{\mu_{a}(n)^{2}-\lambda_{\alpha}(n)}
\end{aligned}
$$

En donde $c$ es el coeficiente de control $c \in[0,1]$ y $\lambda_{a}$ es el segundo momento adaptativo:

$$
\lambda_{a}(n)=\lambda_{a}(n-1)-c\left(\lambda_{a}(n-1)-t_{n-1} \cdot t_{n-1}\right)
$$

La regla de exclusión para este filtro es la siguiente: el intervalo $R-R$ es clasificado como no normal, si

$$
\begin{aligned}
& \left|x_{n}-x_{n-1}\right|>\frac{p}{100} x_{n-1}+c_{f} \cdot \bar{\sigma}_{a} \quad \mathrm{y} \\
& \left|x_{n}-x_{l v}\right|>\frac{p}{100} x_{l v}+c_{f} \cdot \bar{\sigma}_{a}
\end{aligned}
$$

Donde $p$ es el límite proporcional (aquí es usado $10 \%), c_{f} \cdot \bar{\sigma}_{a}$ es una generalización de la regla $3 \sigma, x_{i v}$ es el último intervalo R-R válido y $\bar{\sigma}_{a}$ es el promedio de $\sigma_{a}$. Valores reconocidos como anormales son reemplazados con un número aleatorio proveniente de la expresión $\left[\mu_{a}(n)-\frac{1}{2} \sigma_{a}(n), \mu_{a}(n)+\frac{1}{2} \sigma_{a}(n)\right]$ para evitar falsas variabilidades. Finalmente, el procedimiento de control adaptativo continúa. De las series de tiempo resultantes 
$x_{1}^{\%}, x_{2}^{\%}, x_{3}^{\%}, \ldots$ del filtrado adaptativo, las series de tiempo binomiales filtradas, así como el valor promedio y la desviación estándar son calculados nuevamente. El valor $x_{n}^{\%}$ se considera anormal si:

$$
\left|x_{n}^{\%}-\mu_{a}(n)\right|>c_{f_{1} \cdot \sigma_{a}(n)}+\sigma_{b}
$$

Donde $c_{f_{1}}$ es el coeficiente del filtro (aquí $c_{f_{1}}=3.0$ ) y $\sigma_{b}$ representa una variabilidad básica (para el análisis de las FFC se usa $\sigma_{b}=20 \mathrm{~ms}$ ). Esta variabilidad básica $\sigma_{b}$ es introducida para reducir errores del filtrado para series de tiempo con baja variabilidad (cercanas a la precisión de los intervalos de detección de los $\mathrm{R}-\mathrm{R}$ ). Los valores anormales son sustituidos con los respectivos valores de las series binomiales filtradas. La ventaja de este procedimiento de filtrado adaptativo es la adaptación espontánea de los coeficientes del filtro debido a cambios sutiles en las series (ejemplo un incremento sutil en la frecuencia cardiaca). Un ejemplo del funcionamiento de este algoritmo se muestra en la Figura 2.4, esta Figura es la versión filtrada de la Figura 2.3. Los intervalos R-R de todas las señales adquiridas para este estudio fueron filtradas mediante la metodología descrita con anterioridad. Cabe mencionar que, para todos los casos estudiados, el número de latidos perdidos nunca excedió de un $10 \%$ del tamaño total del registro.

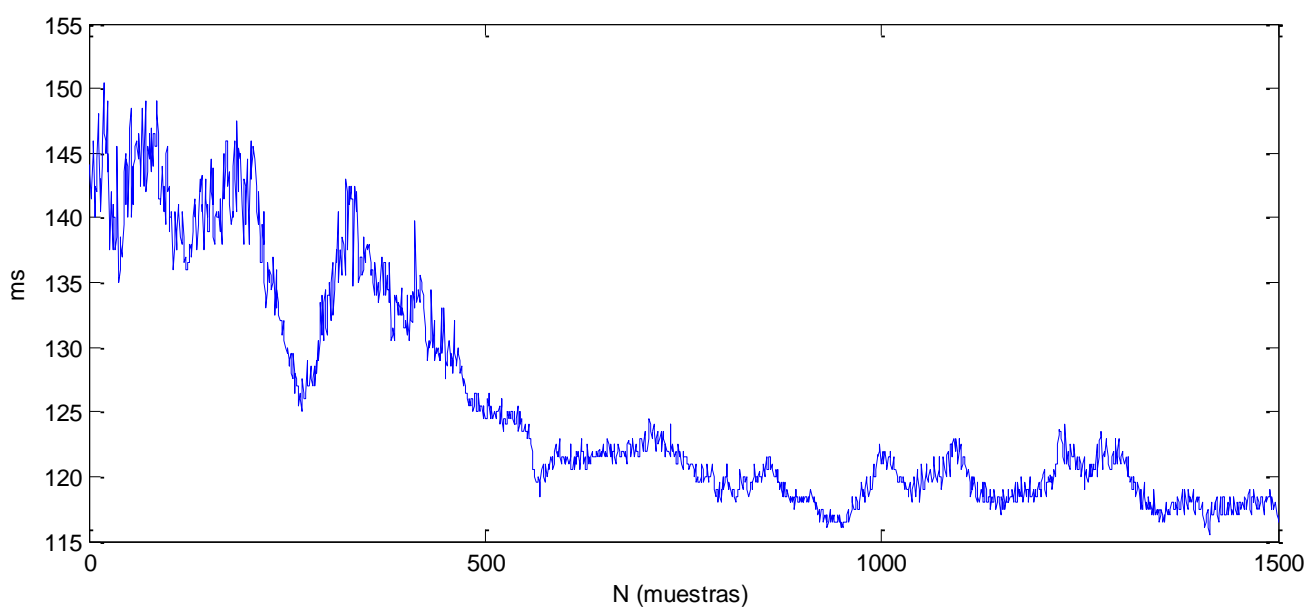

Figura 2.4. Señal de intervalos $R-R$ de una rata posterior a la aplicación del filtrado adaptativo propuesto por Wessel, et al. [135]. 


\subsection{Técnicas lineales del análisis de las FFC}

Las técnicas de análisis lineal de las FFC incluyen al domino del tiempo y al dominio de frecuencia, dichas técnicas fueron estandarizadas tanto para registros de corta duración (5 minutos) como también para registros de larga duración (hasta 24 horas) en un artículo por la Sociedad Europea de Cardiología y la Sociedad Norteamericana de Marcapasos y Electrofisiología [86].

Métodos en el dominio del tiempo. Los métodos en el dominio del tiempo son la manera más simple de evaluar las FFC e involucran análisis estadísticos de los datos, entre estos métodos se encuentran:

- SDNN (ms): Desviación estándar de todos los intervalos normal a normal (N-N) identificados en el electrocardiograma. Este parámetro refleja tanto la actividad simpática como la parasimpática y, por tanto, proporciona un índice de variabilidad total.

- RMSSD (ms): Raíz cuadrada del promedio de la suma de las diferencias cuadráticas entre intervalos $\mathrm{R}-\mathrm{R}$ adyacentes. A nivel fisiológico este parámetro refleja la modulación autonómica predominantemente a nivel vagal; es más estable y recomendable respecto a otros similares [136]. Así mismo, no requiere de longitudes de datos muy extensas para poder estimarlo adecuadamente [137].

- pNN50 (\%): En particular se define como el porcentaje de diferencias absolutas en intervalos normal a normal N-N consecutivos que son mayores a 50 milisegundos. Se ha propuesto que este índice se asocia a la actividad cardiaca vagal [138] .

Es importante indicar que en este trabajo de investigación se construyeron las series de tiempo R-R sin excluir de primera estancia posibles latidos ectópicos de los electrocardiogramas, sin embargo gracias al algoritmo de filtrado adaptativo descrito en la sección anterior (y que está validado para disminuir errores en la detección y latidos ectópicos [139]), las series de tiempo $R-R$ filtradas son consideradas como una aproximación de series de tiempo normal a normal N-N, lo que proporciona la posibilidad de estimar de una manera apropiada los parámetros temporales SDNN y pNN50.

Métodos en el dominio de la frecuencia. Con el análisis de la densidad espectral de potencia (Power spectral density, por sus siglas en inglés PSD) se obtiene una representación en el que se cuantifican los componentes, en frecuencia y amplitud, de una 
señal. De igual manera se analiza el cardiotacograma o señal de fluctuaciones $R-R$ y se obtienen las diferentes bandas espectrales que pueden corresponder a variables fisiológicas determinadas [140]-[142] (Figura 2.5).

El análisis de PSD puede realizarse utilizando diversas estimaciones matemáticas, entre los cuales los más conocidos son los métodos paramétricos, que comúnmente están basados en modelos autorregresivos (AR) y media móvil (MA), y los no paramétricos basados en la transformada discreta de Fourier.

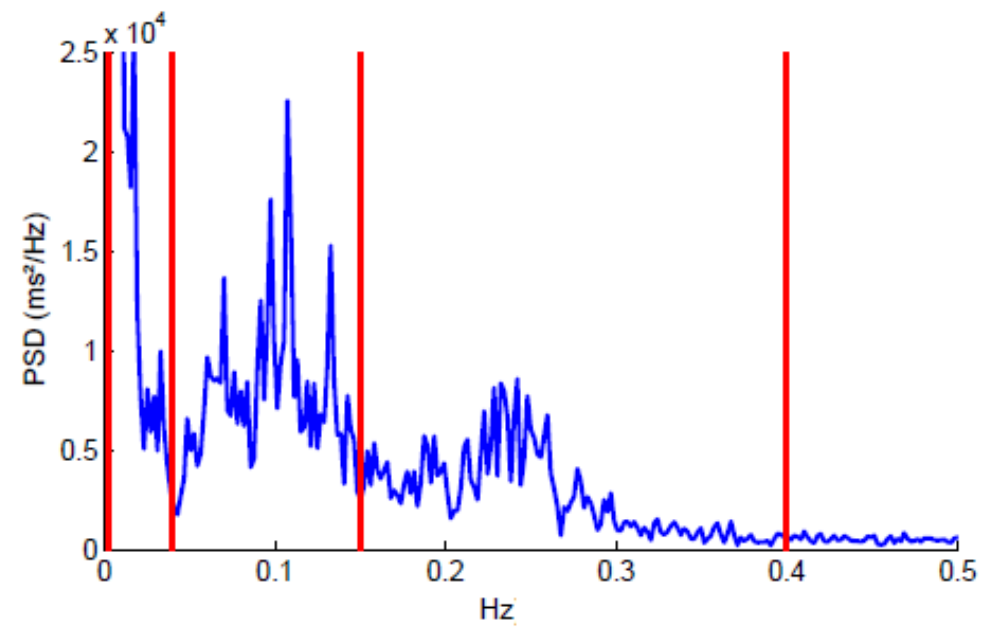

Figura 2.5. Densidad espectral de potencia (PSD) de una señal de fluctuaciones R-R. Las diferentes bandas son indicadas por las líneas rojas verticales: Muy baja frecuencia (VLF, 0-0.04 Hz), baja frecuencia (LF, 0.04$0.15 \mathrm{~Hz}$ ) y alta frecuencia (HF, 0.15-0.4 Hz). Imagen tomada de [143].

En este tipo de métodos se descompone la serie de tiempo R-R, para obtener las bandas espectrales de alta frecuencia (HF), la de baja frecuencia (LF), y la de muy baja frecuencia (VLF) [86], [140], (Tabla 2.1).

Tabla 2.1. Mediciones en el dominio de la frecuencia de las FFC en humanos. Análisis en registro de corta duración (5 minutos). *Tabla de acuerdo a Task Force, 1996.

\begin{tabular}{|c|c|c|c|}
\hline Variable & Unidades & Descripción & $\begin{array}{c}\text { Rango de } \\
\text { frecuencia }\end{array}$ \\
\hline $\begin{array}{c}\text { Potencia total } \\
\mathbf{5} \text { minutos }\end{array}$ & $\mathrm{ms}^{2}$ & Varianza de los intervalos R-R & $<0.4 \mathrm{~Hz}$ \\
\hline VLF & $\mathrm{ms}^{2}$ & Potencia en el rango VLF & $<0.04 \mathrm{~Hz}$ \\
\hline LF & $\mathrm{ms}^{2}$ & Potencia en el rango LF & $0.04-0.15 \mathrm{~Hz}$ \\
\hline LF & $\begin{array}{c}\text { Unidad } \\
\text { normalizada }\end{array}$ & $\begin{array}{c}\text { Potencia LF en unidades normalizadas } \\
\text { LF (Potencia total - VLF) } \times 100\end{array}$ & \\
\hline HF & $\mathrm{ms}^{2}$ & Potencia en el rango HF & $0.15-0.4 \mathrm{~Hz}$ \\
\hline HF & $\begin{array}{c}\text { Unidad } \\
\text { normalizada }\end{array}$ & $\begin{array}{c}\text { Potencia HF en unidades normalizadas } \\
\text { HF (Potencia total }- \text { VLF }) \times 100\end{array}$ & \\
\hline LF/HF & & Relación LF $\left(\mathrm{ms}^{2}\right) / \mathrm{HF}\left(\mathrm{ms}^{2}\right)$ & \\
\hline
\end{tabular}


La actividad vagal se ha asociado principalmente con el parámetro HF [144]. Por otro lado, existe desacuerdo sobre el componente LF. Algunos estudios sugieren que LF es reflejo de una combinación de la actividad simpática como también de la vagal [86]. Por otro lado, la proporción LF/HF se ha considerado que refleja principalmente el balance autonómico [145]. La explicación fisiológica del componente VLF está mucho menos definida y la existencia de un proceso fisiológico específico atribuible a los cambios en el período cardíaco podría incluso ser cuestionada [143]. Los componentes no armónicos que no tienen propiedades coherentes son comúnmente aceptados como contribuciones importantes del componente VLF. Es importante mencionar que el componente VLF evaluado en un tiempo inferior a 5 minutos de registro es una medida dudosa y debe evitarse su interpretación en el corto plazo [143].

\subsection{Técnicas no lineales del análisis de las FFC}

Para fines de este capítulo consideraremos a los sistemas complejos cómo fenómenos compuestos por una gran cantidad de elementos o partes del sistema que interactúan entre sí de forma no lineal, capaces de intercambiar información con su entorno y de adaptar su estructura interna como consecuencia de tales relaciones [146], [147]. Debido al múltiple número de factores de entrada que interactúan en los sistemas biológicos complejos, se obtienen salidas complejas. De hecho, el cuerpo humano es considerado como un sistema biológico complejo per sé, las salidas (un ejemplo de ello serían las señales fisiológicas) tienen la peculiaridad de presentar un comportamiento en donde sus propiedades estadísticas cambian conforme el tiempo avanza, es decir, tienen propiedades no estacionarias, además de que se caracterizan por ser irregulares y no lineales. Se considera que la no linealidad de las series de tiempo fisiológicas generadas por los seres vivos rompe con el paradigma lineal de la homeostasis y las metodologías bioestadísticas tradicionales [148]. En este sentido, para el análisis de los sistemas complejos se ocupan métodos estadísticos que permitan cuantificar el grado de irregularidad de un sistema, y que principalmente, están basados en técnicas de análisis no lineal.

No obstante, los modelos teóricos han estado limitados por un abordaje lineal y reduccionista dominante. Es por ello por lo que el análisis lineal de las FFC, no son precisamente las técnicas más adecuadas para el estudio de señales no estacionarias, como es el caso de series de tiempo R-R. Además, debido a que las series de tiempo son finitas, presentan problemas técnicos para separar las componentes provenientes de ruido de las señales biológicas relevantes [149]. 
El estudio de las irregularidades y la no estacionalidad en la variabilidad de los intervalos cardiacos ha llevado al desarrollo de nuevos métodos matemáticos y ha sido todo un reto en el campo de la biofísica aplicada y la ingeniería biomédica. En este contexto, algunos métodos de física estadística han permitido corroborar que las FFC presenta una complejidad o estructura (geometría fractal) que estadísticamente se repite a lo largo de diferentes escalas temporales [150], [151].

Métodos fractales. El término forma parte de una concepción geométrica para describir y agrupar formas matemáticas o naturales que no son adecuadamente representadas por las estructuras regulares [152]. De esta manera, dicho enfoque se ha utilizado para explorar formas o comportamientos naturales complejos, específicamente en donde se encuentre involucrada cierta aleatoriedad y el grado de irregularidad se repita estadísticamente a lo largo de diferentes escalas o ventanas de observación. De esta manera y como respuesta de un sistema complejo, el ritmo cardiaco normal tiene características fractales, es decir, la estructura del ritmo es autosimilar al ser medida en distintas escalas temporales (Figura 2.6) cuya manifestación se modela a través de una ley de potencia [153]. El objetivo del análisis fractal es identificar la autoafinidad de la serie de tiempo, es decir, la existencia de fluctuaciones estadísticamente similares en diferentes escalas temporales misma que puede ser sugerida por la cuantificación de exponentes de escalamiento [154]. Entre los métodos fractales, se puede mencionar el análisis de fluctuaciones sin tendencia (DFA), que cuantifica los exponentes de escalamiento fractal en el corto y largo plazo, $\alpha_{1}$ y $\alpha_{2}$ respectivamente, así como los métodos de análisis multifractal [148], [155].

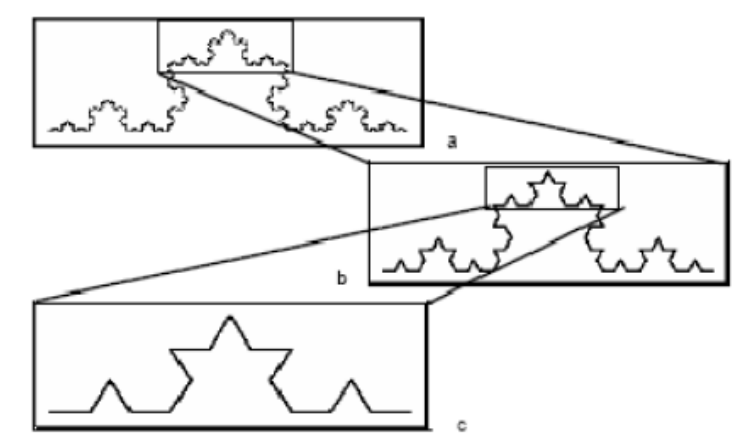

Figura 2.6. Un ejemplo de la propiedad fractal con las características de autosimilitud en distintas escalas temporales: a) copo de nieve de Koch, b y c detalles de la parte superior del copo de nieve. Imagen tomada de [143]. 
Análisis DFA. Se utiliza para cuantificar las propiedades de escalamiento fractal en intervalos cortos de señales. Esta técnica es una modificación del valor cuadrático medio (RMS) de la formalización matemática llamada caminata aleatoria o random walks aplicado a señales no estacionarias [156]. Primero, la serie de tiempo R-R o segmentos se integran o acumulan por:

$$
Y(k)=\sum_{i=1}^{k}\left[R R(i)-R R_{\text {ave }}\right]
$$

Donde $Y(k)$ es el k-ésimo valor que resulta de la suma acumulativa (proceso de integración) de ( $k=1,2, \ldots, L)$. R-R(i) es el i-ésimo intervalo $\mathrm{R}-\mathrm{R}, R R_{a v e}$ es la media de la serie R-R original completa o segmentos de longitud L. El proceso integración exagerará la no estacionalidad de la serie de datos originales. La metodología consiste en estudiar las propiedades fractales de las series de tiempo acumuladas (integradas), en lugar de las de las señales originales. Un ejemplo físico bien conocido con relevancia para las series de tiempo biológicas es la dinámica del movimiento browniano. En este caso, la fuerza aleatoria (ruido) que actúa sobre las partículas está limitada, similar a las series temporales fisiológicas. Sin embargo, la trayectoria (una integración de todas las fuerzas) de la partícula browniana no está limitada y presenta propiedades fractales que pueden ser cuantificadas por un parámetro de autosimilitud.

Posteriormente se miden las características en la ordenada de la serie de tiempo. Para lo cual, la serie de tiempo integrada se divide en segmentos de igual longitud, $n$. Para determinar la tendencia en cada segmento de longitud $n$, se ajustan las variaciones a una recta (por el método de mínimos cuadrados) o a un polinomio de orden mayor. Los valores del segmento de ajuste están dados por $Y_{n}(k)$. Después se eliminan las tendencias en la serie de tiempo integrada, $Y(k)$, al restarle la tendencia local $Y_{n}(k)$, en cada segmento (Figura 2.7a).

Para la serie completa con segmentos de longitud $n$ sin tendencia, se calcula la amplitud de las fluctuaciones de la serie de tiempo integrada (su valor RMS) por medio de:

$$
F(n)=\sqrt{\frac{1}{L} \sum_{k=1}^{L}\left[Y(k)-Y_{n}(k)\right]^{2}}
$$


Este cálculo se repite sobre las escalas de tiempo (o tamaño de los segmentos $n$ ) para dar la relación entre $F(n)$ y el tamaño del segmento $n$. Es de esperarse que $F(n)$ se incremente conforme la longitud $n$ del segmento sea mayor (Figura 2.7b).

La relación existente (gráfica log-log) entre las fluctuaciones $F(n)$ y la escala de tiempo o ventana $n$ se ajusta aproximadamente por un modelo lineal:

$$
F(n) \sim n^{\alpha}
$$

Dicha relación lineal en la gráfica de log $F(n)$ vs. log (n) (Figura 2.7b) sugiere la presencia de autoafinidad en las fluctuaciones, la pendiente de la recta es el exponente fractal $\alpha$, (parámetro o exponente de escalamiento). Si la pendiente resultante o el exponente de escalamiento a es: a) igual a 0.5 indica existencia de ruido blanco y la ausencia de correlaciones de largo plazo; b) $0.5<\alpha<1$ refleja un comportamiento de un proceso que tiene correlaciones de largo plazo o inclusive fractalidad; y c) $\alpha>1$, indica la existencia de correlaciones pero que no necesariamente siguen una ley de potencia 0 presentan un comportamiento estocástico; d) si $\alpha<0.5$ existe un comportamiento anticorrelacionado [157]. En el caso de las FFC normalmente se determina el exponente fractal $\alpha$ para dos regiones de la gráfica, un exponente fractal $\alpha_{1}$ corresponde al corto plazo con tamaño de la ventana entre 4 a 11 latidos, $4 \leq n \leq 11$, y un segundo exponente fractal $\alpha_{2}$ para ventanas con más de once latidos, $n>11$ (Figura 2.7b). Cabe mencionar que el exponente de escalamiento $\alpha_{1}$ presenta cambios debido al tamaño del registro. Dicho exponente se ha validado para obtenerse a partir de registros de corta duración (5-10 minutos con al menos 300 muestras) [158]. 


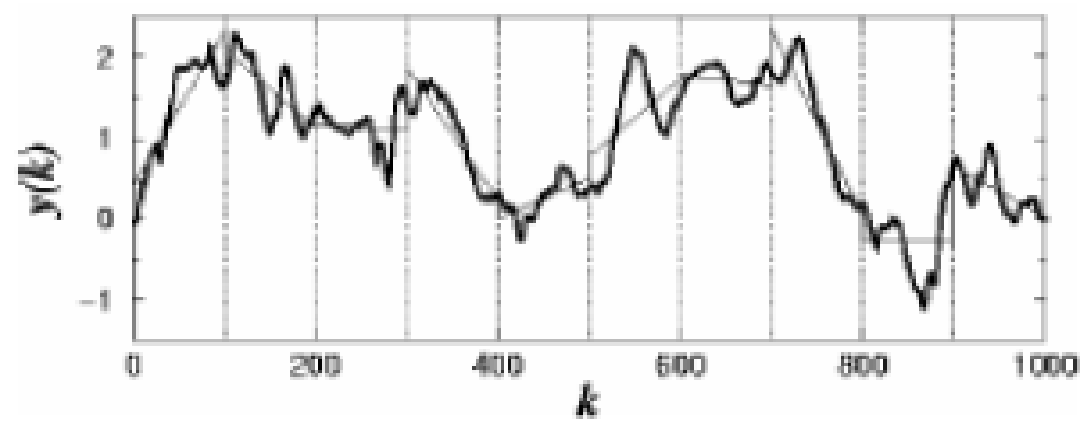

(a)

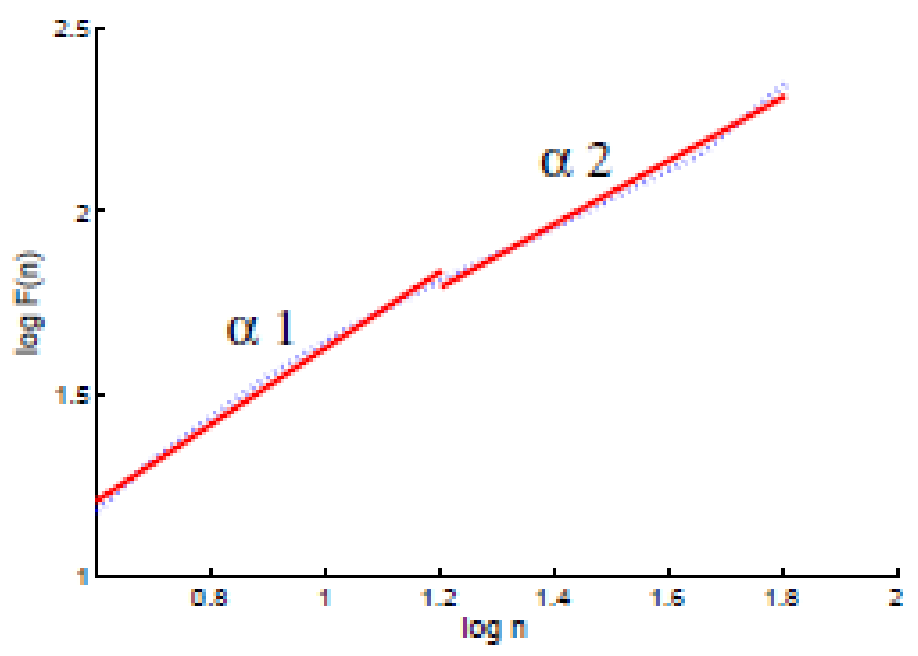

(b)

Figura 2.7. El principio del análisis de fluctuaciones sin tendencia o DFA. (a) La serie de tiempo integrada $y(k)$, calculada a partir de la serie de tiempo del intervalo $\mathrm{R}-\mathrm{R}$ dada en la ecuación (7). Los puntos verticales representan una ventana de $n=100$, y la línea sólida representa la tendencia en cada ventana. La fluctuación, en este caso $F(100)$, se calcula entonces como el cuadrado medio de la diferencia entre las series de tiempo integradas $y(k)$ y la serie de tendencias. Al cambiar el tamaño de ventana $n$, pueden obtenerse otros valores de fluctuación $F(n)$. (b) Gráfico del DFA que representa el logaritmo del tamaño de ventana $n$ vs. el logaritmo de las fluctuaciones $F(n)$. Las líneas rojas trazadas en la parte superior pertenecen al análisis de regresión en dos zonas, cuyas pendientes indican la correlación a corto plazo $\alpha_{1}$ y la correlación en el largo plazo $\alpha_{2}$. Imagen tomada de [143]. 


\section{Análisis de escalamiento de latidos cardiacos sanos}

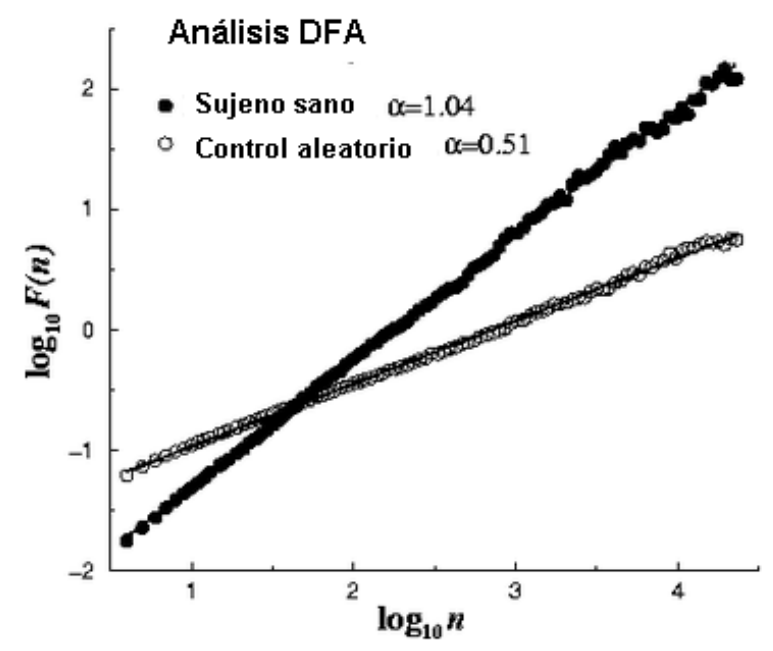

Figura 2.8. Gráfica $\log F(n)$ vs. $\log (n)$ del análisis de fluctuaciones sin tendencia o DFA. Análisis de escalamiento para dos señales de fluctuaciones $\mathrm{R}-\mathrm{R}$ de 24 horas de duración. Los círculos negros representan datos de un sujeto sano, mientras que los círculos blancos indican series generadas artificialmente a partir de datos aleatorios. (Figura tomada de PhysioNet, Is the Healthy Human Heartbeat Fractal?, recuperada al día 05 de abril de 2017).

El análisis de la dinámica de las fluctuaciones de la frecuencia cardíaca con métodos para el estudio de la dinámica de sistemas tales como los métodos basados en la teoría del caos y de sistemas no lineales, han resultado de relevancia [159]. Así, algunos estudios observacionales han sugerido que algunos índices no lineales que describen la dinámica del ritmo cardíaco, como los exponentes de escalamiento fractal, pueden proporcionar información pronostica útil en diversas situaciones clínicas (Figura 2.8) y tienen mejor reproducibilidad que la de los índices tradicionales [159].

Los dos exponentes de escalamiento $\alpha_{1}$ (4 a 11 latidos) y $\alpha_{2}$ (>12 latidos) a corto y a largo plazo respectivamente, se pueden obtener con el método DFA para el análisis de las fluctuaciones $R-R$, dichos exponentes son potencialmente útiles para poder distinguir entre series de tiempo normales y patológicas [156], [157], [160]-[162] (Figura 2.9). Tal como se ha mencionado el exponente $\alpha_{1}$ ha demostrado, entre todos los métodos tradicionales de análisis de las FFC, ser el mejor parámetro para predecir mortalidad en pacientes con función ventricular izquierda disminuida [162]. El comportamiento del exponente fractal $\alpha_{1}$ se encuentra vinculado con los mecanismos de control de corto plazo del sistema de control cardiovascular, como pueden ser los relacionados con el SNA, mientras que el exponente fractal $\alpha_{2}$ se asocia con los mecanismos de largo plazo del sistema de control cardiovascular [156], [157], [160], [161] (Figura 2.9). 

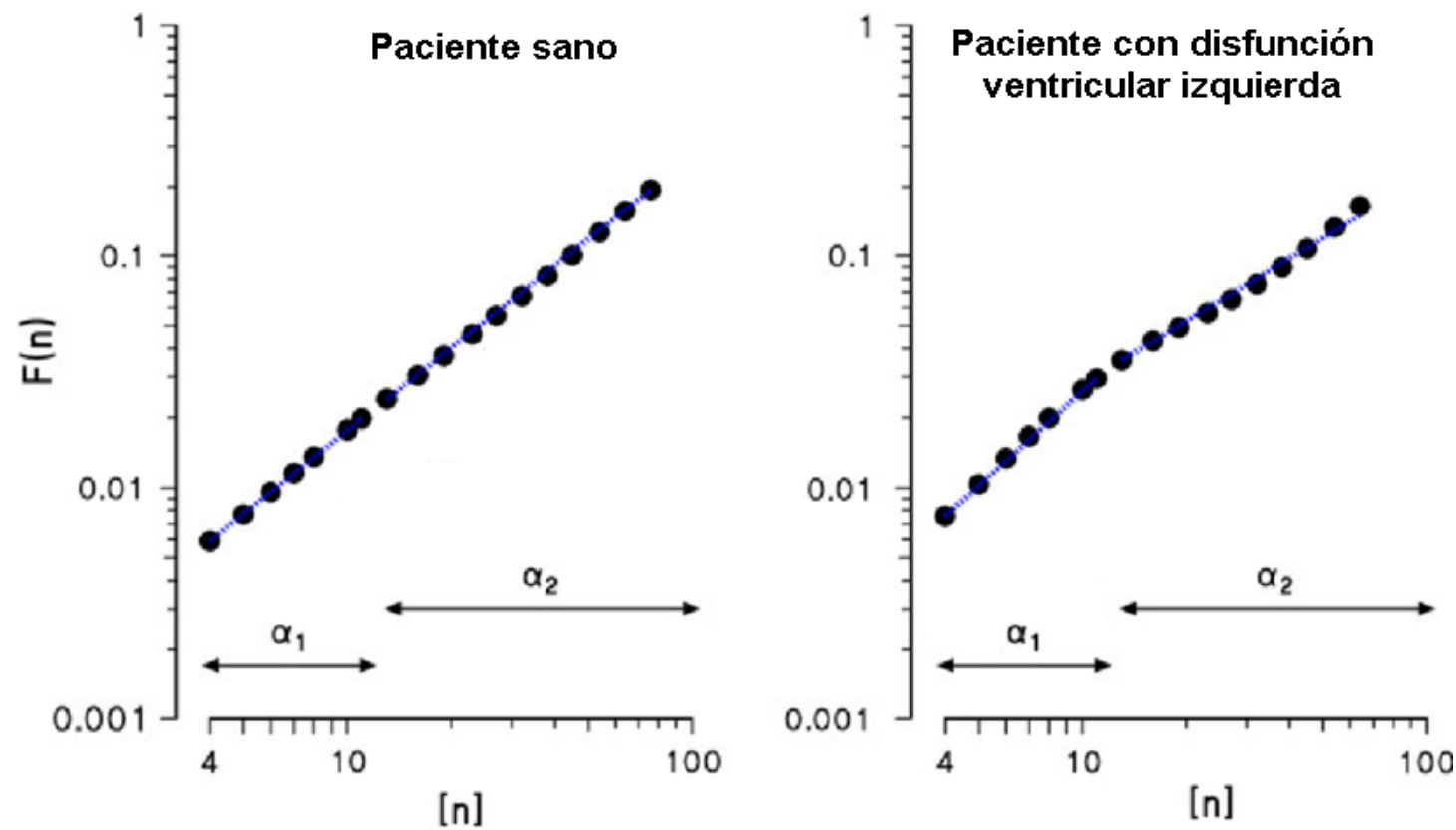

Figura 2.9. Ejemplos del análisis DFA sobre señales de fluctuaciones $R-R$ en un sujeto sano y un paciente con disfunción ventricular izquierda (síndrome de Takotsubo). La raíz cuadrática media de las fluctuaciones sin tendencia, $F(n)$, se representa en función del tamaño de la ventana $n$ en una escala log-log. Los exponentes del corto plazo $\left(\alpha_{1}\right)$ y en el largo plazo $\left(\alpha_{2}\right)$ se calculan como pendientes de las líneas de regresión (segmentos de puntos) calculados sobre los tamaños de ventana $n$. En este ejemplo se observa un cambio en la pendiente en el $\alpha_{2}$ para el paciente con la cardiopatía en comparación del paciente sano. Imagen extraída de [162].

Así mismo, se ha visto que propiedades fractales alteradas de las series de fluctuaciones R-R preceden a un evento de fibrilación ventricular, circunstancia de relevancia en el ámbito clínico ya que incluso los índices tradiciones de las FFC no llegan a presentar valores anormales [163]. Otros estudios sugieren que el comportamiento fractal de las fluctuaciones de la frecuencia cardiaca humana está determinado por las acciones del control simpático y parasimpático, ya que se ha encontrado que una dinámica aleatoria en las FFC está vinculada a una coactivación simpática/parasimpática y así mismo a una pérdida de la fractalidad. En contraste, cambios en la regulación autonómica, por ejemplo, un actividad parasimpática disminuida en el momento que se presenta una actividad simpática aumentada provoca un cambio en la dinámica de las FFC hacia un comportamiento mayormente fractal [164].

Análisis de magnitud y signo (MSA). Estudios han reportado que las fluctuaciones tienen un comportamiento dinámico que podría ser caracterizada por medio de dos componentes, magnitud (valor absoluto) y signo (dirección). Estos dos parámetros reflejan las interacciones subyacentes en un sistema [118]. 
Las correlaciones positivas en las series de magnitud (es decir un $\alpha_{1(\mathrm{MAG})}>0.5$ ) ha mostrado ser un marcador fiable de propiedades no lineales (complejidad), mientras que el exponente de signo $\alpha_{1(\mathrm{SIGN})}$ provee información con respecto a la organización temporal de las series originales en relación a la forma en que los incrementos se alternan (direccionalidad), indicando si un incremento positivo o negativo es más probable que ocurra dado un incremento actual, y se encuentra relacionado con las propiedades lineales de escalamiento de la serie original [118].

Por otro lado, se sabe que las series de magnitud exhiben comportamiento correlacionado en sujetos sanos y las series de signo presentan un comportamiento anticorrelacionado para series menores a 100 latidos; para escalas más grandes de 100 latidos las series de signo pueden perder las correlaciones. Los exponentes $\alpha_{1(\mathrm{MAG})}$ y $\alpha_{1(\mathrm{SIGN})}$ podrían ayudar a distinguir entre grupos de pacientes sanos y patológicos [118]. La utilización de la descomposición de signo y magnitud en las series de la frecuencia cardiaca podría ayudar a sugerir una regla dinámica para incrementos de la frecuencia cardiaca sanos (un incremento en las fluctuaciones en una dirección positiva es probable que sea seguido por un incremento en la dirección opuesta). Estos exponentes podrían ser usados para propósitos de diagnóstico, debido a que la descomposición en series de magnitud y tiempo reflejan aspectos de la regulación autonómica.

Para el cálculo de los exponentes de magnitud y signo, se sigue el siguiente procedimiento previamente propuesto [118]:

Cualquier serie de tiempo a largo plazo $X_{i}$ puede ser descompuesta en dos diferentes subseries formadas por la magnitud y el signo de los incrementos. Se aplica análogamente el método DFA como se describió en la sección anterior para encontrar correlaciones en las series de signo y magnitud.

El análisis de correlación de la descomposición de magnitud y signo consiste en los siguientes pasos:

1. Dada una serie de tiempo $x_{i}$, se crea la serie de incrementos $\Delta X_{i=X_{i+1}-X_{i}}$

2. La serie de incrementos se descompone en series de magnitud $\left|\Delta X_{i}\right|$ y series de signo $(\Delta \mathrm{Xi})$.

3. Se elimina la tendencia al restar a las series de magnitud y signo su respectiva media

4. Debido a las limitaciones en la precisión del método DFA para estimar los exponentes de escalamiento de series anticorrelacionadas (con exponente de escalamiento a $<0.5)$, primero se integran las series de magnitud y signo. Las series integradas son en 
consecuencia correlacionadas y sus exponentes de correlación pueden ser estimados precisamente usando el método DFA.

5. Se aplica el método DFA.

6. Para obtener los exponentes de escalamiento de magnitud y signo de las series, se calcula la pendiente de $F(n) / n$ de una gráfica log-log. Se usa una función de fluctuación normalizada $F(n) / n \sim n^{\alpha-1}$ para compensar la integración realizada en el paso 4 , esto posibilita interpretar los resultados en el nivel de las series de incremento $\left|\Delta X_{i}\right|$, y $\operatorname{signo}\left(\Delta X_{i}\right)$ en lugar del nivel de las series integradas.

En la Figura 2.10 se muestra de manera esquemática los pasos anteriormente descritos para realizar el MSA, posteriormente en la Figura 2.11 se muestra un ejemplo del procesamiento con una serie de tiempo R-R. 


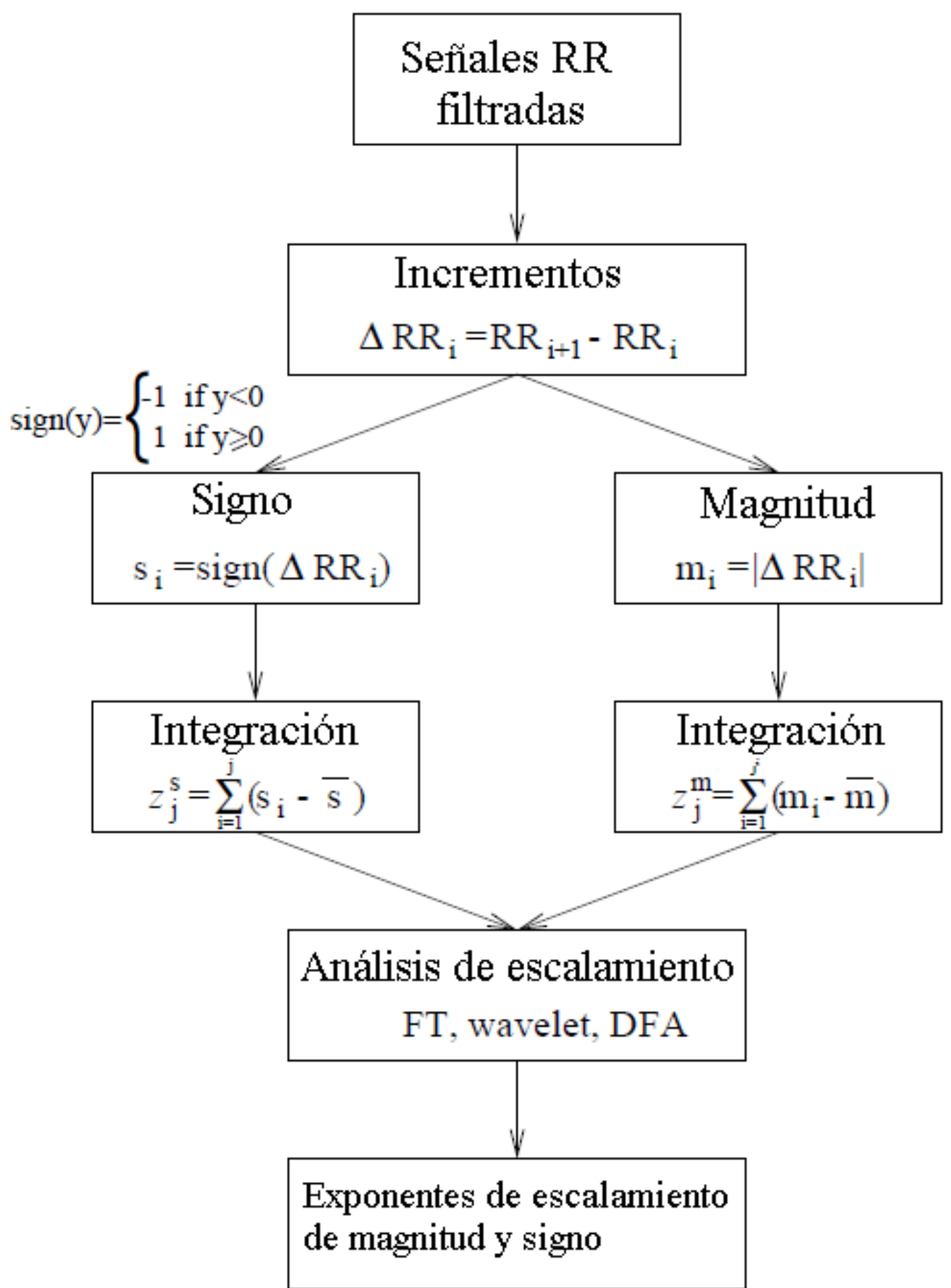

Figura 2.10. Representación esquemática de la descomposición en magnitud y signo de las series de tiempo R-R. FT: Transformada de Fourier, DFA: Análisis de fluctuaciones sin tendencia. Imagen adaptada de [123]. 

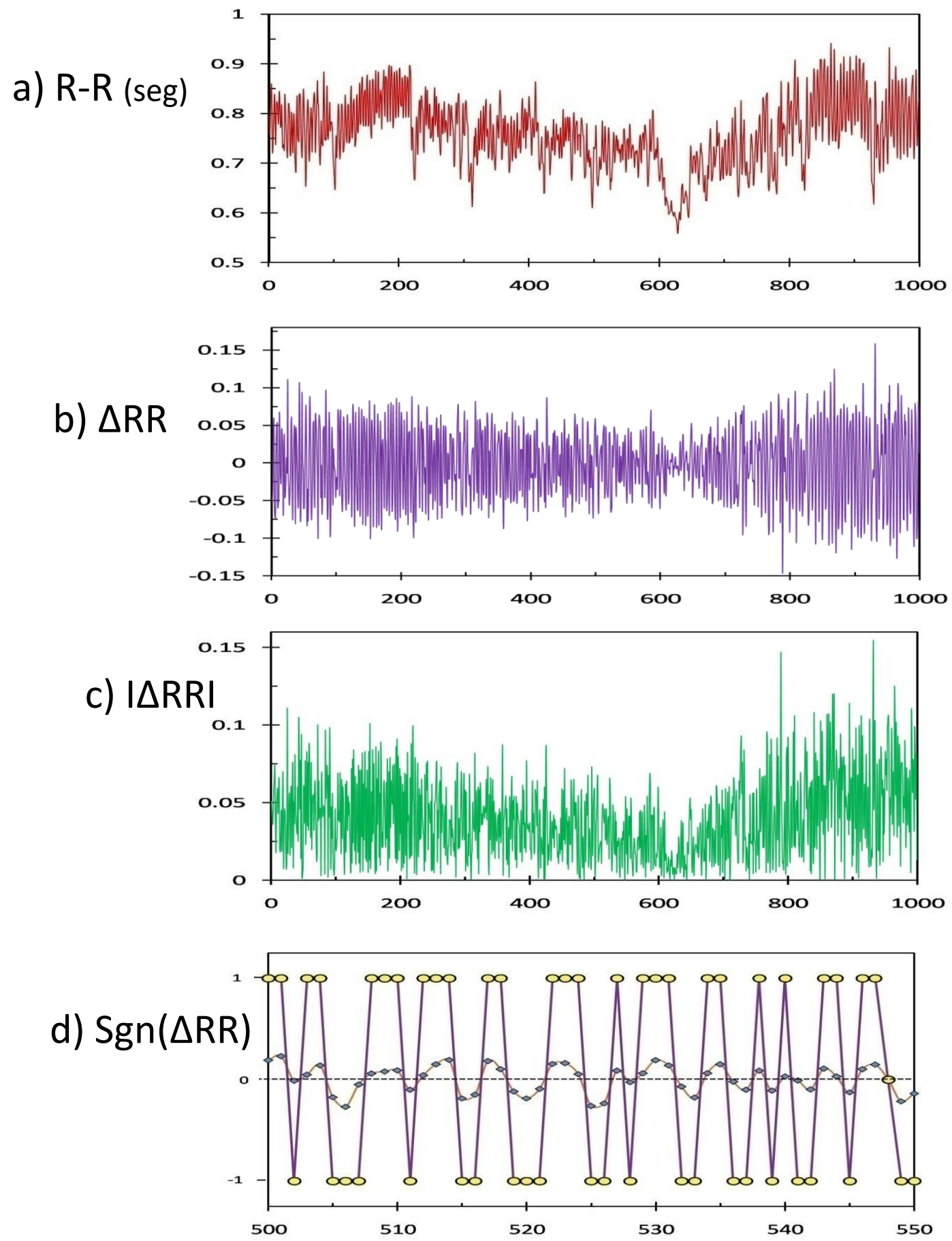

Figura 2.11. Ejemplo del análisis DFA de magnitud y signo. a) Una muestra de 1000 intervalos R-R de una mujer embarazada en la semana 37 de gestación. b) La serie de incrementos $(\Delta R R)$ de la serie de tiempo mostrada en a). c) La serie de magnitud (I $\Delta R R I)$ de la serie de la Figura en a). d) La serie de signo (Sgn $(\Delta R R)$ ) se presenta hasta 550 latidos para una mejor visualización. 
Entropía muestra (SampEn): Es una medida estadística propuesta por Richman y Moorman (2000) [165] que cuantifica la variabilidad de series de tiempo comparando secuencias de puntos de datos consecutivos. Proporciona una medida de la regularidad o previsibilidad de una serie temporal (una alta SampEn se relaciona con baja predictibilidad/alta complejidad). La SampEn se deriva de la probabilidad condicional de que una secuencia de puntos de datos esté dentro de un cierto margen de tolerancia $r$ para $m$ pasos. Esta tolerancia $r$ se mide generalmente en unidades de desviación estándar (DE) de la serie (Figura 2.12). Por lo tanto, la SampEn depende de la longitud de la serie de datos $N$. La longitud $m$ de las secuencias a comparar y el intervalo de tolerancia $r$ que debe ser especificado de datos, pero con una periodicidad diferente. El cálculo de la SampEn se define como:

$$
\operatorname{SampEn}(m, r, N)=-\ln \frac{U^{m+1}(r)}{U^{m}(r)}
$$

Donde $m$ corresponde al tamaño del vector patrón en una serie de tiempo, $r$ indica la tolerancia, $N$ es el tamaño de la serie de tiempo original y $U m(r)$ indica la probabilidad de que ocurra un vector patrón.

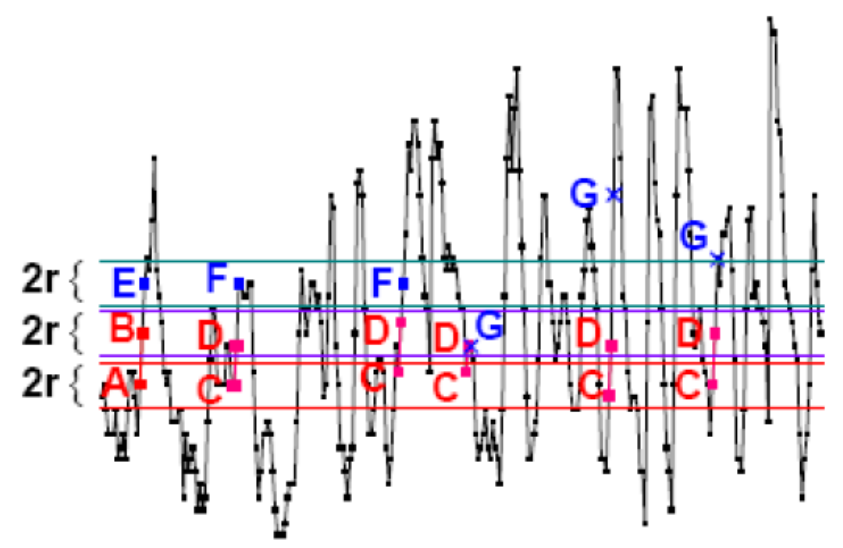

Figura 2.12. Presentación intuitiva del principio de Entropía de Muestra ( SampEn). Para un vector bidimensional $A B$, el nivel de tolerancia $r$ puede representarse por líneas horizontales rojas y violetas alrededor del punto $A$ y $B$ respectivamente, con ancho de $2 r$. DE. Entonces todos los vectores, digamos CD, cuyo primer y segundo punto (respectivamente $C$ y $D$ ) están dentro de los rangos de tolerancia de $A$ y $B( \pm r \cdot D E)$, son contados para medir dentro de un nivel de tolerancia $r$ la regularidad, o frecuencia, de patrones de forma similar a un patrón dado en $A B$. En la Figura, cinco vectores $C D$ están próximos al vector $A B$. Cuando se incrementa la dimensión del vector de 2 a 3 ( $A B E)$, dos vectores, llamados CDF, permanecen cerca mientras que otros tres vectores, CDG, muestran patrones emergentes. Por lo tanto, la probabilidad de permanecer cerca es de aproximadamente $2 / 5$. Es evidente que tal probabilidad tiende a 1 para series regulares y produce SampEn = 0 al tomar el logaritmo, mientras que tiende a 0 para el ruido blanco y resulta infinita teóricamente. Imagen extraída de [166]. 


\subsection{Respiración derivada del electrocardiograma (EDR)}

Durante la respiración y como resultado de los movimientos respiratorios, se modulan diversos parámetros de la señal de ECG como por ejemplo: la amplitud, la frecuencia cardíaca, y la línea de base [167]. La señal respiratoria derivada del electrocardiograma (ECG-derived respiration por sus siglas en inglés EDR) se basa en la observación de que las posiciones de los electrodos de ECG en la superficie del tórax se mueven en relación con el corazón [168]. Además, la impedancia transtorácica varía, a medida que los pulmones se llenan y se vacían de aire. Por lo tanto, las derivaciones cardiacas de los ejes varían en diferentes puntos del ciclo respiratorio y son mediciones suficientemente precisas del eje eléctrico cardiaco medio que muestran variaciones que están correlacionadas con la respiración. Este método es particularmente eficaz si dos o más señales de ECG fueron adquiridas, pero también resulta válido para un solo canal de ECG. La EDR se puede obtener incluso en el contexto de la insuficiencia cardíaca congestiva, en la que arritmia sinusal respiratoria (ASR) puede estar ausente [168] .

Como se mencionó, las influencias físicas de la respiración producen variaciones en la amplitud en el ECG (Figura 2.13). En términos del modelo del dipolo equivalente de la actividad eléctrica cardíaca, la respiración induce una modulación aparente en la dirección del eje eléctrico cardiaco medio. Este fenómeno es independiente de lo que se conoce generalmente como artefacto de movimiento [168].
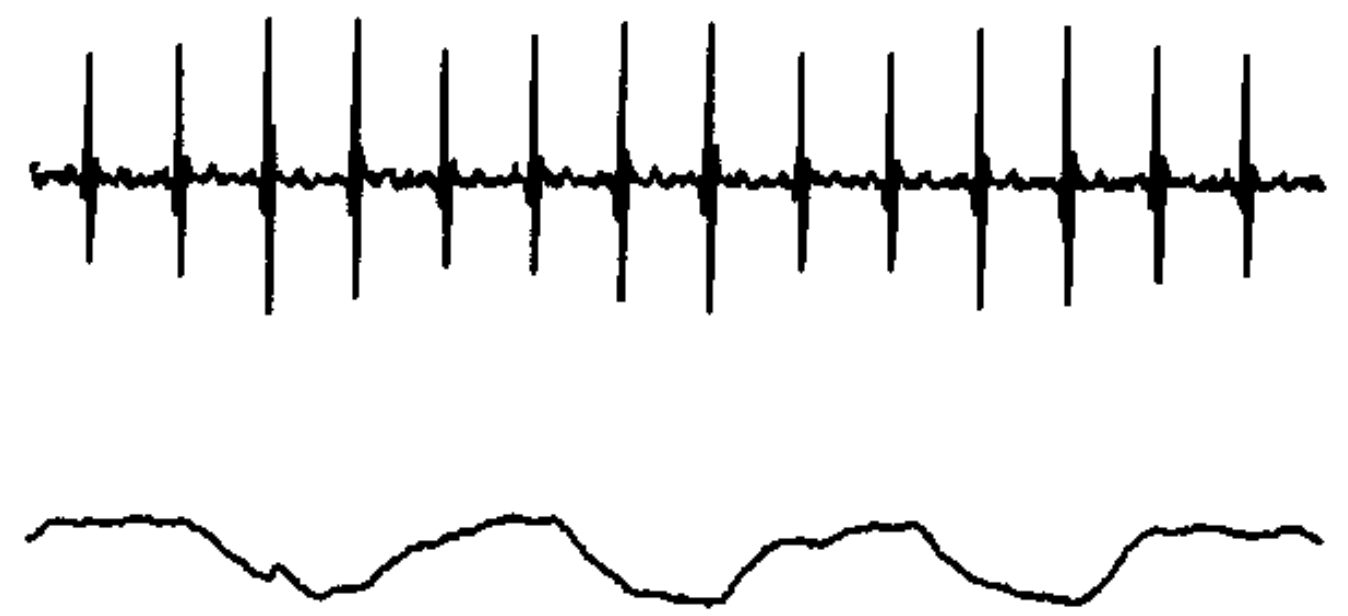

Figura 2.13. Modulación inducida por la respiración en la amplitud del QRS. Trazo superior: ECG; Trazo inferior: respiración medida por un transductor de respiración colocado alrededor del tórax. Duración: 10 segundos [168].

La EDR se confirmó comparando las mediciones de la dirección del eje con mediciones simultáneamente registradas de la circunferencia torácica usando un medidor 
de tensión de mercurio. Estudios posteriores incorporaron el uso de un transductor de respiración [168]. Las mediciones de la dirección del eje basadas en electrodos torácicos se correlacionaron mejor con la circunferencia torácica y la impedancia que con mediciones abdominales, o con mediciones directas [168]. Aunque existen diversas técnicas para medir la dirección del eje y que funcionan relativamente bien, se encontró que las mediciones mostradas en la Figura 2.14 son exactas y computacionalmente simples. Después de sustraer la línea de base, el área de cada complejo QRS normal en cada una de las dos derivaciones cardiacas se mide sobre una ventana fija (cuyo ancho se determina durante la fase de aprendizaje del programa de análisis de ECG para hacer coincidir el intervalo desde la unión PQ hasta el punto J de un QRS normal).

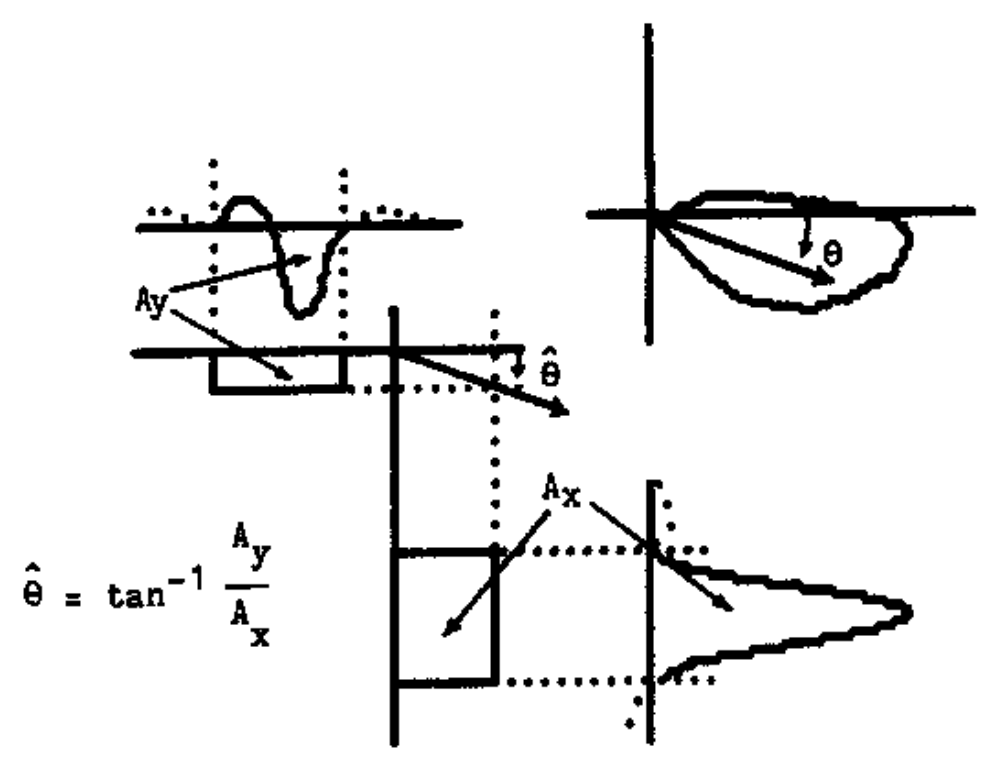

Figura 2.14. Estimación de la dirección del eje eléctrico cardíaco medio a partir de las mediciones del área QRS [168].

Las mediciones de área tales como éstas se realizan rutinariamente por detectores de arritmia. Dado que el ancho de la ventana es fijo, el área es proporcional a la amplitud media de la señal, por lo tanto, a la proyección del vector eléctrico cardíaco medio en el eje principal. Asumiendo que las derivaciones son ortogonales, el arco tangente de la relación de las áreas medidas en las dos derivaciones proporciona el ángulo del eje medio con respecto a uno de los ejes de derivación (Figura 2.14). La medición de la dirección del eje durante el complejo QRS proporciona un estimado de la señal EDR por ciclo cardiaco. Dado que la frecuencia cardíaca es casi siempre mayor que el doble de la frecuencia respiratoria, 
la frecuencia de esfuerzo respiratorio se puede medir bien de este conjunto limitado de muestras. La interpolación mediante splines cúbicos produce una señal EDR continua (Figura 2.15) que tiene una notable semejanza con la señal obtenida a través de un transductor de respiración colocado en el tórax.
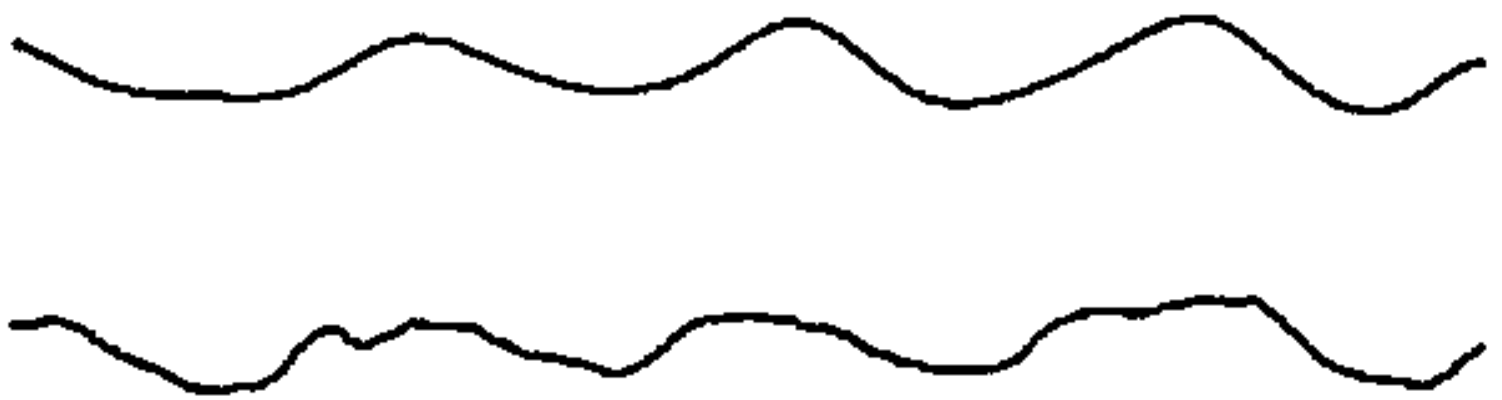

Figura 2.15. Respiración normal. Trazo inferior: señal respiratoria adquirida por un transductor colocado en el pecho. Trazo superior: señal EDR posterior a la interpolación de splines cúbicos. Duración: 10 segundos [168].

\subsection{Sistema de adquisición radiotelemétrico de datos fisiológicos}

Los roedores de laboratorio son las especies animales de elección para la mayoría de las investigaciones biomédicas, tanto en el ámbito académico como en la industria farmacéutica. Los roedores son de un tamaño manejable y relativamente fácil y económicamente de albergar. Estos factores, junto con la disponibilidad de una gran cantidad de roedores mutantes espontáneos y experimentalmente inducidos, hacen que los roedores de laboratorio sean idóneos para una amplia variedad de áreas de investigación [169]. Como se mencionó previamente en el capítulo anterior, de acuerdo con una revisión efectuada por Rowan et al., existe suficiente evidencia para sustentar que las FFC en el roedor (especialmente de ratones y ratas) reflejan de manera similar el comportamiento de la regulación cardiovascular y control autonómico al que se produce en los seres humanos [125].

En la investigación cardiovascular, farmacológica y toxicológica, a menudo se requiere una medición precisa de los parámetros relativos al sistema circulatorio de los animales de laboratorio. Como se mencionó previamente, las FFC se basan en registros de ECG. No obstante, la obtención de registros de ECG fiables, así como datos fisiológicos tales como la temperatura periférica en roedores puede ser difícil usando técnicas de medición convencionales, que requieren conectar sensores y conductores a un animal con movimiento restringido, inmovilizado o anestesiado [169]. Los datos obtenidos de esta manera deben ser interpretados con precaución, ya que es bien sabido que el estrés de la 
restricción y la anestesia pueden tener una influencia importante en los parámetros fisiológicos [170], [171]. La radiotelemetría es una técnica que permite recolectar datos de animales conscientes y en libre movimiento. Esta técnica se ocupó en los capítulos III y IV de la presente tesis. Las mediciones pueden llevarse a cabo incluso en animales que se mueven libremente y sin que el investigador esté en la proximidad del animal. De este modo, se evitan las fuentes de artefactos y se garantizan mediciones precisas y fiables. Esta metodología también reduce la variabilidad inter-animal, reduciendo así el número de animales utilizados, convirtiendo a esta tecnología en el método eficaz de monitoreo de parámetros fisiológicos en animales de laboratorio [172], [173]. Los avances constantes en la tecnología de adquisición de datos y miniaturización de implantes significan que ahora es posible registrar parámetros fisiológicos de forma continua y en tiempo real durante periodos más largos; como horas, días o incluso semanas [173]. En el Apéndice A se describe la técnica quirúrgica para la implantación de un transmisor de telemetría comercialmente disponible utilizado para mediciones continuas de temperatura, actividad locomotora y un biopotencial (en este caso utilizado para adquirir ECG en un único canal), a partir de la cual se puede estimar las FFC. En la Figura 2.16 se muestra un esquema del sistema de adquisición de datos radiotelemétricos.

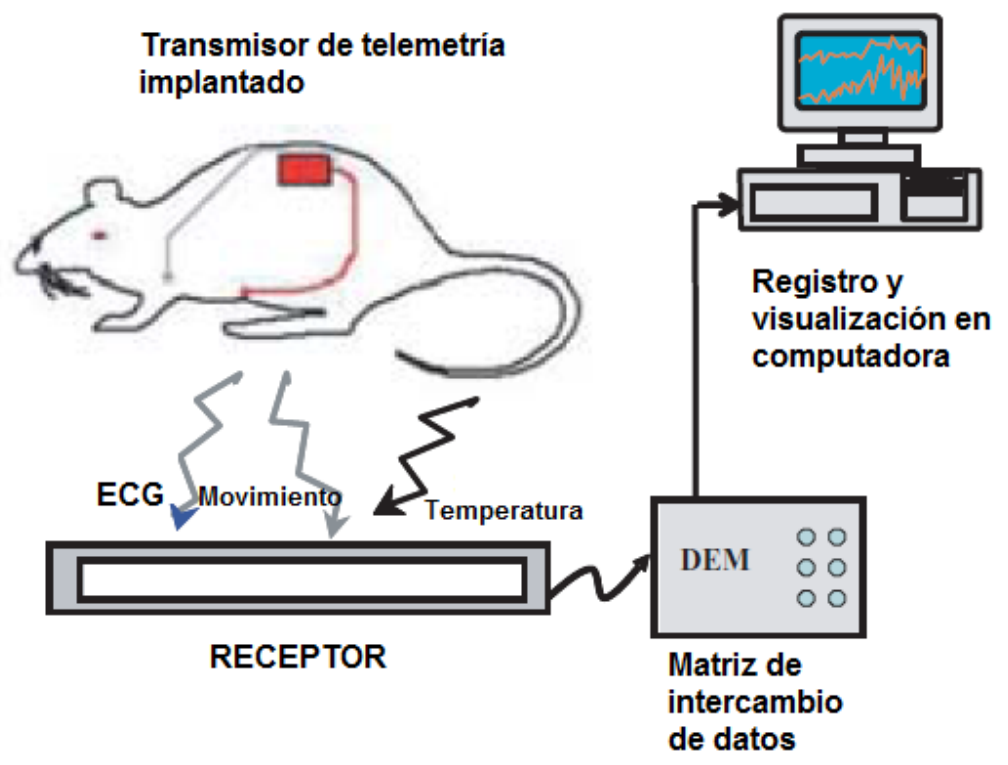

Figura 2.16. Equipo de telemetría para el registro de roedores: Un transmisor implantado dorsalmente registra simultáneamente ECG, movimiento y temperatura. El transmisor envía ondas de radiofrecuencia a un receptor ubicado cerca de la jaula del roedor, posteriormente la señal pasa por un convertidor analógico-digital (matriz de intercambio de datos) y finalmente llega a una computadora para visualización y manipulación de los datos [174]. 


\subsection{Sistema de adquisición de señales fisiológicas materno-fetal portátil}

En los capítulos V y VI se utilizó el sistema de adquisición de señales fisiológicas maternofetales MONICA AN24 (Monica Healthcare, Nottingham, Reino Unido). Este es un dispositivo portátil que permite realizar electrocardiografía (ECG) abdominal de manera no invasiva; así como desplegar parámetros fisiológicos tales como: frecuencia cardiaca materna, frecuencia cardiaca fetal, movimientos maternos y contracciones uterinas a partir de una estimación histerográfica mediante 5 electrodos colocados en el abdomen materno [175].

Antes de la colocación de los electrodos (AMBU®, BlueSensor VL), se limpió la piel con alcohol y se realizó un raspado con papel abrasivo en el lugar de colocación de los electrodos. Se verificó que la impedancia de la piel fuera inferior a $5 \mathrm{k} \Omega$, puesto que el sistema MONICA AN24 cuenta con un sistema de seguridad que impide la realización del registro si no se tiene una impedancia menor a este valor.

Este dispositivo tiene 3 derivaciones para ECG, están dadas por los conectores de colores naranja, blanco y verde. Estos 3 canales tienen un punto de conexión en común que es el conector amarillo, finalmente el conector negro es la tierra (derivación bipolar). Teniendo en cuenta esta información, se colocó sobre el abdomen materno limpio los electrodos desechables de una forma estandarizada de acuerdo con el manual del dispositivo, esto fue independiente de la posición fetal. La colocación fue la siguiente (Figura 2.17):

- Conector amarillo: El electrodo se coloca en la línea media, justo encima de la sínfisis púbica.

- Conector blanco: El electrodo se coloca por arriba del ombligo en gestantes a término.

- Conectores verde y naranja: Los electrodos se colocan en la parte izquierda y derecha del abdomen de la madre, están posicionados para formar un diamante como se observa en la Figura II.17.

- Conector negro: Es el electrodo es la referencia, se coloca cercano al electrodo verde, aunque su posición exacta no es crítica. 


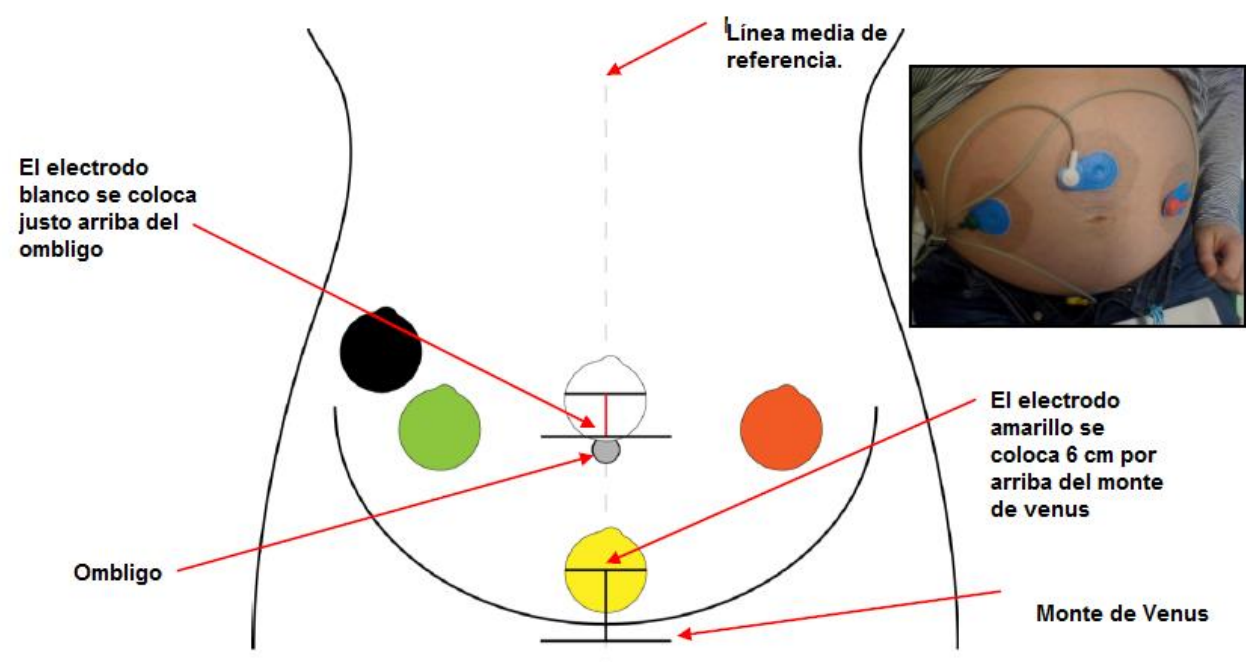

Gestación >= a 33 semanas

Figura 2.17. Forma de colocación de los electrodos en el abdomen materno y dispositivo MONICA AN24 para gestaciones mayores a 33 semanas.

\subsection{Sistema de inmunoensayos múltiples por bioluminicencia acoplada a citometría de flujo}

Los inmunoensayos para la determinación de 37 citoquinas en suero sanguíneo (descripción completa en la sección 5.2. Metodología del Capítulo V) fueron realizados a través de un kit Bio-Plex®, el cual está constituido alrededor de la tecnología Luminex XMAP®, que utiliza una plataforma de citometría de flujo basada en perlas magnéticas destinada al análisis multiplexado. Los ensayos se pueden realizar para muchas clases de moléculas incluyendo citoquinas y hormonas [176]. Es relevante mencionar que para el manejo de las muestras sanguíneas siempre se preservó la cadena fría, esto se encuentra detallado en el apéndice $\mathrm{C}$.

Esta tecnología incorpora un panel metabólico humano diseñado para el estudio de biomarcadores, analíticamente validados e integrados en un solo panel (placa de 96 pozos). Permite investigar la expresión de múltiples analitos simultáneamente, con la ventaja de una mayor velocidad y sensibilidad [176]. En nuestro caso se utilizó un kit para determinar 37 citoquinas durante el tercer trimestre de embarazo y en el trabajo de parto, realizando la determinación de cada analito por duplicado. 
Los ensayos de Bio-Plex® cuantificaron los distintos marcadores en un único pozo de una placa de 96 pozos en un tiempo aproximado de 3-4 horas a través del lector Bio-Plex MAGPIX Multiplex Reader.

El principio de este bioensayo se presenta en la Figura 2.18. Se produce una captura con anticuerpos para el biomarcador deseado acoplados a microesferas (perlas) sintéticas. Estas perlas acopladas reaccionan con la muestra que contiene el biomarcador de interés. Después de una serie de lavados para eliminar la proteína no unida, se añade un anticuerpo de detención biotinilado para crear un complejo de sándwich. El complejo de detención final es el formado con la adición de estreptavidina-ficoeritrina (SA-PE) conjugado. La ficoeritrina sirve como un indicador fluorescente [176], [177].

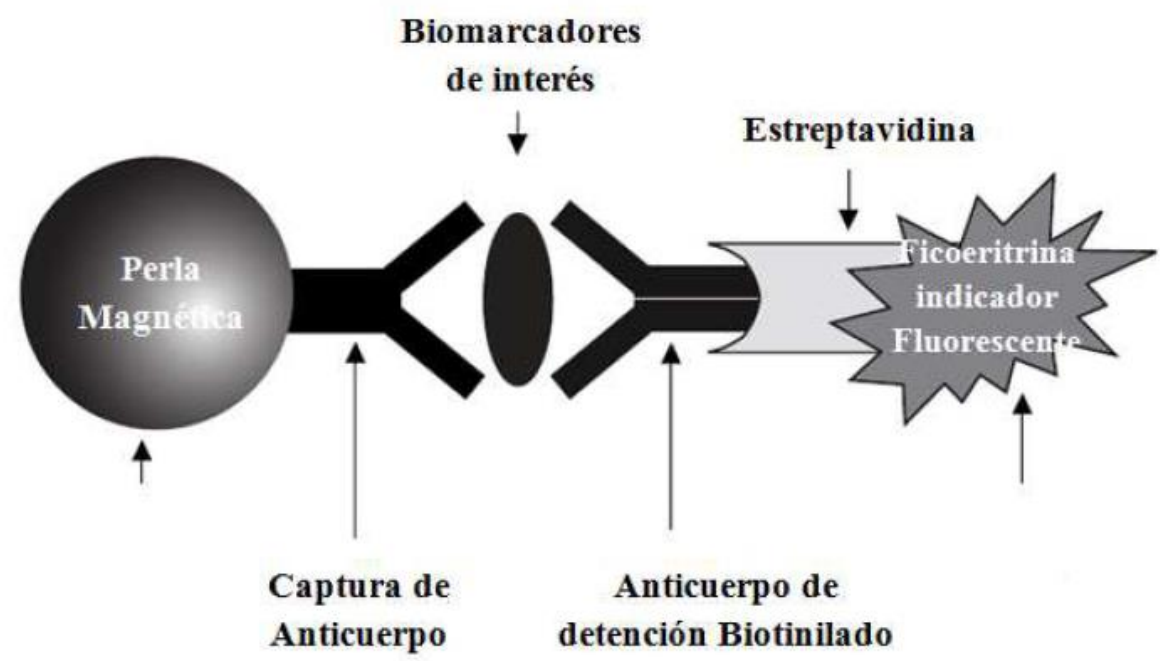

Figura 2.18. Inmunoensayo sándwich Bio-Plex® [177].

Los valores de fluorescencia fueron determinados usando la tecnología Luminex $\mathrm{xMAP} \AA$. Cuando una suspensión de ensayo se introduce en el lector Bio-Plex, un láser de color rojo $(635 \mathrm{~nm})$ ilumina los colorantes fluorescentes, identificando la perla correspondiente. Al mismo tiempo, un láser de color verde $(532 \mathrm{~nm})$ se excita para generar una segunda señal, que es detectada por un tubo fotomultiplicador. Un procesador digital de alta velocidad procesa la salida de datos, y finalmente el software transforma los datos de fluorescencia en concentración $(\mathrm{pg} / \mathrm{mL})$. La concentración de los analitos unidos a cada perla es proporcional a la fluorescencia de la señal [176], [177]. 


\subsection{Síntesis}

El presente capítulo introdujo a las técnicas de análisis de las FFC y a los sistemas de adquisición de datos fisiológicos e inmunológicos que fueron utilizados en los capítulos subsecuentes. En primer lugar, se describió el algoritmo de detección de los picos $\mathrm{R}$ del ECG para la construcción de la señal de fluctuaciones $R-R$, una vez construida dicha señal se le aplican métodos de preprocesamiento, como lo es un filtro adaptativo para corregir artefactos que afectan potencialmente el cálculo de los parámetros del análisis de las FFC. Es posible clasificar a los parámetros del análisis de las FFC en lineales (en el dominio del tiempo y en el dominio de la frecuencia) y en no lineales. En este capítulo se detallaron el uso de índices no lineales como lo son los exponentes de escalamiento fractal del método DFA, los exponentes del MSA y la SampEn, también se describió su aplicación como potenciales herramientas de diagnóstico para distinguir entre procesos de salud y enfermedad. En la parte final del capítulo se abordaron los diferentes sistemas de adquisición de datos fisiológicos e inmunológicos que fueron esenciales en esta investigación. 


\section{Capítulo III}

\section{Estudio I: Efecto de la oxitocina exógena en la dinámica cardiaca de ratas endotoxémicas}

Resumen: Además de las funciones bien conocidas de la oxitocina $(O x)$ en el nacimiento y el trabajo de parto, existe evidencia reciente que demuestra que esta hormona hipotalámica posee propiedades cardioprotectoras, antiinflamatorias y parasimpáticas. En este estudio, exploramos las fluctuaciones de la frecuencia cardíaca (FFC) en un modelo de roedores endotoxémicos en el que fue administrada de manera conjunta oxitocina exógena y lipopolisacárdio (LPS). La evaluación de las FFC se ha utilizado ampliamente como una medida indirecta de la actividad autonómica cardíaca. En este contexto, ratas adultas Dark Agouti fueron implantadas con un transmisor radiotelemétrico para medir de forma continua y remota el electrocaridograma (ECG), la temperatura y la locomoción. En un diseño experimental entre sujetos, las ratas recibieron el siguiente tratamiento periférico: solución salina como vehículo (V); Lipopolisacárido (LPS); Oxitocina (Ox); Lipopolisacárido + oxitocina (LPS + Ox). Posteriormente diversos índices lineales y no lineales del análisis de las FFC fueron estimados 3 horas antes a 24 horas después del tratamiento farmacológico. Los resultados mostraron que la Ox exógena no modificó por sí misma las FFC del grupo de ratas con Ox en comparación con el grupo vehículo. En contraste, en los animales cursando un proceso inflamatorio (LPS) la Ox provocó: a) un patrón menos anticorrelacionado en las FFC, b) disminución de la frecuencia cardíaca media, c) moderación de la magnitud y duración de la hipertermia inducida por LPS y d) un aumento en la locomoción hasta 6 horas después la inyección de LPS. El patrón menos anticorrelacionado en las FFC y la disminución de la frecuencia cardíaca media podrían reflejar un acoplamiento del marcapasos cardíaco modulado por la influencia colinérgica de la oxitocina durante la endotoxemia inducida por LPS. Por último, los efectos anti-letárgicos y termorreguladores en el largo plazo de la administración de Ox durante la endotoxemia podrían ser consecuencia de sus propiedades antiinflamatorias.

Es pertinente mencionar que avances preliminares de este trabajo se presentaron en los siguientes congresos:

Congreso Iberoamericano de Neuroinmunomodulación and II Congreso Mexicano de Neuroinmunoendocrinología, 28 de octubre al 30 de octubre de 2015, Nuevo Vallarta, Nayarit, México.

CXXI Reunión Reglamentaria de la Asociación de Investigación Pediátrica A.C., 4 de diciembre del 2016, Amealco de Bonfil, Querétaro, México.

Este trabajo ha sido publicado como: Reyes-Lagos JJ, Hadamitzky M, Peña-Castillo MÁ, Echeverría JC, Bösche K, Lückemann L, Schedlowski M, Pacheco-López G. Exogenous oxytocin reduces signs of sickness behavior and modifies heart rate fluctuations of endotoxemic rats. Physiol Behav. 2016;165:223-30. doi: 10.1016/j.physbeh.2016.07.013. Una copia de dicho artículo se encuentra en el Apéndice E. 


\subsection{Introducción}

En condiciones sanas, las fluctuaciones cardiovasculares muestran una dinámica fisiológica compleja resultante de las interacciones entre las células del marcapasos cardíaco y el sistema nervioso autónomo (SNA) [150]. Existe evidencia en modelos humanos y experimentales que indica que durante una inflamación sistémica (por ejemplo, la endotoxemia) la regulación de la función cardíaca se manifiesta con fluctuaciones en la frecuencia cardiaca (FFC) disminuidas y un aumento en la regularidad del ritmo cardíaco [97], [100], posiblemente como resultado de un desacoplamiento parcial de las células del marcapasos cardíaco del control neuronal autonómico [99]. Algunos autores también han descrito que los cambios en las FFC podrían utilizarse para identificar indirectamente la denominada respuesta colinérgica antiinflamatoria (RCA) en diversos escenarios [88], e incluso se han considerado como una herramienta potencial no invasiva para estudiar y monitorizar las respuestas inflamatorias y antiinflamatorias fetales [178]. En este sentido, estudios han mostrado que la inhibición sistémica del receptor a7nACHR induce un decremento en las FFC que provoca un aumento de la inflamación y consecuentemente una respuesta febril en ratas endotoxémicas [101]. Esta respuesta sugiere un papel tónico de los receptores nicotínicos periféricos de la acetilcolina para modular la dinámica del ritmo cardíaco durante la inflamación sistémica.

A pesar de que la oxitocina tiene funciones fisiológicas bien conocidas durante el trabajo de parto y la lactancia en humanos y otros mamíferos, estudios han revelado que también posee propiedades inmunológicas y cardioprotectoras; principalmente mediante la modulación de la actividad del sistema nervioso parasimpático [179]. De acuerdo con lo dicho, la oxitocina posee propiedades cardioprotectoras en condiciones isquémicas [126], y disminuye la inflamación inducida por carragenina en ratas [2]. Además, se ha demostrado la participación de vías de señalización en la cardioprotección al ser estimuladas por receptores de oxitocina, que están presentes en el corazón y grandes vasos [180]. Así mismo, hallazgos sugieren que la oxitocina también limita la activación de citoquinas causada por el componente bacteriano de la pared celular del LPS, posiblemente debido a la modulación de la RCA [113].

Algunos estudios han informado de algunos efectos de la administración de oxitocina intranasal en las FFC durante experimentos de cognición social; donde la oxitocina, además de facilitar el comportamiento social, disminuyó la frecuencia cardíaca y aumentó las FFC [181], [182]. Otros hallazgos indican que la administración subcrónica de 
oxitocina induce efectos duraderos en ratas ovariectomizadas, incluyendo un aumento en la actividad motora espontánea y la disminución de los niveles de corticosterona [183].

Recientemente hemos reportado el uso de métodos lineales y no lineales para el análisis de las FFC en el parto humano; una condición que ha sido considerada como un proceso inflamatorio exacerbado [85]. De la misma manera, hemos documentado que el análisis de escalamiento fractal y la SampEn son consideradas como potenciales herramientas analíticas que proporcionan información sobre los mecanismos homeostáticos autonómicos relacionados con la inflamación [116]. En este contexto, el objetivo del presente estudio fue explorar los efectos de la oxitocina exógena en la dinámica de las FFC mediante la aplicación de análisis lineal y no lineal, así como monitorizar la actividad motora y la temperatura periférica en un modelo experimental en ratas endotoxémicas. Siguiendo los hallazgos de Gholami et al. [99], Jankowski et al. [180] y Clodi et al. [113], se planteó la hipótesis de que la administración periférica de oxitocina durante la endotoxemia inducida por LPS aumenta el acoplamiento del marcapasos cardíaco mediado por influencias colinérgicas, lo que se verá reflejado en los parámetros lineales y no lineales de las FFC, reduciendo signos del comportamiento de enfermedad como lo es el letargo y la fiebre.

\subsection{Metodología}

Animales: En el bioterio de la Universidad de Essen (Alemania) se solicitaron ratas adultas Dark Agouti machos (DA / HanRj, 230-250 g) de Janvier Labs (Le Genest-Saint-Isle, Francia) y fueron alojadas en jaulas de plástico estándar con tapas-jaulas metálicas. Los animales se mantuvieron en un ciclo de luz/ oscurida inverso de 12:12 h (la luz se apagada a las 7:00 AM) y tuvieron acceso ad libitum a agua y dieta estándar. Se permitió que las ratas se aclimataran al nuevo entorno durante al menos 2 semanas antes de la cirugía de implantación del radiotransmisor. Todos los procedimientos siguieron los lineamientos del bioterio de la Universidad de Duisburg-Essen, Alemania, y los procedimientos experimentales cumplieron con la Ley de Bienestar Animal (TierSchG) - Alemania, la Directiva Europea 2010/63/UE y con los Institutos Nacionales de Salud E.U.A. Estos procedimientos fueron aprobados por el Comité Institucional de Cuidado y Uso de Animales (LANUV Düsseldorf, Renania del Norte-Westfalia, Alemania).

Drogas: Basándose en un estudio previo [184], se administró oxitocina sintética (Syntocinon®, 3 UI, Novartis GmbH, Nürnberg, Alemania) a una dosis de 3 UI / kg (6 mcg / 
$\mathrm{kg}$ ) administrada subcutáneamente (sc) en un volumen de $1 \mathrm{ml}$. Se diluyó el lipopolisacárido liofilizado (LPS) de Escherichia coli, serotipo O55: B5 (Sigma-Aldrich, Taufkirchen, Alemania) con solución salina estéril ( $\mathrm{NaCl}$ y se administró por vía intraperitoneal (ip) a una dosis de $0.1 \mathrm{mg} / \mathrm{kg}$ en un volumen total de $1 \mathrm{ml}$. Se ha demostrado previamente que esta dosis de LPS induce un aumento en los niveles de citoquinas periféricas y fiebre moderada [185], así como cambios de los parámetros de las FFC [101].

Cirugía de implantación de radiotransmisores telemétricos: Se implantaron quirúrgicamente radiotransmisores de radiotelemetría (ETA-F20, Data Sciences International, St. Paul, Minnesota, E.U.A.) para medir de forma continua el ECG, la temperatura periférica y la actividad locomotora. Las ratas se anestesiaron en una cámara de inducción con isoflurano al $5 \%$ y oxígeno al $2 \%$. La anestesia se mantuvo mediante un flujo de $1,5-2,0 \%$ de isoflurano y oxígeno $(1 \mathrm{~L} / \mathrm{min})$ a través de una máscara durante la cirugía. La piel dorsal de la rata se limpió y desinfectó con povidona-yodo y alcohol. Se realizó una incisión vertical de $2 \mathrm{~cm}$ en el dorso donde se implantó el transmisor de telemetría subcutáneamente (s.c.). Los cables del transmisor fueron guiados bajo la piel con las puntas conductoras (electrodos) a las regiones axilares derecha e izquierda. Para aliviar el dolor Carprofen $5 \mathrm{mg} / \mathrm{kg}$ fue administrado s.c. el día de la cirugía y los siguientes tres días posteriores a la cirugía. Los experimentos se realizaron 14 días después de la cirugía para permitir la recuperación de los animales [174]. La información detallada sobre este procedimiento se encuentra en el Apéndice A. Implantación dorsal de los transmisores telemétricos.

Registro de actividad ECG, temperatura y locomoción a través de telemetría en animales consientes y en libre movimiento: Los animales se asignaron aleatoriamente a uno de los cuatro diferentes grupos de estudio: 1) vehículo $(\mathrm{V}, \mathrm{n}=7) ; 2)$ oxitocina (Ox, 3 $\mathrm{UI} / \mathrm{kg}, \mathrm{n}=8$ ); 3) lipopolisacárido (LPS, $0.1 \mathrm{mg} / \mathrm{kg}, \mathrm{n}=8$ ); 4) LPS + oxitocina (LPS + Ox, administración combinada de $0.1 \mathrm{mg} / \mathrm{kg}$ de LPS y $3 \mathrm{Ul} / \mathrm{kg}$ de oxitocina, $\mathrm{n}=8$ ). Después de las inyecciones, las ratas implantadas se colocaron individualmente en su caja con los receptores de telemetría debajo de dicha caja, los receptores estuvieron conectados a través de una matriz de intercambio de datos a una computadora. El inicio de los registros comenzó a las 7:00 AM y la administración de los fármacos se realizó a las 10:00 AM (tiempo 0) para cada grupo. El ECG fue muestreado a $2000 \mathrm{~Hz}$ utilizando el hardware de Data Sciences International y el software Dataquest $A R T \Theta$. Los ECG's se inspeccionaron 
visualmente y se seleccionaron segmentos confiables de 5 minutos cada hora $(-3 \mathrm{~h}$ a +24 h). Las señales digitalizadas de ECG se analizaron para la detección de picos $R$, al mismo tiempo se registraron datos de la temperatura y la locomoción.

Análisis de datos: Los registros de ECG se pre-procesaron utilizando algoritmos previamente validados de acuerdo con lo descrito en la Sección 2.1. Posteriormente se calcularon algunos parámetros lineales y no lineales para cada segmento de 5 min de todas las señales de fluctuaciones R-R como: la frecuencia cardiaca media (mean heart rate por sus siglas en inglés MHR), el parámetro RMSSD, que cuantifica las fluctuaciones de alta frecuencia mediadas por el vago y el SDNN, utilizado como medida total de las FFC [86].

Los exponentes de escalamiento en el corto plazo $\alpha_{1}, \alpha_{1(\mathrm{MAG})}$ y $\alpha_{1(\mathrm{SIGN})}$ de $4 \leq \mathrm{n} \leq 11$ latidos y los exponentes de escalamiento en el largo plazo $\alpha_{2}, \alpha_{2(\mathrm{MAG})}$ y $\alpha_{2(\mathrm{SIGN})}$ de $n>11$ latidos se evaluaron mediante la aplicación de la metodología DFA y MSA descrito en el Capítulo 2 sección 2.3.

Finalmente, para evaluar la regularidad de la señal de fluctuaciones $R-R$ también se estimó la SampEn como fue descrito por Richman \& Moorman [165]. El parámetro $m$ se fijó a 2 y el nivel de tolerancia $r$ fue 0.2. Los actogramas promedios se calcularon a partir de series de tiempo continuo de movimiento corporal de $-3 \mathrm{a}+24 \mathrm{~h}$ utilizando un paquete de software para el análisis y visualización de actividad cronobiológica [186].

Análisis estadístico: Todos los parámetros se analizaron mediante ANOVA de dos vías con medidas repetidas en el tiempo. De acuerdo con las diferencias identificadas entre los grupos, se aplicó un análisis del área bajo curva (Area under curve, AUC por sus siglas en inglés) en periodos consecutivos de dos horas. El análisis de AUC se realizó posterior a las 6 horas, que fue el tiempo descrito por Mazloom et al. [101] (con el propósito de observar efectos en el largo plazo) y antes de las $9 \mathrm{~h}$, con la intención de evitar variaciones circadianas inducidas por la fase de luz [174]. Sin embargo, con el objetivo de verificar otros efectos de la oxitocina sobre la endotoxemia inducida por LPS, que parecen manifestarse a largo plazo de acuerdo con los resultados previos reportados por Clodi et al. [113], únicamente la AUC de la temperatura corporal se graficó y analizó por separado de +7 a $+9 \mathrm{~h}$ y de $+10 \mathrm{a}+12 \mathrm{~h}$ correspondientes a los periodos de oscuridad y luz, respectivamente. La AUC para cada período se calculó mediante el método del trapecio (los datos de la AUC se expresan como valor promedio $\pm \mathrm{DE}$ ). Finalmente, se realizaron 
comparaciones planeadas de las AUC entre V vs. Ox, V vs. LPS y LPS vs. LPS + Ox y se analizaron por ANOVA de una vía, seguidas por pruebas post hoc de LSD de Fisher y Kolmogorov-Smirnov ( 0.05 se consideró como el nivel de significancia estadística).

\subsection{Resultados}

En la Figura 3.1 se muestran los parámetros lineales de las FFC comenzando $3 \mathrm{~h}$ antes a $24 \mathrm{~h}$ después del tratamiento. Se calculó la AUC de cada parámetro asociado al período de +7 a +9 h (área sombreada); dicho análisis se presenta como insertos en la parte superior derecha de cada panel. Adicionalmente, una barra de color negra/blanca en la parte inferior de cada panel indica los fotoperiodos de oscuridad y luz respectivamente. Nuestros resultados muestran que la inyección de LPS se asoció con una respuesta bifásica caracterizada por un incremento inicial en la MHR (Figura 3.1a) y un SDNN disminuido (Figura 3.1b) seguido por un período prolongado de taquicardia y variabilidad cardiaca disminuida. Cabe mencionar que en las condiciones iniciales (antes de $t=0 \mathrm{~h}$ ), no se encontraron diferencias significativas entre los grupos estudiados.

El efecto del LPS en la MHR fue estadísticamente significativo según las comparaciones planeadas de las AUC ( $F=19.28, p<0.0001$, V vs. LPS). La administración de una única inyección de oxitocina a una dosis de 3 Ul / kg provocó cambios en la MHR 6 $\mathrm{h}$ después del LPS $(F=19.28, p<0.01$, LPS vs. LPS + Ox). Los índices lineales de las FFC como el SDNN (Figura 3.1b) y la RMSSD (Figura 3.1c) exhibieron una reducción significativa $(F=7,52, p<0.01$ y $F=3,60, p<0.05$, respectivamente) 6 horas después de la inyección del LPS.

El efecto de la inyección de la endotoxina sobre la irregularidad de las series de tiempo R-R también se investigó usando el método DFA y la SampEn, estos resultados son mostrados en la Figura 3.2. El $\alpha_{1}$ permaneció disminuido (Figura 3.2a) de +7 a +9 h después de la inyección de LPS según los resultados de las comparaciones planeadas de las AUC $(F=4.25 ; p<0.01)$. El parámetro $\alpha_{1(S I G N)}(F i g u r a 3.2 b)$ también presentó una dinámica bifásica. Se puede observar en la gráfica que en el periodo de $+7 \mathrm{a}+9 \mathrm{~h}$ la inyección de 

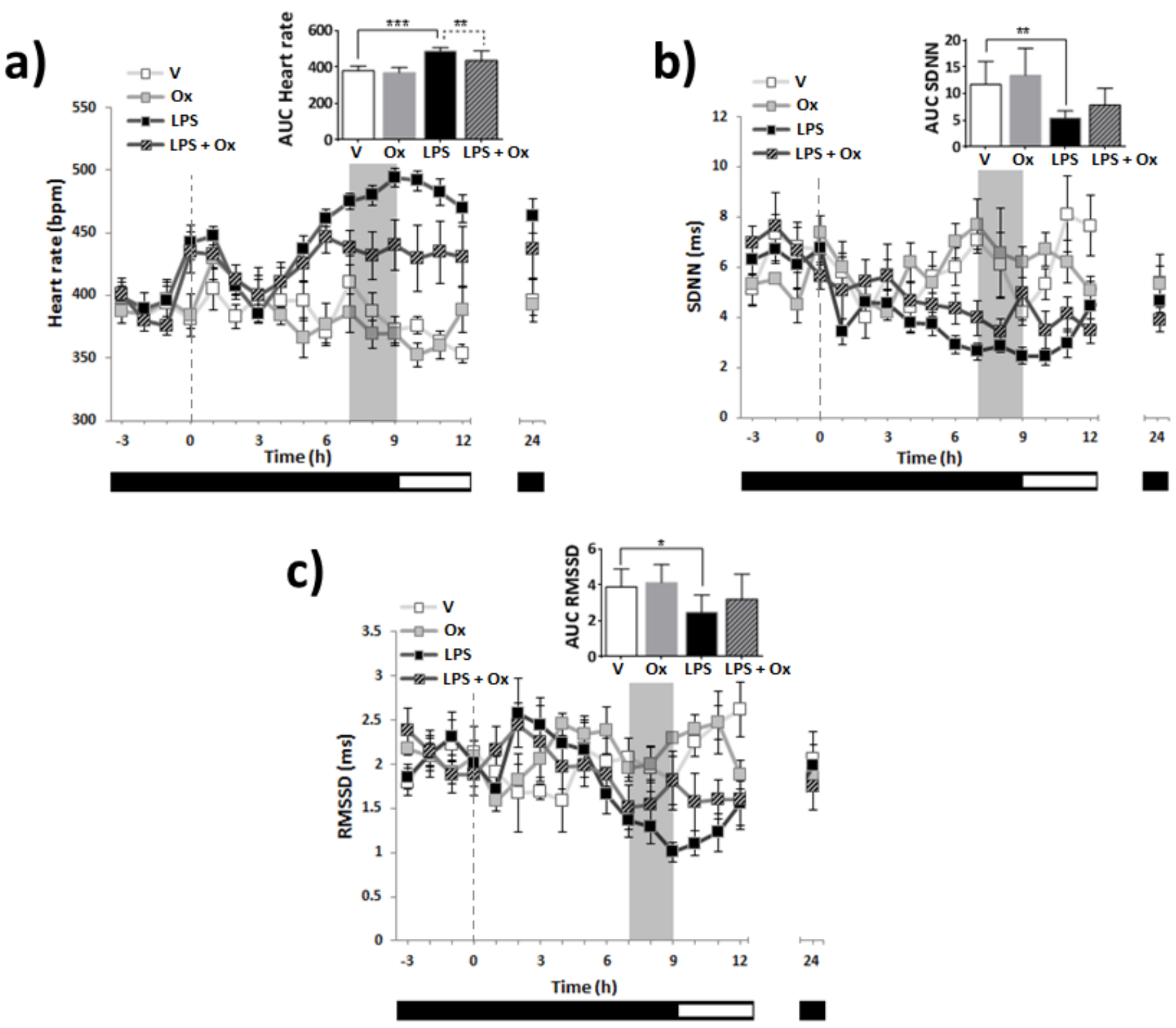

Figura 3.1. Parámetros lineales de las fluctuaciones de la frecuencia cardiaca (FFC) de ratas macho adultas en libertad: a) frecuencia cardíaca media (MHR); b) desviación estándar de los intervalos R-R (SDNN), y c) la raíz cuadrada del promedio de la suma de las diferencias cuadráticas entre intervalos R-R adyacentes (RMSSD). Estos parámetros se estimaron antes y después del tratamiento (tiempo $=0$, indicado por una línea vertical discontinua): vehículo (V), oxitocina (Ox), lipopolisacárido (LPS) y LPS + oxitocina (LPS + Ox). Los datos se reportan como promedio $\pm E E$. El área bajo la curva (AUC) correspondiente al área sombreada de cada parámetro (de $+7 \mathrm{a}+9 \mathrm{~h}$ ) se muestran en los insertos de la Figura. ${ }^{*} p<0.05,{ }^{* *} p<0.01,{ }^{* * *} p<0.0001$ (prueba LSD de Fisher para las AUC). 
LPS produjo valores anticorrelacionados (es decir, pequeños) en este parámetro en comparación con los vehículos ( $F=10.58 ; p<0.0001, V$ vs. LPS), en contraste, la inyección de LPS combinada con oxitocina produjo valores menos anticorrelacionados (grandes) en las ratas endotoxémicas $(F=10.58, p<0.01$, LPS vs. LPS + Ox).

a)

)

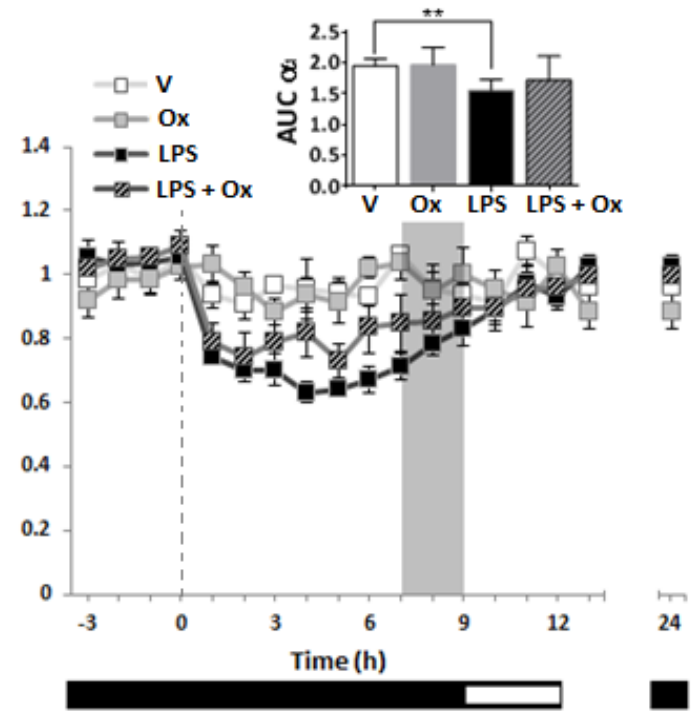

b)

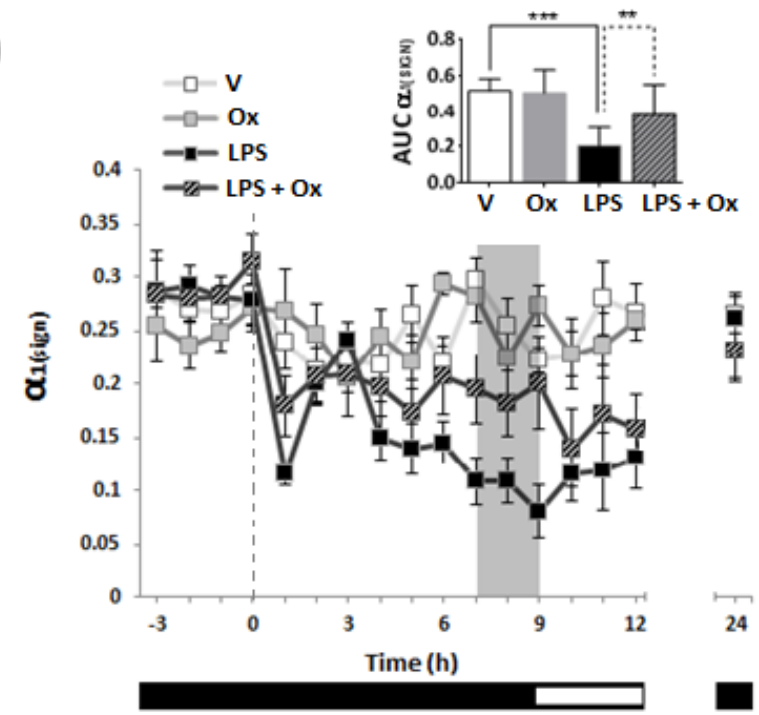

c)

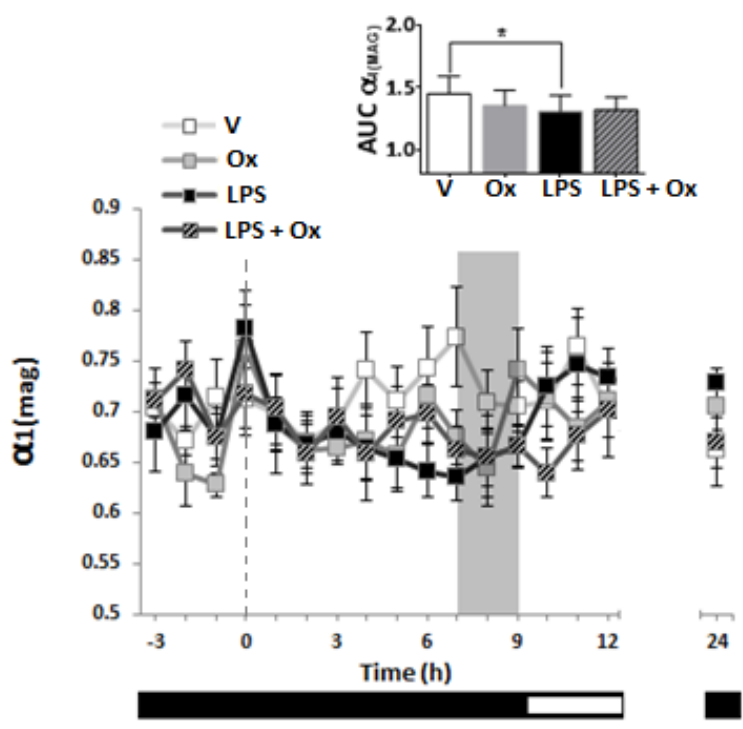

d)

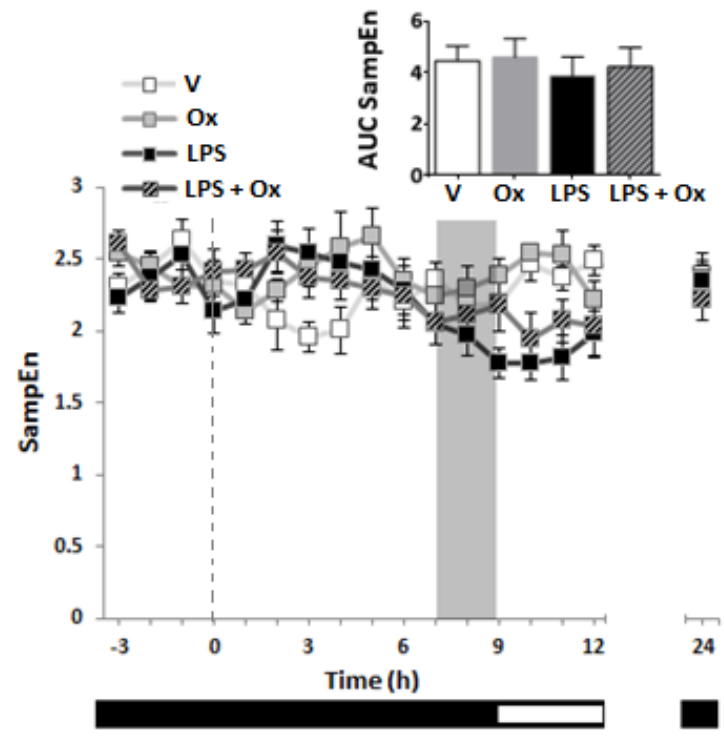

Figura 3.2. Parámetros no lineales de las fluctuaciones de la frecuencia cardiaca (FFC) de ratas macho adultas en libertad: a) exponente de escalamiento en el corto plazo $\left(\alpha_{1}\right)$; b) exponente de escalamiento en el corto plazo de signo $\left(\alpha_{1(\mathrm{SIGN})}\right)$; $\left.C\right)$ exponente de escalamiento en el corto plazo de magnitud $\left(\alpha_{1(\mathrm{MAG})}\right)$, y d) entropía muestra (SampEn). Estos parámetros se estimaron antes y después del tratamiento (tiempo $=0$, indicado por una línea vertical discontinua): vehículo (V), oxitocina (Ox), lipopolisacárido (LPS) y LPS + oxitocina (LPS + Ox). Los datos se reportan como promedio \pm EE. El área bajo la curva (AUC) correspondiente al área sombreada de cada parámetro (de $+7 \mathrm{a}+9 \mathrm{~h}$ ) se muestran en los insertos de la Figura. ${ }^{*} p<0.05,{ }^{* *} p<0.01,{ }^{* * *}$ $\mathrm{p}<0.0001$ (prueba LSD de Fisher para las AUC). 
El exponente $\alpha_{1(\mathrm{MAG})}$ disminuyó significativamente después de la dosis única de LPS $(F=1,90 ; p<0.05, V$ vs. LPS), Figura 3.2c. Sin embargo, el parámetro SampEn no mostró cambios de $+7 \mathrm{a}+9 \mathrm{~h}$, Figura 3.2d. Los parámetros de escalamiento fractal en el largo plazo $\left(\alpha_{2}, \alpha_{2(M A G)}\right.$ y $\left.\alpha_{2(S I G N)}\right)$ no presentaron cambios después de la administración de los fármacos por lo que no son reportados.
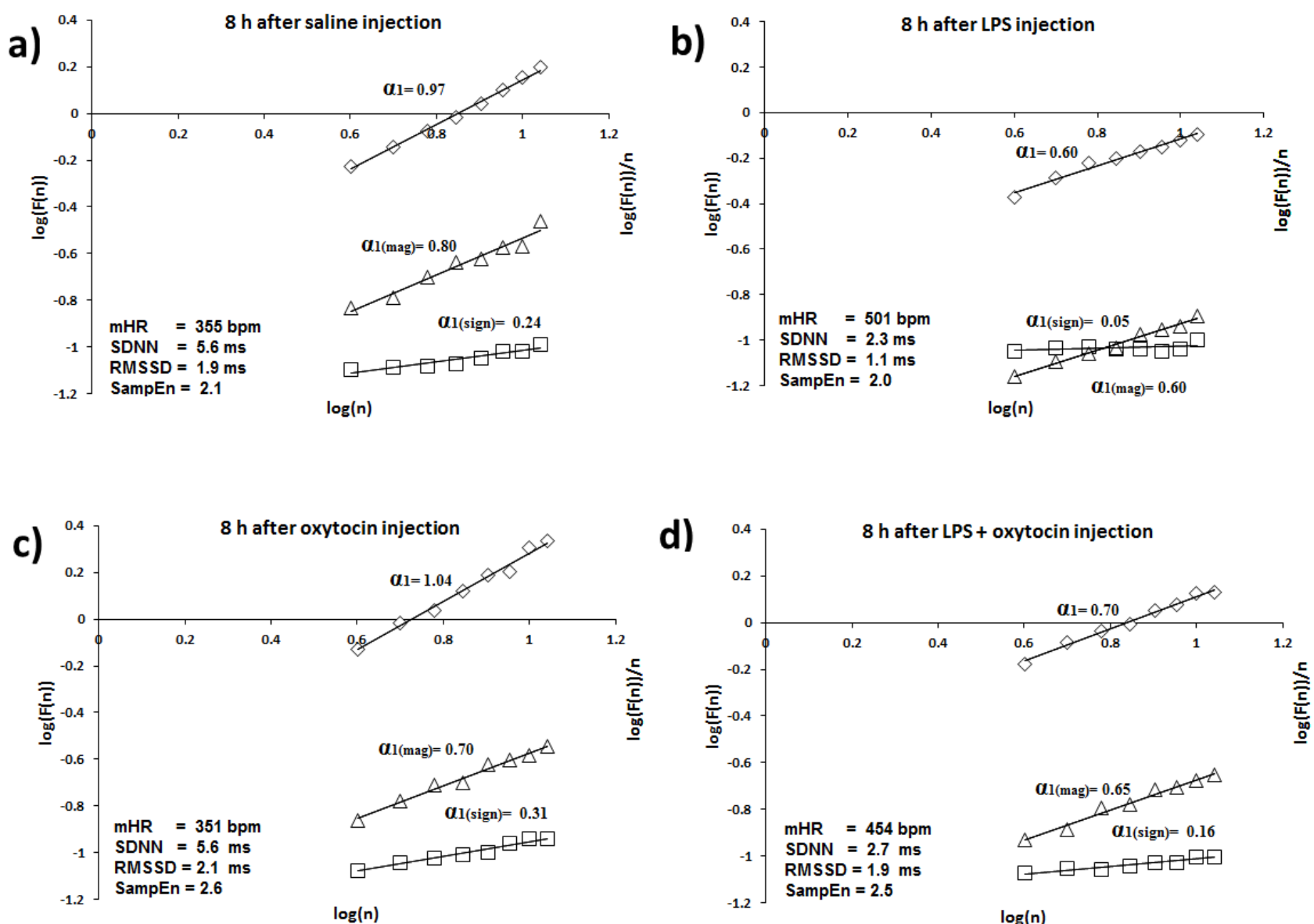

Figura 3.3. Datos representativos de las relaciones log-log $F(n)$ (fluctuación cuadrática media promedio) vs. $n$ (escala) o $\log -\log F(n) / n$ vs. $n$ con respecto a la estimación de los exponentes de escalamiento en el corto

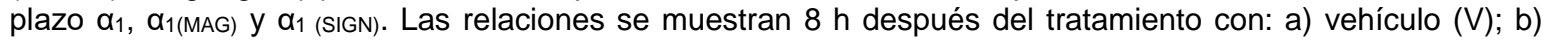
oxitocina (Ox); C) lipopolisacárido (LPS), y d) LPS + oxitocina (LPS + Ox). Los valores de los parámetros de la frecuencia cardíaca media (MHR), la desviación estándar de los intervalos R-R (SDNN), la raíz cuadrada del promedio de la suma de las diferencias cuadráticas entre intervalos R-R adyacentes (RMSSD), $\boldsymbol{\alpha}_{1}, \boldsymbol{\alpha}_{1(\mathrm{MAG})}$,

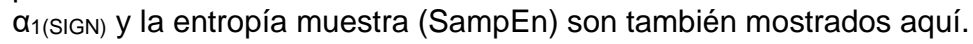

En resumen, una administración de una única dosis de oxitocina exógena no modificó por sí sola la dinámica cardíaca (de $+7 \mathrm{a}+9 \mathrm{~h}$ ) en ningún parámetro (V vs. Ox); pero en presencia de endotoxemia la oxitocina introdujo cambios significativos en la MHR y el $\alpha_{1(\mathrm{SIGN}) \text {. }}$

La Figura 3.3 muestra ejemplos representativos del análisis lineal y no lineal de las FFC de los grupos V, LPS, Ox y LPS + Ox. Las relaciones $\log -\log F(n)$ vs. $n$ y $\log -\log F(n) / n$ 
vs. $n$ proporcionan los exponentes $\alpha_{1}, \alpha_{1(S I G N)}, \alpha_{1(M A G)}$ provenientes de un ajuste lineal dentro del intervalo $n$ de 4 a 11 latidos. Se encontró una relación lineal entre el log (de la fluctuación) y log (del tamaño de la ventana) en todos los grupos en el momento del análisis, que corresponde a la estructura fractal con una dinámica de 1/f [157].

Adicionalmente, la Figura 3.4 muestra una descomposición en signo de datos típicos para los grupos de LPS y LPS + Ox. Esta Figura ilustra un patrón con mayor anticorrelación en las FFC durante la endotoxemia (LPS) en comparación con los datos del grupo LPS + Ox.

a)

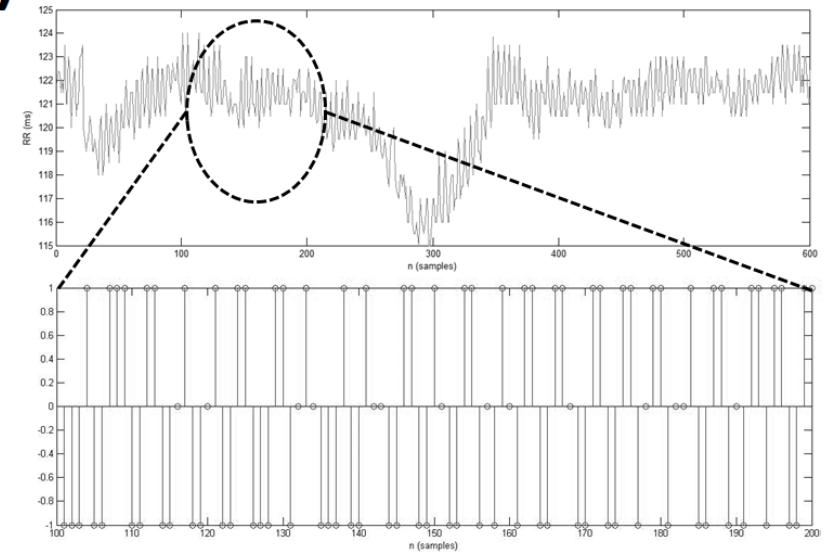

b)

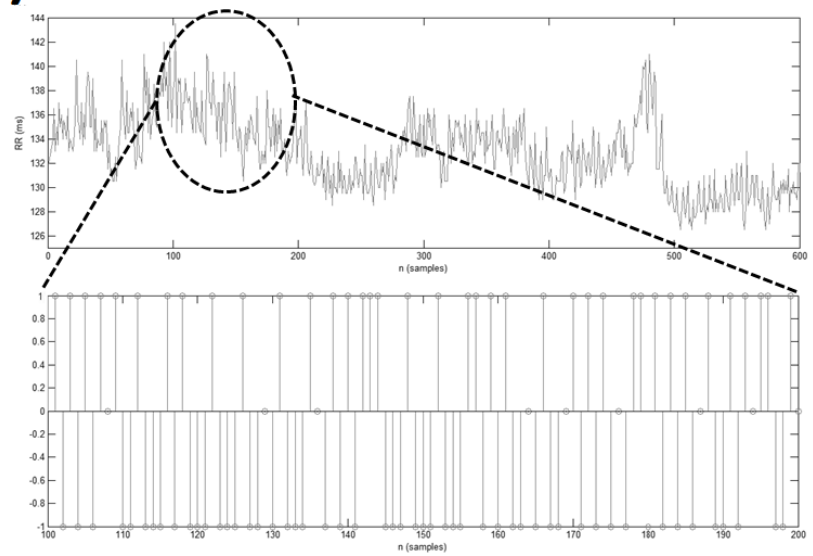

Figura 3.4. Ejemplos representativos de series de fluctuaciones R-R 8 h después de la administración del lipopolisacárido (LPS): $\alpha_{1}$ (SIGN) $=0.05$ (panel a) y LPS + oxitocina (LPS + Ox): $\alpha_{1}($ SIGN) $=0.16$ (panel b). Las series de tiempo del grupo LPS así como su series de signos muestran más alternancias, lo que sugieren un comportamiento mayormente anticorrelacionado comparado con el del grupo LPS + oxitocina.

Es importante destacar que el ritmo circadiano de la temperatura corporal periférica es también alterado por el LPS, puesto que este grupo de ratas presentó una dinámica invertida en comparación con el grupo vehículo (Figura 3.5a). Además, se observó una hipotermia transitoria de $+2 \mathrm{a}+4 \mathrm{~h}$ en las ratas tratadas con LPS, la AUC correspondiente a este período fue menor en relación con el vehículo $\left(70.9{ }^{\circ} \mathrm{C} \cdot \mathrm{h}\right.$ vs. $72.2^{\circ} \mathrm{C} \cdot \mathrm{h}$ respectivamente, con un nivel limítrofe de $F=2.82 ; p=0.06$ ). Curiosamente, la oxitocina no pareció tener ningún efecto sobre la hipotermia transitoria. Sin embargo, la administración del LPS indujo un incremento significativo en la temperatura corporal de +10 $\mathrm{a}+12$ horas después del tratamiento $(F=9.65, p<0.001, V$ vs. LPS), que se modificó significativamente mediante la administración de oxitocina $(F=9.65 p<0.05$, LPS vs. LPS + Ox). 
Finalmente, se encontró que el tratamiento con oxitocina exógena redujo el letargo inducido por LPS; esto fue notado debido a cambios significativos en la locomoción (Fig. III.5b) 6 horas post-LPS (V vs. LPS, $p<0.003$ ) y post-LPS con oxitocina (LPS vs. LPS + Ox, $p<0.05)$, de acuerdo con la prueba no paramétrica de Kolmogorov-Smirnov.

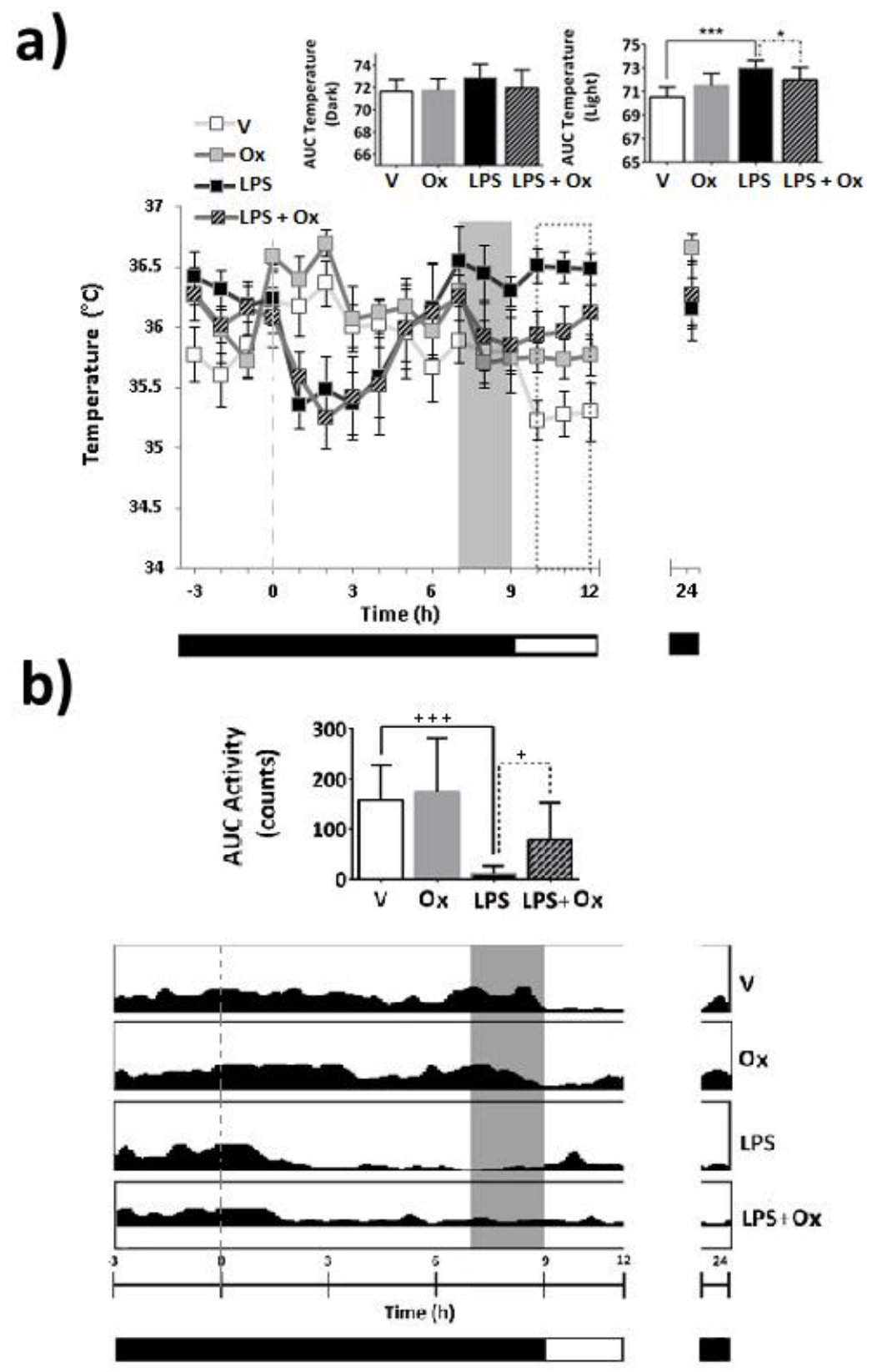

Figura 3.5. a) Temperatura periférica corporal, y b) actograma promedio de ratas macho adultas en libertad. Estos parámetros se registraron antes y después del tratamiento (tiempo $=0$, indicado por una línea vertical discontinua): vehículo (V), oxitocina (Ox), lipopolisacárido (LPS) y LPS + oxitocina (LPS + Ox). Los datos se muestran como promedio $\pm \mathrm{EE}$. El área bajo curva (AUC) correspondiente al área sombreada de cada parámetro (de $+7 \mathrm{a}+9 \mathrm{~h}$, período oscuro) se muestran en el inserto de la Figura. El AUC de la temperatura correspondiente al área blanca (de $+10 \mathrm{a}+12 \mathrm{~h}$, período de luz) también se muestra en el inserto de la Figura. ${ }^{*} \mathrm{p}<0.05,{ }^{* * *}$ $p<0.0001$ (prueba de LSD de Fisher), $+++p<0.003,+p<0.05$ (prueba de Kolmogorov-Smirnov). 


\subsection{Discusión de resultados}

Los resultados de este estudio demuestran que una única dosis de oxitocina exógena no modifica por sí misma las FFC, la temperatura y el movimiento corporal de ratas tratadas con oxitocina (grupo Ox) en comparación con ratas control o vehículo (grupo V). No obstante, en animales sometidos a la endotoxemia esta hormona provocó un patrón menos anticorrelacionado en las FFC indicado por $\alpha_{1 \text { (SIGN) }}$ (Figura 3.2b), disminuyó la MHR (Figura 3.1a), modificó la temperatura periférica (Figura 3.5a) y aumentó la locomoción (Figura 3.5b) hasta 6 horas posteriores a la inyección de LPS.

Un estudio previo demostró que una única administración de oxitocina exógena no afecta los niveles basales de corticotropina, cortisol, TNF- $\alpha$ y otras citoquinas [113]. En nuestro estudio, la falta de cambios en las FFC, la temperatura y el movimiento corporal después de una única administración de oxitocina es congruente con dicho estudio. Sin embargo, la modulación fisiológica introducida por la oxitocina sólo fue evidente durante la endotoxemia inducida por LPS. De hecho, Clodi et al. [113] sugirieron que la oxitocina exógena disminuye la activación neuroendocrina de ciertas citoquinas, e incluso activa la RCA, particularmente durante los escenarios de inflamación; lo que soporta nuestros hallazgos. Por lo tanto, los cambios significativos en la MHR y el $\alpha_{1(\mathrm{SIGN})}$ identificados $6 \mathrm{~h}$ después de la administración de oxitocina, revelan un patrón menos anticorrelacionado en las FFC y una disminución de la frecuencia cardíaca media, lo que sugieren la aparición de un acoplamiento del marcapasos cardíaco modulado por la influencia colinérgica de la oxitocina. Esta consideración está en concordancia con el hecho de que algunos autores han considerado que la oxitocina tiene efectos funcionales como un péptido modulador cardiovascular autonómico [108], [109]; donde estos efectos están mediados por los receptores oxitocinérgicos locales del corazón [187]. De hecho, la administración de oxitocina podría modular el a2-adrenoceptor, lo que resultaría en una mayor actividad de los receptores [188].

En cuanto a los efectos de la inyección de LPS, los resultados para los parámetros lineales de las FFC (MHR y SDNN), así como para el de temperatura periférica (entre $0 \mathrm{~h}$ a +6 h) son similares al de un estudio anterior [101]. En nuestro modelo de rata, se confirmó que la inyección de LPS indujo un patrón de respuesta bifásica: inicialmente se presentó una disminución en la temperatura corporal periférica, acompañada posteriormente por un período prolongado en el aumento de la MHR con FFC totales disminuidas de $0 \mathrm{a}+6 \mathrm{~h}$. Nuestros resultados también indican que después de $+6 \mathrm{~h}$ los efectos del LPS todavía fueron evidentes en las FFC. El grupo de investigación de Essen, Alemania ha 
caracterizado previamente el resultado inmunológico de una administración periférica de LPS a $0.1 \mathrm{mg} / \mathrm{kg}$ (dosis idéntica a la empleada en este experimento); resultando en un incremento substancial de niveles de citoquinas proinflamatorias periféricas como TNF- $\alpha$, IL-1 $\beta$ e IL-6 a los 90 min después del tratamiento [189], así como de niveles de citoquinas proinflamatorias centrales en la amígdala (TNF- $\alpha$, IL-1ß) 150 a 200 minutos después del tratamiento [190]. En este estudio también encontramos que en el largo plazo (es decir, +7 $\mathrm{a}+9 \mathrm{~h}$ ) las FFC siguen siendo afectadas por la dosis única de LPS (como es indicado por valores pequeños del SDNN, Figura 3.1b). Este efecto sobre las FFC podría estar asociado con niveles aún elevados de citoquinas proinflamatorias en el largo plazo como se reportó anteriormente para períodos de tiempo más cortos [33]. De hecho, el SDNN se ha asociado con el pico de expresión máximo de múltiples citoquinas de acuerdo con Fairchild et al. [98], ya que muestra una correlación inversa con niveles de TNF- $\alpha$ [191]. Continuando con la interpretación de los parámetros lineales de las FFC, se sugiere un potencial retiro vagal o desacoplamiento colinérgico para el grupo LPS (indicado por valores de RMSSD reducidos, Figura 3.1c). Se sabe que la función vagal desempeña un papel crítico en la regulación de la respuesta inflamatoria a través de la RCA, puesto que la modulación vagal está inversamente asociada con los procesos inflamatorios [192]. Por lo tanto, cuando la actividad vagal es baja, las influencias que inhiben la inflamación se interrumpen, resultando en un exceso en los niveles de citoquinas proinflamatorias periféricas [193], [194].

En cuanto a los parámetros no lineales de las FFC, se observó una alteración significativa en los parámetros de escalamiento y propiedades no lineales para el grupo LPS. Esto indica que en respuesta a la endotoxemia se modifica la estructura fractal de los períodos cardíacos. Por lo tanto, el decremento de los parámetros $\alpha_{1}$ y $\alpha_{1 \text { (MAG) }}$ (Figuras 3.2a y 3.2c, respectivamente), podría indicar el desacoplamiento del SNA y cardíaco [99].

El parámetro de escalamiento fractal en el corto plazo $\alpha_{1(\mathrm{SIGN})}$ mostró cambios interesantes, disminuyó después de la administración de LPS (Figura 3.2b, V vs. LPS). Las alternancias de la serie de fluctuaciones R-R se pueden visualizar en la serie de signos (Figura 3.4a). Estas alternancias indican un comportamiento más anticorrelacionado (tanto para la serie R-R como para la serie de signos) bajo la influencia del LPS. Teniendo en cuenta que el signo de los incrementos del latido cardíaco está relacionado con la interacción entre el sistema simpático y el parasimpático [123], estas alternancias sugieren un predominio simpático durante la endotoxemia (viéndose reflejadas en un aumento en la MHR, Figura 3.1a). Evidencia adicional apoya que el parámetro de escalamiento $\alpha_{1(\mathrm{SIGN})}$ se modifica después de la administración de un fármaco que bloquea el control autonómico en 
comparación con un grupo placebo [123]. Por otra parte, la administración de oxitocina exógena junto con LPS produjo un patrón menos anticorrelacionado en las FFC durante la endotoxemia inducida por LPS, esto es reflejado en el aumento del $\alpha_{1 \text { (SIGN) }}$ (Figura 3.4b) y que también es manifestado por una disminución de la MHR, (Figura 3.1a). El patrón menos anticorrelacionado encontrado en los grupos de LPS + Ox en comparación con LPS parece estar asociado con un incremento en la amplitud de las FFC debido a la administración de oxitocina.

Por el contrario, el parámetro lineal RMSSD no pudo revelar diferencias entre los grupos LPS vs. LPS + Ox. Esta restricción podría estar relacionada con la manifestación de cambios mínimos en la RMSSD debido a nuestro diseño experimental, ya que el parámetro mostró valores cercanos a la resolución establecida en la frecuencia de muestreo del ECG (es decir, $\approx 0,5 \mathrm{~ms}$ ). Sin embargo, esta restricción no se aprecia en el exponente de

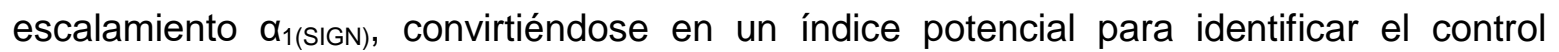
colinérgico cardíaco como de manera similar se reportó en otro de mis estudios [116].

Dado el bien caracterizado comportamiento de enfermedad o "sickness behavior" inducido por el LPS, se descarta que la actividad locomotora sea el factor predominante que explique los cambios en los parámetros de las FFC aquí descritos. Por lo tanto, nuestros resultados podrían ser más bien explicados por la activación de la RCA después de la administración de LPS que fue acompañada con la disminución de la actividad motora (Figura 3.5b, V vs. LPS) y un incremento de la temperatura (Figura 3.5a, $F=1,50 ; p=0,07$ ) de los animales. Esta interpretación es congruente con resultados de estudios que muestran que la locomoción disminuye después de la administración de LPS, de hecho la aplicación de LPS es utilizada como un modelo de depresión en roedores [195].

Los resultados para la temperatura periférica son congruentes con un estudio previo que describió los efectos de la oxitocina en combinación con LPS en seres humanos [113]. Del mismo modo, los efectos de la oxitocina sobre la temperatura durante la endotoxemia parecen manifestarse sólo hacia el final de nuestro período de observación (de +10 h a +12 h). Por lo tanto, estos hallazgos apoyan la consideración de que la oxitocina podría aliviar los síntomas asociados con la inflamación sistémica en el largo plazo [196]. Cabe destacar, que Reid et al. compararon la temperatura central y la temperatura periférica después de una inyección de LPS en novillos Holstein, lo que les llevó a sugerir que la temperatura central y la temperatura periférica no se modifican en sincronía después de un reto de LPS, sino que ambas siguen una relación inversa [197]. En este sentido, nuestros resultados para la temperatura podrían haber sido influenciados debido a la localización de los 
transmisores (es decir, implantados subcutáneamente), por lo tanto, aún son necesarios más estudios para dilucidar las influencias de la oxitocina en respuesta a un reto de LPS en la regulación de la temperatura corporal. Finalmente, la locomoción también fue influenciada por la dosis única de oxitocina (Figura 3.5b, LPS vs. LPS + Ox) que restringió los efectos letárgicos inducidos por el LPS. Esta condición podría reflejar indirectamente las propiedades antiinflamatorias de dicha hormona. En efecto, existe evidencia previa que sugiere que una administración subcrónica de oxitocina reduce la fatiga en adultos mayores [198] y aumenta los efectos de la clonidina (un agonista de los receptores adrenérgicos a2) mediante la reducción de la presión arterial y la modificación de la actividad locomotora en ratas. Aunque la oxitocina tiene una vida media de sólo unos pocos minutos, la reducción de la presión arterial en respuesta a la oxitocina no se ha manifestado hasta alrededor de 6 a 8 horas después de su primera administración [199]. Estos efectos cardiovasculares son coherentes y coincidentes con los cambios tardíos introducidos por la oxitocina en la locomoción de las ratas y en los parámetros de las FFC durante la endotoxemia inducida por LPS de nuestro estudio.

Takayama et al. [200] demostraron que la taquicardia durante la inflamación sistémica está parcialmente relacionada con la activación de tromboxano auricular y receptores de prostaglandinas. Este hallazgo sugiere que la producción local de eicosanoides puede contribuir al desarrollo de taquicardia durante la inflamación sistémica. Aunque este mecanismo necesita ser dilucidado, puede explicar porqué la frecuencia cardíaca todavía está elevada 24 horas después de la inyección de LPS, mientras que todas las otras medidas de las FFC han vuelto a niveles basales. De igual manera es sabido que los receptores de prostaglandinas juegan un rol importante en el control de las respuestas febriles [201]; por lo que también podrían estar afectando la temperatura posterior a las 9 horas de la administración de LPS.

El sistema nervioso autónomo regula la temperatura corporal a través de varios mecanismos: pérdida de calor por evaporación y conducción y modulación hemodinámica. Algunos estudios han caracterizado fallas de la capacidad del SNA de regular en temperaturas extremas (estrés fisiológico) usando el análisis espectral de las FFC. El estrés fisiológico conduce a cambios en los mecanismos reguladores que potencialmente incluyen el SNA. Se sugiere que el estrés fisiológico abrumador conduce a un desacoplamiento de los órganos de los mecanismos de control autonómico y que dichos cambios se ven reflejados en una disminución en las FFC [202] . 
Otros resultados también muestran que la amplitud de los intervalos $\mathrm{R}-\mathrm{R}$ se incrementan en un ambiente de temperatura ambiente más alta. Esto puede ser causado por más vasodilatación a temperaturas más altas, cambiando el flujo sanguíneo en pequeñas arterias y causando variaciones en el ritmo cardiaco por actividad barorrefleja.

\section{Limitaciones}

Se debe reconocer que no se probaron diferentes dosis de oxitocina que podrían modificar nuestros resultados. No obstante, con la administración de una única dosis baja de oxitocina se pudo introducir cambios en los parámetros fractales y no lineales de las FFC durante la endotoxemia. Por otro lado, debido al modelo del transmisor usado en este estudio y su localización, la temperatura central y la presión arterial no fueron variables posibles de ser registradas. Estudios anteriores sugieren que tanto la oxitocina como el LPS disminuyen la presión arterial en roedores [203], [204], así como valores disminuidos de las FFC han sido asociados a valores elevados de presión arterial [205]. Otro estudio indica que el LPS produce un rápido deterioro de la sensibilidad barorrefleja [206], independientemente del nivel de presión arterial, mientras que la oxitocina es probable que también actúe sobre la sensibilidad del reflejo barorreceptor [207]. En trabajos futuros se considerará la aplicación de dosis más altas de oxitocina, así como el monitoreo de la presión arterial y la temperatura central, además de probar otras vías de administración para investigar la relación real entre los niveles de citoquinas periféricas y los parámetros de las FFC.

\subsection{Conclusión}

Durante la endotoxemia inducida por LPS, las FFC en el largo plazo se tornaron más

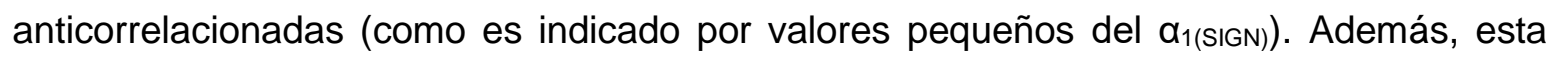
endotoxemia estuvo acompañada de: a) taquicardia, b) pérdida de la dinámica fractal del ritmo cardiaco, c) cambios en la temperatura periférica, y d) comportamiento letárgico. Sin embargo, una dosis única concomitante de oxitocina periférica provocó un patrón menos anticorrelacionado en las FFC en el largo plazo (como es indicado por valores más altos del $\alpha_{1(\mathrm{SIGN})}$ ), la oxitocina restableció los valores normales de la frecuencia cardiaca, redujo el letargo y moderó la hipertermia inducida por LPS. Este estudio sugiere que el patrón menos anticorrelacionado en las FFC y la disminución de la frecuencia cardíaca media podría ser resultado de un acoplamiento autonómico colinérgico cardiaco debido a la administración concomitante de oxitocina exógena durante la endotoxemia inducida por LPS y su interacción con los receptores de oxitocina del corazón. 


\section{Capítulo IV}

\section{Estudio II: El rol de la oxitocina en la actividad cardiorrespiratoria de ratas endotoxémicas}

Resumen: Hallazgos recientes sobre la oxitocina indican sus propiedades moduladoras antiinflamatorias, cardioprotectoras y parasimpáticas. En este estudio se investigaron los efectos de la oxitocina aplicada sistemáticamente sobre la actividad cardiorrespiratoria en un modelo de roedores bajo endotoxemia moderada.

Electrocardiogramas (ECG) telemétricos de animales que recibieron lipopolisacárido (LPS); Oxitocina (Ox); Lipopolisacárido + oxitocina (LPS + Ox) y solución salina (V) se analizaron utilizando la técnica de respiración derivada del ECG (EDR) para estimar la frecuencia respiratoria. El intervalo $R-R$ medio y los parámetros espectrales de las FFC, como el logaritmo natural de los componentes de alta frecuencia (InHF) y baja frecuencia (InLF) también fueron calculados hasta 24 h después del tratamiento.

Los animales endotoxémicos (LPS) mostraron una frecuencia respiratoria elevada, así como un intervalo $R$ - $R$ medio, InHF y InLF disminuidos comparados con los controles (V) de $+5 a+12 h$ después del tratamiento. La administración de oxitocina atenuó significativamente la hiperventilación producida por la endotoxemia inducida por LPS (LPS + Ox) y restauró los valores del intervalo $R-R$ medio y de los parámetros espectrales en diferentes puntos temporales. Nuestros resultados apoyan la existencia de un vínculo entre los sistemas respiratorio, cardiovascular e inmunológico en los que la oxitocina parece actuar como un potencial péptido cardioprotector. Como resultado, la oxitocina disminuyó la taquipnea de los animales y restauró las interacciones cardiorrespiratorias, indicadas por los componentes espectrales de las FFC, independientemente de la administración de endotoxina.

Es pertinente mencionar que avances preliminares de este trabajo se presentaron en los siguientes congresos:

$12^{\circ}$ reunión científica del German Endocrine-Brain-Immune-Network (GEBIN), 23 al 25 de marzo de 2017, Münster, Alemania.

Este trabajo ha sido publicado como: Elorza-Ávila AR, Reyes-Lagos JJ, Hadamitzky M, Peña-Castillo MÁ, Echeverría JC, Ortiz-Pedroza MD, Lückemann L, Schedlowski M, Pacheco-López G. Oxytocin's role on the cardiorespiratory activity of endotoxemic rats. Respir Physiol Neurobiol. 2017;236:19-22. doi: 10.1016/j.resp.2016.10.008. Una copia de dicho artículo se encuentra en el Apéndice $E$.

\subsection{Introducción}

Los sistemas respiratorio y cardiovascular están íntimamente ligados, principalmente a través del SNA [208]. De hecho, algunos autores han sugerido la existencia de un vínculo entre los sistemas respiratorio, cardiovascular e inmunológico donde el NTS en el tallo 
cerebral es el sitio principal de integración neural [208]. Estudios anteriores han demostrado que la inflamación sistémica puede alterar la dinámica cardiorrespiratoria. En particular, la endotoxemia se ha asociado con la disminución del acoplamiento cardiorrespiratorio, lo que resulta en una ineficiencia del intercambio gaseoso [209]. Por otro lado, se ha indicado que algunos péptidos como la oxitocina poseen propiedades cardioprotectores durante la endotoxemia [210]. La oxitocina se ha utilizado para reducir el infarto de miocardio y arritmias ventriculares. Además, mejora la presión arterial media a través de la producción de óxido nítrico, la activación de la proteína quinasa $\mathrm{C}$ y el equilibrio reactivo de especies de oxígeno [210]. Es importante hacer énfasis que el estudio del Capítulo III apoya los hallazgos acerca de las propiedades cardioprotectoras y antiinflamatorias sistémicas de la oxitocina, ya que una dosis baja de oxitocina periférica redujo los signos del comportamiento de enfermedad, como el letargo y la fiebre, y modificó las FFC durante una endotoxemia moderada. En este contexto, el objetivo del presente estudio, fue analizar los efectos de la oxitocina exógena después de un desafío inmune inducido por la administración de lipopolisacárido (LPS) sobre la actividad cardiorrespiratoria. Esto se comprobó mediante la técnica de respiración derivada del ECG (EDR) [211] junto con el análisis espectral de las FFC. Es sabido que las FFC reflejan los procesos fisiológicos asociados al SNA vinculados a los sistemas respiratorio y cardiovascular [208], mientras que la EDR permite estimar la señal respiratoria. Se planteó la hipótesis de que la oxitocina desempeña un papel modulador en el control cardiorrespiratorio durante la endotoxemia, principalmente favoreciendo el acoplamiento autonómico colinérgico cardiaco, lo que resulta en una reducción de la frecuencia respiratoria y en la restauración de los parámetros espectrales de las FFC.

\subsection{Métodos}

Datos experimentales del electrocardiograma: Los registros de ECG del estudio anterior (Capítulo III) se extrajeron de nuestra base de datos; estos registros se obtuvieron de las mismas ratas adultas Dark Agouti (DA / HanRj, 230-250g) implantadas con los transmisores de radio-telemetría (frecuencia de muestreo $2000 \mathrm{~Hz}$ ) como se describió anteriormente (Sección 3.2). Estos animales se mantuvieron en un ciclo de luz / oscuridad invertido de 12:12 h (la luz se apagaba a las 7:00 AM) y tuvieron acceso ad libitum a agua y a dieta estándar. Los datos se dividieron en cuatro grupos de tratamiento: 1) vehículo (V, solución salina, $\mathrm{n}=7$ ); 2) oxitocina (Ox, $3 \mathrm{UI} / \mathrm{kg}$ administrado por vía subcutánea, $\mathrm{n}=8,3$ ) lipopolisacárido (LPS, 0.1 mg / kg administrado por vía intraperitoneal, $\mathrm{n}=8$ ); 4) LPS + 
oxitocina (LPS + Ox; administración combinada de $0.1 \mathrm{mg} / \mathrm{kg}$ de LPS intraperitoneal y 3 UI / kg de oxitocina subcutánea, $\mathrm{n}=8$ ).

Análisis de datos: Se seleccionaron cada hora $(-3 \mathrm{~h}$ a $+24 \mathrm{~h})$ segmentos confiables y representativos de 5 minutos de duración de los ECG's, posteriormente se analizaron los segmentos para la detección de los picos $R$ y generación de los intervalos $R-R$ de acuerdo con el procedimiento descrito en el capítulo II sección 2.1. Los intervalos R-R se analizaron utilizando el software Kubios para el análisis espectral de las FFC (Universidad de Kuopio, Kuopio, Finlandia). Se evaluó la potencia absoluta del componente de LF, que está asociado con influencias simpáticas y parasimpáticas, o incluso relacionado con la función barorrefleja [86]. También se estimó la potencia absoluta del componente de HF, que refleja principalmente la arritmia sinusal respiratoria (ASR), y que por lo tanto es considerado como un índice indirecto del control vagal cardíaco. Los ajustes del software Kubios para el cálculo de los parámetros espectrales de las ratas se realizaron de la siguiente manera: no se eliminaron componentes periódicos de la señal R-R (opción predeterminada en Kubios), se seleccionó una interpolación a $8 \mathrm{~Hz}$ de acuerdo con lo descrito por Gonçalves et al. [212]. Se marcó la opción FFT spectrum con una ventana de 256 puntos con 50\% de traslape, y se reajustaron los valores de los componentes, para LF $(0.04-1.0 \mathrm{~Hz})$ y para el componente HF (1.0-3.0 Hz), esto de acuerdo con la metodología utilizada por Kuwahara et al. [144]. Además, se aplicó la técnica EDR de procesamiento de señales para estimar las señales respiratorias a partir del ECG basada en el área bajo la curva del complejo QRS (como se describió previamente en el Capítulo II, Sección 2.4). Esta técnica está disponible gratuitamente en el sitio web de PhysioNet (www.physionet.org) y ha demostrado proporcionar datos fiables relacionados con la respiración [211]. La ventana móvil del algoritmo se ajustó a $0.1 \mathrm{~s}$. Posteriormente las señales respiratorias estimadas por EDR fueron interpoladas mediante un spline cúbico a $100 \mathrm{~Hz}$ y filtradas digitalmente con un filtro pasa altas usando una frecuencia de corte de $0.5 \mathrm{~Hz}$. El pico de los espectros de las señales EDR $(1.0-3.0 \mathrm{~Hz})$ se calculó a través de la densidad de potencia espectral por el método de Welch con el propósito de estimar la frecuencia respiratoria (al multiplicar por 60 la frecuencia del pico máximo de EDR, Figura 4.1a), para la estimación de la densidad de potencia espectral se ocupó una ventana de 1024 puntos y 50\% de traslape.

Análisis estadístico: Inicialmente y para corregir distribuciones, los parámetros LF y HF fueron transformados logarítmicamente. El siguiente paso fue realizar comparaciones entre 
V vs. Ox, LPS vs. V y LPS vs. LPS + grupos Ox que fueron analizadas por ANOVA de dos vías, seguido de pruebas post hoc LSD de Fisher. Los datos se expresaron como promedio \pm SEM y el nivel de significancia se estableció en $p<0.05$.

\subsection{Resultados}

En la Figura 4.1 se muestra la frecuencia respiratoria estimada por la técnica de EDR, el intervalo R-R medio y los parámetros espectrales estimados del análisis de las FFC (InHF e InLF) a partir de $-3 \mathrm{~h}$ a $+24 \mathrm{~h}$ después del tratamiento. Una barra de color negra/blanca en la parte inferior de cada panel indica, respectivamente, el ciclo de oscuridad/luz. La administración única de oxitocina (es decir, por sí sola) no modificó la dinámica de la frecuencia respiratoria en el largo plazo ( $V$ vs. Ox), mientras que en presencia de endotoxemia la oxitocina indujo cambios significativos (LPS vs. LPS + Ox, Figura 4.1a de $+6 \mathrm{~h} \mathrm{y}+12 \mathrm{~h}, \mathrm{~F}(16.459)=6.487, \mathrm{p}<0.0001)$. También se identificó un incremento de la frecuencia respiratoria estimada, junto con una reducción del intervalo $R-R+5 h$ después del tratamiento (Figura 4.1a y Figura 4.1b, respectivamente). Estos cambios fisiológicos continuaron hasta $+12 \mathrm{~h}$. El parámetro espectral InHF mostró una reducción de $+8 \mathrm{a}+12 \mathrm{~h}$, de hecho, el valor más bajo se detectó a las +9 h (LPS vs. V, Figura 4.1c, F (16.459) = 2.071; $p=0.0083)$. Del mismo modo, se encontró un decremento en InLF de $+1 \mathrm{~h} \mathrm{a}+12 \mathrm{~h}$, con el valor más bajo identificado a las +9 h (LPS vs. V, Figura 4.1d, F (16.459) = 4.450, $\mathrm{p}<00001)$. La administración de oxitocina restauró los parámetros de InHF y InLF alrededor de +9 h después del tratamiento (LPS vs. LPS + Ox, Figura 4.1c, Figura 4.1d, F (16.459) = $2.071 ; p=0.0083, F(16.459)=4.450 ;<0.0001$, respectivamente). La prueba post-hoc LSD de Fisher mostró diferencias significativas entre las comparaciones planeadas $(p<0.05)$.

Por otro lado, la Figura 4.2 muestra datos representativos de las señales respiratorias estimadas por la técnica de EDR. Esta Figura ilustra un mayor patrón de frecuencia respiratoria durante la endotoxemia (LPS) en comparación con los datos del grupo LPS + Ox +6 h después del tratamiento. Aunque no es mostrado en la Figura, se encontraron también diferencias estadísticas entre LPS vs. V $p<0.05$ para la frecuencia respiratoria y el $\mathrm{R}-\mathrm{R}$ promedio posteriores a las $24 \mathrm{~h}$ del tratamiento. 


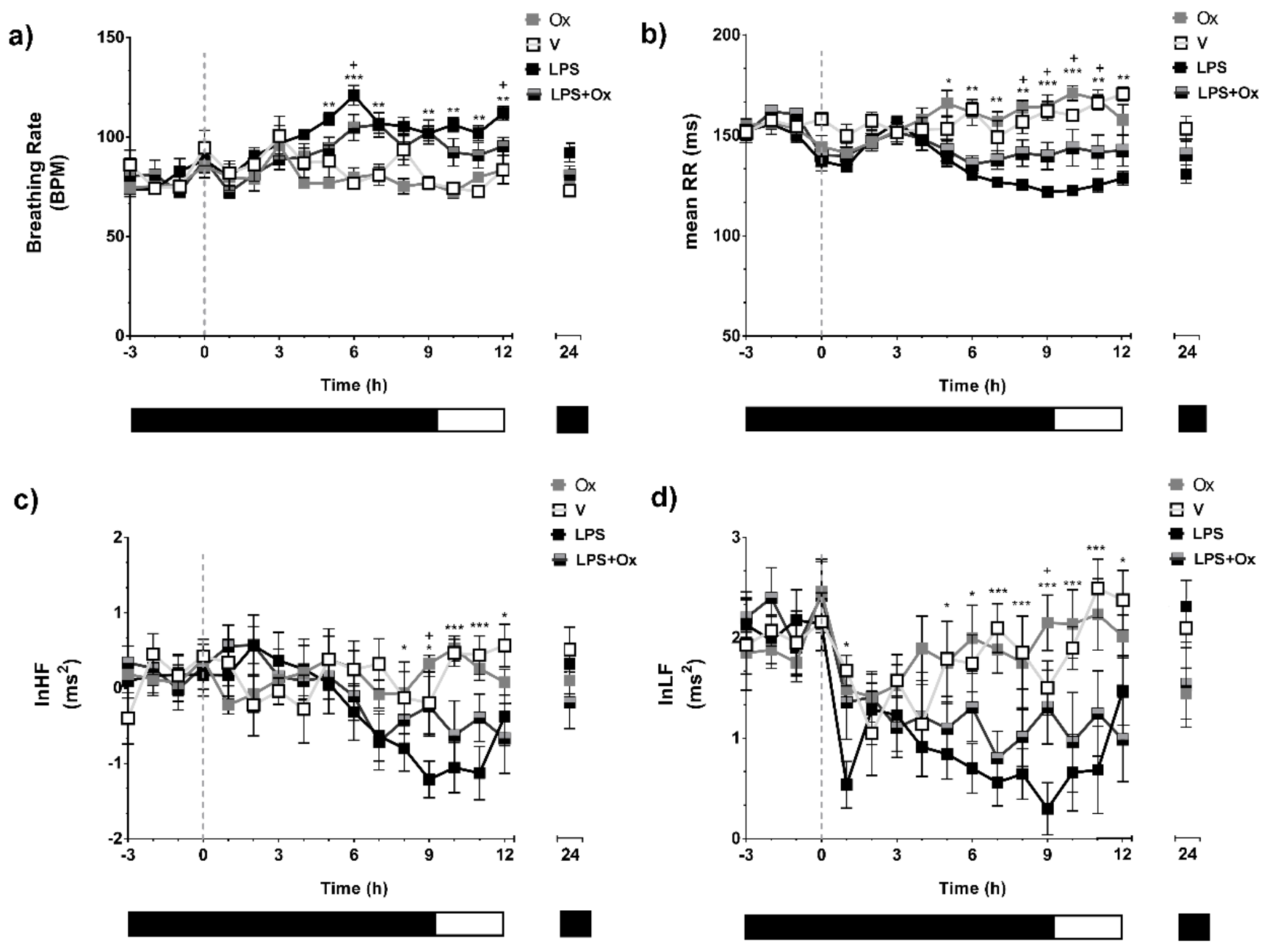

Figura 4.1 Parámetros cardiorrespiratorios de ratas macho adultas en libertad: a) frecuencia respiratoria estimada usando la técnica de respiración derivada del electrocardiograma (EDR); b) intervalo R-R medio; c) logaritmo natural del componente de alta frecuencia (InHF) y d) logaritmo natural del componente de baja frecuencia $(\mathrm{InLF})$. Estos parámetros son reportados antes y después del tratamiento (tiempo = 0): vehículo $(\mathrm{V})$, oxitocina (Ox), lipopolisacárido (LPS) y LPS + oxitocina (LPS + Ox). La barra negra/blanca en la parte inferior de cada panel indica los períodos de oscuridad y luz, respectivamente. Los datos se muestran como promedio \pm EE. ${ }^{*} p<0.05,{ }^{* *} p<0.01,{ }^{\star * *} p<0.001$ entre LPS vs. V $y+p<0.05$ entre LPS vs. LPS + Ox según la prueba posthoc LSD de Fisher. 
a)

$6 \mathrm{~h}$ after LPS injection

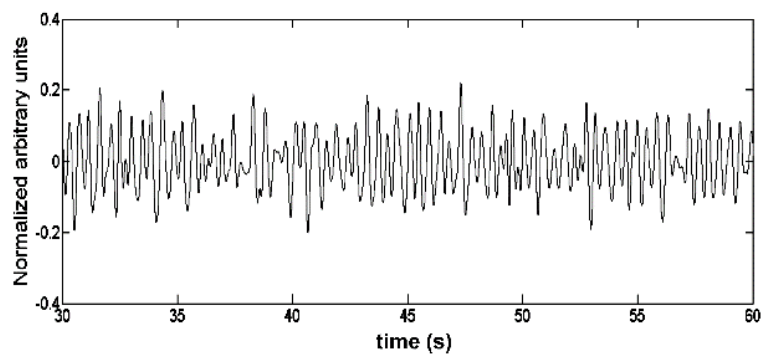

c)

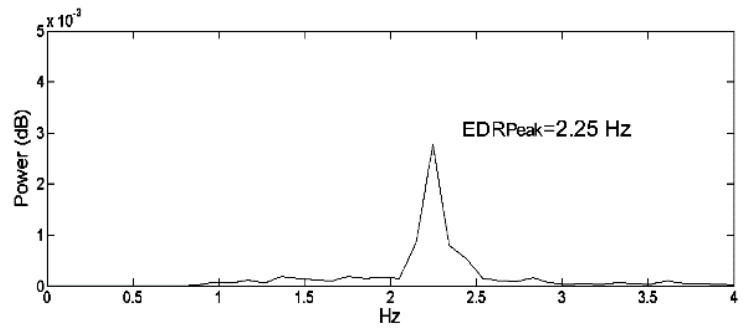

b)

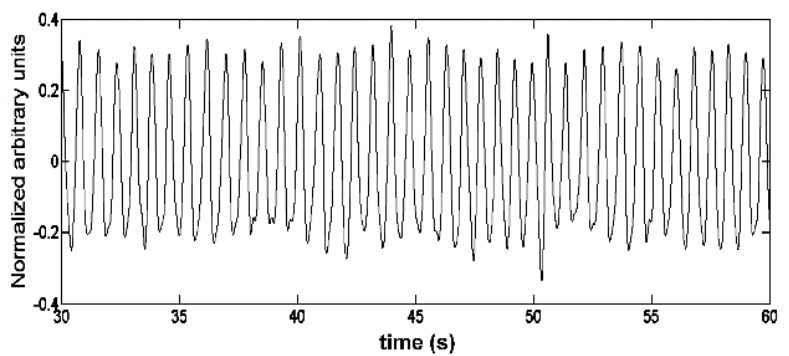

d)

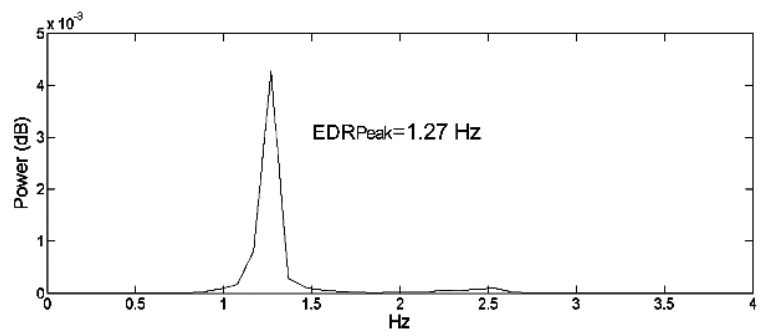

Figura 4.2 Ejemplo representativo de la extracción de 30 segundos de una señal respiratoria derivada del electrocardiograma (superior) con su correspondiente densidad de potencia espectral o PSD (inferior): a) Respiración derivada del electrocardiograma 6 h después de la inyección de lipopolisacárido (LPS); b) Respiración derivada del electrocardiograma 6 h después de la inyección de LPS + oxitocina; c) PSD del panel a) y d) PSD del panel b).

\subsection{Discusión de resultados}

La reducción del parámetro espectral InHF de las FFC indica una disminución de la arritmia sinusal respiratoria (ASR) y sugiere un desacoplamiento parcial del marcapasos cardíaco durante la endotoxemia inducida por LPS en el largo plazo (LPS vs. V, Figura 4.1c). De hecho, una ASR reducida está asociada a una disminución de la eficiencia de intercambio gaseoso del pulmón, al no sincronizar óptimamente la perfusión pulmonar con la ventilación alveolar a través del ciclo ventilatorio (Yasuma y Hayano, 2004). Además, un intervalo R-R pequeño (LPS vs. V, Figura 4.1b) está relacionado con un retiro vagal o bien, con una actividad simpática aumentada. Es de destacar que el valor más bajo del intervalo $R-R$ medio (LPS vs. V, Figura $4.1 \mathrm{~b}$ en $+9 \mathrm{~h}$ ) no coincide con el valor máximo de la frecuencia respiratoria (LPS vs. V, Figura $4.1 \mathrm{a}$ en $+6 \mathrm{~h}$ ). Por lo tanto, estos hallazgos sugieren que, a pesar de manifestarse una ASR reducida durante la endotoxemia inducida por LPS (indicada por valores bajos de InHF), la frecuencia respiratoria estimada presenta un aumento significativo junto con un intervalo R-R reducido en respuesta a un reto por LPS. De hecho, la ASR puede reducirse en respuesta a una frecuencia respiratoria aumentada (datos representativos en la Figura 4.2a) independientemente de la actividad del nervio vago [213]. Sin embargo, la administración de oxitocina (LPS vs. LPS + Ox) parece revertir 
hacia niveles basales la frecuencia respiratoria estimada (Figura 4.1a), el intervalo R-R medio (Figura 4.1b) y también los parámetros espectrales de las FFC InHF y InLF (Figura 4.1c y Figura 4.1d, respectivamente). La disminución de la frecuencia respiratoria se observó incluso +6 h y +12 h después de la administración de oxitocina (LPS vs. LPS + Ox, Figura 4.2b), aunque el incremento en la potencia del componente HF sólo se observó +9 h después de la administración de oxitocina (Figura 4.1c). Por lo tanto, se especula que, entre los diferentes mecanismos fisiológicos atribuidos a los cambios observados en los componentes espectrales InHF y InLF (Figura 4.1c y Figura 4.1d, respectivamente) y en la frecuencia respiratoria estimada en ratas (Figura 4.1a), la presencia de receptores de oxitocina en el corazón [210] podrían tener un efecto directo sobre el acoplamiento del marcapasos cardíaco. Además, los receptores de oxitocina en los pulmones [214], así como la potencial activación de la RCA deben tomarse en consideración [88].

Como se mencionó previamente en nuestro estudio anterior, Takayama et al. [200] demostraron que la taquicardia durante la inflamación sistémica está parcialmente relacionada con la activación de tromboxano auricular y receptores de prostaglandinas. En este sentido, también es sabido que la frecuencia respiratoria se incrementa en presencia de prostaglandinas [215], por lo que en nuestro estudio la taquipnea podría persistir varias horas posteriores a la administración de LPS.

\subsection{Conclusión}

En el presente estudio, se encontró que los parámetros espectrales de las FFC (InHF y InLF) se alteran durante la endotoxemia moderada en ratas. Una depresión en el componente HF podría indicar una reducción de la ASR. Por otro lado, los cambios en ambos componentes HF y LF sugieren la existencia de un desacoplamiento del control autonómico durante la endotoxemia inducida por LPS. Sin embargo, nuestros resultados también apoyan la existencia de un vínculo funcional entre los sistemas respiratorio, cardiovascular e inmunológico en el que la oxitocina parece actuar como un potencial péptido cardioprotector al favorecer el acoplamiento autonómico colinérgico cardiaco. En consecuencia, la oxitocina disminuyó la taquipnea de los animales y restauró las interacciones cardiorrespiratorias indicadas por los componentes espectrales de las FFC a pesar de la administración de la endotoxina. 


\section{Capítulo V}

\section{Estudio III: Reducción de las concentraciones séricas maternas de la familia de las citoquinas IL-10 en el trabajo de parto activo}

Resumen: La familia de la IL-10 son citoquinas que modulan la respuesta inmunológica, principalmente en las células epiteliales. Durante el trabajo de parto activo se pierde la quiescencia miometrial que es acompañada de una alteración del equilibrio de la inmunidad innata. Con la meta de investigar el papel de la familia de las citoquinas IL-10 en el trabajo de parto, se realizó un estudio longitudinal en un grupo de mujeres embarazadas sanas en el tercer trimestre de embarazo $(N=20)$. Su edad gestacional osciló entre las 32 y 38 semanas (36 \pm 2 semanas) y posteriormente en el trabajo de parto activo; su edad gestacional fue de 39 a 41 semanas ( $40 \pm 1$ semanas), no fueron reportadas complicaciones durante ambas etapas. Los niveles séricos de varias citoquinas maternas se midieron utilizando inmunoensayos múltiples. Los resultados indicaron que las concentraciones séricas de las citoquinas IL-10, IL-20, IL-22, IL-28A e IFN-y disminuyen significativamente en el trabajo activo en comparación con el tercer trimestre de embarazo $(p<0.05)$. No se encontró una correlación entre las citoquinas miembros de la familia IL-10 con las semanas de gestación. Los hallazgos sugieren que la disminución sistémica de varios miembros de la familia de la IL-10, desempeña un papel relevante en la activación de células lisas miometriales, asociadas con las contracciones uterinas en el trabajo de parto. De manera interesante, la disminución de la familia de citoquinas IL-10 parece coincidir con la bien documentada retirada funcional de la progesterona que ocurre en el trabajo de parto. Asimismo, las concentraciones plasmáticas bajas de IFN- $\gamma$ indican un rol importante de esta citoquina que contribuye en el trabajo de parto activo.

Es pertinente mencionar que este trabajo ha sido aceptado para su publicación en la revista NeurolmmunoModulation (NIM) y actualmente está en revisión como manuscrito NIM-1956: JJ Reyes-Lagos, MA Peña-Castillo, JC Echeverría, G Pérez-Sánchez, S ÁlvarezHerrera, E Becerril-Villanueva, L Pavón, $R$ Ayala-Yáñez, $R$ González-Camarena, $G$ Pacheco-López, Women serum concentrations of interleukin-10 and IFN- $\gamma$ decrease from third trimester of pregnancy to active labor.

\subsection{Introducción}

El embarazo se define como el período que comienza con el último período menstrual y termina con en el nacimiento [33]. Este es un estado en el que el sistema inmune materno se modifica para lograr la tolerancia inmune hacia las proteínas expresadas por las células fetales, reconocidas como antígenos. Estas modificaciones, que ocurren tanto en la interfase materno-fetal como en la circulación sistémica, son impulsadas por estrógenos y 
progesterona, cuyas concentraciones sanguíneas aumentan durante el embarazo [216]. En circunstancias regulares, después de un período de 37 a 42 semanas de gestación, el trabajo de parto se desencadena [9]. El trabajo de parto es considerado como una actividad miometrial aumentada con un patrón de contractilidad regular. El inicio del trabajo de parto ha sido considerado como un estado proinflamatorio que promueve la culminación del embarazo [85]. En realidad, parece estar asociado con el restablecimiento en el sistema inmune de las mujeres embarazadas hacia un perfil Th1 en lugar de un perfil Th2 [70].

El trabajo de parto prematuro se define como el trabajo de parto que comienza antes de alcanzar las 37 semanas de gestación y se sabe que hasta el 30\% de los nacimientos prematuros están asociados con infecciones intrauterinas en México[217]. Estos procesos de infección producen una alteración sustancial de las citoquinas [16]. De hecho, una predisposición a un cambio prematuro de un estado antiinflamatorio hacia un estado proinflamatorio puede explicar varios factores de riesgo en los trabajos de parto prematuros [218]. Varios estudios genéticos y funcionales han asociado a las citoquinas proinflamatorias y antiinflamatorias con el trabajo de parto. Sin embargo, estos estudios generalmente han analizado a citoquinas individuales, centrándose en escenarios como el trabajo de parto prematuro [83], [218]-[220]. Hasta el momento, hay evidencia limitada que describa múltiples citoquinas inflamatorias durante embarazos y trabajos de parto sin complicaciones.

Entre las citoquinas antiinflamatorias, la IL-10 desempeña un papel importante durante el embarazo como regulador de la inmunidad materna, asociada con la aceptación del aloinjerto fetal y la facilitación de sus privilegios inmunológicos [221]. Este efecto parece estar también mediado por niveles elevados de progesterona, que se ha demostrado que estimulan la secreción de citoquinas Th2 y reducen la secreción de citoquinas Th1 [222], [223]. Sin embargo, cuando se desencadena espontáneamente el trabajo de parto y este ocurre a término, dichos privilegios inmunológicos ya no se conservan, probablemente causando una inflamación estéril que implica la dilatación del cuello uterino, borramiento cervical y contracciones uterinas [85]. Las citoquinas tales como IL-19, IL-20, IL-24, IL-26, IL-28A, IL-28B e IL-29 están estructuralmente relacionadas con la IL-10, y por lo tanto pertenecen a la denominada "familia de citoquinas de la IL-10" [224]. Curiosamente, estas citoquinas desencadenan diversos mecanismos de defensa, principalmente en las células epiteliales, incluyendo el endometrio [225]. De hecho, una función clave de la familia de citoquinas de la IL-10 es la protección tisular [225]. 
El objetivo de este trabajo fue explorar longitudinalmente si la familia de citoquinas de la IL-10, así como otros marcadores inflamatorios asociados al trabajo de parto, se modifican entre el tercer trimestre de embarazo y el trabajo de parto activo y a término en mujeres sanas. Se planteó la hipótesis de que el trabajo de parto espontáneo y a término presenta cambios sutiles pero notables en la concentración sistémica de citoquinas, debido a su origen inflamatorio estéril [85].

\subsection{Metodología}

Participantes: Veinte mujeres embarazadas de 35 a 38 semanas de gestación, sin complicaciones durante el embarazo y sin ninguna manifestación clínica de encontrarse en trabajo de parto estuvieron involucradas en este estudio. Las participantes se atendieron en el Centro de Investigación Materno Infantil del grupo de estudios al nacimiento (CIMIGen) en la Ciudad de México, México. Este protocolo fue aprobado por la Comisión de Ética de la División de Ciencias Biológicas y de la Salud (CBS) de la Universidad Autónoma Metropolitana Unidad Iztapalapa con el dictamen CAEDCBS.01.2017, adicionalmente se obtuvo el consentimiento informado de cada participante (el formato se encuentra en el Apéndice B: Carta de consentimiento informado). Este estudio se realizó de acuerdo con la Declaración de Helsinki [226] y siguió todos los procedimientos institucionales del CIMIGen.

Todas las participantes fueron mujeres mexicanas entre 18 y 32 años, residentes en la Ciudad de México o su Área Metropolitana. Siguiendo un diseño experimental longitudinal, las 20 participantes fueron estudiadas en el tercer trimestre de embarazo y posteriormente en el trabajo de parto activo a término ( $40 \pm 1$ semanas). El número de semanas que pasaron entre ambas mediciones fue de $3.6 \pm 2$ semanas. El trabajo de parto activo fue identificado por la presencia de 3 a 4 contracciones uterinas en 10 minutos, dilatación cervical de al menos $4 \mathrm{~cm}$ y borramiento del cérvix del $50 \%$, los criterios de selección de las participantes se detallan a continuación.

\section{Criterios de inclusión del estudio:}

- Intervalo de edad entre 18-32 años.

- Embarazo a término.

- Índice de masa corporal normal antes del embarazo (18.5 - $\left.24.9 \mathrm{~kg} / \mathrm{m}^{2}\right)$ [227].

- Ganancia de peso gestacional óptima (11.5 - 16 kg) [227]. 
- Residentes en la Ciudad de México o su área metropolitana.

- En el tercer trimestre de gestación y posteriormente en el trabajo de parto.

- Sin complicaciones reportadas durante el transcurso del embarazo.

- Sin anestesia epidural administrada durante el registro de trabajo de parto.

- Normotensas.

- Primigestas o multigestas.

\section{Criterios de exclusión/eliminación del estudio:}

- Información prenatal incompleta.

- APGAR del recién nacido de 5 minutos menor a 7 puntos [228].

- Peso al nacer del recién nacido inferior a $2500 \mathrm{~g}$ [229].

- Productos con malformaciones congénitas.

- Bajo tratamiento farmacológico de esteroides.

- Presencia de alergias, hipertensión, diabetes, cardiopatías, hepatitis, enfermedades renales crónicas u otras enfermedades sistémicas crónico degenerativas o autoinmunes.

- Presencia de infecciones crónicas.

- Pacientes con consumo de sustancias de abuso (alcohol, tabaco, drogas).

- Sangrado vaginal.

- Presencia de meconio durante el trabajo de parto.

- Registro de electrocardiograma con artefactos que impidan la detección del complejo QRS.

- No firmar la carta de consentimiento informado.

Es importante hacer hincapié que no se administró anestesia epidural durante el proceso del trabajo de parto a ninguna de las participantes, de hecho, se ha reportado que la anestesia podría interferir de alguna forma en la activación de algunas citoquinas [230]. Al tener valores clínicos favorables de los neonatos se apoya la consideración de que los embarazos fueron saludables y de bajo riego. En realidad, no se produjeron complicaciones mayores en los recién nacidos, como es indicado por los pesos adecuados al nacimiento (es decir, 3000 a $3500 \mathrm{~g}$ ), puntajes APGAR de 5 minutos por encima de los 8.5 puntos, edad gestacional entre 39 a 41 semanas y la ausencia de malformaciones al nacimiento. 
Psicometría de ansiedad: Las participantes respondieron a la versión mexicana del Inventario de Ansiedad de Beck (BAI), con el propósito de evaluar la gravedad de su ansiedad durante el embarazo [231]. Estudios anteriores han mostrado una correlación positiva entre los síntomas de ansiedad y los marcadores inflamatorios [232], [233]. La prueba BAI se aplicó únicamente al tercer trimestre de gestación.

Tamaño de la muestra: Con base en el estudio de Vassiliadis et al., 1998 [234], en donde se midieron citoquinas durante el trabajo de parto y no embarazo, se calculó el tamaño de la muestra mediante la fórmula 10. Se estimó que para encontrar una diferencia significativa con un nivel de a de 0.05 y una potencia del $80 \%$ era necesario tener al menos 16 participantes.

$$
n=2\left[\frac{\left(z_{\propto}-z_{\beta}\right) \sigma}{\mu_{1}-\mu_{2}}\right]^{2}
$$

En donde:

$Z \alpha=$ valor de la $t$ de Student para el nivel de confianza especificado

$\mathrm{Z} \beta=$ valor de la $\mathrm{t}$ de Student para el poder o potencia especificada

$\sigma=$ desviación estándar esperada

$\mu 1=$ media esperada de la población 1

$\mu 2=$ media esperada de la población 2

$\mu 1-\mu 2=$ diferencia entre las dos medias esperadas

Muestras de suero: Se obtuvieron muestras consecutivas de sangre en ambos momentos del estudio: tercer trimestre de embarazo y trabajo de parto. Específicamente para el trabajo de parto la muestra de sangre se obtuvo 2 horas después de la admisión al hospital o cuando los participantes alcanzaron al menos $4 \mathrm{~cm}$ de dilatación cervical y 50 por ciento de borramiento. Todas las muestras de sangre se centrifugaron inmediatamente a 1200 RPM durante $15 \mathrm{~min}$. Las muestras de suero se separaron en alícuotas y se almacenaron a $-80^{\circ} \mathrm{C}$ hasta su análisis. Los procedimientos en cuanto al procesamiento, transporte y conservación e las muestras se encuentran plasmados más a detalle en el Apéndice C: Toma de muestra sanguínea, centrifugación y conservación de las muestras.

Inmunoensayos múltiples en suero: La concentración de cada analito de interés se obtuvo usando un panel Bio-Plex Pro ${ }^{\mathrm{TM}}$ Human Inflammation, 37 plex (Bio-Rad Laboratories 
Inc., CA, USA; Cat.171-AL001M). La concentración de los analitos se detectó y cuantificó a través del lector Bio-Plex MAGPIX ${ }^{\text {TM }}$ Multiplex Reader siguiendo las instrucciones del fabricante. Finalmente, la concentración de las citoquinas se calculó mediante interpolación utilizando curvas estándar con el software Bio-Plex TM Manager (Bio-Rad). Los rangos de trabajo para los ensayos múltiples de los analitos fueron: $(\mathrm{pg} / \mathrm{mL})$ : APRIL/TNFSF13: 30.04123027.00; BAFF/TNFSF13B: 0.81-3337.00; sCD30/TNFRSF8: 0.06-244.94; sCD163: 3.06-12529.39; Chitinase-3-like1: 0.4-1643.92; gp130/sIL-6Rß: 0.83-3391.66; IFN- $\alpha 2$ : 0.05-212.16; IFN- $\beta$ : 0.01-22.39; IFN-ץ: 0.03-132.81; IL-2: 0.02-90.50; sIL-6Ra: 0.22-919.27; IL-8: 0.03-139.66; IL-10: 0.01-44.91; IL-11: 0.00-5.42; IL-12(p40): 0.05-205.95; IL-12(p70): 0.00-12.61; IL-19: 0.03-104.23; IL-20: 0.06-260.30; IL-22: 0.03-128.73; IL-26: 0.02-73.11; IL-27(p28): 0.03-134.91; IL-28A/IFN- $\lambda 2: 0.05-200.38 ; \quad I L-29 / I F N-\lambda 1: 0.09-350.48 ; \quad I L-32$ : 0.04-177.64; IL-34: 0.25-1020.42; IL-35: 0.14-576.91; LIGHT/TNFSF14: 0.03-139; MMP-1: 1.21-4975.66; MMP-2: 0.59-2410.50; MMP-3: 1.36-5582.16; Osteocalcina: 0.49-1989.11; Osteopontina: 1.15-4717.8; Pentraxina-3: 0.08-335.38; sTNF-R1: 0.21-873.63; sTNF-R2: 0.25-1008.16; TSLP: 0.01-46.25; TWEAK/TNFSF12: 0.04-158.91

Análisis estadístico: Todos los valores se expresaron como promedio \pm SEM. Habiendo verificado la normalidad (por asimetría, curtosis y pruebas omnibus), las comparaciones entre las concentraciones séricas de citoquinas en el tercer trimestre y el trabajo fueron analizadas por una prueba $t$ pareada. De lo contrario, se realizó una prueba de rango con signo de Wilcoxon. Los análisis estadísticos se realizaron utilizando el software estadístico NCSS (Kaysville, UT, EUA). Además, se realizaron pruebas de correlación para investigar la asociación de la edad gestacional con la familia de citoquinas IL-10, así como entre los miembros de la familia IL-10. Es de destacar que, para resolver la cuestión de la no independencia entre las medidas repetidas, se consideró el promedio de los datos de medidas repetidas para cada participante antes de evaluar la correlación [235]. E coeficiente de correlación rho de Spearman se utilizó para estimar dichas correlaciones debido a que es menos sensible a outliers o valores atípicos que el coeficiente de correlación de Pearson [236] . En todas las pruebas, la hipótesis nula fue rechazada cuando $p<0.05$.

\subsection{Resultados}

Las características demográficas y clínicas de las pacientes en las etapas de tercer trimestre de embarazo y trabajo de parto se encuentran listadas en la Tabla 5.1. 
Tabla 5.1 Datos demográficos de las mujeres estudiadas en el tercer trimestre del embarazo y posteriormente durante el parto activo. Se reporta valor promedio \pm desviación estándar.

\begin{tabular}{|c|c|c|}
\hline Descripción & \multicolumn{2}{|c|}{ Participantes ( $\mathrm{N}=20)$} \\
\hline $\begin{array}{l}\text { Edad materna (años) } \\
\text { Altura materna }(\mathrm{m}) \\
\text { Peso materno }(\mathrm{kg}) \\
\text { Gestas } \\
\text { Índice de Masa Corporal }\left(\mathrm{kg} / \mathrm{m}^{2}\right) \text { actual } \\
\text { Test del inventario de ansiedad de } \\
\text { Beck (puntos) }\end{array}$ & & $\begin{array}{r}24.1 \pm 4.9 \\
1.6 \pm 0.0 \\
69.7 \pm 12.8 \\
0.8 \pm 0.6 \\
27.3 \pm 4.2 \\
11.2 \pm 5.0\end{array}$ \\
\hline & $\begin{array}{c}\text { Tercer trimestre de } \\
\text { gestación }\end{array}$ & $\begin{array}{r}\text { Trabajo de parto } \\
\text { activo }\end{array}$ \\
\hline $\begin{array}{l}\text { Presión arterial (mm/Hg) } \\
\text { Frecuencia cardiaca (LPM) } \\
\text { Edad gestacional (semanas) } \\
\text { Dilatación cervical (cm) } \\
\text { Borramiento cervical (\%) } \\
\text { Conducción con oxitocina } \\
\text { Anestesia epidural } \\
\text { Peso al nacer del neonato (g) } \\
\text { Altura del neonato (cm) } \\
\text { Diámetro cefálico(cm) } \\
\text { Apgar de } 5 \text { minutos (puntos) }\end{array}$ & $\begin{array}{r}96.1 \pm 10.2 / 65.5 \pm 7.6 \\
89.9 \pm 9.0 \\
36.1[33.6 ; 38.7] \\
- \\
- \\
- \\
- \\
- \\
- \\
- \\
-\end{array}$ & $\begin{array}{r}108.5 \pm 5.9 / 70.8 \pm 6.1 \\
93.0 \pm 11.0 \\
39.8[38.0 ; 41.2]^{*} \\
5.1 \pm 1.9 \\
69.7 \pm 16.0 \\
10 / 20 \\
0 / 20 \\
3312.0 \pm 310.6 \\
50.3 \pm 1.5 \\
33.7 \pm 1.3 \\
9.0[8.0 ; 9.0]\end{array}$ \\
\hline Malformaciones & - & $0 / 20$ \\
\hline
\end{tabular}

$\overline{p<0.0001 ~ e n t r e ~ e l ~ t e r c e r ~ t r i m e s t r e ~ d e ~ e m b a r a z o ~ y ~ e l ~ t r a b a j o ~ d e ~ p a r t o ~ a c t i v o ~(p r u e b a ~ d e ~ r a n g o s ~ d e ~}$ signo de Wilconxon).

Parámetros clínicos y psicométricos: No se encontraron diferencias significativas en parámetros fisiológicos relevantes como la presión arterial y la frecuencia cardíaca entre el tercer trimestre y el trabajo de parto (Tabla 5.1). Las diferencias temporales entre el tercer trimestre y el trabajo de parto fueron confirmadas por la edad gestacional $(p<0.0001$, Tabla 5.1). Las pacientes en el tercer trimestre tuvieron una puntuación BAI promedio de $11.2 \pm$ 5.0 puntos correspondiente a una baja ansiedad. Una puntuación total de 0-9 puntos se interpreta como normal o sin ansiedad; 10-16 como baja ansiedad; 17-29 como ansiedad moderada; y de 30-63 como ansiedad severa [231].

Citoquinas sin variaciones significativas: Debido a que este fue un estudio longitudinal, tanto la concentración de citocinas del tercer trimestre de gestación como la del trabajo de parto debieron estar presentes para poder realizar las comparaciones pareadas. De lo contrario, si alguno de los dos datos estuvo fuera de rango (es decir, fuera del intervalo 
dinámico del equipo de inmunoensayos), el analito se descartó debido a que no se contaba con su respectivo par. Se consideraron únicamente las citocinas que tuvieron por arriba del $70 \%$ de las comparaciones pareadas (es decir, al menos con $\mathrm{N}=14$ pares completos). Siendo descartadas los siguientes marcadores por no cumplir dicho criterio: APRIL/TNFSF13, Quitinasa 3, gp130/sIL-6Rß; IL-2, sIL-6Ra, IL-8, IL-11, IL-12(p40), IL12(p70), IL-19, IL-26, IL-27, IL-29/IFN- 1 , IL-32, IL-34, LIGHT/TNFSF14, MMP-1, MMP-2, Osteopontina, sTNF-R2 y TWEAK/TNFSF12. Aplicando esta consideración, ninguna de las citoquinas siguientes mostró diferencias significativas entre el tercer trimestre y el trabajo de parto, respectivamente (promedio \pm error estándar) : BAFF/TNFSF13B: $801.1 \pm 126.9$ vs. $755.1 \pm 97.3$; SCD30/TNFRSF8: $54.5 \pm 7.9$ vs. $52.2 \pm 10.2$; SCD163: $4246.2 \pm 848.9$ vs. $3431.5 \pm 721.4$; MMP-3: $20.2 \pm 2.3$ vs. $17.2 \pm 1.6$; Osteocalcina: $284.1 \pm 70.1$ vs. $201.1 \pm$ 38.4; Pentraxina-3: $31.9 \pm 9.9$ vs. $16.5 \pm 3.6$; STNF-R1: $65.7 \pm 19.4$ vs. $70.9 \pm 21.4$ y TSLP: $1.28 \pm 0.2$ vs. $1.0 \pm 0.2(\mathrm{pg} / \mathrm{mL})$.

IL-35: Varios modelos murinos de autoinmunidad han sugerido que la IL-35 pueden tener efectos potentes en la regulación de la inmuno-reactividad a través de mecanismos dependientes de la IL-10 [237]. Sin embargo, en este análisis no se detectaron diferencias significativas $(p=0,43)$ entre el tercer trimestre de embarazo y el trabajo de parto para IL$35: 2.4 \pm 0.5$ vs. $3.9 \pm 2.5 \mathrm{pg} / \mathrm{mL}$, respectivamente.

Familia de citoquinas de la IL-10: Todos los monómeros de la familia de citoquinas de la IL-10 son topológicamente similares a la cadena única de la IL-10. Aunque, diferencias menores en su estructura molecular producen una variedad de efectos biológicos de estas citoquinas [238]. El papel de varias citoquinas de este grupo durante el embarazo aún no se ha dilucidado por completo, a pesar de que comparten los receptores IL-10R, IL-20R e IL-22R y la misma vía intracelular [239]. En este sentido, la Figura 5.1 muestra las concentraciones sanguíneas de la familia de citoquinas de la IL-10 en mujeres sanas en el tercer trimestre de embarazo y posteriormente en el trabajo de parto. Los niveles de la IL10 (Figura 5.1a), la IL-20 (Figura 5.1b), la IL-22 (Figura 5.1c) e IL28A (Figura 5.1d) disminuyeron significativamente $(\mathrm{p}<0.05)$ en el trabajo de parto activo en comparación con el tercer trimestre de gestación.

Interferón tipo I y II: Las células del sistema inmune liberan interferones en respuesta a patógenos o células tumorales. Estas proteínas señalizan a otras células inmunes para 
iniciar los mecanismos de defensa del cuerpo. Las dos clases de interferón (tipos I y II) tienen diferentes receptores y efectos distintos sobre las células [240]. En relación con esto, los interferones del tipo I (IFN- $\alpha 2$ e IFN- $\beta$ ) no mostraron diferencias entre el tercer trimestre de embarazo y el trabajo de parto: $0.7 \pm 0.1$ vs. $0.8 \pm 0.1$ y $8.3 \pm 0.9$ vs. $6.5 \pm 0.8 \mathrm{pg} / \mathrm{mL}$, respectivamente. Por el contrario, los niveles del interferón tipo II IFN- $\gamma$ disminuyeron significativamente $(p<0.05)$ en el parto trabajo de parto en comparación con el tercer trimestre del embarazo (Figura 5.1e).

Análisis de correlación: Se examinaron las correlaciones entre los miembros de la familia IL-10 y su asociación con la edad gestacional. Este análisis se realizó para evaluar la producción de citoquinas durante el progreso del embarazo y para investigar la relación entre los miembros de familia IL-10 y otras citoquinas relevantes como la IL-35 y el IFN- $\gamma$. La Figura 5.2 muestra el diagrama de dispersión que relaciona la edad gestacional promedio con la concentración media de citoquinas de la familia IL-10 (IL-10, IL-20, IL-22 e IL-28A) con el promedio del tercer trimestre gestación y el trabajo de parto. Las concentraciones séricas de citoquinas de la familia IL-10 no mostraron correlaciones significativas con la edad gestacional: IL-10 (Figura 5.2a, rho $=0.29, \mathrm{p}=0.10$ ); IL-20 (Figura $5.2 b$, rho $=-0.17, p=0.22$ ); IL-22 (Figura 5.2c, rho $=-0.16, p=0.26$ ) e IL-28A (Figura 5.2d, rho $=-0.33$, nivel de tendencia de $p=0.07$ ). Por otro lado, el promedio de medidas repetidas de las concentraciones séricas de la familia de citoquinas IL-10, IFN- $\gamma$ e IL-35 en el tercer trimestre del embarazo y en el trabajo de parto se correlacionó significativa y positivamente entre sí (Tabla 5.2). Específicamente, las correlaciones más altas fueron exhibidas entre IL20 vs. IL-22 (rho $=0.63, p<0.01$ ), IL-20 vs. IFN- $\gamma$ (rho $=0.61, p<0.01$ ), IL-20 vs. IL-35 (rho = $0.87, p<0.01)$ e IL-35 vs. IFN- $\gamma($ rho $=0.62, p<0.01)$. 
A

IL-10

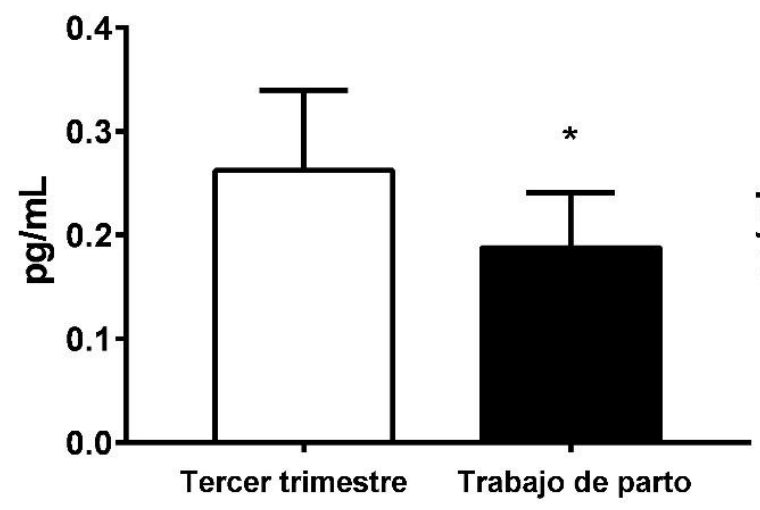

C

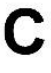

IL-22

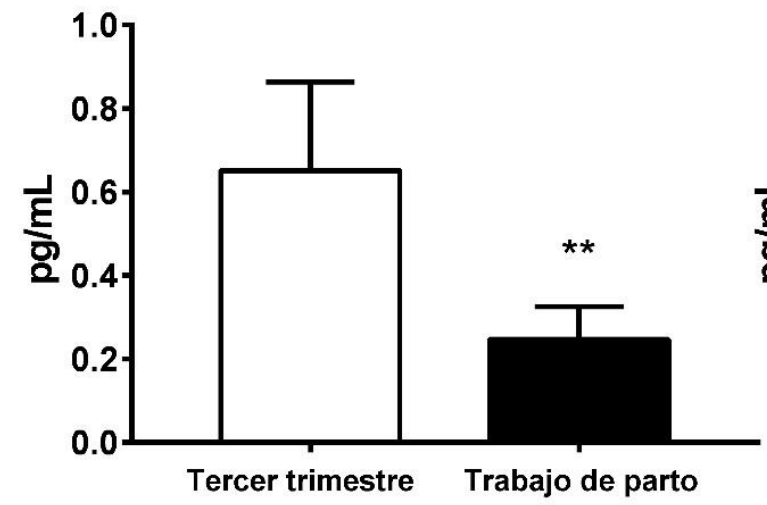

E
B
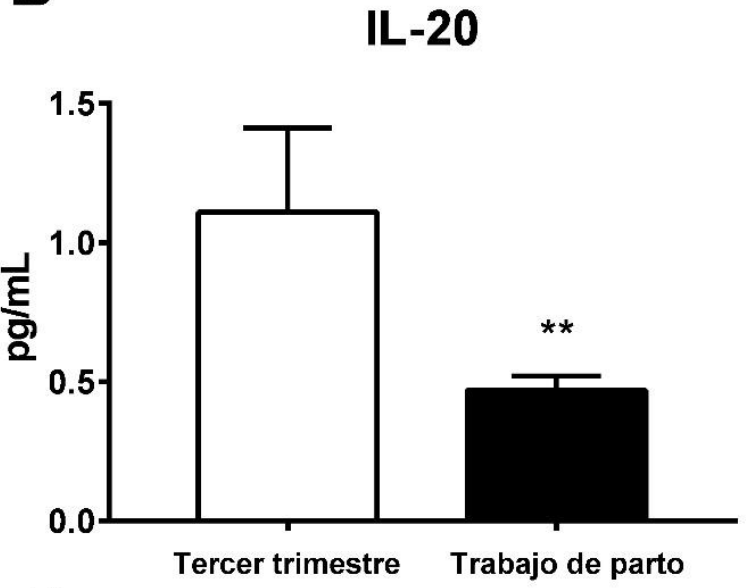

\section{IL-28A}

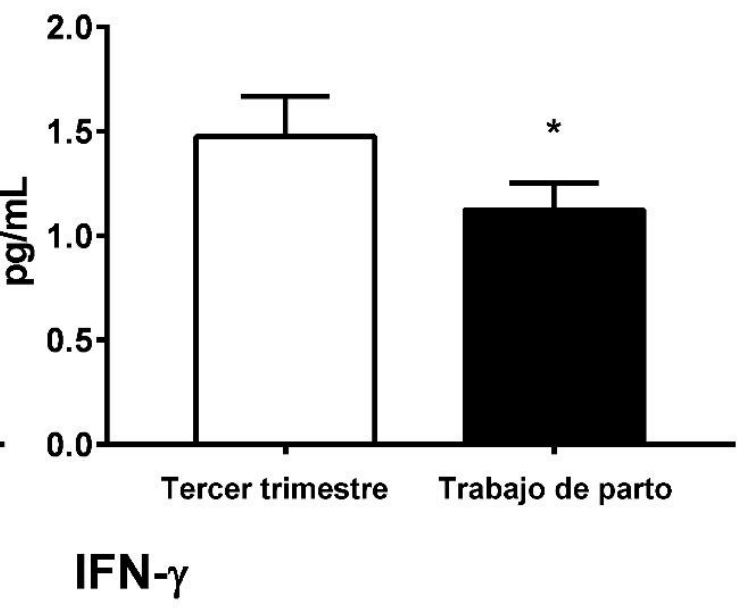

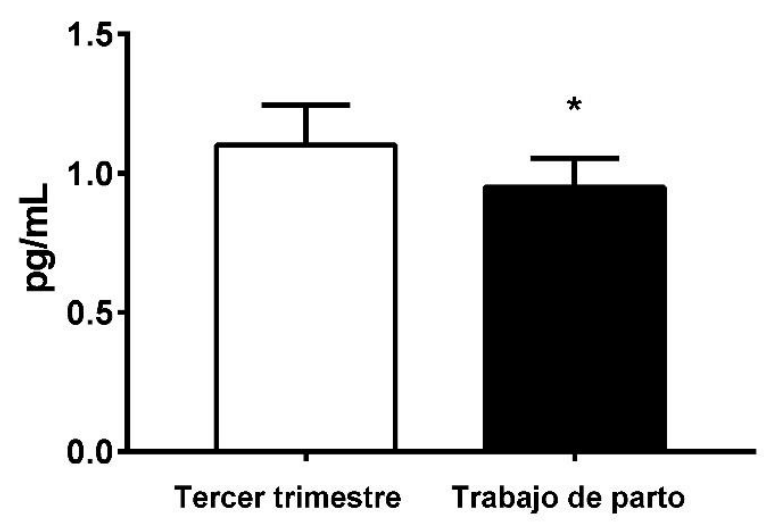

Figura. 5.1. Promedio de los niveles séricos de citoquinas ( \pm SEM) en participantes voluntarias sanas en el tercer trimestre de gestación y posteriormente en el trabajo de parto activo: a) IL-10; B) IL-20; C) IL-22; D) IL$28 \mathrm{~A}$ y e) IFN-y. * $p<0.05$ entre el tercer trimestre de embarazo y el trabajo de parto activo (prueba t pareada / prueba de rango con signo de Wilcoxon). ${ }^{* *} p<0.01$ entre el tercer trimestre de embarazo y el trabajo de parto activo (prueba t pareada / prueba de rango con signo de Wilcoxon). 
A

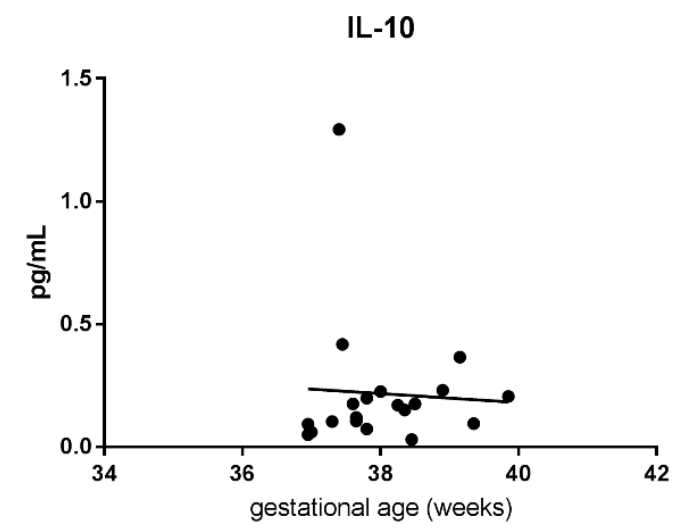

C

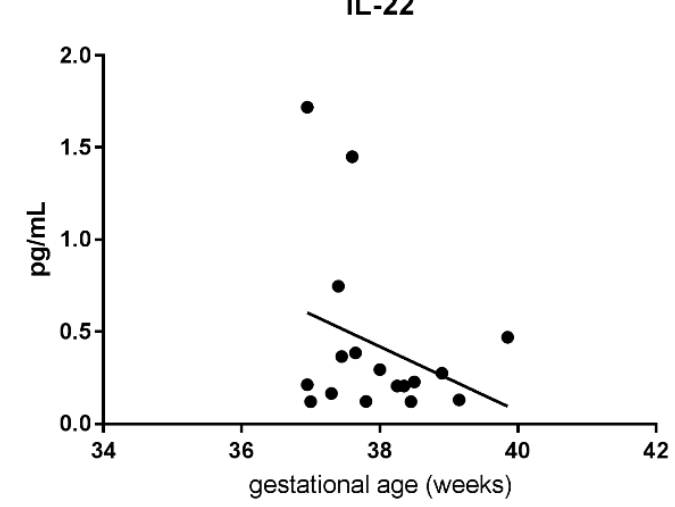

B

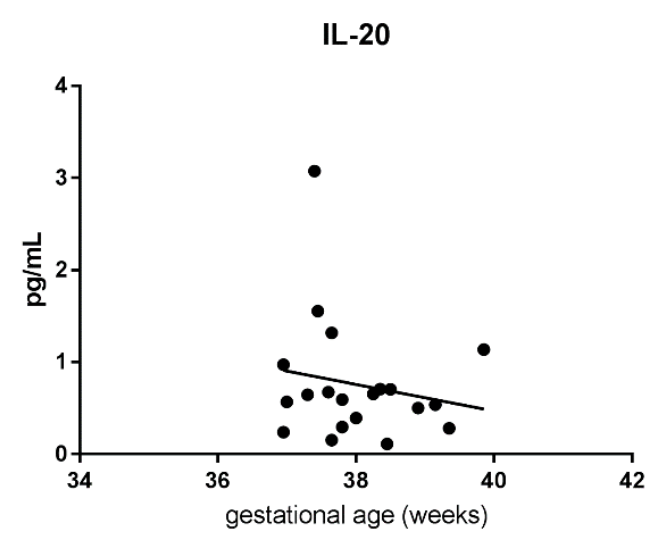

D

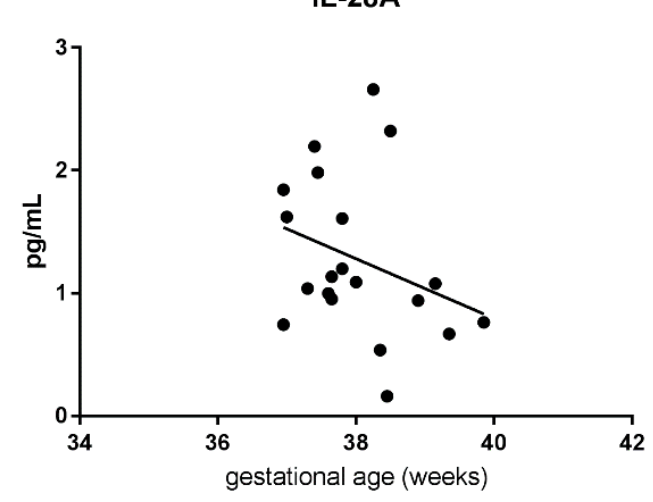

Figura 5.2. Gráficos de dispersión del promedio de edad gestacional vs. concentración sérica $(\mathrm{pg} / \mathrm{mL})$ de citoquinas de la familia IL-10 para las etapas de tercer trimestre de embarazo y trabajo de parto activo: a) entre la edad gestacional y la IL-10; (b) entre la edad gestacional y la IL-20; (c) entre la edad gestacional y la IL-22 y (d) entre la edad gestacional y la IL-28A. Se realizó análisis no paramétrico para todos los análisis de correlación.

Tabla 5.2 Matriz de correlación de Spearman para la familia de las citoquinas IL-10, IFN- $\gamma$ e IL-35

\begin{tabular}{c|cccccc}
\hline & IL-10 & IL-20 & IL-22 & IL-28 & IFN- $\gamma$ & IL-35 \\
\hline IL-10 & 1.00 & & & & & \\
IL-20 & $0.44^{\mathrm{a}}$ & 1.00 & & & & \\
IL-22 & $0.47^{\mathrm{a}}$ & $0.63^{\mathrm{b}}$ & 1.00 & & & \\
IL-28A & 0.30 & $0.51^{\mathrm{b}}$ & 0.19 & 1.00 & & \\
IFN- $\gamma$ & 0.36 & $0.61^{\mathrm{b}}$ & 0.24 & $0.40^{\mathrm{a}}$ & 1.00 & \\
IL-35 & 0.39 & $0.87^{\mathrm{b}}$ & 0.24 & $0.45^{\mathrm{a}}$ & $0.62^{\mathrm{b}}$ & 1.00
\end{tabular}

a La correlación es significativa al nivel de 0.05 (dos colas)

b La correlación es significativa al nivel de 0.01 (dos colas) 


\subsection{Discusión de resultados}

Durante el embarazo, las modificaciones en los niveles de neurotransmisores, hormonas y citoquinas se modulan recíprocamente [241]. El trabajo de parto es un momento crucial, en el que se requieren adaptaciones rápidas para lograr un nacimiento exitoso. En este estudio, los niveles de las citoquinas IL-10, IL-20, IL-22 e IL28A disminuyeron significativamente $(p<0.05)$ en el trabajo de parto activo en comparación con el tercer trimestre del embarazo (Figura 5.1). Cabe destacar que todas estas citoquinas pertenecen a la familia de la IL-10. Nuestros datos sugieren que la reducción sistémica de algunos miembros de la familia de la IL-10 podría desempeñar un rol importante, por un lado, en la activación de las células lisas miometriales asociadas con las contracciones uterinas, así como también en la promoción de un estado proinflamatorio durante el trabajo de parto activo. Interesantemente, nuestros resultados son concordantes con evidencia previa que indica un papel importante de la IL-10 sobre la actividad uterina: por ejemplo, la administración intravenosa de IL-10 fue capaz de bloquear las contracciones uterinas inducidas por IL-1 $1 \beta$ en monas Rhesus embarazadas; efecto atribuido potencialmente a una disminución en la producción de prostaglandinas. De hecho, se ha observado una relación inversa entre las concentraciones de IL-10 del líquido amniótico y la intensidad de la actividad uterina inducida por IL-1 $\beta$ [242]. Conjuntamente, un estudio reciente ha sugerido que en el trabajo de parto la IL-10 y la progesterona tienen múltiples efectos sobre las interacciones monocito-miocito, incluyendo la inhibición de las contracciones de los miocitos [243].

La progesterona es crucial para el mantenimiento del embarazo, y actúa para promover la quiescencia uterina. Se ha propuesto que la retirada funcional de la progesterona está asociada con el inicio del trabajo de parto y se han sugerido varios mecanismos efectores [244]. De hecho, también se demostró que, bajo los efectos de la progesterona, los niveles séricos de IL-10 son elevados, lo que resulta en la supresión y activación de citoquinas Th1 y Th2, respectivamente [84]. Cabe señalar que la actividad simultánea de la progesterona y la IL-10 en los trofoblastos puede suprimir respuestas proinflamatorias y mejorar la regulación entre la placenta y la decidua [245].

Las citoquinas relacionadas con la familia de la IL-10 tienen baja identidad y similitud con la citoquina IL-10 (25\% de identidad y 50\% de similitud en promedio) [246]. A pesar de ello, es sabido que las funciones centrales de la familia de la IL-10 convergen para la protección de tejidos en respuesta a un proceso inflamatorio [225]. Esto se encuentra en concordancia con los resultados mostrados en la Tabla 5.2, ya que varios miembros de la 
familia IL-10 exhibieron correlación entre ellos mismos en el promedio del tercer trimestre de embarazo y el trabajo de parto. Por ejemplo, la IL-20 y la IL-22 presentaron la mayor correlación positiva ( $r$ o $=0.63, \mathrm{p}<0.01$ ). Por otra parte, la IL-35 puede tener efectos potentes en la regulación de la inmunoreactividad a través de mecanismos dependientes de la IL-10 [237]. Esta consideración es mostrada por la correlación positiva más alta que se encontró entre IL-20 e IL-35 (rho = 0.87, p<0.01).

En el presente estudio, no se encontró correlaciones entre las citoquinas de la familia IL-10 y la edad gestacional (Figura 5.2). Sin embargo, se encontró una asociación débil entre la IL-28A y la edad gestacional (Figura $5.2 \mathrm{~d}$, rho $=-0.33$, con un nivel de tendencia de $p=0.07$ ), lo que sugeriría una dependencia temporal. Es decir, algunos miembros de la familia de citoquinas IL-10 tenderían a disminuir a medida que se aproxima el trabajo de parto, por lo que esta disminución podría estar relacionada con el cambio hacia el perfil Th1 [32], [70], [247]. Otros estudios han reportado una correlación negativa entre la concentración de IL-10 en el líquido amniótico y la edad gestacional al momento del parto [248]. Es necesario enfatizar que aún se necesitan más investigaciones para abordar la actividad biológica de las citoquinas de la familia IL-10 durante el embarazo y el trabajo de parto.

Por último, los niveles de IFN-y también disminuyeron significativamente $(p<0.05)$ en el trabajo de parto activo en comparación con el tercer trimestre de embarazo (Figura 5.1e). Nuestros resultados están en concordancia con los hallazgos reportados por [249], que informaron que el IFN-y plasmático materno disminuye en el trabajo de parto. Este estudio concluyó que durante el embarazo se suprime la inmunidad mediada por células, por lo que un contenido más bajo de concentraciones plasmáticas de IFN-y podría indicar un papel contributivo del IFN-y en el parto [249]. Otro estudio propuso que la retirada de IFN- $\gamma$ podría estar involucrada en el inicio del trabajo de parto a prematuro o a término a través de la regulación positiva de la expresión de la ciclo-oxigenasa y de la producción de prostaglandina E2 [250].

En general, las citoquinas desempeñan un papen importante en el mantenimiento de un embarazo saludable, por desgracia pocos estudios han medido múltiples niveles de citoquinas longitudinalmente durante el embarazo. Hasta donde sabemos, este es el primer estudio longitudinal en el que se determinan múltiples citoquinas durante el embarazo y el trabajo de parto en mujeres sanas. 
Limitaciones: Este estudio tiene algunas limitaciones que merecen mención. En primer lugar, 10 de 20 mujeres recibieron conducción del trabajo de parto utilizando oxitocina. Es importante mencionar que un análisis estadístico complementario fue llevado a cabo con el objetivo de observar si existían diferencias entre las mujeres que recibieron oxitocina exógena durante el trabajo de parto y las mujeres que no recibieron oxitocina. Estos resultados complementarios se describen en el Apéndice $\mathrm{D}$. Los resultados de este análisis complementario indicaron que no se observaron efectos de la aplicación de oxitocina exógena en las concentraciones de citoquinas durante el trabajo de parto. Estos resultados podrían explicarse por el hecho de que, a pesar que la mitad de las mujeres no fueron conducidas con oxitocina, se ha reportado que los receptores endógenos de oxitocina se incrementan de manera natural durante el trabajo de parto a término [251]. De igual manera, los resultados de dicho análisis complementario deben tomarse con precaución debido al pequeño tamaño de la muestra al subdividir los grupos de estudio $(N=10)$. Es importante mencionar que la conducción del trabajo de parto con oxitocina es un procedimiento que se realiza con relativa frecuencia en los hospitales de Latinoamérica [252].

Finalmente, nuestros datos en el trabajo de parto están constituidos por un solo punto en el tiempo. No obstante, se ha demostrado que las concentraciones circulantes de citoquinas en las mujeres durante el trabajo de parto cambian a lo largo del tiempo desde la admisión hasta el alumbramiento [253]. En cualquier caso, nuestras muestras siempre se obtuvieron en el trabajo de parto activo.

\subsection{Conclusión}

El trabajo de parto es un proceso complejo que involucra varios factores maternos y fetales, la manera en cómo estos interactúan aún no es totalmente entendido. En nuestro estudio, los niveles séricos de citoquinas de la familia IL-10 como: IL-20, IL-22 e IL-28A no se correlacionaron con la edad gestacional durante el tercer trimestre del embarazo y el trabajo de parto. Adicionalmente, los miembros de la familia IL-10 exhibieron correlaciones entre ellos mismos, lo que sugiere que algunos miembros de dicha familia de citoquinas podrían poseer propiedades similares, específicamente en las células epiteliales. Finalmente, nuestros datos sugieren que la disminución de la familia de citoquinas IL-10 parece coincidir con la bien informada retirada funcional de la progesterona que ocurre en el trabajo de parto. Asimismo, las concentraciones plasmáticas bajas de IFN- $\gamma$ indican un rol importante de esta citoquina que contribuye en el trabajo de parto activo. 


\section{Capítulo VI}

\section{Estudio IV: Análisis de la dinámica cardiaca y su correlación con marcadores inflamatorios en el trabajo de parto activo}

Resumen: Con el propósito de evaluar si la inflamación sistémica sugerida por el estudio anterior (Capítulo V) está vinculada con la dinámica del ritmo cardiaco, se registró longitudinalmente la actividad eléctrica cardiaca de mujeres sanas en el tercer trimestre de embarazo y posteriormente en el trabajo de parto activo. Los electrocardiogramas (ECG) abdominales de las participantes ( $n=20$, edad media de $24.1 \pm 4.9$ años) fueron procesados para estimar índices autonómicos cardíacos derivados del análisis lineal y no lineal de las fluctuaciones de la frecuencia cardiaca (FFC). Por otra parte, los datos referentes a la concentración de citoquinas fueron recopilados del estudio del capítulo anterior. Diversos tipos de análisis matemático como el de correlación simple, correlación canónica y técnicas de reconocimiento de patrones fueron utilizados para investigar la relación entre las FFC y los niveles de citoquinas durante el tercer trimestre y trabajo de parto. Durante la etapa del trabajo de parto se observaron cambios significativos en la dinámica de las FFC en el corto plazo. Adicionalmente los parámetros de las FFC resultaron tener niveles más altos de sensibilidad, especificidad y certeza para discriminar entre ambas etapas en comparación a los marcadores inmunológicos al usar un clasificador K-NN (o de vecinos más cercanos). Se encontró una correlación canónica moderada pero significativa (0.752) entre los parámetros de las FFC ligados a la función vagal y la IL-22 en el tercer trimestre y en el trabajo de parto, así como diversas correlaciones simples entre parámetros de las FFC y citoquinas. Nuestros resultados sugieren que, valores menos anticorrelacionados y la mayor variabilidad total en las FFC del trabajo de parto podrían reflejar una interacción distinta entre las ramas simpática y parasimpática del control cardiaco en comparación con el tercer trimestre de embarazo. Finalmente, el hallazgo de que diversas citoquinas están correlacionadas con los parámetros vagales de las FFC, sugiere un vínculo funcional entre la inflamación sistémica y la regulación autonómica en el embarazo y el trabajo de parto. Estas asociaciones electrofisiológicas e inmunológicas se podrían manifestar como consecuencia de la posible respuesta colinérgica antiinflamatoria ocasionada en el embarazo y el trabajo de parto.

Es pertinente mencionar que este trabajo se ha presentado en el congreso internacional " $X$ Congress of the Internatinal Society for NeurolmmunoModulation (ISNIM)", Mayo 26-28, Roma, Italia como: JJ Reyes-Lagos, MA Peña-Castillo, JC Echeverría, G Pérez-Sánchez, $S$ Alvarez-Herrera, E Becerril-Villanueva, L Pavón, $R$ Ayala-Yáñez, $R$ González-Camarena, G Pacheco-López, Heart Rate Dynamics and Serum Inflammatory Markers During Pregnancy and Active Labor In Women. Se anexa el resumen en el Anexo F.

Adicionalmente, el manuscrito correspondiente está en preparación para someterse a publicación. 


\subsection{Introducción}

Las contracciones uterinas durante el trabajo de parto están generalmente asociadas con un aumento de la frecuencia cardíaca materna y la presión arterial media, así como el aumento en el gasto cardíaco resultante de incrementos tanto en el volumen sistólico y la frecuencia cardíaca [254]. Los detalles de cómo estos cambios hemodinámicos son impulsados por las adaptaciones autonómicas y, por otra parte, el papel real del sistema nervioso autónomo (SNA) a lo largo del embarazo no han sido entendidos por completo [255]. En este sentido, varios hallazgos inducen a considerar al trabajo de parto como un evento inflamatorio que no sólo se inicia debido a factores hormonales [15]. Algunos estudios anteriores (Capítulo I, sección 1.7) sugieren que durante el trabajo de parto se presenta menor antagonismo autonómico en la direccionalidad de las fluctuaciones de la frecuencia cardiaca (FFC), lo que posiblemente podría también vincularse, entre otros aspectos, a una respuesta antiinflamatoria colinérgica (RCA) como resultado de la inflamación exacerbada durante el trabajo de parto [116]. De hecho, el nervio vago parece desempeñar un papel importante en la regulación de la inflamación y la prevención del daño tisular durante respuestas inflamatorias excesivas. La actividad vagal disminuye la producción de citoquinas proinflamatorias como el TNF- $\alpha$ e inhibe la migración de leucocitos a sitios de inflamación, en parte por su acción sobre el sistema reticuloendotelial del hígado y el bazo, donde se producen citoquinas, y esta actividad puede funcionar para regular los procesos inflamatorios sistémicos [256].

Se ha estudiado la actividad del SNA de mujeres embarazadas mediante el análisis de las FFC [257], que es un método no invasivo para cuantificar la respuesta autonómica cardiaca en sus influencias adrenérgicas y colinérgicas [258]. En general, se han aplicado los análisis en el dominio temporal y espectral, así como también métodos de escalamiento para obtener parámetros que son utilizados para estimar la respuesta autonómica, como por ejemplo el análisis de fluctuaciones sin tendencia o DFA, descrito previamente en el Capítulo II, Secciones 2.2 y 2.3. De manera interesante, se encontró que parámetros de las FFC, principalmente vinculados al nervio vago, se correlacionan negativamente con diversos marcadores inflamatorios medidos en el suero sanguíneo, como la IL-6, el fibrinógeno y la proteína $C$ reactiva [256].

En consecuencia, considerando que el trabajo de parto a término es un estado inflamatorio, y que a su vez éste involucra una intensa actividad muscular, gasto energético y daño tisular, entonces en esta etapa el análisis de las FFC reflejará una respuesta autonómica cardiaca con participación colinérgica como mecanismo homeostático [60]. 
En este estudio, se evalúo el uso de parámetros lineales y no lineales para analizar las FFC durante el tercer trimestre de embarazo y el trabajo de parto de manera longitudinal. Así mismo se buscaron posibles asociaciones entre las diversas citoquinas medidas en nuestro estudio anterior (Capítulo V, Sección 5.2) con parámetros lineales y no lineales del análisis de las FFC. Hipotetizamos que al vincularse las FFC con la regulación cardíaca autonómica, se encontrarán diversas asociaciones entre parámetros de las FFC y múltiples citoquinas durante el tercer trimestre de embarazo y trabajo de parto.

\subsection{Metodología}

Se registraron 10 minutos de electrocardiogramas (ECG) abdominales de 20 mujeres embarazadas en el tercer trimestre de gestación en posición semi-Fowler, de 35 a 38 semanas de gestación, sin complicaciones durante el embarazo y sin ninguna manifestación clínica de encontrarse en trabajo de parto. Cabe mencionar que se estudiaron a las mismas participantes del Capítulo V. De igual manera como se describe en la Sección 5.2 del Capítulo V, este protocolo fue aprobado por la Comisión de Ética de la División de Ciencias Biológicas y de la Salud (CBS) de la Universidad Autónoma Metropolitana Unidad Iztapalapa con el dictamen CAEDCBS.01.2017. Adicionalmente, se obtuvo el consentimiento informado de cada participante (el formato se encuentra en el Apéndice B: Carta de consentimiento informado).

Siguiendo un diseño longitudinal, las participantes se estudiaron en las etapas de tercer trimestre de embarazo y en la fase activa del trabajo de parto. El trabajo de parto activo se identificó al presentarse por lo menos $4 \mathrm{~cm}$ de dilatación cervical, de 3 a 4 contracciones en 10 minutos y al menos $50 \%$ de borramiento cervical. Para ambas etapas, es decir tercer trimestre y trabajo de parto, los ECG fueron registrados abdominalmente utilizando el sistema de adquisición portátil de señales fisiológicas materno-fetal Monica AN24 (Monica Healthcare, Nottingham, Reino Unido). La forma de colocación de los electrodos, así como generalidades de este sistema están descritos en el Capítulo II, Sección 2.6. La frecuencia de muestreo para los registros electrocardiográficos fue de a $900 \mathrm{~Hz}$. La estimación electrohisterográfica con el dispositivo Mónica AN24 permitió adicionalmente confirmar las 3 o 4 contracciones en 10 minutos que el personal clínico de CIMIGen reportaba por medio de palpación abdominal (Figura 6.1). Durante el trabajo de parto, las participantes eran libres de elegir su postura preferida debido a la portabilidad del sistema. Sin embargo, los segmentos de ECG fueron sólo seleccionados cuando las 
mujeres mantenían una posición semi-Fowler. Las características demográficas y clínicas de la población durante el tercer trimestre y trabajo de parto se reportan en las Tablas 5.1 y 5.2 del Capítulo V, respectivamente.

Análisis de datos: Los registros de ECG materno se procesaron usando los algoritmos de nuestros estudios anteriores para generar las series de tiempo $R-R$ correspondientes al tercer trimestre de embarazo y al trabajo de parto usando la metodología descrita en el Capítulo II, Sección 2.1. Todas las series de tiempo R-R fueron preacondicionadas por el método de filtrado adaptativo [135], también descrito previamente en la Sección 2.1 del Capítulo II., nunca se tuvo más del $10 \%$ de latidos perdidos del registro total.

Diversos parámetros lineales del análisis de las FFC fueron calculados con el software Kubios a partir de las series de tiempo R-R filtradas. Los ajustes del software Kubios se fijaron como predeterminados, es decir sin eliminación de tendencias, con un ajuste de interpolación a $4 \mathrm{~Hz}$, tamaño de ventana de 256 puntos y con un traslape del $50 \%$ (se ocupó el método de Welch para estimar la PSD). Los parámetros que se midieron fueron: el valor medio de la frecuencia cardiaca, la raíz cuadrada del promedio de la suma de las diferencias cuadráticas entre intervalos R-R adyacentes (RMSSD); el logaritmo natural de las altas frecuencias (InHF, 0.15-0.4 Hz), el porcentaje de intervalos $R-R$ consecutivos que se diferencian en más de cincuenta milisegundos (pNN50). Cabe señalar que, estos últimos tres parámetros permiten cuantificar fluctuaciones de alta frecuencia mediadas por el vago [12]. Por otro lado, también fueron calculados la desviación estándar de los valores NN (SDNN), que cuantifica la variabilidad total de las fluctuaciones, el logaritmo natural de muy bajas frecuencias (InVLF, 0.0-0.04 Hz) y las bajas frecuencias (InLF, 0.04-0.15 Hz). Los parámetros no lineales incluyeron: los exponentes de escalamiento fractal en $\alpha_{1}$ y $\alpha_{2}$, los exponentes del análisis de magnitud y signo ( $\alpha_{1 \text { (MAG) }}$ y

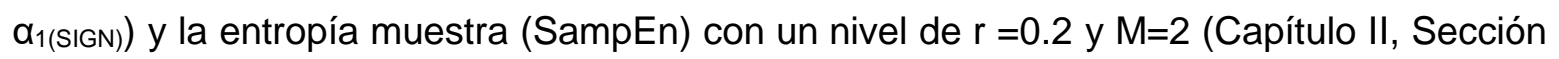
2.3). 


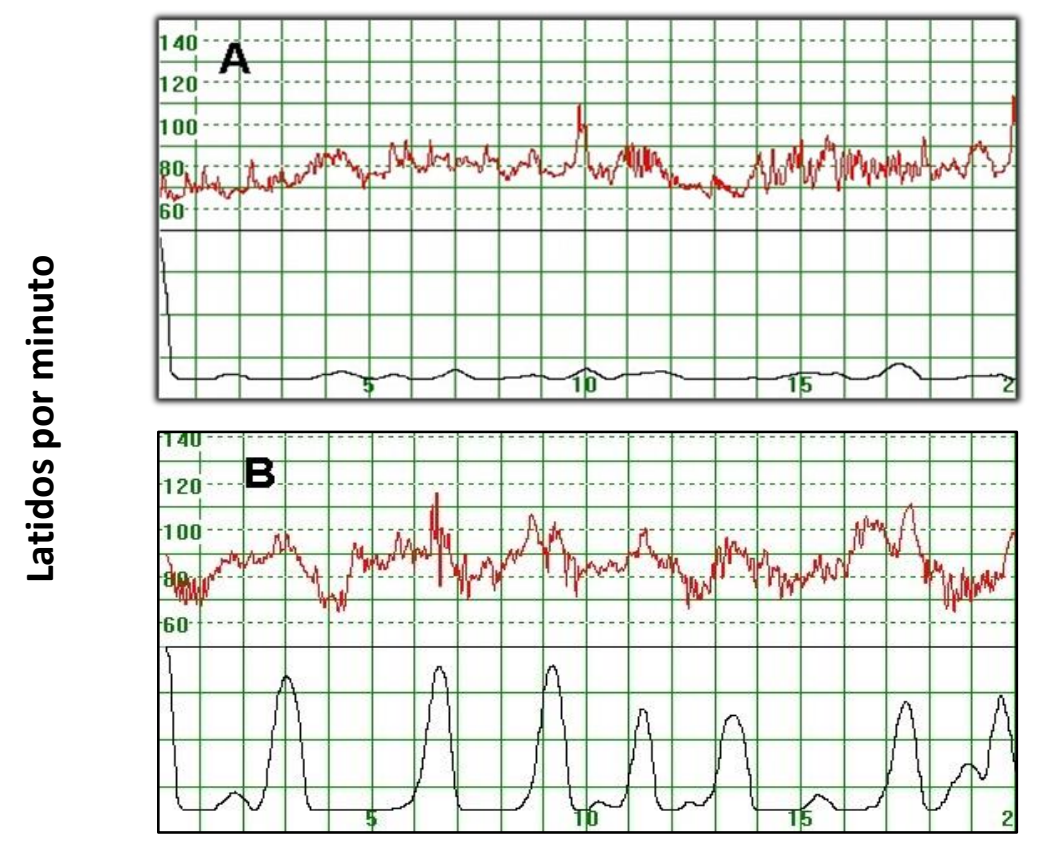

Tiempo (minutos)

Figura 6.1 a) Frecuencia cardiaca materna (rojo) y señal de actividad uterina (negro) durante el tercer trimestre de embarazo. b) Frecuencia cardiaca materna (rojo) y señal de actividad uterina (negro) durante el trabajo de parto activo correspondiente a la misma participante del panel a).

Análisis estadístico de las FFC: Todos los valores fueron expresados como promedio \pm DE. Habiendo verificado la normalidad (por la prueba de normalidad de omnibus), las comparaciones entre los parámetros de las FFC entre el tercer trimestre de embarazo y el trabajo fueron analizadas por una prueba t pareada. De lo contrario, se realizó una prueba de rango con signo de Wilcoxon. Los análisis estadísticos se realizaron utilizando el software estadístico NCSS (Kaysville, UT, EUA). Además, se realizaron pruebas de correlación simple para investigar la asociación entre los parámetros de las FFC con diversas citoquinas medidas en el estudio anterior (Capítulo V) para los grupos de tercer trimestre y trabajo de parto. El coeficiente de correlación rho de Spearman se utilizó para estimar dichas correlaciones debido a que es menos sensible a outliers o valores atípicos que el coeficiente de correlación de Pearson, además que en nuestro estudio hay un tamaño de muestra pequeña [236]. De igual manera que en el Capítulo V, para resolver la cuestión de la no independencia entre las medidas repetidas, se consideró el promedio de los datos de medidas repetidas para cada participante antes de evaluar la correlación [235] (este análisis complementario se encuentra en el apéndice D). 
Análisis de curvas ROC y reconocimiento de patrones: Se generaron dos vectores, el primero con rasgos electrofisiológicos correspondientes a los parámetros de las FFC, el segundo con rasgo inmunológicos pertenecientes a la familia de la IL-10, citoquinas de interés encontradas en nuestro estudio previo (Capítulo V). Ambos vectores fueron creados con datos del tercer trimestre de embarazo y trabajo de parto, con la finalidad de observar el comportamiento individual de cada parámetro y construir su curva ROC (Relative Operating Characteristic, por sus siglas en inglés). La curva ROC revela la capacidad informativa de un rasgo o parámetro para discriminar entre dos clases [259], en este caso entre las clases de trabajo de parto y tercer trimestre de embarazo.

Para la elección entre pruebas diagnósticas distintas, se recurrió a las curvas ROC, ya que es una medida global e independiente del punto de corte. Por esto, en el ámbito sanitario, las curvas ROC también se denominan curvas de rendimiento diagnóstico. La elección se realiza mediante la comparación del área bajo la curva de pruebas. Esta área posee un valor comprendido entre 0.5 y 1 , donde 1 representa un valor diagnóstico perfecto y 0.5 es una prueba sin capacidad discriminatoria diagnóstica [259].

Las curvas ROC fueron construidas por el método no paramétrico, al representar todos los pares FPR vs. TPR, False Positive Rate (Razón de verdaderos negativos) y True Positive Rate (Razón de verdaderos positivos). Es decir, los pares (1-especificidad, sensibilidad) para todos los posibles valores de corte de cada parámetro y se calculó el área bajo la curva $\mathrm{ROC}(\mathrm{Az})$ de cada uno para revelar cual discriminaba mejor entre las clases, por convención se tomó positivo al trabajo de parto (1) y negativo al tercer trimestre de embarazo (0).

De acuerdo a estudio previos [116], [260], el parámetro que presentaba una diferencia

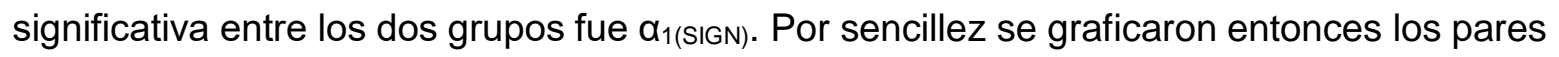
de rasgos en torno a dicho parámetro (es decir RMSSD vs. $\alpha_{1(\text { SIGN); }} \alpha_{1}$ vs. $\alpha_{1(S I G N)}$, etc.) con el fin de explorar visualmente el comportamiento de las clases de trabajo de parto y tercer trimestre de embarazo. Por medio de la inspección visual de los pares de rasgos, se buscó observar cual par tenía mayor separabilidad de clases. Adicionalmente se seleccionaron pares de clases conjuntando los parámetros inmunológicos pertenecientes a los miembros de la familia de la IL-10 (familia de citoquinas que exhibió cambios significativos en el estudio del Capítulo V) con dos de los parámetros de las FFC que tuvieron la mayor área ROC.

Debido a que visualmente los pares no presentaron una separabilidad lineal se decidió usar los clasificadores de K-NN o K-vecinos más cercanos, con $\mathrm{K}=3$, se escogió este $\mathrm{K}$ debido a que debía ser un valor impar y arrojaba la menor tasa de mala clasificación, además de 
que dichos clasificadores asumen modelos no paramétricos en concordancia con lo sugerido por los histogramas de los rasgos [261].

Para la implementación del clasificador K-NN se hizo uso del algoritmo del paquete NETLAB [262]. Se entrenó al clasificador con 28 datos (14 de la clase de tercer trimestre y 14 de la clase de trabajo de parto) y se probó con 12 datos (6 de la clase de tercer trimestre y 6 de la clase de trabajo de parto). Posteriormente, por medio de validación cruzada aleatoria, se generaron matrices de confusión para cada iteración (1000 veces), y se reportaron matrices de confusión promedio; así como sensibilidad, especificidad y certeza promedio de los dos clasificadores correspondientes a las combinaciones de rasgos.

Análisis de correlación canónica: El análisis de correlación canónica busca identificar y cuantificar las asociaciones lineales entre dos grupos de variables [263]. Este análisis se enfoca en la correlación entre combinaciones lineales pertenecientes a los grupos de variables. La idea es determinar el par de combinaciones lineales que tienen la correlación más alta, luego el segundo par cuya correlación es menor o igual a la primera, y así sucesivamente. A estos pares de combinaciones lineales se los denomina variados canónicos $\left(\mathrm{U}_{\mathrm{p}} \mathrm{V}_{\mathrm{q}}\right)$, por consiguiente, sus correlaciones son llamadas correlaciones canónicas, las mismas que miden la fuerza de asociación entre los dos grupos de variables. El primer grupo de variables está representado por el vector aleatorio $p$ variado $X$, el segundo grupo, de $q$ variables es representado por $Y$, donde el primer conjunto de variables tiene menos componentes que el segundo es decir $p \leq q$. En este análisis el vector $X$ estará formado por las variables de las FFC que han sido asociadas al control autonómico como por ejemplo RMSSD, InHF, $\alpha_{1(S I G N)}$ y $\alpha_{1}$ (variables dependientes) es decir $p=4$, y el vector $Y$ contienen 4 variables pertenecientes a las citoquinas de la familia de la IL-10, es decir $q$ $=4$ (variables independientes). Cada par de variables canónicas es representado como una combinación lineal de las variables tanto del grupo $X$ como del grupo $Y$.

\subsection{Resultados}

Dinámica cardiaca: Se encontraron diferencias en la actividad autonómica cardiaca durante el trabajo de parto en comparación al tercer trimestre de embarazo. La Figura 6.2 muestra un ejemplo representativo del análisis longitudinal de las FFC maternas durante el tercer trimestre de embarazo y subsecuentemente en el trabajo de parto de una participante. En esta Figura se observan las series R-R para ambas etapas. La Figura también incluye resultados de algunos de los parámetros lineales y no lineales de las FFC. 
De igual manera, en la Tabla 6.1 se encuentran los promedios ( $\pm \mathrm{DE}$ ) de los parámetros lineales y no lineales de las FFC para la etapa del tercer trimestre de embarazo y el trabajo de parto. Entre los parámetros influenciados potencialmente por la dinámica uterina durante el trabajo de parto se encuentran: $\alpha_{2}$, InVLF, SampEn y SDNN $(p<0.01$, potencia estadística mayor a 80\%). Así como el parámetro ligado a la direccionalidad de las $F F C \alpha_{1(\mathrm{SIGN})}(\mathrm{p}<0.01$, potencia estadística mayor a 80\%) y el exponente de escalamiento $\alpha_{1}, p<0.05$, potencia estadística de 70\%). Se debe tener presente que en 10 de 20 casos a las participantes se les condujo con oxitocina exógena, por lo que un análisis estadístico complementario se presenta en el apéndice $D$ (no se encontraron diferencias estadísticas en ningún parámetro de las FFC entre los grupos de trabajo de parto a los que se les administró o no oxitocina).

\section{RR Tercer trimestre}

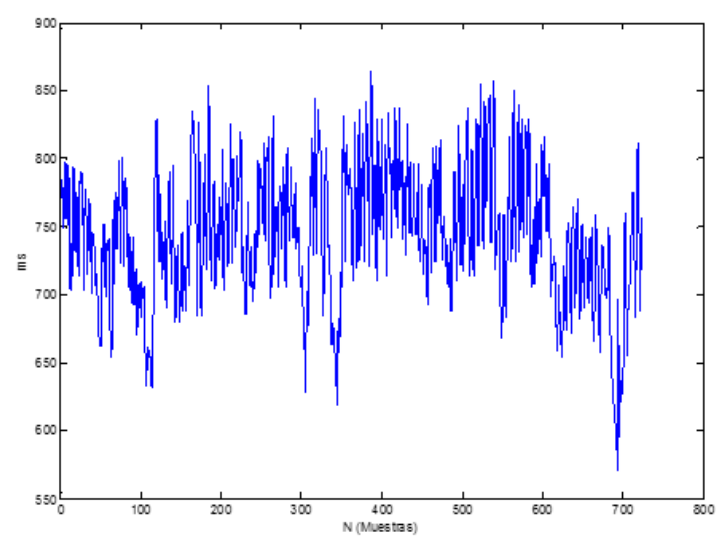

$$
\begin{array}{ll}
\mathrm{HR}= & 81 \mathrm{LPM} \\
\alpha 1= & 0.981 \\
\alpha 2= & 0.8348 \\
\alpha 1 \mathrm{sign}= & 0.2250 \\
\text { SDNN= } & 49.63 \mathrm{~ms} \\
\text { LnVLF= } & 6.98 \mathrm{~ms} 2 \\
\text { SampEn }= & 1.78
\end{array}
$$

\section{RR Trabajo de parto}

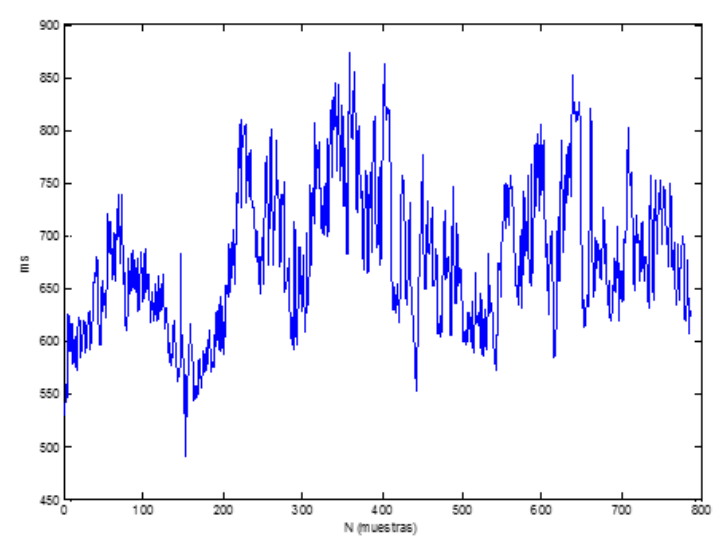

$$
\begin{array}{ll}
\mathrm{HR}= & 90 \mathrm{LPM} \\
\alpha 1= & 1.10380 \\
\alpha 2= & 1.1096 \\
\alpha 1 \mathrm{sign}= & 0.3301 \\
\text { SDNN }= & 68.46 \mathrm{~ms} \\
\text { LnVLF= } & 8.06 \mathrm{~ms} 2 \\
\text { SampEn } & 1.27
\end{array}
$$

Figura 6.2 Ejemplo representativo de una señal $R-R$ cruda para la etapa de tercer trimestre de embarazo (izquierda) y para el trabajo de parto (derecha, con presencia de $\mathbf{4}$ contracciones). Algunos parámetros del análisis lineal y no lineales de las fluctuaciones de la frecuencia cardiaca se reportan debajo para cada serie de tiempo. 
Tabla 6.1 Valores promedio $( \pm D E)$ de los parámetros de las fluctuaciones de la frecuencia cardiaca (FFC) de nuestro estudio para las etapas de tercer trimestre de embarazo y trabajo de parto $(n=20)$

\begin{tabular}{|c|c|c|}
\hline Parámetro & Tercer Trimestre & Trabajo de parto \\
\hline$\alpha_{1}$ & $1.08 \pm 0.22^{*}$ & $1.23 \pm 0.20$ \\
\hline$\alpha_{2}$ & $0.98 \pm 0.16^{\star}$ & $1.16 \pm 0.11$ \\
\hline $\boldsymbol{\alpha}_{1(\mathrm{MAG})}$ & $0.72 \pm 0.13$ & $0.77 \pm 0.16$ \\
\hline$\alpha_{1(\mathrm{SIGN})}$ & $0.31 \pm 0.10^{*}$ & $0.42 \pm 0.09$ \\
\hline HR (LPM) & $89 \pm 9$ & $93 \pm 11$ \\
\hline SDNN (ms) & $52.32 \pm 16.55^{\star}$ & $67.33 \pm 21.51$ \\
\hline RMSSD (ms) & $32.52 \pm 15.51$ & $29.60 \pm 12.39$ \\
\hline PNN50 (\%) & $13.72 \pm 13.54$ & $9.76 \pm 9.56$ \\
\hline $\operatorname{InVLF}\left(\mathrm{ms}^{2}\right)$ & $7.15 \pm 0.79^{\star}$ & $7.87 \pm 0.67$ \\
\hline $\operatorname{lnLF}\left(\mathrm{ms}^{2}\right)$ & $6.06 \pm 0.67$ & $6.30 \pm 0.61$ \\
\hline $\operatorname{lnHF}\left(\mathrm{ms}^{2}\right)$ & $5.65 \pm 1.22$ & $5.68 \pm 0.77$ \\
\hline LF/HF & $6.06 \pm 0.67$ & $6.30 \pm 0.61$ \\
\hline SampEn & $1.33 \pm 0.36^{\star}$ & $1.03 \pm 0.26$ \\
\hline
\end{tabular}

${ }^{*} \mathrm{p}<0.01$ entre el tercer trimestre de embarazo y el trabajo de parto activo (prueba t pareada / prueba de rango con signo de Wilcoxon).

Análisis de curvas ROC y reconocimiento de patrones: A continuación, se presentan los resultados al implementar herramientas de reconocimiento de patrones y curvas ROC como se describió en la sección de metodología. De la Figura 6.3 se puede apreciar que la gráfica que posee mayor área bajo la curva ROC de los rasgos temporales de las FFC es la perteneciente al panel c, SDNN (Az=0.725). 
a)

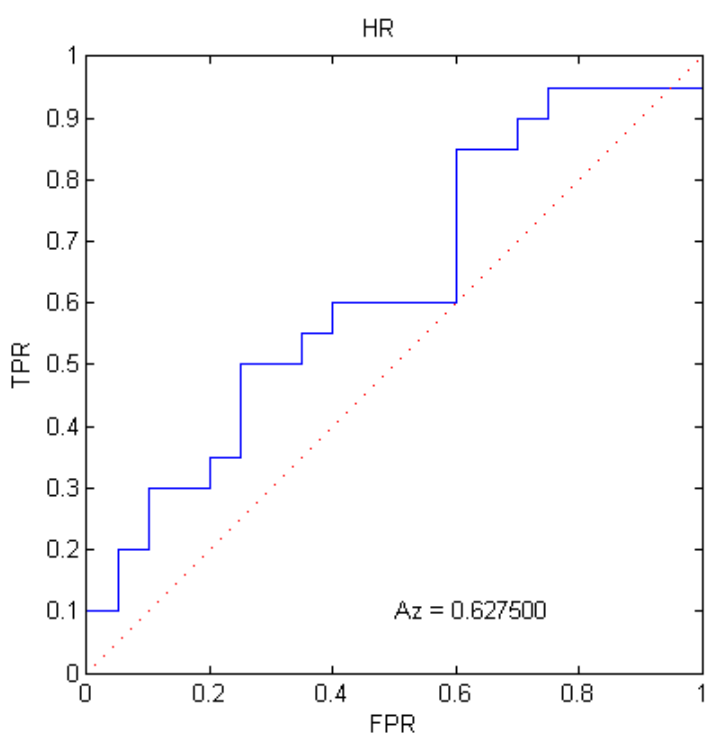

c)

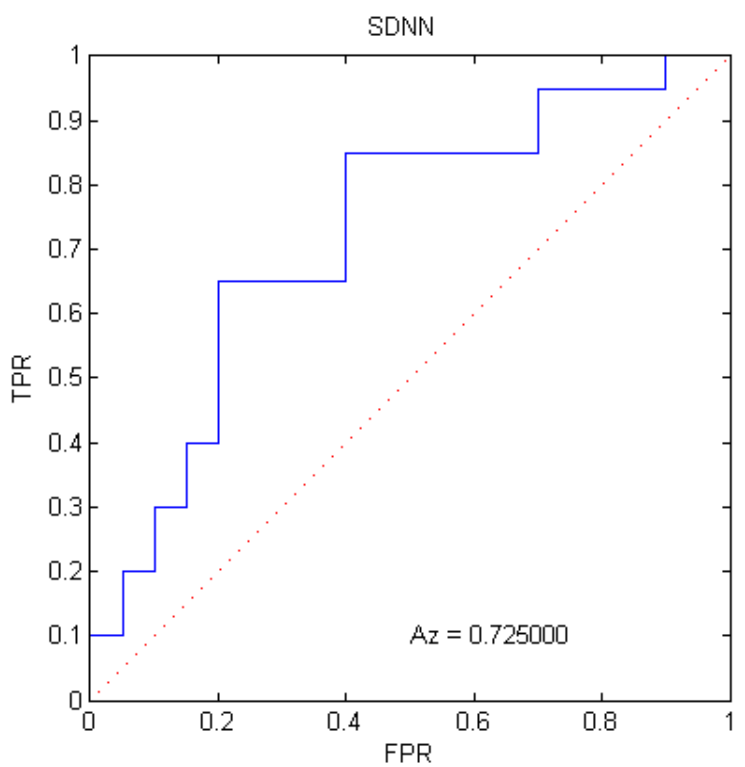

b)

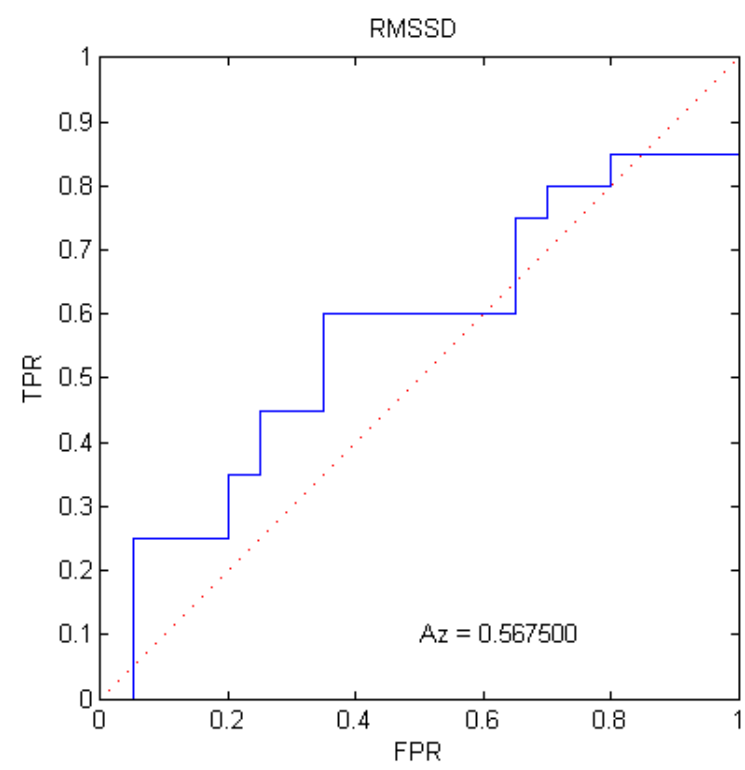

d)

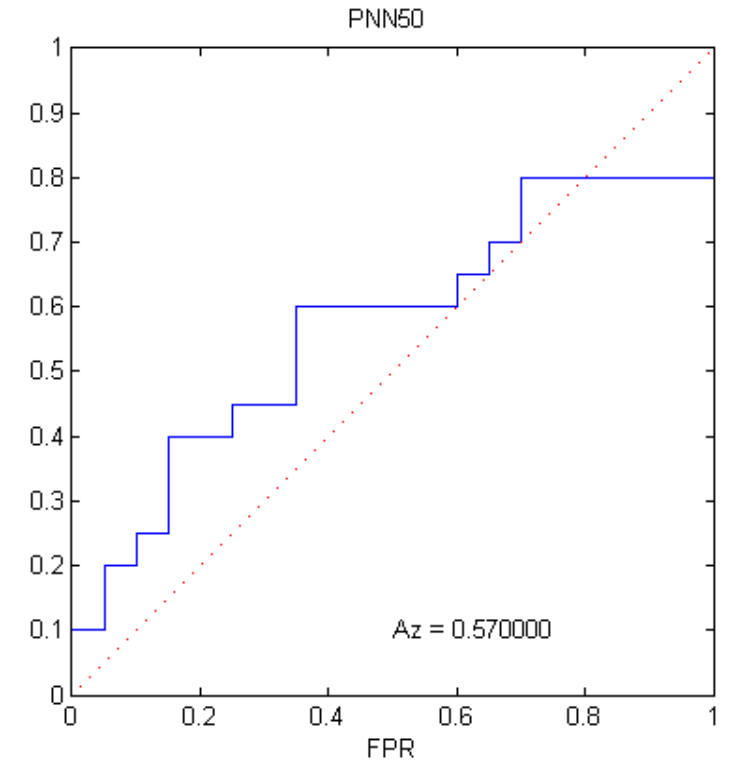

Figura 6.3 Curvas ROC (FPR vs. TPR) para los rasgos temporales de las fluctuaciones de la frecuencia cardiaca: a) frecuencia cardiaca media -también en otros lados- (HR, heart rate), b) raíz cuadrada del valor medio de la suma de las diferencias al cuadrado de todos los intervalos R-R sucesivos (RMSSD), c) desviación estándar de los intervalos normal a normal (SDNN) y d) porcentaje de intervalos R-R consecutivos, que discrepan más de 50 ms entre sí (PNN50).

Por otro lado, de la Figura 6.4 se puede apreciar que la gráfica que posee mayor área bajo la curva $R O C$ de todos los rasgos espectrales de las FFC es la perteneciente al panel a, $\operatorname{lnVLF}(\mathrm{Az}=0.725)$. 

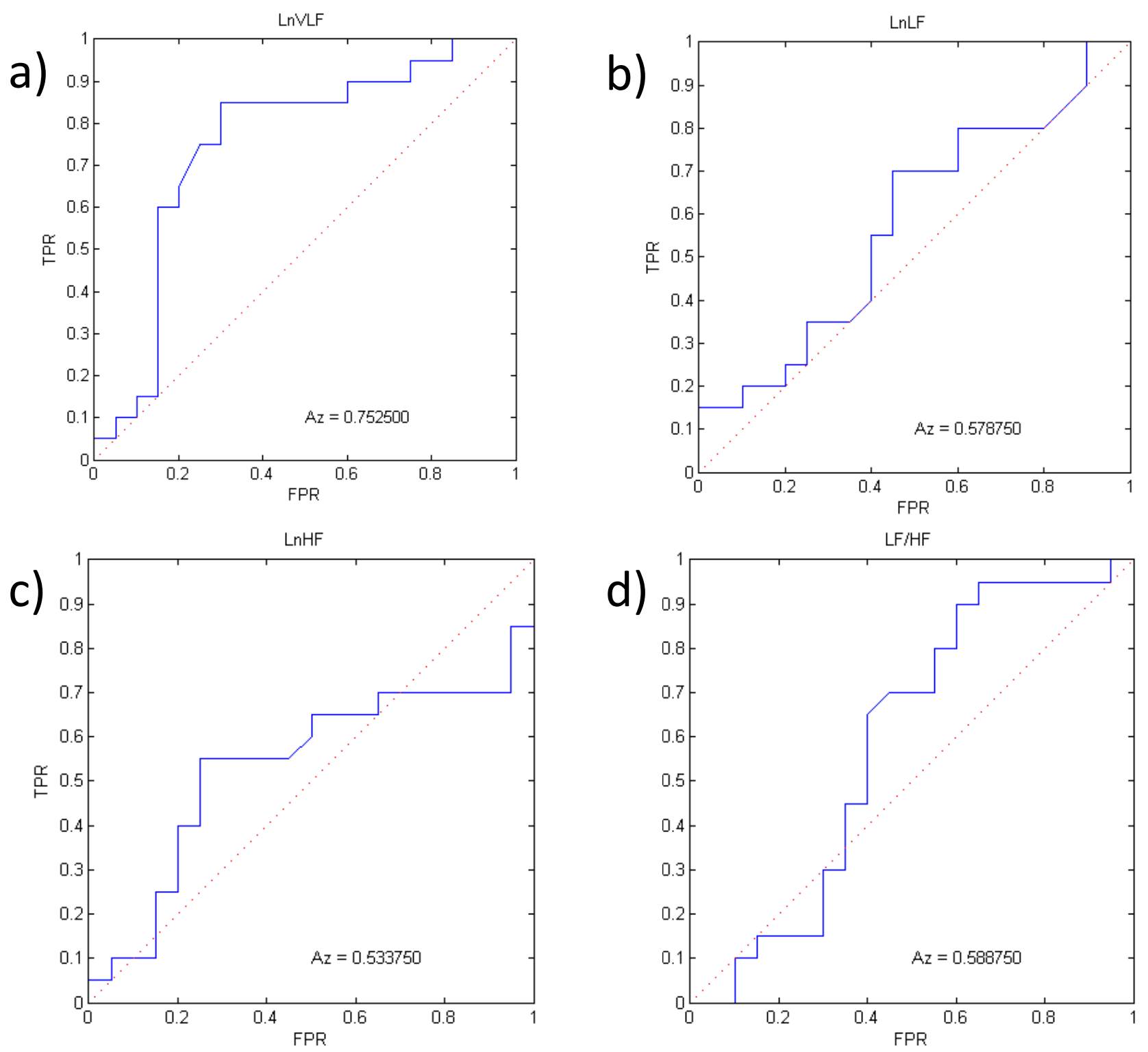

Figura 6.4 Curvas ROC (FPR vs. TPR) para los rasgos espectrales de las fluctuaciones de la frecuencia cardiaca: a) InVLF (logaritmo natural de muy baja frecuencia); b) InLF (logaritmo natural de bajas frecuencias); c) InHF (logaritmo natural de altas frecuencias) y d) LF/HF (proporción de altas y bajas frecuencias).

De igual manera, de la Figura 6.5 se puede observar que las gráficas que poseen mayor área bajo la curva $\mathrm{ROC}$ de todos los rasgos no lineales de las FFC son las pertenecientes a los paneles $\mathrm{c}, \alpha_{1(\mathrm{SIGN})}(\mathrm{Az}=0.77)$ y $d, \alpha_{2}(\mathrm{Az}=0.77)$. 
a)

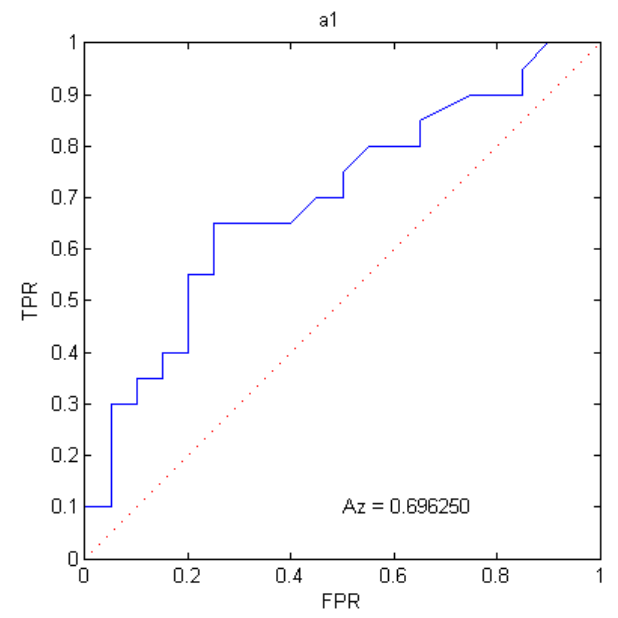

c)

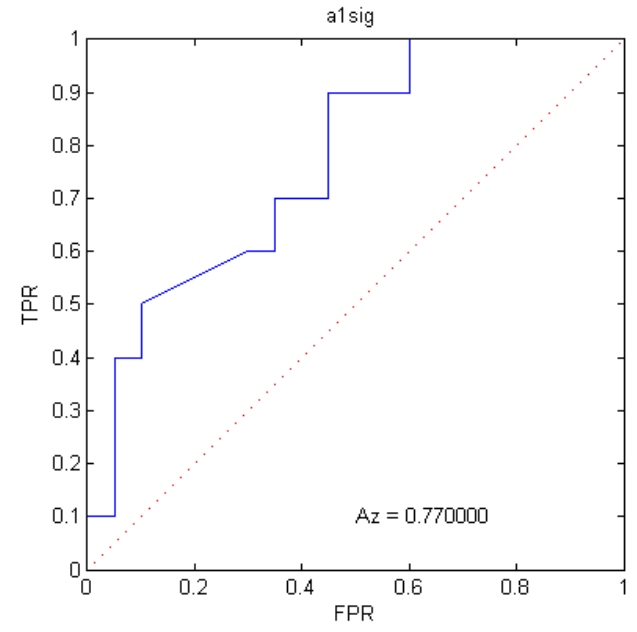

b)

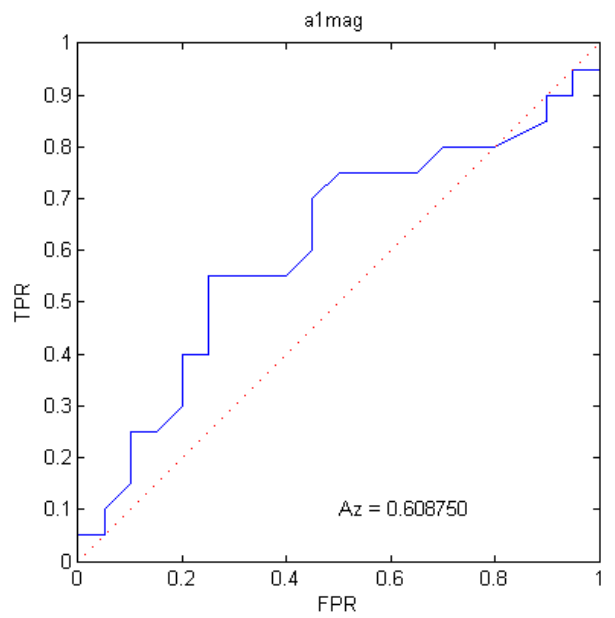

d)

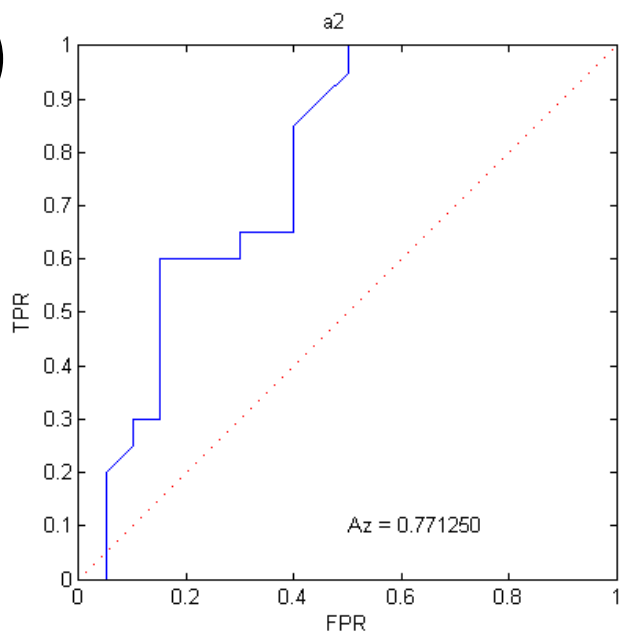

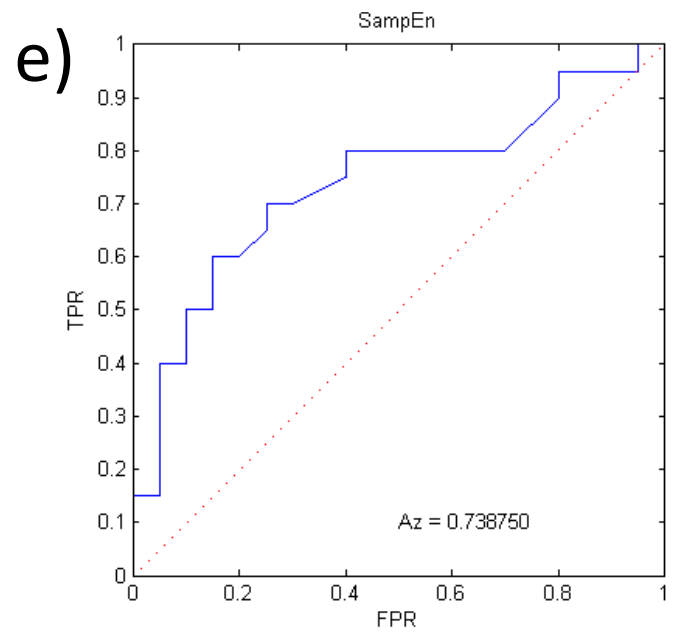

Figura 6.5 Curvas ROC (FPR vs. TPR) para los rasgos no lineales de las fluctuaciones de la frecuencia cardiaca: a) exponente de escalamiento fractal en el corto plazo $\left(\alpha_{1}\right)$, b) exponente de escalamiento fractal de magnitud $\left(\alpha_{1(M A G))}, c\right)$ exponente de escalamiento fractal de signo $\left(\alpha_{1(S I G N))}, d\right)$ exponente de escalamiento fractal en el largo plazo $\left(\alpha_{2}\right)$ y e) entropía muestra (SampEn). 
Finalmente, de la Figura 6.6 se puede observar que la gráfica que posee mayor área bajo la curva ROC de los parámetros inmunológicos de la familia de citoquinas de la IL-10 es la perteneciente al panel c, IL-22 ( $\mathrm{Az}=0.65)$.
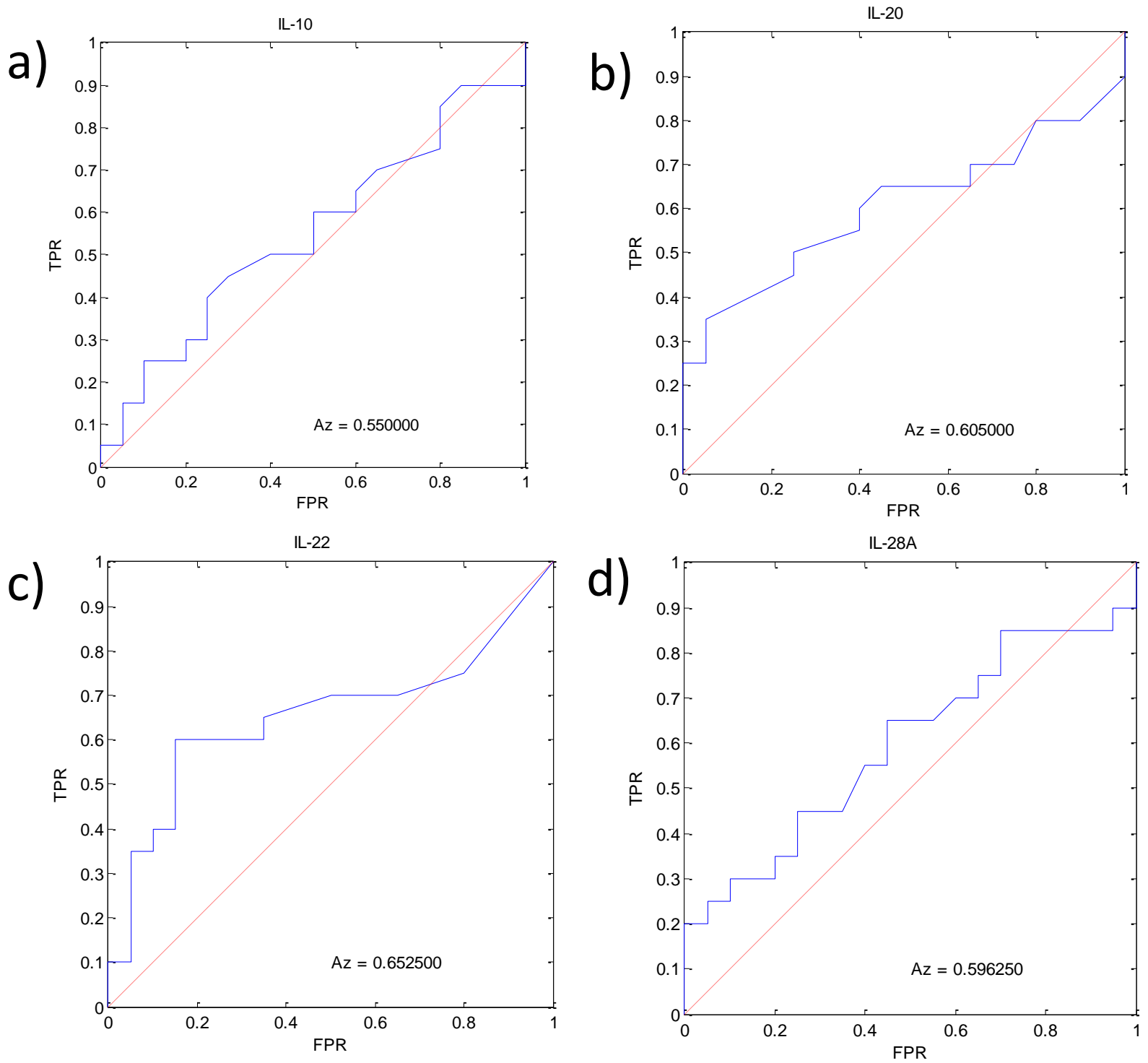

Figura 6.6 Curvas ROC (FPR vs. TPR) para los rasgos de las citoquinas de la familia de la IL-10: a) IL-10; b) IL-20; c) IL-22 y d) IL-28A. 
En la Figura 6.7 se muestran diversos pares de rasgos de las FFC en combinación con el

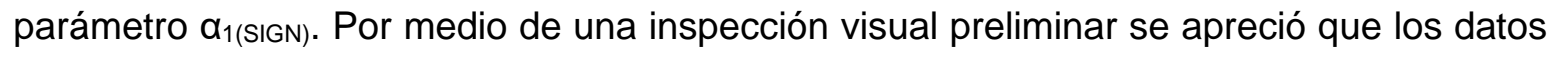
tienden a una separación en regiones o conglomerados, pero siendo dicha separación del tipo no lineal (ejemplo paneles a, e, c, etc.).

a)

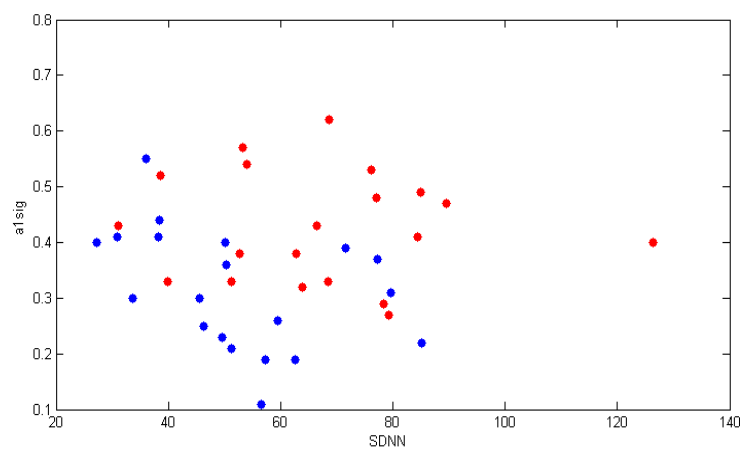

c)

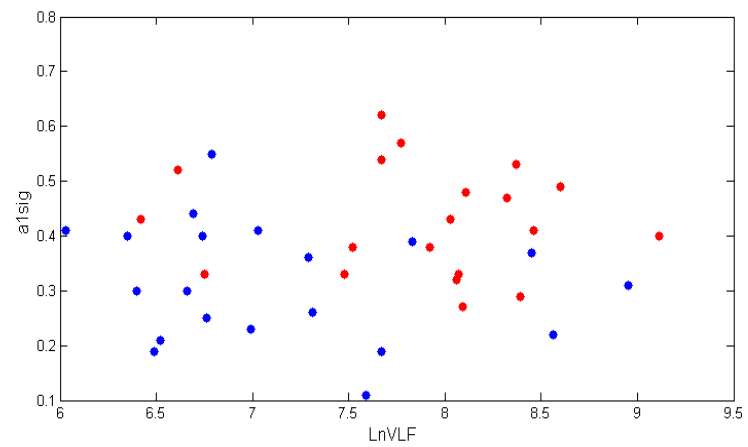

e)

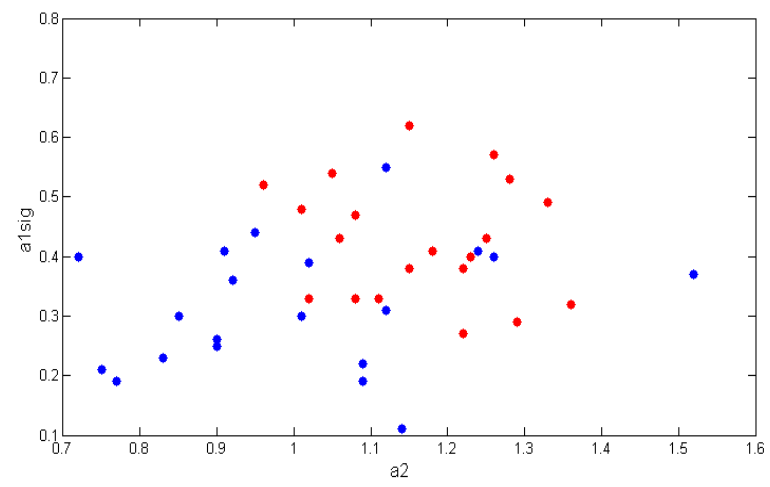

b)

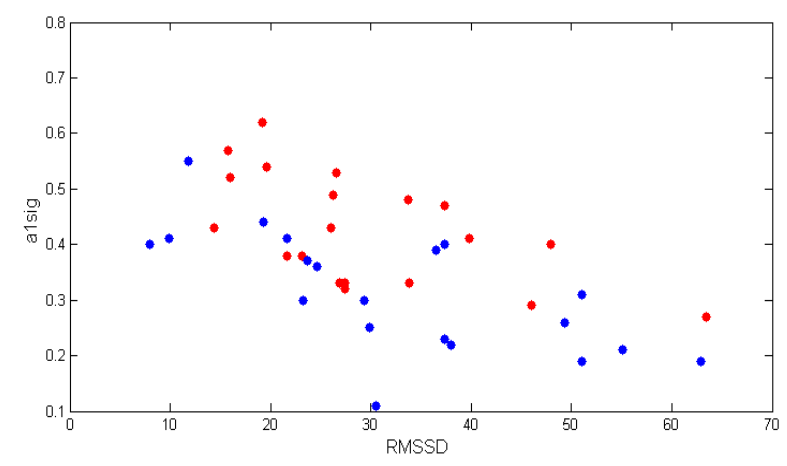

d)
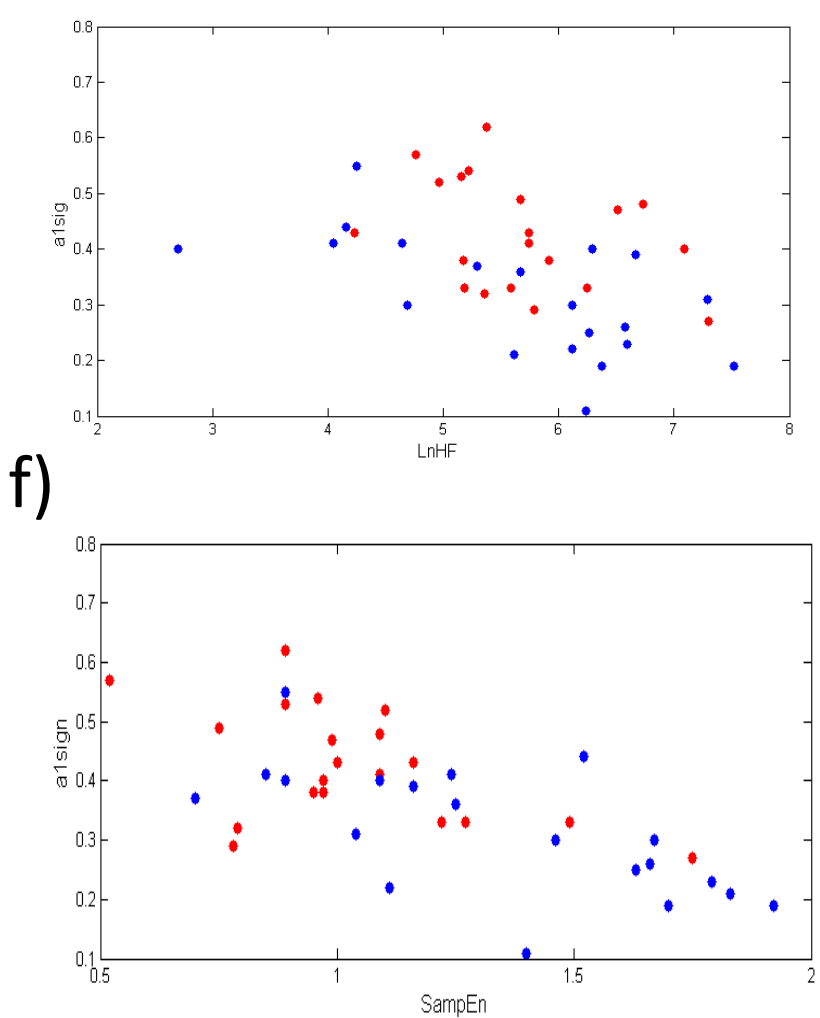

Figura 6.7 Gráficas de algunas combinaciones de pares de rasgos con el exponente de escalamiento fractal de

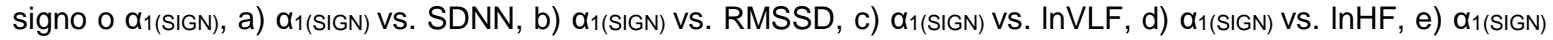
vs. $\alpha_{2}$ y f) $\alpha_{1(\text { SIGN) }} v s$. SampEn. Los puntos azules pertenecen a la clase de tercer trimestre de embarazo y los puntos rojos a la clase de trabajo de parto. 
Utilizando el clasificador de vecinos más cercanos (K-NN) se estableció qué combinación muestra valores mayores de sensibilidad, especificidad y certeza que el resto de las combinaciones (Tabla 6.2).

Tabla 6.2 Valores de sensibilidad, especificidad y certeza del clasificador de vecinos más cercanos (K-NN) de cada rasgo o combinaciones de rasgos del análisis de las FFC (Se realizaron 1000 iteraciones aleatorias). Se reporta valor promedio \pm desviación estándar.

\begin{tabular}{cccc}
\hline Rasgo (s) & Sensibilidad & Especificidad & Certeza \\
\hline $\boldsymbol{\alpha}_{1(\mathrm{SIGN})}$ & $0.70 \pm 0.38$ & $0.45 \pm 0.51$ & $0.58 \pm 0.10$ \\
$\alpha_{2}$ & $0.87 \pm 0.23$ & $0.56 \pm 0.44$ & $0.71 \pm 0.10$ \\
SDNN vs. $\alpha_{1(\mathrm{SIGN})}$ & $0.77 \pm 0.32$ & $0.40 \pm 0.58$ & $0.59 \pm 0.11$ \\
RMSSD vs. $\boldsymbol{\alpha}_{1(\mathrm{SIGN})}$ & $0.70 \pm 0.37$ & $0.26 \pm 0.69$ & $0.48 \pm 0.11$ \\
InVLF vs. $\boldsymbol{\alpha}_{1(\mathrm{SIGN})}$ & $0.81 \pm 0.28$ & $0.56 \pm 0.42$ & $0.68 \pm 0.10$ \\
InHF vs. $\boldsymbol{\alpha}_{1(\mathrm{SIGN})}$ & $0.74 \pm 0.34$ & $0.43 \pm 0.49$ & $0.59 \pm 0.10$ \\
$\boldsymbol{\alpha}_{2}$ vs. $\boldsymbol{\alpha}_{1(\mathrm{SIGN})}$ & $\mathbf{0 . 9 7} \pm \mathbf{0 . 1 3}$ & $\mathbf{0 . 5 5 \pm 0 . 4 5}$ & $\mathbf{0 . 7 6} \pm \mathbf{0 . 1 0}$ \\
SampEnvs. $\boldsymbol{\alpha}_{1(\mathrm{SIGN})}$ & $0.73 \pm 0.33$ & $0.45 \pm 0.49$ & $0.59 \pm 0.09$ \\
\hline
\end{tabular}

Los mejores valores de sensibilidad, especificidad y certeza correspondieron al par $\alpha_{2}$ vs. $\alpha_{1(S I G N)}$ que fueron los rasgos que exhibieron mayor área bajo la curva ROC individualmente.

Tabla 6.3 Matriz de confusión promedio del clasificador K-NN para el par de rasgos $\alpha_{2}$ vs.a. a $_{\text {(SIGN) }}$

\begin{tabular}{c|c}
$\mathrm{VP}=5.83 \pm 0.50$ & $\mathrm{FP}=0.16 \pm 0.50$ \\
\hline $\mathrm{FN}=2.66 \pm 1.16$ & $\mathrm{VN}=3.33 \pm 1.16$
\end{tabular}

\footnotetext{
${ }^{*} \mathrm{VP}=$ Verdaderos positivos. $\mathrm{FP}=$ Falsos positivos. $\mathrm{FN}=$ Falsos negativos. $\mathrm{VN}=$ Verdaderos negativos. El entrenamiento se realizó con 28 datos de los parámetros de fluctuaciones de la frecuencia cardiaca correspondientes a 14 datos de la clase tercer trimestre y 14 correspondientes a la clase trabajo de parto). La prueba se realizó con 12 datos, de igual manera 6 datos provienen de la clase de trabajo de parto y 6 datos provienen de la clase tercer trimestre de embarazo.
} 
Tabla 6.4 Valores de sensibilidad, especificidad y certeza del clasificador de vecinos más cercanos (K-NN) para los rasgos correspondientes a parámetros de las FFC y citoquinas (Se realizaron 1000 iteraciones aleatorias). Se reporta valor promedio \pm desviación estándar.

\begin{tabular}{|c|c|c|c|}
\hline Rasgo (s) & Sensibilidad & Especificidad & Certeza \\
\hline $\mathbf{\alpha}_{1(\mathrm{SIGN}) \text { VS. IL-10 }}$ & $0.82 \pm 0.26$ & $0.32 \pm 0.58$ & $0.57 \pm 0.09$ \\
\hline $\mathbf{a}_{1(\mathrm{SIGN})}$ vs. IL-20 & $0.91 \pm 0.21$ & $0.26 \pm 0.67$ & $0.59 \pm 0.09$ \\
\hline $\mathbf{a}_{1(\mathrm{SIGN}) \text { vs. IL-22 }}$ & $0.85 \pm 0.24$ & $0.37 \pm 0.51$ & $0.61 \pm 0.09$ \\
\hline$\alpha_{1(S I G N)}$ vs. IL-28A & $0.80 \pm 0.30$ & $0.26 \pm 0.71$ & $0.53 \pm 0.10$ \\
\hline$\alpha_{2}$ vs. IL-10 & $0.86 \pm 0.26$ & $0.32 \pm 0.59$ & $0.59 \pm 0.10$ \\
\hline$\alpha_{2}$ vs. IL-20 & $0.91 \pm 0.23$ & $0.45 \pm 0.47$ & $0.68 \pm 0.10$ \\
\hline$\alpha_{2}$ vs. IL-22 & $0.90 \pm 0.18$ & $0.40 \pm 0.47$ & $0.65 \pm 0.09$ \\
\hline 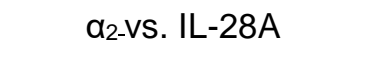 & $0.89 \pm 0.27$ & $0.31 \pm 0.66$ & $0.60 \pm 0.11$ \\
\hline$\alpha_{2}$ vs. $\alpha_{1(\mathrm{SIGN})}$ vs. IL-10 & $0.93 \pm 0.18$ & $0.38 \pm 0.51$ & $0.65 \pm 0.09$ \\
\hline$\alpha_{2}$ vs. $\alpha_{1(\mathrm{SIGN})}$ vs. IL-20 & $0.98 \pm 0.11$ & $0.49 \pm 0.44$ & $0.74 \pm 0.09$ \\
\hline$\alpha_{2}$ vs. $\alpha_{1(\mathrm{SIGN})}$ vs. IL-22 & $0.95 \pm 0.13$ & $0.42 \pm 0.50$ & $0.68 \pm 0.09$ \\
\hline$\alpha_{2}$ vs. $\alpha_{1(S I G N)}$ vs. IL-28A & $0.91 \pm 0.22$ & $0.37 \pm 0.60$ & $0.64 \pm 0.10$ \\
\hline
\end{tabular}

Tabla 6.5 Matriz de confusión promedio del clasificador K-NN con el vector de rasgos $\alpha_{2}$ vs. $\alpha_{1(\mathrm{SIGN})}$ vs. IL-20

\begin{tabular}{c|c}
$\mathrm{VP}=5.90 \pm 0.36$ & $\mathrm{FP}=0.09 \pm 0.36$ \\
\hline $\mathrm{FN}=2.98 \pm 1.07$ & $\mathrm{VN}=3.01 \pm 1.07$
\end{tabular}

${ }^{*} \mathrm{VP}=$ Verdaderos positivos. $\mathrm{FP}=$ Falsos positivos. $\mathrm{FN}=$ Falsos negativos. $\mathrm{VN}=$ Verdaderos negativos. El entrenamiento se realizó con 28 datos de los parámetros de fluctuaciones de la frecuencia cardiaca correspondientes a 14 datos de la clase tercer trimestre y 14 correspondientes a la clase trabajo de parto). La prueba se realizó con 12 datos, de igual manera 6 datos provienen de la clase de trabajo de parto y 6 datos provienen de la clase tercer trimestre de embarazo.

Análisis de correlaciones: En las Tablas 6.7 y 6.8 se muestran los valores de los coeficientes de correlación de Spearman (rho) para los parámetros inmunológicos (variable independiente) y los índices lineales y no lineales del análisis de las FFC (variable dependiente) del para el grupo de tercer trimestre de embarazo y el trabajo de parto respectivamente. Las correlaciones significativas entre los parámetros electrofisiológicos e inmunológicos se especifican en color rojo $\mathrm{p}<0.05$. 
Tabla 6.6 Análisis de correlación lineal entre las citoquinas y los parámetros de las fluctuaciones de la frecuencia cardiaca en el tercer trimestre de embarazo $(N=20)$.

\begin{tabular}{|c|c|c|c|c|c|c|c|c|c|c|c|c|c|}
\hline & \multicolumn{13}{|c|}{ Coeficiente de correlación (Spearman rho) } \\
\hline & $\alpha_{1}$ & $\alpha_{2}$ & $\boldsymbol{\alpha}_{1 \mathrm{mag}}$ & $\boldsymbol{\alpha}_{1(\mathrm{SIGN})}$ & HR & SDNN & RMSSD & PNN50 & InVLF & InLF & InHF & LF/HF & $\begin{array}{c}\text { SampE } \\
n\end{array}$ \\
\hline APRIL/TNFSF13 & -0.27 & 0.09 & 0.14 & -0.31 & -0.60 & 0.25 & 0.02 & 0.02 & 0.07 & -0.20 & 0.11 & -0.40 & 0.00 \\
\hline BAFF/TNFSF13B & -0.03 & 0.43 & 0.30 & -0.07 & -0.07 & 0.34 & 0.05 & 0.06 & 0.31 & -0.12 & -0.08 & -0.05 & -0.32 \\
\hline sCD30/TNFRSF8 & 0.03 & 0.30 & 0.13 & -0.05 & 0.34 & 0.34 & 0.13 & 0.10 & 0.27 & 0.23 & 0.05 & 0.04 & -0.31 \\
\hline sCD163 & -0.07 & 0.51 & -0.04 & -0.11 & -0.00 & 0.05 & 0.04 & 0.01 & 0.01 & -0.21 & -0.07 & 0.00 & -0.14 \\
\hline IFN- $\alpha 2$ & -0.15 & 0.15 & 0.16 & -0.17 & -0.10 & 0.24 & 0.14 & 0.14 & 0.00 & -0.06 & -0.01 & -0.09 & -0.24 \\
\hline IFN- $\beta$ & 0.18 & 0.54 & 0.11 & -0.12 & 0.02 & 0.15 & -0.07 & -0.04 & 0.34 & -0.20 & -0.05 & -0.06 & -0.33 \\
\hline IFN-gamma & -0.03 & 0.31 & 0.27 & -0.06 & 0.20 & 0.49 & 0.22 & 0.23 & 0.43 & 0.22 & 0.27 & -0.27 & -0.48 \\
\hline IL-10 & -0.05 & 0.07 & 0.18 & 0.00 & -0.00 & 0.08 & 0.09 & 0.08 & 0.07 & -0.12 & -0.04 & -0.15 & -0.26 \\
\hline IL-20 & -0.27 & 0.26 & 0.44 & -0.30 & -0.22 & 0.42 & 0.32 & 0.32 & 0.28 & 0.01 & 0.32 & -0.50 & 0.23 \\
\hline IL-22 & 0.39 & 0.03 & 0.10 & 0.18 & -0.07 & -0.30 & -0.29 & -0.33 & -0.25 & -0.10 & -0.23 & 0.18 & -0.23 \\
\hline IL-28A/IFN-2 & -0.27 & 0.13 & 0.22 & -0.29 & -0.24 & 0.38 & 0.30 & 0.37 & 0.21 & -0.00 & 0.20 & -0.36 & -0.11 \\
\hline IL-35 & -0.24 & 0.22 & 0.42 & -0.29 & -0.16 & 0.40 & 0.26 & 0.26 & 0.32 & -0.07 & 0.27 & -0.50 & -0.27 \\
\hline MMP-3 & -0.09 & 0.08 & -0.05 & -0.19 & -0.11 & 0.14 & 0.04 & 0.07 & 0.00 & -0.11 & 0.02 & -0.23 & -0.21 \\
\hline Osteocalcina & 0.16 & 0.08 & 0.42 & 0.01 & 0.23 & -0.03 & 0.02 & 0.01 & -0.08 & 0.07 & -0.15 & 0.18 & -0.32 \\
\hline Pentraxina-3 & -0.10 & 0.44 & 0.27 & -0.22 & -0.06 & 0.38 & 0.18 & 0.13 & 0.36 & -0.04 & 0.13 & -0.33 & -0.42 \\
\hline sTnf-R1 & -0.58 & 0.36 & 0.09 & -0.39 & -0.19 & 0.77 & 0.48 & 0.46 & 0.70 & 0.20 & 0.51 & -0.68 & -0.03 \\
\hline TSLP & 0.00 & 0.22 & 0.27 & -0.07 & 0.19 & 0.29 & 0.11 & 0.13 & 0.27 & 0.05 & 0.01 & -0.13 & -0.47 \\
\hline
\end{tabular}

La correlación es significativa con una $p<0.05$ (en negritas rojas). 
Tabla 6.7 Análisis de correlación lineal entre las citoquinas y los parámetros de las fluctuaciones de la frecuencia cardiaca en el trabajo de parto $(\mathrm{N}=20)$.

\begin{tabular}{|c|c|c|c|c|c|c|c|c|c|c|c|c|c|}
\hline & & & & & & oeficie & e de corr & ación (S & arman & & & & \\
\hline & $\alpha_{1}$ & $\alpha_{2}$ & $\alpha_{1 \text { mag }}$ & $\alpha_{1(\mathrm{SIGN})}$ & HR & SDNN & RMSSD & PNN50 & InVLF & InLF & InHF & LF/HF & $\begin{array}{c}\text { SampE } \\
n\end{array}$ \\
\hline APRIL/TNFSF13 & -0.16 & -0.46 & -0.25 & -0.30 & -0.10 & -0.41 & 0.01 & -0.16 & -0.49 & -0.15 & -0.12 & -0.05 & 0.57 \\
\hline BAFF/TNFSF13B & 0.02 & -0.11 & -0.03 & 0.42 & -0.08 & 0.39 & -0.26 & -0.19 & -0.17 & -0.23 & -0.23 & -0.06 & -0.01 \\
\hline sCD30/TNFRSF8 & -0.48 & 0.39 & 0.25 & -0.65 & -0.04 & 0.27 & 0.63 & 0.55 & 0.32 & 0.12 & 0.55 & -0.58 & 0.09 \\
\hline sCD163 & -0.07 & 0.10 & 0.01 & 0.21 & 0.06 & -0.07 & 0.02 & -0.11 & -0.01 & -0.21 & -0.11 & -0.20 & -0.10 \\
\hline IFN- $\alpha 2$ & -0.22 & 0.05 & -0.17 & -0.52 & 0.08 & -0.12 & 0.19 & 0.05 & -0.09 & -0.16 & 0.04 & -0.40 & 0.20 \\
\hline IFN- $\beta$ & 0.08 & 0.40 & 0.01 & 0.00 & -0.14 & 0.32 & 0.24 & 0.18 & 0.46 & 0.13 & -0.01 & 0.07 & -0.35 \\
\hline IFN-gamma & -0.17 & 0.19 & 0.06 & -0.39 & 0.22 & -0.13 & 0.01 & -0.04 & -0.06 & -0.20 & 0.04 & -0.42 & 0.05 \\
\hline IL-10 & -0.36 & 0.38 & 0.21 & -0.46 & 0.12 & 0.25 & 0.48 & 0.37 & 0.28 & 0.05 & 0.27 & -0.23 & -0.13 \\
\hline IL-20 & -0.14 & -0.15 & -0.19 & -0.54 & 0.08 & -0.08 & 0.33 & 0.14 & -0.07 & 0.07 & 0.21 & -0.33 & 0.38 \\
\hline IL-22 & -0.40 & 0.02 & -0.17 & -0.55 & -0.26 & 0.18 & 0.41 & 0.30 & 0.18 & 0.13 & 0.05 & 0.09 & 0.21 \\
\hline IL-28A/IFN-2 & -0.15 & -0.13 & 0.05 & -0.25 & 0.07 & -0.09 & 0.05 & -0.07 & -0.09 & -0.12 & -0.11 & -0.02 & 0.17 \\
\hline IL-35 & -0.39 & -0.11 & 0.07 & -0.59 & -0.02 & -0.17 & 0.22 & 0.03 & -0.12 & -0.17 & 0.07 & -0.39 & 0.21 \\
\hline MMP-3 & -0.23 & -0.00 & 0.18 & -0.20 & -0.03 & -0.32 & -0.20 & -0.30 & -0.22 & -0.34 & -0.42 & 0.00 & 0.15 \\
\hline Osteocalcina & -0.06 & 0.53 & 0.30 & -0.17 & -0.09 & 0.03 & 0.04 & 0.01 & 0.16 & -0.23 & -0.06 & 0.18 & -0.33 \\
\hline Pentraxina-3 & 0.10 & -0.35 & -0.41 & -0.06 & 0.32 & -0.18 & -0.14 & -0.30 & -0.27 & -0.13 & -0.05 & -0.18 & 0.06 \\
\hline sTnf-R1 & -0.10 & -0.22 & -0.17 & -0.32 & 0.10 & -0.21 & 0.11 & -0.02 & -0.13 & 0.01 & 0.01 & -0.22 & 0.26 \\
\hline TSLP & -0.04 & 0.17 & 0.35 & -0.15 & 0.30 & -0.13 & -0.10 & -0.08 & -0.05 & -0.27 & -0.10 & -0.14 & -0.12 \\
\hline
\end{tabular}

La correlación es significativa con una $p<0.05$ (en negritas rojas).

En el análisis de correlación canónica los conjuntos de variables $X$ y $Y$ tuvieron $p=4$ y $q=$ 4 variables, respectivamente. De esta forma, se formaron cuatro variables canónicas $\left(U_{p} V_{q}\right)$ (usualmente llamadas variados canónicos), las correlaciones canónicas entre ellas se presentan en la Tabla 6.8.

Como se muestra en la Tabla 6.8, la primera correlación canónica (0.752) del primer variado canónico $\left(\mathrm{U}_{1} \mathrm{~V}_{1}\right)$ fue significativa $(\mathrm{p}<0.005)$; sin embargo, otras correlaciones no fueron significativas. Por lo que sólo se interpretó la primera correlación canónica en la Tabla 6.9. 
Este análisis multivariado se realizó entre los datos de las FFC asociados principalmente al componente vagal y únicamente con las citoquinas de la familia IL-10.

Tabla 6.8 Correlaciones canónicas entre los variados canónicos

\begin{tabular}{ccccc}
\hline $\begin{array}{c}\text { Variado } \\
\text { canónico }\end{array}$ & $\begin{array}{c}\text { Correlación } \\
\text { canónica }\end{array}$ & Valor de $\mathbf{F}$ & Valor de $\mathbf{P}$ & $\begin{array}{c}\text { Lambda de } \\
\text { Wilks }\end{array}$ \\
\hline $\mathrm{U}_{1} \mathrm{~V}_{1}$ & 0.752 & 2.42 & 0.005 & 0.264 \\
$\mathrm{U}_{2} \mathrm{~V}_{2}$ & 0.514 & 1.46 & 0.183 & 0.610 \\
$\mathrm{U}_{3} \mathrm{~V}_{3}$ & 0.391 & 1.22 & 0.315 & 0.830 \\
$\mathrm{U}_{4} \mathrm{~V}_{4}$ & 0.139 & 0.51 & 0.480 & 0.980 \\
\hline
\end{tabular}

Tabla 6.9 Cargas canónicas y pesos canónicos estandarizados entre el primer variado canónico y las variables originales $\left(U_{1} V_{1}\right)$

\begin{tabular}{lrr|lrr}
\hline & Variable X & & \multicolumn{3}{c}{ Variable Y } \\
\hline Variables & $\begin{array}{c}\text { Cargas } \\
\text { canónicas }\end{array}$ & $\begin{array}{c}\text { Pesos } \\
\text { canónicos } \\
\text { estandarizados }\end{array}$ & Variables & $\begin{array}{c}\text { Cargas } \\
\text { canónicas }\end{array}$ & $\begin{array}{c}\text { Pesos } \\
\text { canónicos } \\
\text { estandarizados }\end{array}$ \\
\hline IL-10 & -0.040 & -0.273 & $\alpha_{1}$ & -0.389 & -1.246 \\
IL-20 & -0.032 & 0.510 & $\alpha_{1(\text { SIGN) }}$ & -0.128 & 0.699 \\
IL-22 & -0.915 & -1.102 & RMSSD & 0.406 & -1.391 \\
IL-28 & -0.036 & 0.112 & LnHF & 0.727 & 1.611 \\
\hline
\end{tabular}

De acuerdo a Tabachnick \& Fidell [264], las correlaciones entre las variables originales y las cargas canónicas se deben de interpretar a partir del valor de 0.300. Sin embargo, hay que tener precaución en la interpretación de estos resultados debido a problemas de multicolinealidad entre las variables, ya que tanto las citoquinas de la familia IL-10 presentan dependencia entre ellas, como también presentan dependencia lo parámetros de las FFC seleccionados (ejemplo RMSSD y LnHF).

\subsection{Discusión de resultados}

Parámetros de las FFC: El principal hallazgo del presente estudio longitudinal es la identificación de un sutil, pero significativo, cambio en la direccionalidad de la las FFC

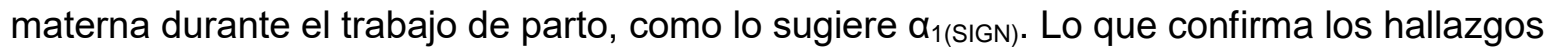
de nuestro estudio transversal preliminar en mujeres durante el trabajo de parto y el tercer trimestre de embarazo [116]. Así, las FFC durante el trabajo de parto muestran un comportamiento menos anticorrelacionado en comparación con el comportamiento anticorrelacionado del grupo en tercer trimestre de embarazo $\alpha_{1(\mathrm{SIGN})}(0.42 \pm 0.09$ vs. $0.31 \pm$ 0.10 , respectivamente), Tabla 6.1 . 
Es importante mencionar que de acuerdo con Peña et al, [265] se mantiene una fuerte anticorrelación en las FFC a lo largo de los tres trimestres de gestación. En otro tipo de estudios, se han observado cambios en la direccionalidad de las FFC, al ir $\alpha_{1(\mathrm{SIGN})}$ de valores anticorrelacionados (pequeños, $\left.\alpha_{1(\mathrm{SIGN})}<0.5\right)$ a menos anticorrelacionados (grandes, $\alpha_{1(S I G N)} \simeq 0.5$ ). Esto se ha visto en casos patológicos, pero también en estudios de sueño y de envejecimiento, pero que el contexto fisiológico de dichos cambios no ha sido esclarecido con precisión [119], [120].

En términos matemáticos de los "paseos aleatorios" [29], la interacción autonómica se manifiesta con diferentes niveles de atracción para la frecuencia cardiaca. Por ejemplo, la dinámica mayormente anticorrelacionada durante el tercer trimestre, sugeriría la dominancia de un atractor, que podría corresponder esencialmente a la influencia de la actividad simpática [265]. En la Figura 1.14 del Capítulo I se ejemplifica intuitivamente la idea de atractores: puesto que al suprimir la influencia simpática a través de un bloqueador adrenérgico, un atractor dominante (el parasimpático) oscilaría con valores anticorrelacionados.

En el trabajo de parto, la causa fisiológica de encontrar un nivel de menor anticorrelación en las FFC parece posible asociarse a un menor antagonismo autonómico en la direccionalidad de las FFC, que posiblemente podría también vincularse, entre otros aspectos, a una respuesta antiinflamatoria como resultado de la inflamación durante el trabajo de parto, y que en nuestro estudio de citoquinas (Capítulo V) se confirma. Es por lo que, para contender ante esta situación de inflamación extrema, el reflejo antiinflamatorio podría estar involucrado para suprimir la liberación de citoquinas proinflamatorias por medio de un mecanismo de sinergia de los sistemas simpático/parasimpático (dos atractores manifestados por los valores menos anticorrelacionados del parámetro $\alpha_{1(\text { SIGN) }}$ de acuerdo con lo propuesto por Karasik et al. [266]). Adicionalmente es importante indicar que estudios han demostrado que el útero tiene inervaciones vagales [267], por lo que se podría especular la participación vagal en el trabajo de parto para regular las contracciones uterinas.

Originalmente, se asumió que la probable activación del reflejo antiinflamatorio colinérgico estimularía la liberación de la IL-10 [66]; sin embargo, la sinergia simpática/parasimpática del reflejo antiinflamatorio manifestada en las FFC, que se

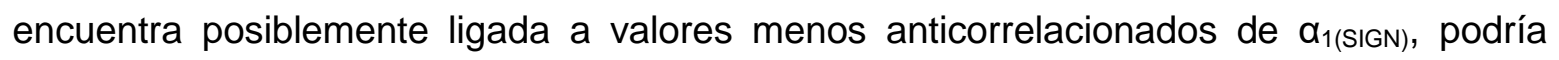
continuar hasta que no se resuelva el proceso inflamatorio, es decir durante el puerperio (etapa no analizada). En otras palabras, el trabajo de parto involucra un proceso 
inflamatorio caracterizado por una disminución de la citoquina antiinflamatoria IL-10 que es acompañado por cambios en la direccionalidad de las FFC (ligado probablemente a cambios autonómicos) en el corto plazo. Esto podría cambiar después del nacimiento hacia un microambiente mayormente antiinflamatorio, lo que favorecería la protección y reparación tisular [225] y una dominancia colinérgica. De manera interesante, se han reportado niveles de concentración de IL-10 aumentadas en mujeres en el puerperio en comparación con mujeres no embarazadas [268].

El exponente de escalamiento fractal en el largo plazo $\left(\alpha_{2}\right)$ de 12 a 140 latidos, resultó incrementado en el trabajo de parto activo. Este incremento se puede manifestar debido a los componentes periódicos introducidos en las series de tiempo en el largo plazo [153]. Así dichos componentes parecen coincidir con el incremento de la actividad uterina que caracteriza al trabajo de parto activo [33]. Otro de los parámetros que se comportó conforme a nuestro estudio anterior fue la SampEn (Capítulo II, sección 2.3); los cambios de SampEn son también introducidos muy probablemente por las contracciones uterinas, ya que, teniendo en cuenta que este parámetro mide la regularidad de las series temporales [165], una disminución de su valor podría estar relacionada con cambios de muy baja frecuencia en la series $R-R$, y que de igual manera parecen estar influenciadas por la periodicidad de la actividad electrohisterográfica durante el trabajo de parto. De hecho, esto también es confirmado por cambios en el parámetro espectral InVLF, que también resultó elevado por la presencia específica de contracciones uterinas. Se debe precisar que las contracciones uterinas son eventos fisiológicos de muy baja frecuencia $(0.005$ a $0.008 \mathrm{~Hz})$ en comparación a la actividad eléctrica cardiaca, ya que se manifiestan de tres a cuatro contracciones en 10 minutos [33]. Interesantemente, el índice InVLF fue previamente estudiado por Suzuki et al. [269] y resultó como un parámetro cardiaco característico asociado a la presencia específica de contracciones uterinas durante el trabajo de parto. Los autores concluyeron que la actividad simpática materna aparentemente aumentó durante los períodos de contracción uterina en comparación a segmentos sin contracción uterina [269]. Sin embargo, la interpretación de este parámetro en registros de corta duración debe de tomarse con precaución para una interpretación relacionada con la actividad simpática del SNA [86]. Adicionalmente el tamaño de ventana utilizado en el presente estudio (256 puntos en el software Kubios) no fue suficiente para observar un ciclo completo de contracciones, por lo que resultados de este parámetro se deben tomar con precaución. 
Durante el trabajo de parto existe un aumento en el gasto cardíaco resultante de incrementos tanto en el volumen sistólico como en la frecuencia cardíaca [254]. Los detalles de cómo estos cambios hemodinámicos son impulsados por el SNA no han sido completamente entendidos. En este sentido, el SDNN representa una evaluación global del equilibrio del SNA, que depende de la modulación de la rama simpática y la parasimpática [270]. El aumento en el SDNN presentado en el trabajo de parto podría vincularse a que, a diferencia del tercer trimestre de embarazo, la regulación cardiaca requiere de un mayor control autonómico debido al aumento y descenso constante de la frecuencia cardiaca introducido por las contracciones uterinas [271] (y que se lograría con la presencia de más de un atractor dominante si lo vinculamos con los cambios en el parámetro de signo) o bien, también podemos especular que, debido a la presencia específica de contracciones uterinas la señal de fluctuaciones R-R podría perder estacionalidad y verse reflejado en el parámetro SDNN.

Un ejemplo característico en la señal $\mathrm{R}-\mathrm{R}$ se puede apreciar en la Figura 6.2. De acuerdo con la literatura, un aumento en el SDNN se puede interpretar como un signo de mayor variabilidad cardiaca [272]. Se esperaría que eventos estresantes, como en este caso el trabajo de parto, causen una fase de dominancia simpática debido al bien conocido reflejo de lucha - huida [273]; por lo tanto, una disminución en las FFC. Sin embargo, se sabe que en el ganado vacuno, el aumento de la actividad simpática inhibe el trabajo de parto a través de la activación de los receptores $\beta 2$ del miometrio [274]. Es de llamar la atención que no se encontraron diferencias estadísticas en la frecuencia cardiaca entre las etapas de tercer trimestre de embarazo y el trabajo de parto. En un estudio también en ganado, la frecuencia cardíaca sólo aumentó significativamente hasta la etapa expulsiva o de alumbramiento [275], y que nosotros no estudiamos en el presente trabajo de investigación.

En nuestro estudio, no se encontraron diferencias estadísticas en los parámetros vinculados a la actividad vagal, como lo son el pNN50, la RMSSD y el LnHF como se hubiera esperado. Una posible explicación de la falta de cambios en dichos parámetros puede ser debido a outliers o datos discordantes. De hecho, en nuestra investigación anterior se tuvo que hacer uso de un análisis de discordantes para revelar cambios significativos en el parámetro RMSSD [116] . Ese análisis no se implementó en este estudio debido al tamaño pequeño de la muestra y a que fue un estudio longitudinal.

Finalmente, el parámetro de escalamiento fractal del corto plazo $\alpha_{1}$ mostró diferencias entre el tercer trimestre del embarazo y en el trabajo de parto, este resultado 
indica la existencia de correlaciones pero que no necesariamente siguen una ley de potencia o presentan un comportamiento estocástico. Así, la dinámica en el corto plazo de las FFC durante el trabajo de parto parece seguir un comportamiento influenciado por componentes periódicos en el corto plazo $\left(\alpha_{1}>1\right)$ [153] y no lineal $\left(\alpha_{1 \text { (MAG) }}>0.5\right.$, a pesar de que éste no cambió del tercer trimestre de gestación al trabajo de parto), posiblemente debido al haberse incrementado la demanda cardiovascular que requiere el trabajo de parto y el efecto de las contracciones uterinas.

Un análisis estadístico complementario de ANOVA para muestras repetidas se muestra en el Apéndice $D$, en este análisis se separaron los grupos de pacientes a las que se les administró oxitocina exógena durante el trabajo de parto $(n=10)$ y a las que no se les administró oxitocina $(n=10)$. De forma interesante, la oxitocina no pareció influenciar a los parámetros de las FFC. Esto podría explicarse debido a que durante el trabajo de parto se libera oxitocina endógena, de hecho, es sabido que durante el trabajo de parto los receptores de oxitocina endógena aumentan hasta 150 veces más que en el embarazo [114]. Adicionalmente, el tamaño pequeño de los grupos $(n=10)$ es una limitante para este tipo de análisis.

Análisis de reconocimiento de patrones: De las Figuras 6.3 a 6.5 se pueden apreciar que las gráficas que poseen mayor área bajo la curva $\mathrm{ROC}(\mathrm{Az})$ de todos los rasgos tanto

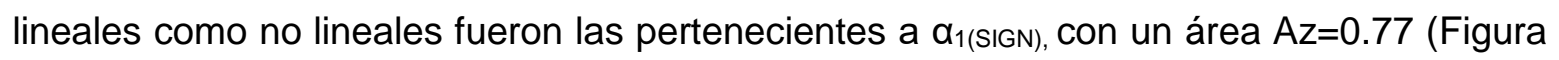
$6.5 \mathrm{c}$ ) y $\alpha_{2}$ con un área también de $A z=0.77$ (Figura $6.5 \mathrm{~d}$ ). Este resultado revela que ambos rasgos de las FFC tienen una mayor capacidad discriminatoria para identificar la condición de trabajo de parto o tercer trimestre que el resto de los demás rasgos (siguiendo el criterio de que un valor cercano a 1 representa un valor diagnóstico perfecto). Es de llamar la atención, que la mayor parte de los rasgos de las FFC poseen incluso una mayor capacidad discriminatoria que los rasgos pertenecientes a la familia de citoquinas de la IL-10 (Figura 6.6).

Como se mencionó en la sección anterior, se graficaron algunas combinaciones de pares de rasgos que involucraron al exponente de escalamiento $\alpha_{1(\mathrm{SIGN})}$ (Figura 6.7), ya que se ha descrito que este parámetro mejora la separación de conglomerados de datos de las FFC [276], lo que permitiría mejorar la clasificación entre el tercer trimestre de embarazo y el trabajo de parto. Visualmente en la Figura 6.7 no es claro cuál combinación de parámetros posee una mayor separación entre conglomerados. Sin embargo, se tomó la 
combinación de $\alpha_{2}$ vs. $\alpha_{1 \text { (SIGN) }}$ (Figura 6.7e) debido a que ambos parámetros tuvieron una mayor área bajo la curva ROC.

En concordancia con los hallazgos del área $\mathrm{ROC}$, la combinación de rasgos $\alpha_{2}$

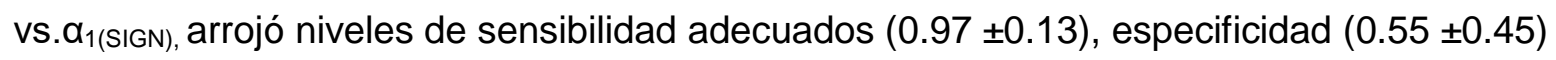
y certeza $(0.76 \pm 0.10)$. Estos datos se encuentran en la Tabla 6.2 y los datos provienen de su matriz de confusión promedio en la Tabla 6.3. De las tablas subsecuentes, como por ejemplo la Tabla 6.4 se puede notar que, al introducir rasgos inmunológicos, no se mejoran los niveles de sensibilidad, especificidad y certeza del clasificador en ningún caso.

Análisis de correlaciones: Usando una muestra pequeña de mujeres sanas en el tercer trimestre de embarazo y durante el trabajo de parto, encontramos que diversos parámetros lineales y no lineales del análisis de las FFC se correlacionaron significativamente con varios marcadores inflamatorios (Tablas 6.6 y 6.7). Estos resultados se encuentran en concordancia con los de Cooper et al. [256], quienes demostraron una asociación entre diversos parámetros del análisis de las FFC, como por ejemplo el parámetro HF, con la proteína $\mathrm{C}$ reactiva y el conteo de glóbulos blancos en una población compuesta principalmente de hombres americanos en edad media y edad avanzada, datos provenientes de un estudio longitudinal $(\mathrm{N}=1255)$.

Hay que destacar que la correlación simple más alta encontrada en el trabajo de parto fue entre el parámetro $\alpha_{1(\text { SIGN) }}$ con el SCD30 $(r=-0.65, p<0.05)$, seguida de la correlación del parámetro vagal RMSSD también con el $\operatorname{SCD} 30(r=0.63, p<0.05)$. El receptor CD30 pertenece a la superfamilia del TNF/ factor del crecimiento neural (NGF). EI CD30 se expresa normalmente en un subconjunto de células $\mathrm{T}$ activadas que producen citoquinas del tipo Th2 (antiinflamatorias). La forma soluble del CD30, es decir el sCD30, es liberada tras la activación de células T. Por ejemplo, se han detectado niveles elevados de sCD30 en enfermedades dominadas por la respuesta Th2, como el lupus eritematoso sistémico [277]. En este sentido, se considera al SCD30 como un marcador indirecto de una respuesta inmune Th2, y en el embarazo puede ser inducido por la progesterona junto con la producción de IL-4. De hecho, se espera un aumento de sCD30 durante el embarazo [277]. Por lo que con estos datos podemos suponer que las influencias colinérgicas cardiacas están asociadas a una respuesta Th2 en el trabajo de parto, donde este hallazgo podría deberse a la respuesta colinérgica antiinflamatoria que se debe manifestar como mecanismo homeostático de regulación [88]. Por otro lado, respecto a la correlación negativa entre $\alpha_{1 \text { (SIGN) }}$ con el SCD30; este resultado sugiere que una menor anticorrelación 
(valores de $\alpha_{1(\text { SIGN) }}$ cercanos a 0.5) de las FFC estaría ligada a la participación de más de un atractor, por ejemplo (el parasimpático y el simpático de acuerdo con lo propuesto por Karasik et al. [266]) que regularían a la baja la respuesta la Th2. En cambio, cuando existe un atractor dominante, esta respuesta podría regular a la alta el perfil Th2 en el trabajo de parto.

El parámetro de interés de las FFC $\alpha_{1(\mathrm{SIGN})}$ resultó tener el mayor número de correlaciones significativas con los parámetros inmunológicos (35\%) en el trabajo de parto, de hecho, se correlacionó negativamente con varios miembros de la familia de la IL-10, como: IL-10 (rho=-0.46, p<0.05), IL-20 (rho=-0.54, p<0.05) e IL-22 (rho=-0.55, p<0.05). Asimismo, la IL-10 se correlacionó positivamente con el parámetro RMSSD (rho=0.48, $p<0.05)$, este hallazgo refuerza la idea de la probable participación de la respuesta colinérgica antiinflamatoria durante el trabajo de parto de bajo riesgo, al ser la IL-10 una citoquina clave que regula la respuesta antiinflamatoria [88].

Una citoquina de gran interés es la IL-22, ya que es una citoquina perteneciente a la familia de las citoquinas de la IL-10 y que mostró un decremento estadístico significativo durante el trabajo de parto en comparación con el tercer trimestre de gestación (Capítulo V, Sección 5.3). La IL-22 es el miembro mejor estudiado de la subfamilia IL-20, y ejemplifica diversos efectos biológicos de esta subfamilia. La IL-22 provoca diversas respuestas inmunes innatas a partir de células epiteliales y es esencial para la defensa del huésped contra varios patógenos invasores, incluyendo Citrobacter rodentium y Klebsiella pneumonia [278]. La IL-22 también protege la integridad de los tejidos y mantiene la homeostasis de la mucosa. Por otra parte, la IL-22 se ha considerado como una citoquina proinflamatoria con la capacidad de amplificar respuestas inflamatorias, lo que podría dar lugar a daño tisular, por ejemplo, la necrosis dependiente de IL-22 del intestino delgado durante la infección por Toxoplasma gondii [278]. De hecho, la asociación encontrada entre el parámetro $\alpha_{1(\text { SIGN) }}$ con estas citoquinas podría indicar un rol en la neuroinmunomodulación de la inflamación en el trabajo de parto.

El primer variado canónico $\left(U_{1}\right)$ para el conjunto de variables $X$ (citoquinas de la familia IL-10) contiene una carga canónica negativa grande de IL-22 y cargas canónicas negativas pequeñas de las demás citoquinas. Se puede decir que el variado canónico $\bigcup_{1}$ está compuesto en diferentes grados de las variables IL-22, IL-10, IL-28A e IL-20. Sin embargo, a partir de las cargas canónicas, se concluyó que la citoquina IL-22 explica casi en su totalidad al variado canónico $U_{1}$. 
En este caso en particular, la variable IL-22 en el conjunto $X$ tienen asociaciones

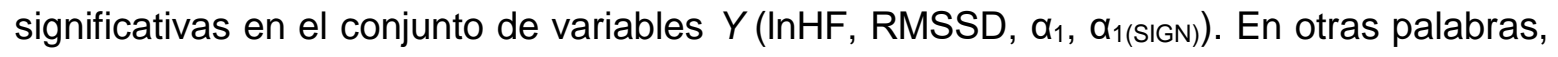
el conjunto de variables $Y$, es decir las FFC, se asocian mayoritariamente con la variable IL-22 del conjunto $X$. Se puede concluir que la disminución de IL-22 (-0.91) se vincula a un aumento significativo en los parámetros vagales InHF (0.72) y RMSSD (0.40). De manera global, se ajustó un modelo con una correlación canónica de $0.75, p<0.05$. Los resultados del análisis univariado y multivariado son interesantes, puesto que una relación inversa entre parámetros vagales como el InHF y la RMSSD con la citoquina proinflamatoria IL-22, apoyaría el papel de la actividad del nervio vago en la limitación y la prevención de reacciones inflamatorias excesivas durante el embarazo o el trabajo de parto. Sin embargo, estos resultados deben tomarse con precaución debido a problemas de multicolinealidad en las variables.

Es relevante indicar que debido a que el tercer trimestre de embarazo y el trabajo de parto son etapas que involucran procesos fisiológicos e inmunológicos distintos, como se mencionó en el Capítulo I sección 1.1., es de esperarse que las correlaciones entre los parámetros de las FFC e inmunológicos difieran entre ambas etapas. En particular el receptor tipo 1 (sTNF-R1) tuvo la correlación más alta en el tercer trimestre de embarazo (rho=0.77, $\mathrm{p}<0.05$ ), esta citoquina está asociada al TNF- $\alpha$ y se ha vinculado a enfermedades relacionadas con la edad y enfermedades cardiovasculares [279]. En ese estudio se encontró una correlación inversa entre el sTNF-R1 y el SDNN en pacientes que sobrevivieron a enfermedades cardiovasculares, lo que se atribuye como un hallazgo interesante para entender los mecanismos de regulación autonómica durante procesos inflamatorios [279]. Es de llamar la atención que en nuestro estudio también se haya encontrado una correlación significativa entre el sTNF-R1 y el SDNN, sin embargo los mecanismos fisiológicos e inmunológicos de esta y otras correlaciones se deben dilucidar para el tercer trimestre de embarazo.

En nuestro conocimiento, este es el primer estudio que explora las relaciones entre marcadores inflamatorios y parámetros lineales y no lineales de las FFC en el embarazo y el trabajo de parto. A diferencia de otros estudios en un contexto diferente al embarazo, aquí se examinó un panel más grande de marcadores inflamatorios [280]. En general, la consistencia de estos hallazgos a través de diversos marcadores inflamatorios fortalece aún más la participación de la vía colinérgica antiinflamatoria durante el trabajo de parto como una posible respuesta reguladora de la inflamación sistémica. 


\subsection{Conclusión}

En resumen, durante el trabajo de parto normal, confirmamos que la regulación cardíaca materna en el corto plazo muestra una dinámica no lineal concomitante que debe proporcionar capacidades estables y adaptativas [281]. Nuestros resultados sugieren que los valores menos anticorrelacionados en las FFC (indicado por valores elevados de

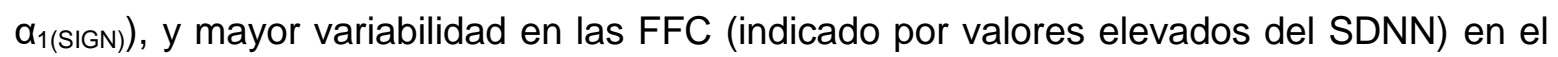
trabajo de parto, parecen reflejar una interacción distinta entre las ramas simpática y parasimpática del control autonómico cardiaco. Este comportamiento podría reflejarse como probables efectos dinámicos concomitantes durante el trabajo de parto. Otra posible explicación es que las contracciones uterinas hayan introducido no estacionalidad a las series de tiempo R-R y que este efecto se vea reflejado en el parámetro SDNN. Finalmente, el hallazgo de que diversas citoquinas, principalmente el SCD30 y los miembros de la familia de la IL-10 estén correlacionados con parámetros vagales de la FFC, sugiere un vínculo funcional entre la inflamación sistémica y la regulación autonómica el trabajo de parto. Estas asociaciones electrofisiológicas e inmunológicas se podrían manifestar como consecuencia de la posible respuesta colinérgica antiinflamatoria provocada por la inflamación sistémica durante el trabajo de parto. 


\section{Conclusiones generales}

1. De acuerdo con nuestro estudio anterior en mujeres durante el trabajo de parto [116] surgió la necesidad de validar si los parámetros lineales y no lineales del análisis de las FFC son sensibles para identificar procesos inflamatorios sistémicos. En el presente estudio, se proporciona evidencia acerca de la conveniencia de usar los parámetros de escalamiento fractal del análisis DFA para investigar un proceso inflamatorio sistémico, como lo es la bien caracterizada endotoxemia inducida por LPS. De manera interesante, estos parámetros parecen revelar respuestas autonómicas cardiacas asociadas a la inflamación y que los parámetros lineales de las FFC no identificaron. De nuestro modelo animal podemos resumir lo siguiente a partir de nuestros hallazgos: Encontramos que la endotoxemia inducida por LPS produjo que las FFC en el largo plazo se tornaran más

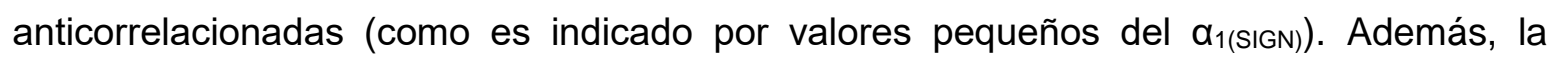
endotoxemia estuvo acompañada de taquicardia, taquipnea, pérdida de la dinámica fractal del ritmo cardiaco, disminución en parámetros espectrales de las FFC, baja variabilidad cardiaca, cambios en la temperatura periférica, y conducta letárgica. En contraste, la mayoría de estas manifestaciones fueron amortiguadas en las ratas a las que se les administró oxitocina, posiblemente como resultado de favorecer un acoplamiento autonómico colinérgico cardiorrespiratorio debido a la administración concomitante de oxitocina exógena durante la endotoxemia inducida por LPS.

2. Una vez identificado en nuestro modelo animal que los parámetros de las FFC fueron sensibles a un proceso inflamatorio, se analizaron longitudinalmente en un estudio clínico múltiples marcadores inflamatorios en suero materno el tercer trimestre de embarazo y en el trabajo de parto activo. Los resultados de este estudio sugieren que la reducción sistémica de algunos miembros de la familia de la IL-10 podrían desempeñar un rol importante, por un lado, en la activación de las células lisas miometriales asociadas con las contracciones uterinas, así como también en la promoción de un estado proinflamatorio durante el trabajo de parto activo. Interesantemente, nuestros resultados parecen coincidir con la bien documentada retirada funcional de la progesterona que ocurre durante el trabajo de parto. 
3. En paralelo a la toma de muestras sanguíneas de nuestro estudio clínico, se registraron electrocardiogramas de corta duración (10 minutos) para investigar la dinámica cardiaca en el tercer trimestre de embarazo y en el trabajo de parto activo. Nuestros resultados sugieren que, valores menos anticorrelacionados en las FFC (indicado por valores elevados de

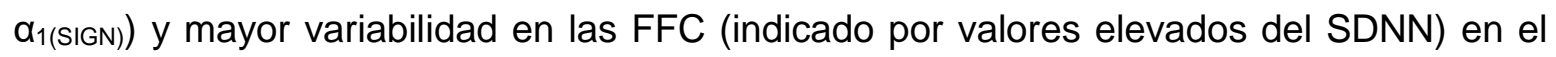
trabajo de parto parecen reflejar un cambio hacia una influencia concomitante de las ramas simpática y parasimpática del control autonómico cardiaco en comparación con el tercer trimestre de embarazo. Otra posible explicación es que las contracciones uterinas hayan introducido no estacionalidad a las series de tiempo $R-R$ y que este efecto se vea reflejado en el parámetro SDNN. De manera grupal los parámetros InVLF, SampEn y $\alpha_{2}$ parecen sensibles a la actividad uterina que se manifiesta en el trabajo el parto.

Por otro lado, se buscaron asociaciones entre parámetros de las FFC y marcadores inmunológicos, encontrándose que diversas citoquinas, principalmente el sCD30 y miembros de la familia de la IL-10 están correlacionadas con parámetros vagales de la FFC, este hallazgo refuerza la existencia de este vínculo funcional entre la inflamación sistémica y la regulación autonómica en el trabajo de parto. Estas asociaciones electrofisiológicas e inmunológicas se podrían manifestar como consecuencia de la posible respuesta colinérgica antiinflamatoria provocada por la inflamación sistémica durante el trabajo de parto. Con todos estos hallazgos, de manera general podemos identificar que el trabajo de parto es un proceso inflamatorio acompañado de una posible influencia antiinflamatoria concomitante simpática/parasimpática que podría perdurar hasta que la inflamación no se resuelva, es decir en el puerperio.

Una potencial aplicación de los parámetros de las FFC se muestra en el análisis de reconocimiento de patrones que se implementó en esta investigación, puesto que se identificó que los parámetros no lineales de las FFC tuvieron valores superiores de sensibilidad, especificidad y certeza para clasificar a los grupos de tercer trimestre de embarazo y de trabajo de parto en comparación con marcadores inmunológicos. Este tipo de herramientas de reconocimiento de patrones están siendo recientemente utilizadas para la clasificación automática de partos prematuros usando señales fisiológicas [282].

4. De manera global se puede concluir que el modelo de rata propuesto en este estudio dista de ser un modelo adecuado de inflamación sistémica del trabajo de parto, principalmente porque uno tiene un origen bacteriano (la endotoxemia inducida por LPS) en comparación con el otro escenario (el trabajo de parto a término y espontáneo), que 
probablemente tiene un origen estéril en el daño tisular. Es importante hacer hincapié que el propósito del modelo de ratas endotoxémicas permitió validar los parámetros de las FFC en un modelo bien caracterizado de inflamación, por lo que el objetivo de esta parte de la investigación no fue el de modelar el proceso inflamatorio del trabajo de parto. Sin embargo, si reflexionamos de manera conjunta en los hallazgos encontrados, es posible realizar una analogía entre el grupo de ratas que recibió oxitocina (LPS + Ox) y el grupo de mujeres en trabajo de parto, puesto que se notó que la frecuencia cardiaca disminuyó en el grupo de ratas de LPS + Ox vs. LPS y que la frecuencia cardiaca no aumentó durante el trabajo de parto vs. el tercer trimestre. Estos resultados parecen sugerir que la oxitocina también estaría ejerciendo efectos autonómicos cardiacos con influencias colinérgicas en el trabajo de parto como se observó en las ratas endotoxémicas (ambos considerados como escenarios de inflamación sistémica). De hecho, esto es consistente con el aumento en el parámetro de escalamiento $\alpha_{1(\mathrm{SIGN})}$ en el modelo animal (menor anticorrelación), y un aumento también en el $\alpha_{1(\text { SIGN) }}$ y el SDNN en el trabajo de parto.

Continuando con esta reflexión, de acuerdo con estudios realizados por Clodi et al. [113] se encontró que el tratamiento con oxitocina exógena no indujo diferencias significativas en la concentración de citoquinas liberadas en cultivos in vitro de monocitos no estimulados y estimulados con LPS, pero la concentración de citoquinas sí presentó cambios in vivo en un grupo de hombres sanos, concluyendo que la oxitocina es un neuromodulador que regula la liberación de citoquinas durante escenarios de inflamación sistémicos (endotoxemia) a través de la modulación de la vía colinérgica antiinflamatoria. Como se mencionó en los capítulos V y VI, la mitad de las participantes estudiadas durante el trabajo de parto fueron conducidas con oxitocina para favorecer la actividad uterina, sin embargo, en un análisis estadístico complementario no observamos diferencias significativas en los parámetros de las FFC e inflamatorios cuando se separaron los grupos de pacientes a las que se les administró oxitocina exógena durante el trabajo de parto $(n=10)$ y a las que no se les administró oxitocina $(n=10)$. Es natural preguntarse el porqué la oxitocina exógena sí tuvo efectos en los parámetros de las FFC en el modelo animal y porqué la administración o falta de administración de oxitocina no modificó las FFC de los grupos de trabajo de parto. Esta falta de cambios podría explicarse debido a que durante el trabajo de parto se libera naturalmente oxitocina endógena, de hecho, es sabido que durante el trabajo de parto los receptores de oxitocina endógena aumentan hasta 150 veces más que en el embarazo [114], en este sentido en ambos grupos de trabajo de parto circulaba oxitocina. Por otro lado, en el modelo de ratas se conocía la dosis exacta de oxitocina administrada, mientras 
que en el trabajo de parto no se conocía con exactitud ese dato, además la vía de administración de la oxitocina fue diferente en ambos escenarios, en el trabajo de parto por vía intravenosa y en el modelo animal por vía subcutánea, provocando diferentes tiempos de absorción y efectos.

Finalmente, el seguimiento de todos estos estudios individuales conllevó a la

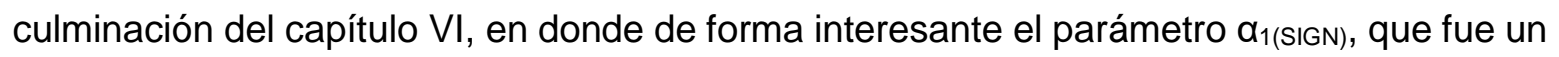
parámetro que presentó los cambios más significativos en presencia de LPS en el modelo animal, se correlacionó con diversos marcadores inflamatorios (35\%) del total de marcadores analizados. Estos hallazgos abren la puerta para seguir explorando la asociación de parámetros de las FFC con marcadores inflamatorios en diversos contextos clínicos y experimentales.

5. Como propuestas para trabajos a futuro se plantea realizarlos en dos contextos:

a) Modelo experimental en roedores:

-Probar si la oxitocina aplicada de manera central (i.e. intracerebroventricular) tiene los mismos efectos en las FFC, temperatura, respiración y letargia que en este estudio.

-Caracterizar los perfiles de citoquinas posterior a un tratamiento análogo al de este estudio. Se pretender observar si la oxitocina tuvo efecto en antiinflamatorio, así como en los niveles de ansiedad.

-Observar los efectos en las FFC posterior a la administración de un bloqueador colinérgico (atropina), junto con LPS y la mezcla de LPS y oxitocina.

-Observar el efecto de diversas dosis de oxitocina y otras rutas de administración.

-Realizar pruebas de coherencia entre los respirogramas estimados por EDR y las señales R-R, con la finalidad de observar si existe un acoplamiento cardiorrespiratorio.

b) Clínico:

-Aplicar a nuestras señales R-R diversas técnicas de análisis no lineal: análisis simbólico, gráficas de recurrencia, entropía cruzada, etc.

- Investigar la posible asociación entre la dinámica cardiaca y la uterina, posiblemente debido a un acoplamiento cardioelectrohisterográfico presente en el trabajo de parto. -Correlacionar los niveles de las citoquinas de este estudio con parámetros de las FFC fetales.

-Calcular las señales respiratorias a partir del ECG de las participantes y evaluar el acoplamiento cardiorrespiratorio durante el embarazo y el trabajo de parto. 
-Caracterizas los niveles de citoquinas y las FFC en el puerperio, así como en etapas tempranas del embarazo (primer y segundo trimestre).

-Repetir este análisis en las diferentes fases del trabajo de parto.

-Explorar en términos de las indagaciones del gasto energético planteadas en el Capítulo 1, sección 1.2, las diferencias entre el tercer trimestre de embarazo.

- Explorar el rol de la actividad uterina en la inducción de la inflamación durante el trabajo de parto.

-Caracterizar la microbiota vaginal en ambas etapas de la gestación, puesto que se actualmente se poseen dichas muestras de exudado vaginal.

- Cuantificar los niveles de oxitocina y progesterona en mujeres durante el trabajo de parto y correlacionarlos con parámetros inmunológicos e inflamatorios.

- Registrar a pacientes con partos prematuros e implementar otras técnicas de reconocimiento su identificación. 


\section{Apéndice A. Implantación dorsal de los transmisores telemétricos.}

\begin{tabular}{|l|l|l|l|}
\hline & Standard Operating Procedure & Procedure No: & 1 \\
$\begin{array}{l}\text { Casa abierta al tiempo } \\
\text { S: Universitätsklinikum Essen }\end{array}$ & & \\
\hline Title: & $\begin{array}{l}\text { Version No: } \\
\text { Issue date: }\end{array}$ & 1 \\
\cline { 2 - 4 } & Page: & 1 of 4 \\
\hline
\end{tabular}

\begin{tabular}{|cll|}
\hline J. Javier Reyes-Lagos & Gustavo Pacheco-López (UAM) & $\mathbf{2 4 . 0 9 . 1 4}$ \\
& Martin Hadamitzky (UKE) & Approved Date \\
\hline Prepared by & Approved By & . \\
\hline
\end{tabular}

\subsection{OBJECTIVE}

This document describes how to implant ETA-F20 transmitter (Data Sciences International) to Dark Agouti male rats.

2.0 SCOPE

This SOP applies to all researchers performing work within Institute of Behavioral Immunobiology and Medical Psychology at University of Duisburg-Essen and Metropolitan University (UAM).

\subsection{RESPONSIBILITIES}

This procedure may only be performed by personnel familiar with an animal license in rodents care, handling and surgery.

4.0 MATERIALS

- Alkaline proteases (Tergazyme 1\% solution)

-Isoflurane

-Oxygen bottles.

- Glutaraldehyde ( $2 \%$ solution)

- Gloves

- 5-0 Prolene sutures (Non-resorbable)

- Cotton swabs

- lodine (Betadine)

- Gauzes

- Sterile saline

- Analgesic treatment (Carprofen)

-Syringes (1 ml)

-Needles

-Ethanol 70\%

\subsection{EQUIPMENT}

-Magnet

-AM radio, frequency 530

- 2 pairs of sterilized forceps

- Scalpel

- Blunt-ended scissors 
-Small scissors

- Needle driver

- Hair shaver

- Scale

- ETA-F20 transmitter

-Anesthesia machine

-Sterilizer

-Thermal pad.

\subsection{PROCEDURE}

\section{Preparation of telemeter}

6.1. Before inserting an ECG telemeter into the rat, it is important to make sure the ECG telemeter is sterile and in good working order. ECG telemeters can be reused provided the device is cleaned using Tergazyme 1\% solution for at least 4 hours. You may rinse the telemeter with sterile water after cleaning with Tergazyme. Additionally, use Glutaraldehyde ( $2 \%$ solution) disinfectant overnight to sterilize the ECG telemeter. Be sure to wash disinfectant off with sterile water 48 hours before implantation into rats. Store in a sterile container.

6.2. Check the telemeter leads for integrity of both the conducting wires and the insulating sheath. Turn on the telemetry transmitter using a magnet waved within $5 \mathrm{~cm}$ of the telemeter, and test the signal with an AM radio, frequency $530 \mathrm{KHz}$. The signal should be strong and clear and should vary in intensity and pitch based on manipulation of the wires. Record the model number, the telemeter serial number, and the ECG calibration value.

6.3. Remove the insulating sheath to expose $7 \mathrm{~mm}$ of wire. Paint the end of the metal lead with sterile superglue, such as Vet-Bond, and then attach lead caps to the metal tips. These caps will avoid skin erosion due to lead placement. Approximately 2-3 $\mathrm{mm}$ metal wire should be exposed for electrical sensing of native heart rhythm.

\section{Surgical Implantation}

FIG 1

\subsection{Administer appropriate dose of anesthesia.}

6.5. Remove the body hair liberally from all intended incision sites using a gauze with ethanol ( $70 \%$ solution).

6.6. Position the animal in sternal recumbency on the surgery table and provide supplemental warmth (thermal pad) during the surgery.

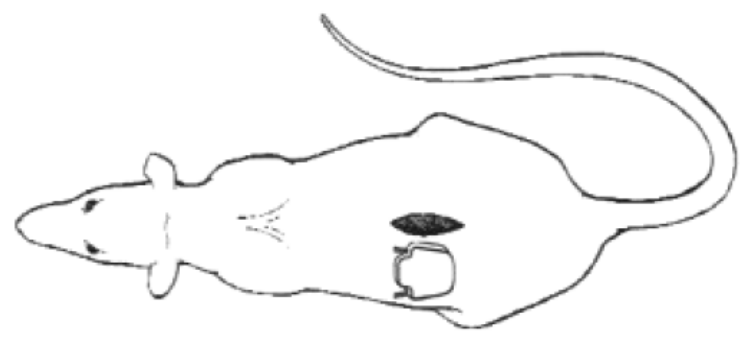
6.7. Apply subcutaneous Carprofen $5 \mathrm{mg} / \mathrm{kg}$ injection.

6.8. Clean with iodine the incision sites using a cotton swab.

6.9. Using a scalpel, make a $1.5-2.0 \mathrm{~cm}$ midline incision through the skin on the dorsal back, cranial to the hind limbs (FIG 1).

6.10. On one side of the incision, make a subcutaneous pocket along the dorsal flank by blunt dissection. Ensure the pocket size is adequate for the type of transmitter being implanted. Making the pocket too small will result in tissue necrosis.

6.11 Place the transmitter inside the pocket with the leads oriented cranially. Fix the transmitter with suture. 
6.12 Use a gauze to cover the transmitter and then position the animal in dorsal recumbency on the surgery table with the feet closest to the surgeon.

6.13 The ECG leads are placed in the lead conFiguration (FIG 2). The lead with the white/transparent sheath is positive, and is placed in the left upper abdomen. First, create a $0.5 \mathrm{~cm}$ skin incision in the rat's upper right chest. (FIGURE 2). Next, use the blunt scissors to create a tunnel back to the dorsal incision. Pull the lead through the tunnel and use a 5-0 Prolene suture to anchor the lead to the muscle.

6.14. Make sure the suture is on top of FIG 2 the exposed part of the lead, and creates a good contact between lead and underlying muscle.

6.15. Close the skin incision using the 50 Prolene suture.

6.16. The negative lead (red sheath) is placed in the left abdomen below the left diaphragm and below the heart.

6.17. Close the skin incision using the 50 Prolene suture.

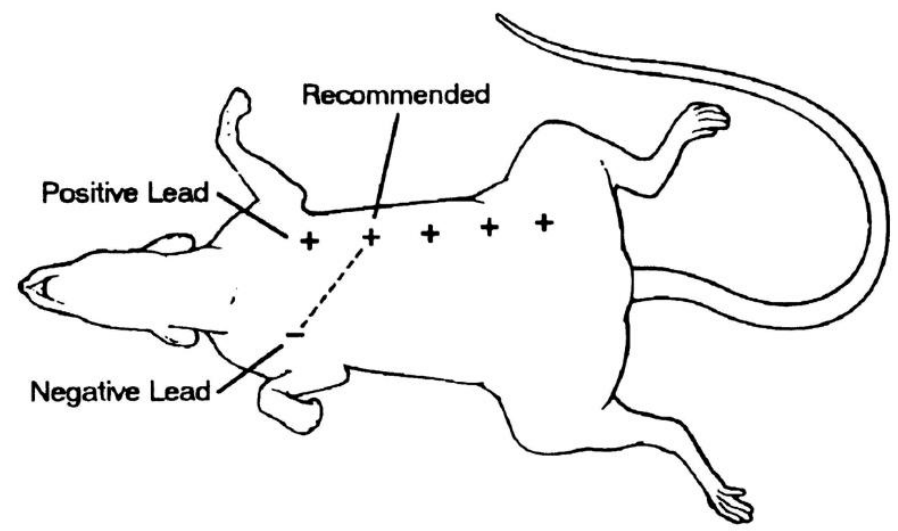

6.18. Position the animal in sternal recumbency again, take off the gauze and close the dorsal incision (put saline solution to keep moisture before).

6.19. Keep the animal warm while it recovers from the anesthetic.

6.20. Once fully conscious, house the animals individually after surgery.

6.21. Provide analgesic treatment (Carprofren $5 \mathrm{mg} / \mathrm{kg}$ ) again 24, 48 and $72 \mathrm{~h}$ post-surgery.

6.22. Wait 2 weeks for recovery. 


\section{SUPPORTING PICTURES}

\section{Material \& Equipment}
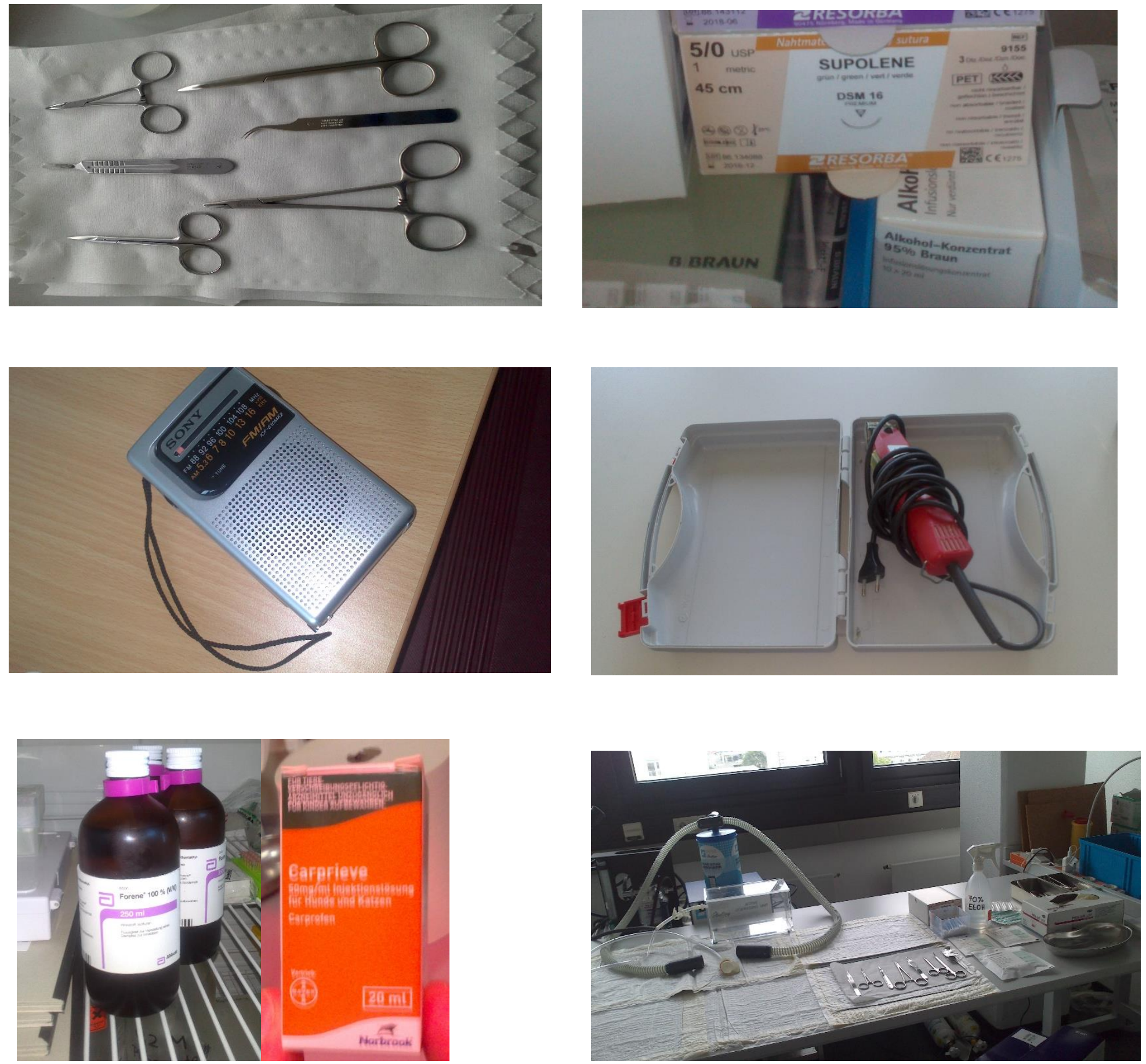
Step 6.4

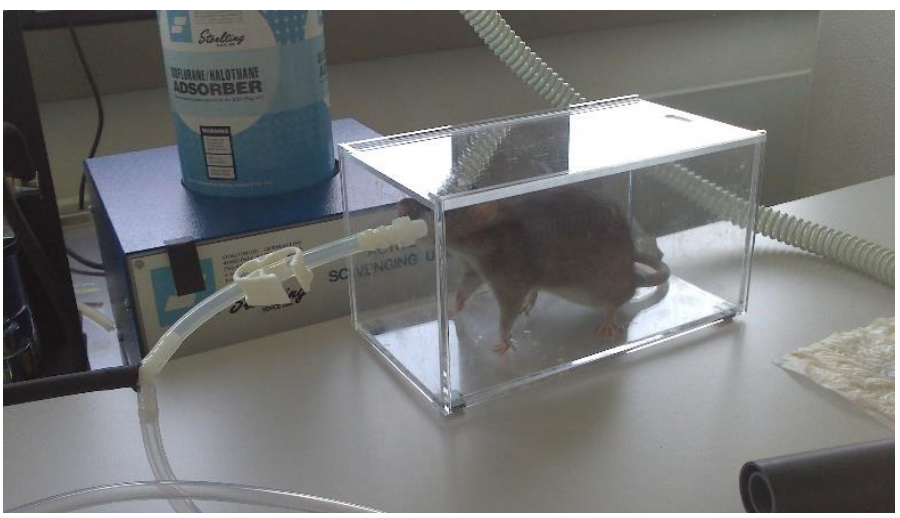

Step 6.5

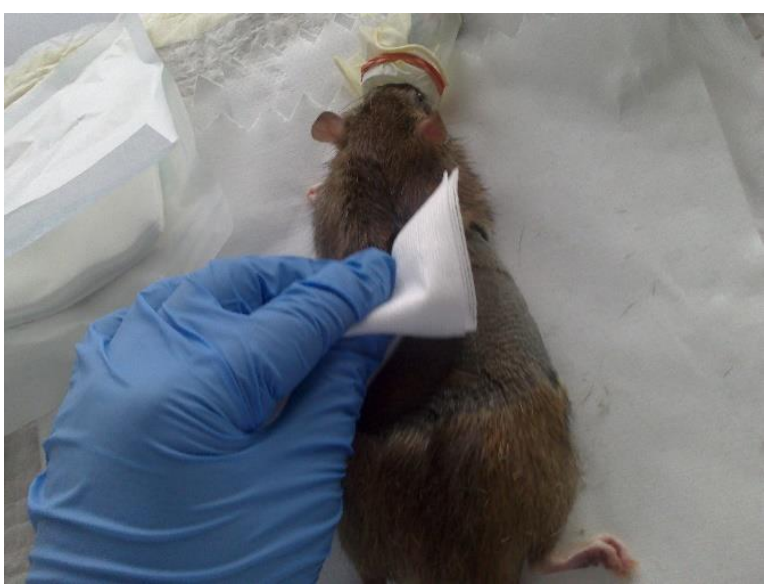

Step 6.5

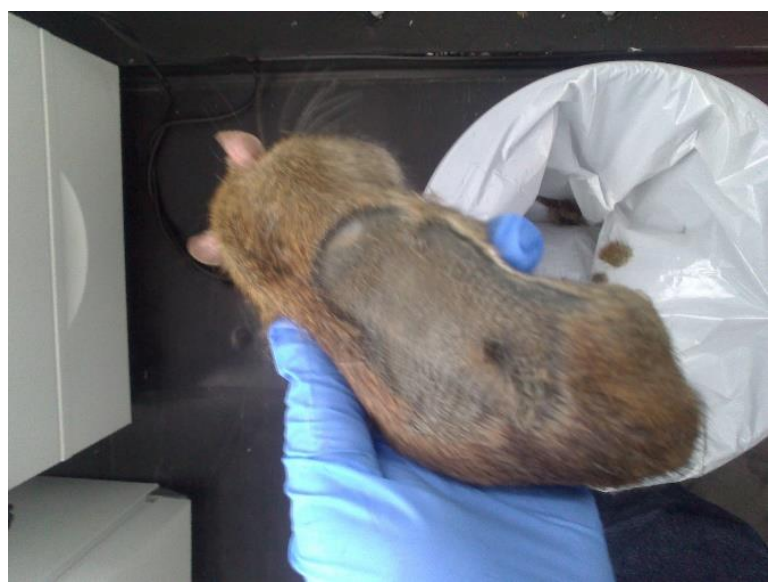

Step 6.8

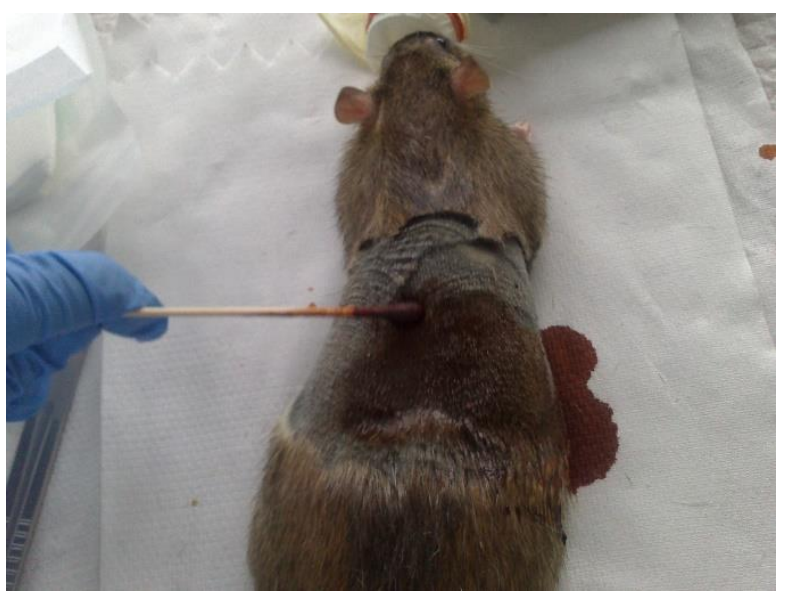

Step 6.9

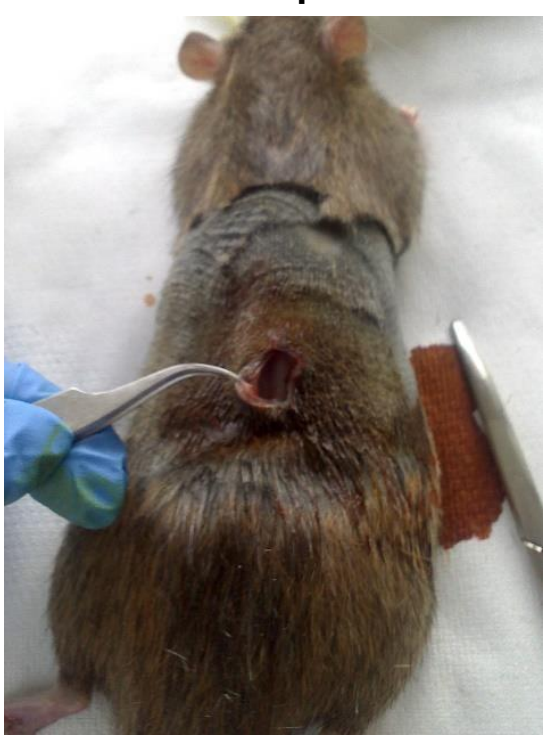

Step 6.10

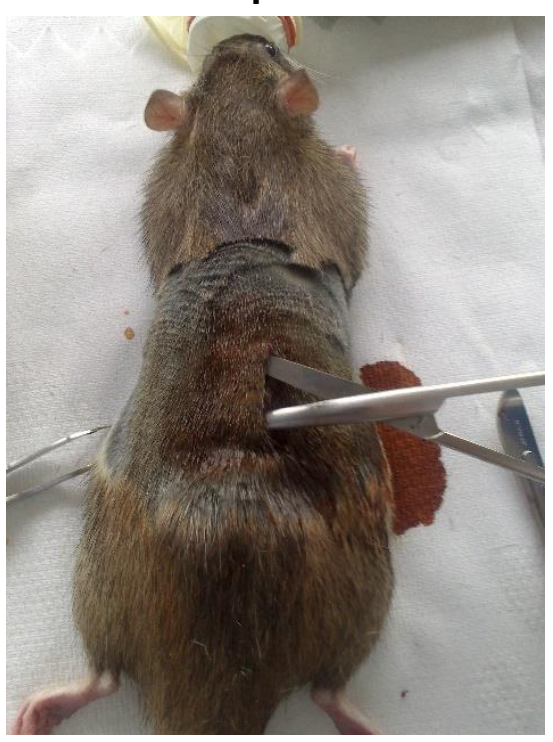

Step 6.11

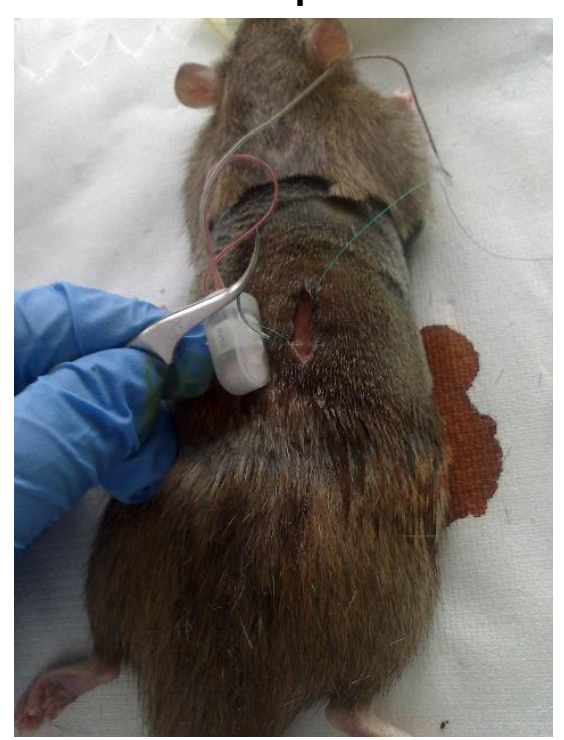


Step 6.12

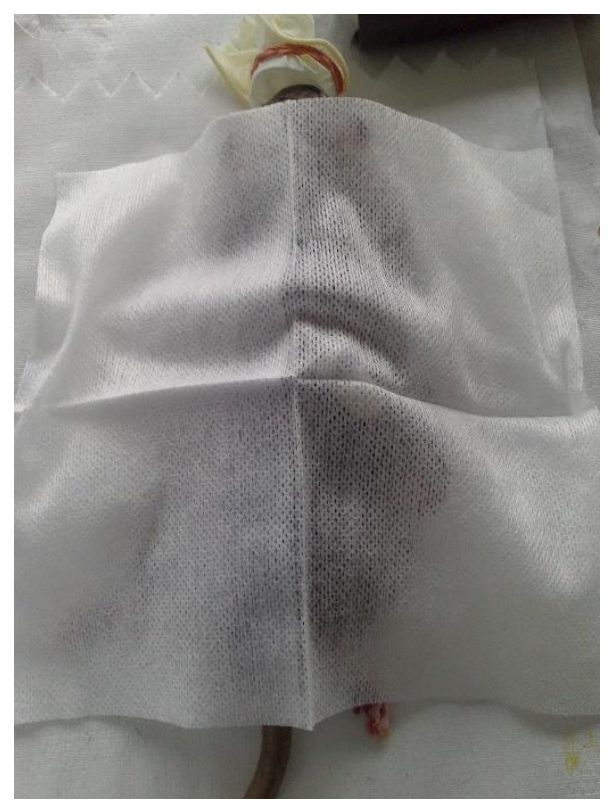

Step 6.14

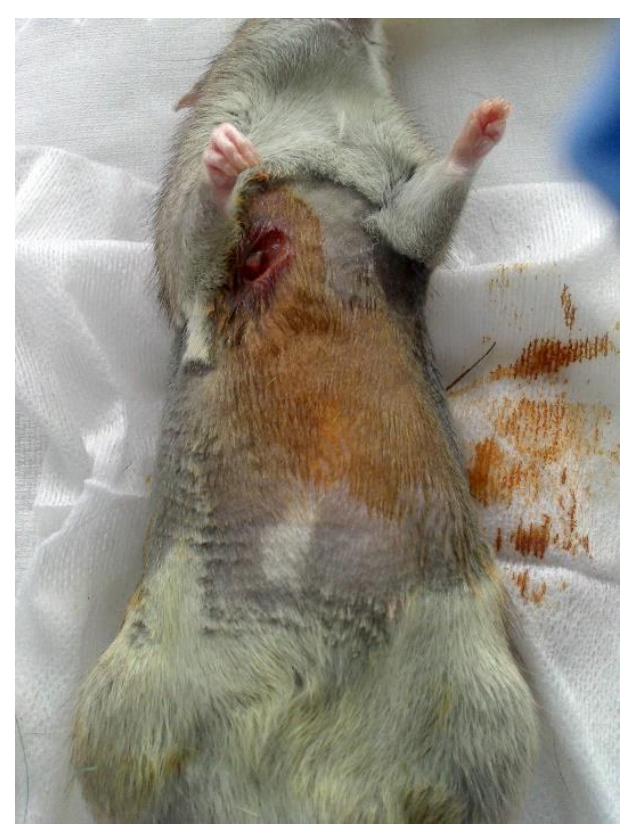

Step 6.12

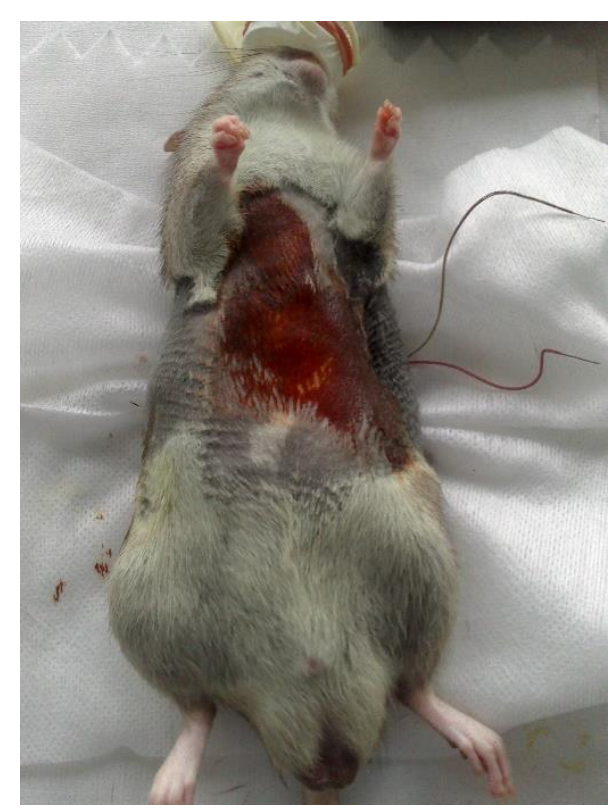

Step 6.15

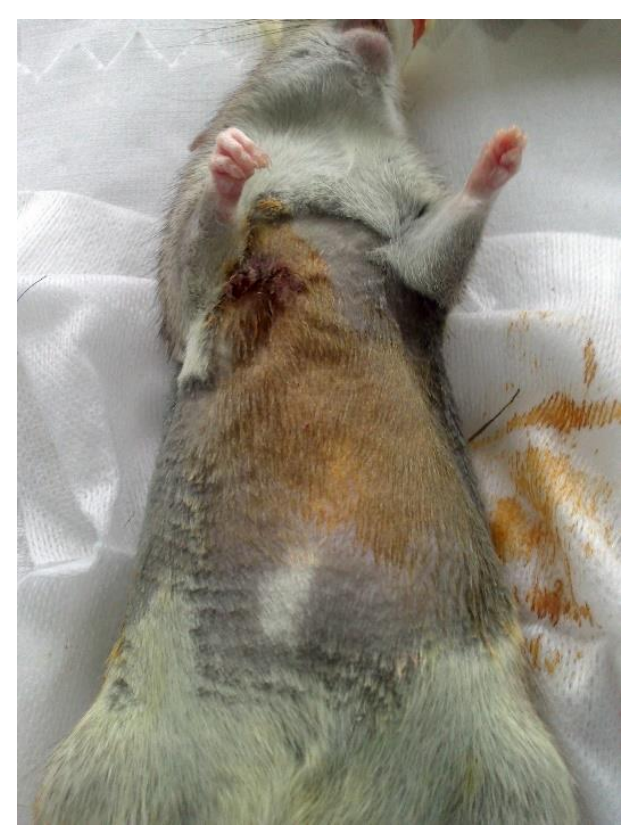

Step 6.13

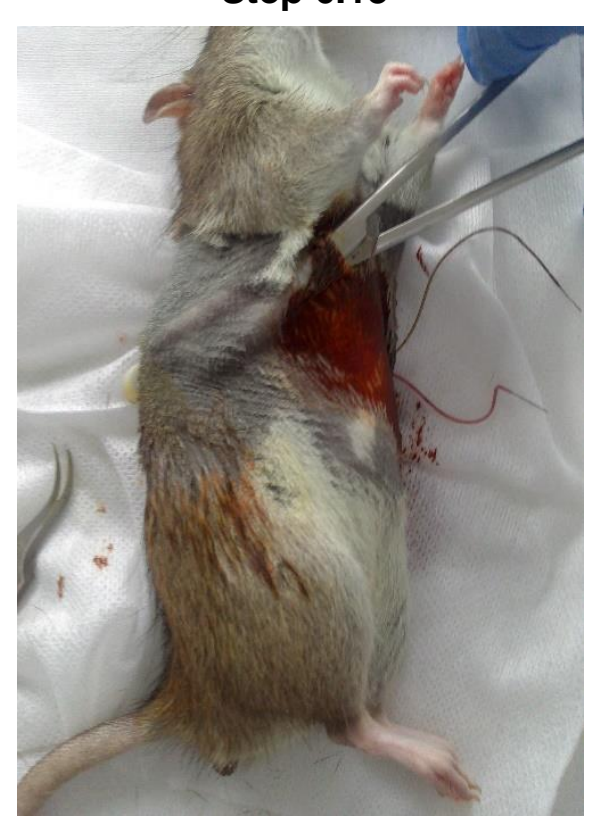

Step 6.16

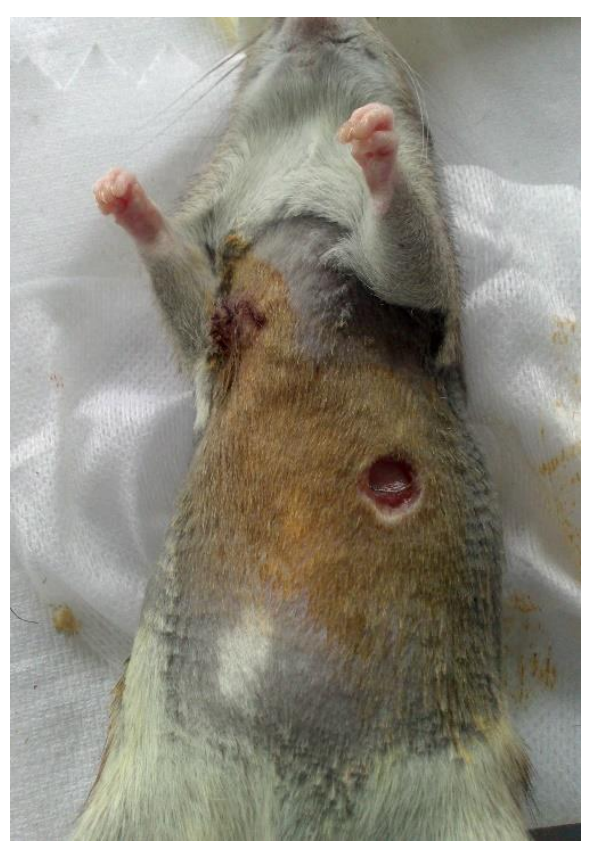



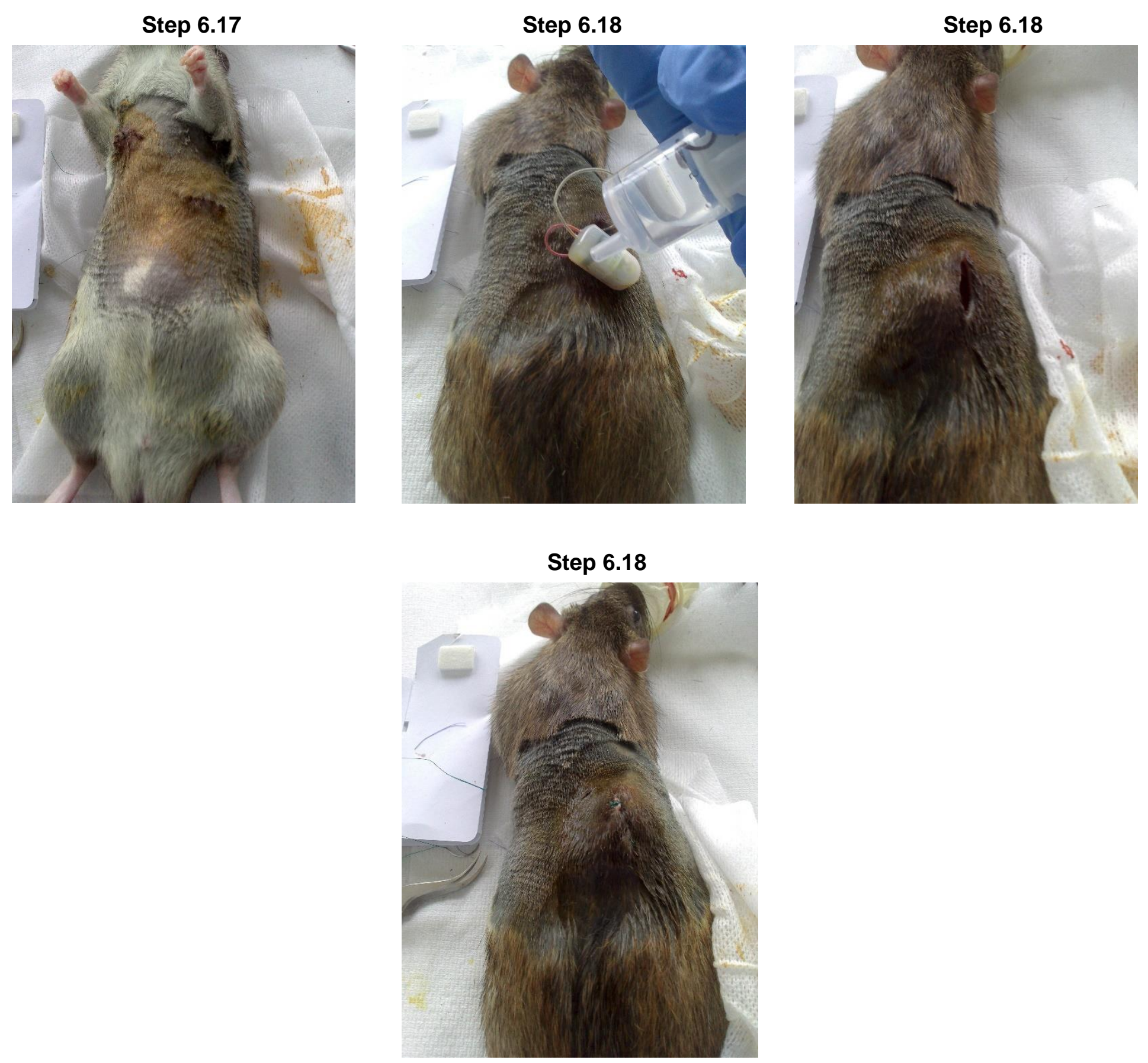


\title{
Apéndice B. Carta de consentimiento informado
}

\author{
CONSENTIMIENTO INFORMADO \\ Identificación de una respuesta inmune durante el trabajo de parto a través \\ del análisis de las fluctuaciones de la frecuencia cardiaca y la microbiota vaginal

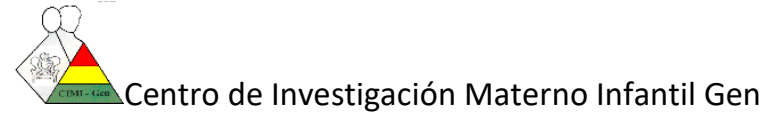 \\ QSi \\ Casa abierta a tiempo Universidad Autónoma Metropolitana
}

Por medio de la presente, nos permitimos invitarlas a participar en un estudio de investigación que se realiza en el Centro de Investigación Materno Infantil del Grupo de Estudios al Nacimiento (CIMIGen), en colaboración con la Universidad Autónoma Metropolitana, Unidades Iztapalapa y Lerma (UAM-I y UAML).

\section{¿Cuál es el objetivo del estudio?}

El presente estudio tiene por objetivo identificar una respuesta inmune durante el trabajo de parto a término y de bajo riesgo a través del análisis de la dinámica de los latidos de su corazón, buscando similitudes con marcadores inflamatorios y comunidades de bacterias (lactobacilos) que forman parte de su flora vaginal.

\section{¿Qué procedimientos involucra el estudio?}

1.- Documentar la edad de la madre, la fecha de la última menstruación, semanas de gestación, ganancia de peso óptima, índice de masa corporal normal antes del embarazo, dilatación y borramiento del cérvix (sólo para el caso del trabajo de parto).

2.-Documentar el peso al nacer de su bebé y la puntuación de APGAR posterior al nacimiento.

3.-Pesar, medir la talla y la presión arterial de la madre.

4.-Limpiar y exfoliar el abdomen materno con una gasa con alcohol.

5.-Colocar 5 sensores superficiales en el abdomen materno en el tercer trimestre de gestación y durante el trabajo de parto.

6.-Registrar la señal (actividad eléctrica) generada por el corazón materno durante el tercer trimestre de gestación y trabajo de parto.

7.- Realizar una punción venosa con una aguja pequeña para extraer una muestra de sangre durante el tercer trimestre y trabajo de parto.

8.-Tomar una muestra de flujo vaginal mediante un hisopo durante el tercer trimestre y el trabajo de parto.

\section{¿Cuánto tiempo dura el estudio?}

El estudio se dividirá en dos etapas: tercer trimestre y durante su trabajo de parto (siempre y cuando las condiciones lo permitan y no se interfiera en el curso normal del trabajo de parto). Los registros cardiacos durante el trabajo de parto y tercer trimestre durarán entre 30-60 minutos.

\section{¿Cuáles son los riesgos y beneficios del estudio?}

Este estudio de clasifica como de riesgo mínimo: algunos efectos colaterales que podría presentar debido a la colocación de los electrodos (sensores) involucran irritación de la piel. Respecto a la toma de muestras biológicas usted podría presentar hematomas, lesiones de nervio, infecciones, molestia o dolor pélvico, calambres y sangrado vaginal.

No será posible emitir ninguna conclusión individual al terminar la prueba realizada a cada voluntaria. La decisión de participar o no en el estudio es: completamente voluntaria, gratuita, e independiente de la atención médica que se le proporciona en el CIMIGEN. Al final del registro cardiaco se le proporcionará información de su frecuencia cardiaca materna y fetal (cuando sea posible). Es importante señalar que usted puede retirarse del estudio en cualquier momento si así lo desea y sin represalia alguna. 


\section{¿Mis datos personales estarán protegidos?}

Se garantiza que la información obtenida de estos estudios en ningún momento se usará en contra de las participantes, y que los datos derivados no podrán ser divulgados a personas no-médicas (tales como empleados y agentes de seguros) sin el consentimiento por escrito de la persona examinada. Los resultados obtenidos sólo se utilizarán para los fines de esta investigación y se darán a conocer en reuniones de tipo científico, respetando el anonimato de las participantes.

Para poder ser aceptadas en este estudio, deberán contestar las siguientes preguntas:

\begin{tabular}{|c|c|c|}
\hline & Sí & No \\
\hline $\begin{array}{l}\text { ¿Está(n) de acuerdo en que se le practiquen los estudios durante el tercer trimestre de } \\
\text { embarazo? }\end{array}$ & & \\
\hline ¿Está(n) de acuerdo en que se le practiquen los estudios durante el trabajo de parto? & & \\
\hline ¿Ha(n) entendido esta carta completamente y no tiene $(n)$ ninguna duda? & & \\
\hline $\begin{array}{l}\text { ¿Está(n) de acuerdo en que los datos recopilados de las evaluaciones de la madre y de su } \\
\text { hijo(a) sean utilizados con fines de investigación, conservando la confidencialidad y el } \\
\text { anonimato? }\end{array}$ & & \\
\hline
\end{tabular}

\section{Consentimiento}

Después de haber leído la información anterior y aclarando todas las dudas, he aceptado consciente y libremente ser estudiada y agrupada para los fines de investigación de la Universidad Autónoma Metropolitana Unidades Iztapalapa y Lerma y el CIMIGen.

CDMX. a de de 20

Nombre y firma de la participante

Nombre y firma del testigo $1^{\circ}$

Nombre y firma de testigo $2^{\circ}$ 


\section{Apéndice C. Toma de muestra sanguínea, centrifugación y conservación de las muestras}

\begin{tabular}{|c|c|c|c|}
\hline $\mathrm{Casa}_{\text {Cabierta al tiempo }}$ & $\begin{array}{l}\text { Procedimiento operativo estándar } \\
\text { (POE) }\end{array}$ & $\begin{array}{l}\text { Procedimiento } \\
\text { No: }\end{array}$ & 1 \\
\hline 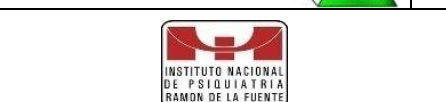 & $\mathrm{T}$ & $\begin{array}{l}\text { Versión No: } \\
\text { Fecha }\end{array}$ & $\begin{array}{l}1 \\
08.12 .2015\end{array}$ \\
\hline \multicolumn{2}{|c|}{$\begin{array}{l}\text { Título: Obtención, conservación y transporte de suero } \\
\text { sanguíneo para el análisis de citoquinas. }\end{array}$} & Páginas: & 1 de 2 \\
\hline \multirow[t]{4}{*}{ J. Javier Reyes Lagos } & \multicolumn{3}{|l|}{ Gustavo Pacheco López (UAM) } \\
\hline & \multicolumn{3}{|l|}{ Miguel A. Peña Castillo (UAM) } \\
\hline & \multicolumn{3}{|l|}{ Lenin Pavón (INPRF) } \\
\hline & \multicolumn{3}{|l|}{ Enrique Becerril (INPRF) } \\
\hline Preparado por: & Aprobador por: & \multicolumn{2}{|c|}{ Fecha de aprobación: } \\
\hline
\end{tabular}

\subsection{OBJETIVO}

Este documento describe como obtener una muestra de sangre periférica en el tercer trimestre de embarazo y durante el trabajo de parto a las pacientes del Centro de Investigación Materno Infantil del Grupo de estudios del nacimiento (CIMIGen).

\subsection{ALCANCE}

Este POE se aplica a todos los investigadores adscritos al laboratorio en ingeniería en fenómenos fisiológicos perinatales de la UAM-I, tanto como al personal médico, de enfermería y de laboratorio del CIMIGen, así como a los miembros del laboratorio de psicoinmunología del Instituto Nacional de Psiquiatría "Ramón de la Fuente".

\subsection{RESPONSABILIDAD}

El procedimiento de obtención de muestra sanguínea periférica sólo podrá ser realizado por el personal de enfermería y de laboratorio clínico debidamente capacitado.

4.0 MATERIALES

-Tubo BD Vacutainer® No. Cat. 36798.

-Aguja

-Algodón

-Curita

-Alcohol

-Tubos Eppendorf de $250 \mu \mathrm{l}$

-Tubos Eppendorf de $500 \mu \mathrm{l}$.

\subsection{EQUIPO}

-Hielera

-Refrigerador

-Ultracongelador 


\subsection{PROCEDIMIENTO}

1. La obtención de la muestra será a partir de sangre periférica, se realizará por punción venosa humeral en el antebrazo por el personal capacitado de laboratorio clínico o licenciadas en enfermería obstétrica del CIMIGen.

2. Al palpar hágalo con la punta de sus dedos, tratando de seguir el rastro de las venas. En ocasiones si no visualiza la vena, puede forzar la sangre dentro de la vena a través de un suave masaje de abajo hacia arriba.

3.-Una vez que se ha decidido por la vena a puncionar, debe proceder a descontaminar el área con alcohol etílico o isopropílico al $70 \%$ utilizando algodón y con movimientos circulares del interior al exterior.

4.- Inserte la jeringa y colecte $8.5 \mathrm{~mL}$ de sangre venosa utilizando 1 tubo con activador de coágulo y gel separador (BD Vacutainer ${ }^{\circledR}$ No. Cat. 367988). Coloque una curita o algodón en el antebrazo del paciente.

5.- Coloque en refrigeración $\left(4^{\circ} \mathrm{C}\right)$ la muestra mientras se realizan otros procedimientos en el CIMIGen (registro electrocardiográfico y reclutamiento de pacientes, no exceder más de 6 horas).

6.- Extraiga el tubo del refrigerado y centrifugue a $1125 \mathrm{x} \mathrm{g} \mathrm{(2500} \mathrm{rpm)} \mathrm{por} 15$ minutos.

7.- Divida el suero en 10 alícuotas de $100 \mu \mathrm{L}$ cada una

8.- Colecte el suero restante en tubos de $500 \mu \mathrm{L}$.

9.-Transporte inmediatamente los tubos en una hielera con placas de hielo a un ultracongelador.

10.- Las muestras se congelarán a $-80^{\circ} \mathrm{C}$ para su posterior uso (no exceder 1 año). 


\section{Apéndice D. Análisis estadísticos complementarios}

Tabla 1. Valores promedio $( \pm D E)$ de las características demográficas de la población en el tercer trimestre de embarazo de los grupos que les fue administrada oxitocina durante el trabajo de parto.

\begin{tabular}{lrr}
\hline \multicolumn{1}{c}{ Parámetro } & $\begin{array}{c}\text { Oxitocina } \\
\mathbf{n = 1 0}\end{array}$ & $\begin{array}{c}\text { Sin oxitocina } \\
\mathbf{n = 1 0}\end{array}$ \\
\hline \hline Edad (años) & $23.5 \pm 4.5$ & $24.4 \pm 5.2$ \\
Peso actual (kg) & $67.8 \pm 10.8$ & $71.5 \pm 14.9$ \\
Ganancia de peso en el embarazo $(\mathrm{kg})$ & $11.3 \pm 1.14$ & $11.7 \pm 1.33$ \\
Talla $(\mathrm{m})$ & $1.60 \pm 0.05$ & $1.59 \pm 0.06$ \\
IMC $\left(\mathrm{kg} / \mathrm{m}^{2}\right)$ & $26.29 \pm 3.52$ & $28.39 \pm 4.82$ \\
Edad gestacional (semanas) & $35.6 \pm 1.8$ & $36.9 \pm 0.9$ \\
Cintura (cm) & $99.7 \pm 7.5$ & $103.5 \pm 7.9$ \\
Cadera (cm) & $103.4 \pm 7.8$ & $108.62 \pm 10.9$ \\
Gestas previas & $0.8 \pm 0.7$ & $0.9 \pm 0.5$ \\
Presión sistólica (mmHg) & $91.6 \pm 8.6$ & $106.6 \pm 10.1$ \\
Presión diastólica (mmHg) & $59.7 \pm 5.0$ & $65.4 \pm 8.8$ \\
Nivel de hemoglobina (g/dL) & $11.9 \pm 1.2$ & $11.9 \pm 1.3$ \\
Test de ansiedad BAl (puntos) & $12.2 \pm 5.8$ & $10.2 \pm 4.2$ \\
\hline
\end{tabular}

Tabla 2. Valores promedio $( \pm D E)$ de las características demográficas de la población en el trabajo de parto de los grupos con Oxitocina y Sin Oxitocina así como datos del neonato.

\begin{tabular}{lrr}
\hline \multicolumn{1}{c}{ Parámetro } & $\begin{array}{c}\text { Oxitocina } \\
\mathbf{n = 1 0}\end{array}$ & \multicolumn{2}{c}{$\begin{array}{c}\text { Sin oxitocina } \\
\mathbf{n = 1 0}\end{array}$} \\
\hline Edad gestacional & $40.3 \pm 0.65$ & $39.3 \pm 0.88$ \\
Dilatación cervical $(\mathrm{cm})$ & $4.7 \pm 2.2$ & $5.5 \pm 1.45$ \\
Borramiento (\%) & $70 \pm 16$ & $69 \pm 15$ \\
Cantidad de oxitocina $(\mathrm{mU})$ & $8.3 \pm 5.2$ & $0.0 \pm 0.0$ \\
Presión sistólica (mmHg) & $107 \pm 5$ & $110 \pm 6$ \\
Presión diastólica (mmHg) & $69 \pm 6$ & $73 \pm 6$ \\
APGAR de 1 minuto (puntos) & $7.9 \pm 0.3$ & $8.1 \pm 0.8$ \\
APGAR de 5 minutos (puntos) & $9.0 \pm 0.0$ & $8.8 \pm 0.4$ \\
Peso al nacer $(\mathrm{g})$ & $3263 \pm 230$ & $3362 \pm 362$ \\
Talla del neonato (cm) & $50.8 \pm 1.5$ & $49.9 \pm 1.3$ \\
Perímetro cefálico (cm) & $33.3 \pm 1.2$ & $34 \pm 1.3$ \\
Cesáreas & $6 / 10$ & $1 / 10$ \\
Malformaciones congénitas & 0 & 0 \\
\hline
\end{tabular}


Tabla 3. Valores promedio ( $\pm E E$ ) de las concentraciones de citoquinas de nuestro estudio para los grupos de tercer trimestre de embarazo y trabajo de parto considerando la administración de oxitocina.

\begin{tabular}{|c|c|c|c|c|c|}
\hline \multirow{3}{*}{ Citoquina } & \multicolumn{4}{|c|}{ Niveles de citoquinas ( $\mathrm{pg} / \mathrm{mL} \pm \mathrm{SEM}$ ) durante los siguientes estados: } & \multirow{3}{*}{$\begin{array}{l}\text { Rango de } \\
\text { trabajo del } \\
\text { ensayo }\end{array}$} \\
\hline & \multicolumn{2}{|c|}{ Oxitocina } & \multicolumn{2}{|c|}{ Sin oxitocina } & \\
\hline & Embarazo & $\begin{array}{c}\text { Trabajo de } \\
\text { parto }\end{array}$ & Embarazo & $\begin{array}{c}\text { Trabajo de } \\
\text { parto }\end{array}$ & \\
\hline APRIL/TNFSF13 & $430.50 \pm 82.62$ & $354 \pm 88.32$ & $446.16 \pm 95.40$ & $493.61 \pm 88.32$ & $30.04-123027.00$ \\
\hline BAFF/TNFSF13B & $921.19 \pm 75.79$ & $719.10 \pm 75.79$ & $680.98 \pm 75.79$ & $791.14 \pm 75.79$ & $0.81-3337.00$ \\
\hline SCD30/TNFRSF8 & $64.9 \pm 14.00$ & $57.23 \pm 13.28$ & $44.01 \pm 14.00$ & $47.43 \pm 14.00$ & $0.06-244.94$ \\
\hline SCD163 & $4605 \pm 987.24$ & $3074.81 \pm 825.99$ & $3994.93 \pm 825.99$ & $4430.68 \pm 825.99$ & $3.06-12529.39$ \\
\hline Chitinase-3-like1 & $897.08 \pm 0.00$ & $1346.51 \pm 0.00$ & $1044.7 \pm 0.00$ & $1193.07 \pm 0.00$ & $0.4-1643.92$ \\
\hline gp130/sIL-6R $\beta$ & OOR & OOR & OOR & OOR & $0.83-3391.66$ \\
\hline IFN- $\alpha 2$ & $0.85 \pm 0.15$ & $0.72 \pm 0.15$ & $0 . .61 \pm 0.15$ & $0.89 \pm 0.15$ & $0.05-212.16$ \\
\hline IFN- $\beta$ & $9.18 \pm 1.15$ & $6.52 \pm 1.02$ & $7.61 \pm 1.08$ & $7.32 \pm 1.02$ & $0.01-22.39$ \\
\hline IFN-y & $1.38 \pm 0.07^{\star}$ & $1.05 \pm 0.07$ & $0.82 \pm 0.08$ & $0.9 \pm 0.07$ & $0.03-132.81$ \\
\hline IL-2 & OOR & OOR & OOR & OOR & $0.02-90.50$ \\
\hline sIL-6Ra & OOR & OOR & OOR & OOR & $0.22-919.27$ \\
\hline IL-8 & $0.37 \pm 0.09$ & $0.20 \pm 0.09$ & $0.20 \pm 0.09$ & $0.17 \pm 0.08$ & $0.03-139.66$ \\
\hline IL-10 & $0.29 \pm 0.02$ & $0.22 \pm 0.02$ & $0.21 \pm 0.03$ & $0.14 \pm 0.02$ & $0.01-44.91$ \\
\hline IL-11 & $0.15 \pm 0.03$ & $0.14 \pm 0.03$ & $0.08 \pm 0.03$ & $0.16 \pm 0.03$ & $0.00-5.42$ \\
\hline IL-12(p40) & $1.89 \pm 0.31$ & $0.70 \pm 0.44$ & $0.99 \pm 0.31$ & $1.06 \pm 0.36$ & $0.05-205.95$ \\
\hline IL-12(p70) & $0.02 \pm 0.00$ & $0.02 \pm 0.00$ & $0.01 \pm 0.00$ & $0.01 \pm 0.00$ & $0.00-12.61$ \\
\hline IL-19 & $0.25 \pm 0.38$ & $0.12 \pm 0.41$ & $0.10 \pm 0.38$ & $0.87 \pm 0.41$ & $0.03-104.23$ \\
\hline IL-20 & $1.39 \pm 0.26$ & $0.39 \pm 0.26$ & $0.75 \pm 0.30$ & $0.54 \pm 0.26$ & $0.06-260.30$ \\
\hline IL-22 & $0.83 \pm 0.19$ & $0.21 \pm 0.21$ & $0.44 \pm 0.21$ & $0.27 \pm 0.18$ & $0.03-128.73$ \\
\hline IL-26 & $1.14 \pm 0.61$ & $0.34 \pm 0.53$ & $0.80 \pm 0.75$ & $0.24 \pm 0.61$ & $0.02-73.11$ \\
\hline IL-27(p28) & OOR & OOR & OOR & OOR & $0.03-134.91$ \\
\hline IL-28A/IFN- $\lambda 2$ & $1.77 \pm 0.13$ & $1.20 \pm 0.13$ & $1.13 \pm 0.13$ & $1.04 \pm 0.13$ & $0.05-200.38$ \\
\hline IL-29/IFN- $\lambda 1$ & $1.81 \pm 0.00$ & $0.26 \pm 0.00$ & $0.67 \pm 0.00$ & $0.44 \pm 0.00$ & $0.09-350.48$ \\
\hline IL-32 & $1.73 \pm 0.16$ & $0.47 \pm 0.17$ & $1.05 \pm 0.20$ & $0.21 \pm 0.23$ & $0.04-177.64$ \\
\hline IL-34 & OOR & OOR & OOR & OOR & $0.25-1020.42$ \\
\hline IL-35 & $2.96 \pm 2.42$ & $1.15 \pm 2.42$ & $1.78 \pm 2.55$ & $6.93 \pm 2.55$ & $0.14-576.91$ \\
\hline LIGHT/TNFSF14 & OOR & OOR & OOR & OOR & $0.03-139$ \\
\hline MMP-1 & $27.68 \pm 6.17$ & $15.74 \pm 6.67$ & $16.33 \pm 6.67$ & $17.47 \pm 6.17$ & $1.21-4975.66$ \\
\hline MMP-2 & $91.71 \pm 0.00$ & $0.07 \pm 0.00$ & $351.28 \pm 0.00$ & $0.07 \pm 0.00$ & $0.59-2410.50$ \\
\hline MMP-3 & $23.77 \pm 1.73^{\star}$ & $17.32 \pm 1.73$ & $16.34 \pm 1.83$ & $17.52 \pm 1.73$ & $1.36-5582.16$ \\
\hline Osteocalcin & $333.27 \pm 52.02$ & $235.63 \pm 52.02$ & $235.04 \pm 52.02$ & $166.68 \pm 52.02$ & $0.49-1989.11$ \\
\hline Osteopontin & OOR & OOR & OOR & OOR & $1.15-4717.8$ \\
\hline Pentraxin-3 & $45.87 \pm 8.84$ & $11.73 \pm 8.39$ & $19.29 \pm 8.39$ & $19.72 \pm 8.39$ & $0.08-335.38$ \\
\hline sTNF-R1 & $78.55 \pm 13.51$ & $49.99 \pm 12.09+$ & $54.35 \pm 12.74^{\star}$ & $95.97 \pm 12.09$ & $0.21-873.63$ \\
\hline sTNF-R2 & $288.29 \pm 0.00$ & $636.24 \pm 0.00$ & $93.13 \pm 0.00$ & $558.58 \pm 0.00$ & $0.25-1008.16$ \\
\hline TSLP & $1.63 \pm 0.15$ & $1.18 \pm 0.15$ & $0.89 \pm 0.15$ & $0.92 \pm 0.15$ & $0.01-46.25$ \\
\hline TWEAK/TNFSF12 & $25.51 \pm 6.82$ & $0.12 \pm 8.36$ & $15.92 \pm 7.47$ & $0.22 \pm 6.32$ & $0.04-158.91$ \\
\hline
\end{tabular}

* $\mathrm{p}<0.05$ entre tercer trimestre de embarazo y trabajo de parto con oxitocina o entre embarazo y trabajo de parto sin oxitocina de acuerdo con prueba post-hoc LSD de Fisher. $+p<0.05$ entre trabajo de parto sin oxitocina y trabajo de parto con oxitocina. OOR (out of range o fuera de rango) 
Tabla 4. Valores promedio $( \pm D E)$ de los parámetros de las fluctuaciones de la frecuencia cardiaca (VFC) de nuestro estudio $(n=20)$ para los grupos de tercer trimestre de embarazo y trabajo de parto bajo la aplicación de oxitocina y sin oxitocina exógena.

\begin{tabular}{lrrrr}
\hline \multirow{2}{*}{ Parámetro } & \multicolumn{2}{c}{ Oxitocina $(\mathbf{n}=\mathbf{1 0})$} & \multicolumn{2}{c}{ Sin oxitocina $(\mathbf{n}=10)$} \\
\cline { 2 - 5 } & Tercer trimestre & Trabajo de parto & Tercer Trimestre & Trabajo de parto \\
\hline \hline$\alpha_{1}$ & $1.10 \pm 0.28$ & $1.20 \pm 0.25$ & $1.07 \pm 0.16$ & $1.27 \pm 0.15$ \\
$\alpha_{2}$ & $1.03 \pm 0.25$ & $1.19 \pm 0.08$ & $0.99 \pm 0.13$ & $1.14 \pm 0.14$ \\
$\alpha_{1 \mathrm{mag}}$ & $0.76 \pm 0.09$ & $0.77 \pm 0.14$ & $0.70 \pm 0.16$ & $0.77 \pm 0.19$ \\
$\alpha_{1 \text { (SIGN) }}$ & $0.33 \pm 0.13$ & $0.42 \pm 0.10$ & $0.30 \pm 0.08$ & $0.43 \pm 0.10$ \\
HR (LPM) & $90.3 \pm 8.7$ & $92.2 \pm 11.4$ & $87.2 \pm 9.2$ & $94.5 \pm 12.0$ \\
SDNN (ms) & $52.38 \pm 16.71$ & $76.28 \pm 23.89$ & $52.27 \pm 17.30$ & $58.39 \pm 15.12$ \\
RMSSD (ms) & $32.42 \pm 18.71$ & $34.21 \pm 15.37$ & $32.62 \pm 12.58$ & $25.00 \pm 6.42$ \\
PNN50 (\%) & $14.34 \pm 16.70$ & $13.35 \pm 12.12$ & $13.10 \pm 10.37$ & $6.18 \pm 4.22$ \\
InVLF & $7.18 \pm 0.89$ & $8.08 \pm 0.70$ & $7.12 \pm 0.74$ & $7.66 \pm 0.62$ \\
LnLF & $6.05 \pm 0.77$ & $6.40 \pm 0.74$ & $6.09 \pm 0.60$ & $6.20 \pm 0.49$ \\
LnHF & $5.50 \pm 1.48$ & $5.81 \pm 0.94$ & $5.81 \pm 0.96$ & $5.56 \pm 0.60$ \\
LF/HF & $2.52 \pm 2.11$ & $2.06 \pm 1.03$ & $1.51 \pm 0.80$ & $2.02 \pm 0.82$ \\
SampEn & $1.25 \pm 0.41$ & $1.05 \pm 0.27$ & $1.43 \pm 0.32$ & $1.02 \pm 0.28$ \\
\hline
\end{tabular}

ANOVA para muestras repetidas (sin diferencias significativas).

Tabla 5. Análisis de correlación lineal entre las citoquinas y los parámetros de las fluctuaciones de la frecuencia cardiaca a partir del promedio de datos del tercer trimestre de embarazo y trabajo de parto $(\mathrm{N}=20)$.

\begin{tabular}{|c|c|c|c|c|c|c|c|c|c|c|c|c|c|}
\hline & & & & & & Coefic & nte de co & elación & earson & & & & \\
\hline & $\alpha_{1}$ & $\alpha_{2}$ & $\alpha_{1 \mathrm{mag}}$ & $\alpha_{1(\mathrm{SIGN})}$ & HR & SDNN & RMSSD & PNN50 & InVLF & InLF & InHF & LF/HF & $\begin{array}{c}\text { SampE } \\
n\end{array}$ \\
\hline APRIL/TNFSF13 & - & - & - & -0.28 & -0.22 & -0.20 & -0.02 & - & -0.21 & -0.13 & 0.06 & -0.21 & 0.33 \\
\hline $\mathrm{BAFF/TNFSF13B}$ & - & - & - & 0.01 & 0.42 & -0.10 & - & - & - & -0.47 & 0.34 & - & -0.32 \\
\hline sCD30/TNFRSF8 & -0.55 & 0.06 & - & -0.51 & -0.20 & 0.37 & 0.60 & 0.64 & 0.23 & 0.17 & 0.45 & - & 0.23 \\
\hline sCD163 & - & 0.60 & - & -0.12 & -0.09 & 0.00 & -0.08 & - & 0.09 & -0.42 & -0.19 & - & - \\
\hline IFN- $\alpha 2$ & - & 0.21 & - & -0.43 & -0.11 & 0.08 & 0.15 & - & 0.08 & -0.19 & 0.11 & -0.35 & 0.07 \\
\hline IFN- $\beta$ & 0.24 & - & - & 0.08 & 0.21 & 0.11 & -0.23 & -0.24 & 0.21 & -0.21 & -0.20 & 0.10 & -0.43 \\
\hline IFN-gamma & - & 0.58 & - & -0.15 & 0.20 & 0.34 & 0.04 & - & 0.40 & -0.06 & 0.10 & -0.25 & -0.31 \\
\hline IL-10 & - & - & - & 0.06 & 0.00 & 0.21 & 0.13 & - & 0.12 & 0.24 & 0.16 & -0.01 & -0.19 \\
\hline IL-20 & - & - & - & -0.09 & 0.07 & 0.31 & - & - & 0.19 & - & 0.26 & -0.25 & -0.14 \\
\hline IL-22 & - & - & -0.55 & 0.05 & -0.07 & -0.40 & -0.29 & -0.28 & - & -0.39 & -0.49 & 0.58 & -0.03 \\
\hline IL-28A/IFN-2 & -0.29 & 0.31 & - & -0.21 & -0.02 & - & 0.20 & 0.24 & 0.09 & -0.15 & -0.07 & -0.15 & -0.01 \\
\hline IL-35 & - & -0.21 & - & -0.28 & -0.18 & 0.03 & 0.10 & - & 0.03 & 0.06 & 0.22 & -0.28 & 0.23 \\
\hline MMP-3 & - & 0.37 & - & -0.15 & 0.12 & -0.17 & -0.11 & - & -0.16 & -0.50 & -0.20 & -0.07 & -0.06 \\
\hline
\end{tabular}




\begin{tabular}{|c|c|c|c|c|c|c|c|c|c|c|c|c|c|}
\hline Osteocalcina & - & - & - & -0.03 & 0.30 & -0.21 & -0.12 & - & - & -0.42 & -0.41 & - & -0.25 \\
\hline Pentraxina-3 & 0.00 & - & - & -0.23 & 0.25 & 0.38 & 0.06 & - & 0.41 & -0.07 & 0.11 & -0.26 & -0.28 \\
\hline sTnf-R1 & - & 0.42 & - & -0.26 & -0.08 & 0.26 & 0.12 & - & 0.35 & -0.01 & 0.21 & -0.37 & 0.00 \\
\hline TSLP & - & 0.63 & 0.19 & -0.04 & 0.20 & 0.15 & -0.13 & - & 0.24 & -0.23 & -0.12 & -0.12 & -0.42 \\
\hline
\end{tabular}

La correlación es significativa con una $p<0.05$ (en negritas rojas).

Tabla 6. Análisis de correlación lineal entre las citoquinas y los parámetros de las fluctuaciones de la frecuencia cardiaca a partir del promedio de datos del tercer trimestre de embarazo y trabajo de parto $(\mathrm{N}=20)$.

\begin{tabular}{|c|c|c|c|c|c|c|c|c|c|c|c|c|c|}
\hline & \multicolumn{13}{|c|}{ Coeficiente de correlación (Spearman rho) } \\
\hline & $\alpha_{1}$ & $\alpha_{2}$ & $\boldsymbol{\alpha}_{1 \mathrm{mag}}$ & $\boldsymbol{\alpha}_{1(\mathrm{SIGN})}$ & HR & SDNN & RMSSD & PNN50 & InVLF & InLF & InHF & LF/HF & $\begin{array}{c}\text { SampE } \\
n\end{array}$ \\
\hline APRIL/TNFSF13 & -0.34 & -0.42 & -0.33 & -0.29 & -0.23 & -0.02 & 0.11 & 0.11 & -0.23 & -0.09 & 0.10 & -0.22 & 0.36 \\
\hline BAFF/TNFSF13B & -0.03 & 0.31 & 0.07 & 0.02 & 0.36 & 0.21 & -0.00 & 0.01 & 0.15 & -0.13 & -0.11 & -0.04 & -0.36 \\
\hline sCD30/TNFRSF8 & -0.25 & 0.16 & 0.15 & -0.41 & 0.05 & 0.43 & 0.47 & 0.47 & 0.19 & 0.23 & 0.36 & -0.44 & -0.05 \\
\hline sCD163 & -0.18 & 0.40 & 0.04 & -0.17 & -0.10 & 0.27 & 0.02 & -0.00 & 0.15 & -0.20 & -0.09 & -0.17 & -0.24 \\
\hline IFN- $\alpha 2$ & -0.32 & 0.03 & 0.00 & -0.46 & -0.06 & 0.23 & 0.26 & 0.26 & -0.02 & -0.20 & 0.15 & -0.43 & -0.04 \\
\hline IFN- $\beta$ & 0.24 & 0.30 & -0.08 & 0.14 & 0.15 & 0.19 & -0.08 & -0.08 & 0.23 & -0.10 & -0.05 & 0.00 & -0.37 \\
\hline IFN-gamma & 0.03 & 0.26 & 0.13 & -0.16 & 0.33 & 0.35 & 0.19 & 0.25 & 0.25 & 0.03 & 0.26 & -0.39 & -0.37 \\
\hline IL-10 & -0.15 & 0.10 & 0.22 & -0.27 & 0.01 & 0.32 & 0.30 & 0.27 & 0.10 & 0.02 & 0.12 & -0.20 & -0.14 \\
\hline IL-20 & -0.12 & 0.05 & -0.25 & -0.40 & 0.07 & 0.40 & 0.31 & 0.30 & 0.18 & 0.03 & 0.40 & -0.49 & -0.03 \\
\hline IL-22 & 0.07 & 0.14 & -0.30 & -0.21 & 0.00 & -0.06 & 0.05 & -0.02 & -0.03 & -0.10 & -0.02 & 0.02 & -0.04 \\
\hline IL-28A/IFN-2 & -0.22 & 0.14 & 0.01 & -.016 & -0.06 & 0.36 & 0.18 & 0.17 & 0.07 & -0.05 & -0.03 & -0.10 & -0.11 \\
\hline IL-35 & -0.21 & -0.03 & 0.10 & -0.35 & -0.06 & 0.42 & 0.25 & 0.27 & 0.12 & -0.11 & 0.31 & -0.53 & -0.10 \\
\hline MMP-3 & -0.11 & 0.08 & 0.00 & -0.15 & 0.10 & -0.06 & -0.14 & -0.11 & -0.29 & -0.47 & -0.13 & -0.08 & -0.10 \\
\hline Osteocalcina & 0.30 & 0.23 & 0.34 & 0.05 & 0.18 & 0.04 & 0.02 & -0.02 & -0.06 & -0.06 & -0.14 & 0.07 & -0.39 \\
\hline Pentraxina-3 & -0.07 & 0.14 & -0.15 & -0.36 & 0.22 & 0.41 & 0.19 & 0.20 & 0.23 & -0.06 & 0.36 & -0.51 & -0.14 \\
\hline sTnf-R1 & -0.48 & 0.05 & -0.03 & -0.45 & -0.03 & 0.37 & 0.39 & 0.42 & 0.33 & 0.12 & 0.38 & -0.57 & 0.09 \\
\hline TSLP & 0.16 & 0.24 & 0.16 & -0.02 & 0.49 & 0.19 & -0.02 & 0.01 & 0.07 & -0.10 & -0.02 & -0.07 & -0.44 \\
\hline
\end{tabular}

La correlación es significativa con una $p<0.05$ (en negritas rojas). 


\section{Apéndice E. Publicaciones y presentaciones en eventos académicos relacionadas}

- JJ Reyes-Lagos, MA Peña-Castillo, JC Echeverría, G Pérez-Sánchez, S AlvarezHerrera, E Becerril-Villanueva, L Pavón, R Ayala-Yáñez, R González-Camarena, G Pacheco-López, Heart Rate Dynamics and Serum Inflammatory Markers During Pregnancy and Active Labor In Women, Congress of the Internatinal Society for NeurolmmunoModulation (ISNIM)", Mayo 26-28, Roma, Italia.

- $\quad 12^{\circ}$ reunión científica del German Endocrine-Brain-Immune-Network (GEBIN), 23 al 25 de marzo de 2017, Münster, Alemania.

- Elorza-Ávila, A.R., Reyes-Lagos, J.J., Hadamitzky, M., Peña-Castillo, M.Á., Echeverría, J.C., Ortiz-Pedroza, M. del R., Luckemann, L., Schedlowski, M., Pacheco-López, G., 2017. Oxytocin's role on the cardiorespiratory activity of endotoxemic rats. Respir. Physiol. Neurobiol. 236, 19-22. doi:10.1016/j.resp.

- Reyes-Lagos J.J., Hadamitzky M., Peña-Castillo M. A., Echeverría J., Bösche K., Lückemann L., Schedlowski M., Pacheco-López G., Exogenous oxytocin reduces signs of sickness behavior and modifies heart rate fluctuations of endotoxemic rats, Physiology \& Behavior (2016), doi:10.1016/j.physbeh.2016.07.013

Disponible en http://www.sciencedirect.com/science/article/pii/S0031938416305546

- Congreso Iberoamericano de Neuroinmunomodulación and II Congreso Mexicano de Neuroinmunoendocrinología, 28 de octubre al 30 de octubre de 2015, Nuevo Vallarta, Nayarit, México.

- CXXI Reunión Reglamentaria de la Asociación de Investigación Pediátrica A.C., 4 de diciembre del 2016, Amealco de Bonfil, Querétaro, México.

- Reyes-Lagos J.J., Hadamitzky M., Peña-Castillo M.A., Echeverría-Arjonilla J.C., Bösche K., Lückemann L., Schedlowski M., Pacheco-López G. Efectos de la oxitocina exógena en la dinámica cardiaca de ratas endotoxémicas. Revista Bio Ciencias 3(3)(Supl): 82, ISSN 2007-3380, 2015. Disponible en: http://editorial.uan.edu.mx/BIOCIENCIAS/article/view/215/206

- Reyes-Lagos, J.J., Echeverría-Arjonilla, J.C., Peña-Castillo, M.Á., García-González, M.T., Ortiz-Pedroza, M.D.R., Pacheco-López, G., Vargas-García, C., Camal-Ugarte, S., González-Camarena, R., A comparison of heart rate variability in women at the third trimester of pregnancy and during low-risk labour. Physiol. Behav. 149, 255-261. doi:10.1016/j.physbeh.2015.05.04, 2015. Disponible en: http://www.sciencedirect.com/science/article/pii/S0031938415003352

- Reyes-Lagos JJ, Echeverría-Arjonilla JC, Peña-Castillo MA, Montiel-Castro AJ, Pacheco-López G. Physiological, Immunological and Evolutionary Perspectives of Labor as an Inflammatory Process. Advances in Neuroimmune Biology. August 28; Volume 5, Number 2 / 2014:75-89, 2014.Disponible en: http://content.iospress.com/articles/advances-in-neuroimmunebiology/nib140085 
HEART RATE DYNAMICS AND SERUM INFLAMMATORY MARKERS DURING PREGNANCY AND ACTIVE LABOR IN WOMEN

J Javier Reyes-Lagos ${ }^{1,}$ Miguel Ángel Peña-Castillo', Juan Carlos Echeverría', Gilberto PérezSánchez ${ }^{2}$, Samantha Alvarez-Herrera ${ }^{2}$, Enrique Becerril-Villanueva ${ }^{2}$, Lenin Pavón ${ }^{2}$, Rodrigo Ayala-Yáñez ${ }^{3}$, Ramón González-Camarena", Gustayo Pacheco-Lónez

${ }^{1}$ Basic Sciences and Engineering Division, Metropolitan Autonomous University (UAM). Campus Iztapalapa, Mexico; ${ }^{2}$ Department of Psychoimmunology. National Institute of Psychiatry (INPRFM). Mexico; ${ }^{3}$ Maternal and Childhood Research Center (CIMIGen). Mexico; ${ }^{4}$ Biological and Health Sciences Division, UAM, Campus Iztapalapa, Mexico; ${ }^{5}$ Biological and Health Sciences Division, UAM, Campus Lerma, Mexico.

To investigate whether inflammation plays a role in term active labor we assessed short-term heart rate dynamics and circulating cytokines. Healthy women ( $n=20$; mean age $24.1 \pm 4.9$ years) were longitudinally studied at the third trimester of gestation (3G) and at term active labor (AL) to measure consecutive cardiac autonomic indices derived from heart rate variability (HRV) analysis and circulating maternal inflammatory markers, which included serum levels of the interleukin (IL)10 family (IL-10, IL-20, IL-22 and IL-28A). The presence of $3-4$ uterine contractions in 10 minutes. cervical dilatation and effacement of at least $4 \mathrm{~cm}$ and $50 \%$, respectively, identified outgoing AL. A canonical correlation analysis was used to summarize the relationship between HRV and cytokines during $3 G$ and AL. During AL significant changes were observed in the short-term heart rate dynamics, showing higher values of $a_{1}$ (above 1.0). which indicate a more regular behavior, as well as a weakly anticorrelated pattern (indicated by higher values of $a_{118 i c k}, p<0.05$ ) in comparison to the 3G. No significant changes were manifested in other HRV parameters. Additionally. the concentrations of IL-10, IL-20, IL-22 and IL-28A were significantly diminished at AL in comparison to $3 G(p<0.05)$. Moderate but significant canonical correlation $(0.752)$ was found between HRV parameters linked to vagal function and the $\mathrm{LL}-10$ family during $\mathrm{AL}$. The systemic downregulation of several members of the IL-10 cytokines family may play an active role in the activation of the myometrial smooth cells associated with uterine contractions at AL. Likewise, the regular and weaker anticorrelations of the maternal fluctuations at labor could then reflect a different interplay between the sympathetic and parasympathetic branches. Finally, the finding that some IL-10 family members are correlated to vagal HRV parameters suggests a link between inflammation and the autonomic regulation in pregnancy and labor.

I would like to submit this abstract for:

\section{Oral presentation}

Please, indicate the ISNIM Session to which your abstract would fit better (if appropriated, please indicate at least 2 choices, in order of preference: 1, 2) ISNIM Session:

1 Long and short loops in Neuroimmunomodulation

2 Neuroimmunomodulation and infections 


\begin{tabular}{lc}
\hline & Contents lists available at ScienoeDirect \\
ELSEYILR & Respiratory Physiology \& Neurobiology \\
& journal homepage: www.elsevier.com/locate/resphysiol \\
\hline
\end{tabular}

Short communication

\section{Oxytocin's role on the cardiorespiratory activity of endotoxemic rats}

Ana Rosa Elorza-Ávila ${ }^{2}$, José Javier Reyes-Lagos ${ }^{2, b}$, Martin Hadamitzky c, Miguel Ângel Peña-Castillo ${ }^{b}$, Juan Carlos Echeverría ${ }^{b}$, María del Rocío Ortiz-Pedroza ${ }^{\text {b }}$, Laura Lückemann ${ }^{c}$, Manfred Schedlowskic, Gustavo Pacheco-López ${ }^{\mathrm{d}, \mathrm{e}, \mathrm{t}}$

anutanomoes University of the Stute of Medico (LMBMex), Faculty of Medictine, Tobuca, 50180, Merico

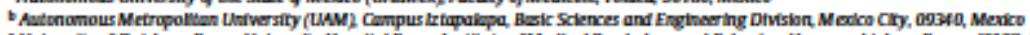

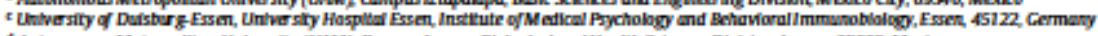

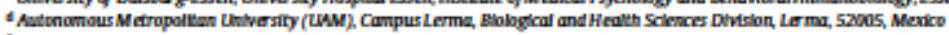

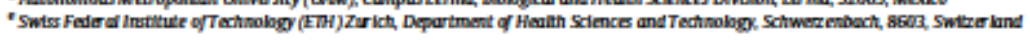

\section{A RTICLE I N F O}

Article hustary:

Riecrived 14 September 2016

Miecrived in revised form 24 Octuber 2016

Accepted 24 Octuber 2016

Nrallable online 29 October 2016

Keywords:

ECL-derived respiration

Anti-inflammatory cholinergic pattiway

HinV

Oxytocin

LPS

\section{A B S T R A C T}

Backgound: Recent findings concerning oxytocin indicate its anti-inflammatory, cardioprotective and parasympathetic modulating properties. In this study, we investigated the effects of systemically applied axytocin on the cardiorespiratory activity in a rodent model of moderate endotoxemia Methods: Telemetrically recorded electrocardiogram (ECG) from animals which recrived lipopolysaccharide (LPS); oxytocin ( $\mathrm{Ox}$ ); lipopolysaccharide + oxytocin (LPS + Ox), or vehicle (V) were analyzed using the ECG-derived respiration (EDR) technique to estimate the respiratory rate. The mean R-R interval and the spectral parameters of heart rate variability $(H R V)$ such as the natural logarithm of the high frequency (InHF) and low frequency (InL.F) components were also estimated up to $24 \mathrm{~h}$ after treatment.

Results: The endotoxemic animals (LPS) showed an elevated respiratory rate as well as a reduced mean R-Rinterval, InHF and InLF components compared to controls (V) from +5 to $+12 \mathrm{~h}$ after the treatment. The administration of axytocin significantly attenuated the hyperventilation produced by the LPS-induced endotoxemia (LPS $+0 x$ ) and restored the values of the mean $R-R$ interval and such spectral parameters endotoxemia (LPS $+0 x$ )

Conclusions: Our results support the existence of a link among the respiratory, cardiovascular, and immune systems in which oxytocin seems to act as a potential cardioprotective peptide by favoring cardiac cholinergic autonomic coupling. As a result, oxytocin diminished animal's endotoxemic tachypnea and restored the cardiorespiratory interactions, which was indicated by the spectral components of HRV.

O 2016 घlsevier B.V. All rights reserved.

\section{Introduction}

The respiratory and cardiovascular systems are intimately linked, primarily via the autonomic nervous system (ANS) (Thayer et al., 2011). In fact, some authors have suggested the existence of a link among the respiratory, cardiovascular, and immune systems where the nucleus of the solitary tract (NTS) at the brain stem is the main site of neural integration (Thayer et al, 2011).

Previous reports have shown that systemic inflammation may alter cardiac pacemaker dynamics. In fact, endotoxemia has been

\footnotetext{
* Corresponding author at: Universidad Aut Lerma, División de Cienclas Bablógicas y de la Salud, Departamentr de Cendizs of la Salud, Av. de Las Garzas 1Q, CP. 52005 , Lema, Edo Mex, Méxicn.
}

E-mail adtress: g.pachecoifcurrea.ler.alm.mx (C. Pacheco-LEpex)

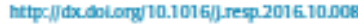

1569-904B/D 2016 Elevier BV. All rights reserved associated with the partial uncoupling of cardiac pacemaker cells from autonomic neural control, resulting in decreased HRV (Gholami et al., 2012). On the other hand, studies have indicated that some peptides like oxytocin possess cardioprotective properties during ischemia-reperfusion injury (Faghihi et al, 2012). Oxytocin has been used to reduce myocardial infarction extension and ventricular arrhythmias. Also, it improves mean arterial pressure via nitric oxide production, protein kinase $\mathrm{C}$ activation, and reactive oxygen species balance (Faghihi et al., 2012). Actually, our previous study supports the findings of systemic cardioprotective and anti-inflammatory properties of oxytocin because a low dose of peripheral axytocin reduced the signs of sickness behavior, such as lethargy and fever, and modified the heart rate variability (HRV) during moderated endotoxemia (Reyes-Lagos et al, 2016).

Within this framework, the aim of the present study was to analyze the effects of exogenous oxytocin after an immune chal- 
lenge induced by the administration of lipopolysaccharide (LPS) on the cardiorespiratory activity by using the ECG-derived respiration (EDR) technique (Silva and Moody, 2014) in conjunction with the spectral analysis of HRV. Accordingly, the HRV reflects the associated physiological processes of the ANS linked to the respiratory and cardiowascular systems (Thayer et al., 2011), whilst the EDR allows to estimate the respiratory signal. We hypothesize that oxytocin plays a modulating role in the cardiorespiratory control during endotoxemia, mainly by favoring cardiac cholinergic autonomic coupling, resulting in a reduction of the respiratory rate and the restoration of spectral HRV parameters.

\section{Methods}

\subsection{Electrocardiogram exper imental data}

Electrocardiogram (ECG) data from our previous study (ReyesLagos et al., 2016) were extracted from our database; these recordings were obtained from adult male Dark Agouti rats (DA/HanRj, 230-250 g) implanted with a telemetry transmitter (sampling frequency $2000 \mathrm{~Hz}$ ) as described previously (ReyesLagos et al., 2016). These animals were maintained on a reversed 12:12 h light/dark cycle (lights off at 7:00 AM) and had od libitum access to water and standard diet. The data were splitted into four different treatment groups: 1) vehicle (V; saline solution, $n-7$ ); 2) oxytocin (Ox; $3 \mathrm{Iu} / \mathrm{kg}$ administered subcutaneously, n-8, 3) lipopolysaccharide (LPS; $0.1 \mathrm{mg} / \mathrm{kg}$ administered intraperitoneally. $\mathrm{n}-8$ ); 4) LPS + oxytocin (LPS +Ox; combined administration of $0.1 \mathrm{mg} / \mathrm{kg}$ LPS intraperitoneally and $3 \mathrm{IU} / \mathrm{kg}$ oxytocin subcutaneously, $\mathrm{n}-8$ ). Baseline recordings started at 7:00 AM (time- $-3 \mathrm{~h}$ ) and drug administration was performed at 10:00 AM (time- $0 \mathrm{~h}$ ) in each group. All experimental procedures were followed in accordance with the animal facilities of the University of Duisburg-Essen, the Animal Welfare Act (TierSchG) - Germany, the European Directive 2010/63/EU, and with the National Institutes of Health - USA Animal Care guidelines. All procedures were approved by the institutional Animal Care and Use Committee (LANUV Duisseldorf, North Rhine-Westphalia, Germany).

\subsection{Data analysis}

Reliable and representative ECG segments of five minutes length were selected every hour $(-3 h$ to $+24 h)$, the ECG segments were analyzed for ECG-QRS detection and generation of $R-R$ intervals using validated algorithms developed for MATLAB (The MathWorks Inc., Massachusetts, USA). The R-R intervals were analyzed using the Kubios software for HRV spectral analysis (University of Kuopio, Kuopio, Finland). We assessed the absolute power of the low frequency (LF) component, which is associated with the sympathetic and parasympathetic influences or even related to the baroreflex function, as well as the absolute power of the high frequency (HF) component, reflecting mainly the respiratory sinus arrhythmia (RSA), which is thereby considered as an indirect index of cardiac vagal control. The Kubios settings for the calculation of the spectral parameters were adjusted as follows; component LF $(0.04-1.0 \mathrm{~Hz})$ and $\mathrm{HF}(1.0-3.0 \mathrm{~Hz})$, window of 256 points, $50 x$ overlap, interpolation rate of $8 \mathrm{~Hz}$ (Kuwahara et al_, 1994). Additionally. we applied a signal processing technique for deriving respiratory signals from ECC'S (EDR) based on the QRS area under curve. This technique is freely available in PhysioNet (www.physionet.org) and provides reliable respiratory-related data (Silva and Moody, 2014). The moving window was adjusted at $0.1 \mathrm{~s}$. Respiratory derived signals were interpolated by a cubic spline fit at $100 \mathrm{~Hz}$ and digitally high-pass filtered using a cutoff frequency of $0.5 \mathrm{~Hz}$. The EDR spectra peak $(1.0-3.0 \mathrm{~Hz})$ was calculated through Welch's power spectral density estimated with a window of 1024 points and $50 \%$ overlap.

\subsection{Statistical analysis}

For correcting skewed distributions, the LF and HF parameters were logarithmically transformed. Data were tested for normality using Kolmogorov-Smirnov test. We applied planned comparisons between V vs, Ox, LPS vs. V and LPS vs. LPS + Ox groups by twoway ANOVA, followed by Fisher's LSD post-hoc tests. Data were expressed as mean \pm SEM, and the level of significance was set at $p<0.05$.

\section{Results}

In Fig 1 we show the estimated breathing rate by EDR, the mean $R-R$ interval and the estimated spectral parameters from HRV (InHF and lnLF) starting from $-3 \mathrm{~h}$ to $+24 \mathrm{~h}$ after treatment A black/white bar at the bottom of each panel indicates, respectively, the dark/light cycle. Single administration of oxytocin by itself did not modify the respiratory rate dynamics in the longterm (V vs. Ox), whereas in the presence of endotoxemia oxytocin did induce significant changes (LPS vs, LPS + Ox; Fig. 1a at $+6 \mathrm{~h}$ and $+12 \mathrm{~h}, \mathrm{~F}(16,459)-6.487$; $<<0.0001$ ). An increment of estimated respiratory rate, matched with a reduction of $\mathbb{R}-\mathbb{R}$ interval at +5 h after treatment was also identified (Fig. la \& b). These physiological changes continued until $+12 \mathrm{~h}$.

The spectral parameter lnHF was diminished from +8 to $+12 \mathrm{~h}$, the lowest value was detected at $+9 \mathrm{~h}$ (IPS vs. V; Fig. ic $F(16,459)-2.071 ; p=0.0083)$. Similarly, a decrement of lnLF was found from $+1 \mathrm{~h}$ to $12 \mathrm{~h}$, with the lowest value identified at $+9 \mathrm{~h}$ (LPS vs. V; Fig. 1d, F(16,459)- 4.450; $p<0.0001$ ). The administration of oxytocin restored the lnHF and InLF parameters $+9 \mathrm{~h}$ afterthe treatment (LPS vs LPS + Ox; Fig. 1c \& d, F(16,459) - 207 1; p-0.0083 \& F 16,459)- 4.450; $p<0,0001$, respectively). Fisher's LSD post-hoc test showed significant differences among planned comparisons $(p<0.05)$

Fig. 2 shows representative data of the estimated respiratory signals extracted by EDR technique. This figure illustrates a higher respiratory rate pattern during endotoxemia (LPS) compared to the data from the LPS $+0 x$ group $+6 \mathrm{~h}$ after the treatment.

\section{Discussion}

The reduction in the spectral parameter lnHF of HRV indicates a decreased respiratory sinus arrhythmia (RSA) and suggests partial uncoupling of cardiac pacemaker during LPS-induced endotoxemia at the long-term (LPS vs. v, Fig. 1c). in fact, a reduced RSA may decrease the gas exchange efficiency of the lung by failing to optimally synchronize the pulmonary perfusion to the alveolar ventilation through the ventilatory cycle (Yasuma and Hayano, 2004). Additionally, a reduced mean $R-R$ interval (LPS vs. V, Fig. 1b) is related to either a vagal withdrawal or increased sympathetic activity. Noteworthy, the lowest value of the mean $\mathbf{R}-\mathbf{R}$ interval (LPS vs. V; Fig. 1b at +9 h) is not in coincidence with the maximum value of respiratory rate (LPS vs. V; Fig. $1 \mathrm{a}$ at $+6 \mathrm{~h}$ ). Thus, these findings indicate that, despite a reduced RSA during UPS-induced endotoxemia (indicated by lower lnHF values), the estimated respiratory rate presents a significant augmentation in conjunction with reduced mean $R-R$ interval in response to a 1 PS challenge. In fact, the RSA may become reduced by an increased respiration rate (representative data in Fig. 2a) independently of the vagal nerve traffic (Eckberg and Eckberg, 1982). Yet the administration of oxytocin (UPS vs LPS +Ox) seems to revert at baseline levels the estimated respiratory rate (Fig. 1a), the mean $\mathbf{R}-\mathbf{R}$ interval (Fig. 1b) 
and the spectral HRV parameters InHF and InLF (Fig. Ic \& d). The decreased respiratory rate was found even $+6 \mathrm{~h}$ and $+12 \mathrm{~h}$ after oxytocin administration (UPS vs. LPS +Ox; Fig. 2b), although the increment in the HF power was only observed at $+9 \mathrm{~h}$ of oxytocin administration (Fig. 1c). Thus, we speculate that, among different physiological mechanisms attributed to the observed changes in the spectral components InHF and InLF (Fig. Ic \& d) and the estimated breathing rate in rats (Fig, la), the presence of oxytocin receptors in the heart (Faghihi et a L 2012) may have a direct effect on the cardiac pacemaker coupling. Additionally, oxytocin receptors in the lungs (Pequeux et al, 2005) as well as the activation of the cholinergic anti-inflammatory pathway should be both taken into consideration (Huston and Tracey, 2011)

\section{Conclusion}

In the present study, we found that spectral HRV parameters (InHF and InLF) are altered during moderate endotoxemia in rats. A depression in the HF component may indicate a reduced respiratory sinus arrhythmia and the changes in both HF and LF may indicate an uncoupling of the autonomic control during LPS-induced endotoxemia.

Yet our results also support the existence of a functional link among the respiratory, cardiovascular, and immune systems in which oxytocin seems to act as a potential cardioprotective peptide by favoring cardiac cholinergic autonomic coupling. Consequently. oxytocin diminished animal's tachypnea and restored the cardiorespiratory interactions indicated by the spectral components of HRV despite the administration of endotoxin. Finally, these finding confirm the suitability of the electrocardiogram derived respiration (EDR) technique to obtain the estimated respiration signal in rodent models.

\section{Conflict of interest}

The authors declare no conflict of interests.

\section{Acknowledgments}

JJRL thanks the Mexican Council for Science and Technology (CONACYT) for providing a graduate scholarship (CVU/Scholarship number: $381983 / 253449$ ). This work was partially funded by the Autonomous Metropolitan University (UAM) - Mexico research and mobility Metropolitan University (UAM) - Mexico research and mobility funds to GPL, MAPC and JCE, as well as institutional funds of Univers funds to GPL, MAPC and JCE, as well as institutional funds of University Hospital of Essen - Germany. Additional financial support was provided by CONACYT, DAAD-PROALMEX fund No. 267761 to GPL, and the Council for Science and Technology of the Estate of Mexico (COMECYT) scientific and technological research stay fund to GPL

\section{References}

Echbery, D.L., Echtery MJ, 1982. Human sines node repponses to repetitive, ramped carotid taroreceptor stimull. Am. \&. Physiol. 242, 1538 - 44

Faghinh, M, Altzadeh, AM. Khori, V., Latifpour, M, Khodayari, S, 2012. The role of nitric woide, resctive axygen species, and protein kinase $\mathrm{C}$ in mytndin-induce cardioprotertion in ischemic rat heart. Peptides 37, 314-312, hitip;id dx.dolory $10.1016 /$.ppeptides 201208.001.

Cholami, M, Marzaheri P, Mohamad, A, Dehpour, T, Safari, F, Hajlzadeh, S, Moore, K.P., Mani, AR, 2012. Endotoxemia is assodated with partial uncoupling of cardiac pacemaker from chollinergic neural control in rats. Shock

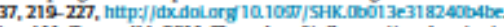

Hustom,,$M$, Tracey, $K$, , 2011. The pulse of inflammation: heart rate variability. the chollinergic anti-inflammatory pattwway and implications for therapy. I In

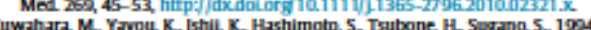

Fow $M$. Power spectral analysis of heart rate variability as a new method for assessing $10.1016 / 50022-0736(05) 902 / 2-9$

Pequex, C, Bretan C, Hagestein, M.-T, Geenen, V, Legras, J-1, 2005. Oxytacin receptor pattern of expression in primary lung cancer and in normal human

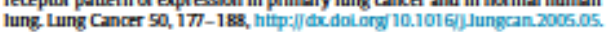
a27.

Reyes-Lagos, H. Hadamitzky, M. Peha-Castillo, MA K, Echeverria, JC, Bosche, K, Lickemann, L, Schedlowsid, M, Pachecto-Loper, C, 2016. Exogenous axytocin reduces signs of sidkness behavior and modifies heart rate fluctuations of

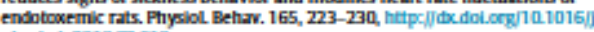
physbeh.2016.07.013.

Silna, L, Moody, CaR, 2014. An open-source toolbax for analysing and processing

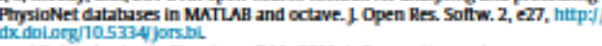

Thuyer, $J F$, Leetrobis, $\Lambda$, Stermberg, EM, 2011. Inflammation and Cardilarespiratory control: the role of the vages nerve. Respir. Physiol.

Neut 5 .

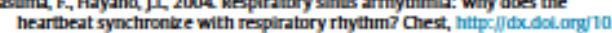
heartbeat synchronie 


\section{Exogenous oxytocin reduces signs of sickness behavior and modifies heart rate fluctuations of endotoxemic rats}

Josế Javier Reyes-Lagos a, Martin Hadamitzky ${ }^{\text {b }}$, Miguel Ángel Peña-Castillo a , Juan Carlos Echeverría ${ }^{2}$, Katharina Bösche ${ }^{b}$, Laura Lückemann ${ }^{\text {', }}$ Manfred Schedlowski ${ }^{b}$, Gustavo Pacheco-López ${ }^{\text {c,d.* }}$

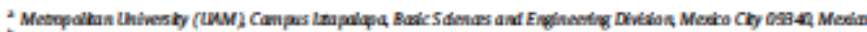

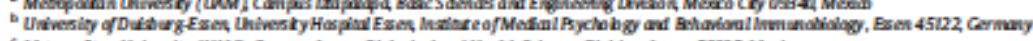

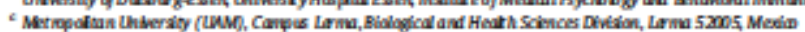

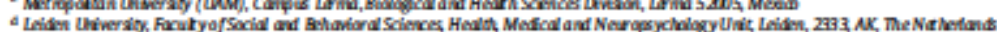

H I G H LI GH TS

- We studied heart rate flucturtians (HRF) during endotowemia in a rodent model

- Endotwermia produces lethargy, tachycardia, more regular and anticorrdated HRF.

- A single dose of exogenous caybain does not madify by itsedf the HIF.

- Obytodin reduces lethrargy, heart rate and anticorrelation in $\mathrm{HRF}$ during endotonemiz

- Oxytodin moderates the magnitude and durzion of the IPS induced hyperthemiz

A R TICLE I N F O

\section{Mriblenbaray}

Recelved 8 Fetroniy 2016 Bectived in revtsed form 21 Jne 2016

Necepand 18 Jy 2016 Mraible online 20)ay 2016

\section{Kigmant:}

Heart crevalably

Sibless trewwibr

Aunomicativisy

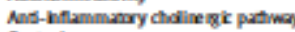

Oxprocin

uPS

\begin{abstract}
A B S T R A C T
Besides the well-known roles of axytaxin on birth, maternal banding and laction, reantevidenceshows that this hypothalamic hormone possesses candioprotective, anti-inflammatory and parasympsthetic neuromodulation properties in this study, weexplore the heart rzte fluctuations (HFF) in an endotacemic ro. dent model that was accompanied by the administration of exogenous axytodin. The assessment of HRF hx been widdy used $\mathrm{x}$ an indirect measure of the cardix autonomicfunction. In this contect, adul male Dark Agputirats were equipped with a telemetric transmitter tocontinuous y and remotely measure the dectrox ardiogram, temperzure, and locomotion. In a between-subjects experimental design, rats recedved the following peripheral

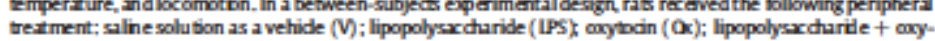

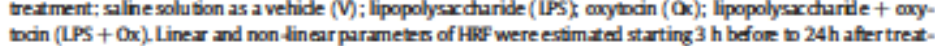
ments Our results showed th $x$ exogenausaxytax in does not modify by itsedf the HRF of axytodin-trested ats in comparison to vehicle-treated ats. However, in animals undergoing endotocemia it; a) provolkes a less antionrrelated pattem in HRF, b) decrezed mean heart rate, c) malerated the magnitude and duration of the LPS induced hyperthermin, andd) incressed locomotion, up to $6 \mathrm{~h}$ after the LPS injection. The less anticorredated pattern in the HRF and decrexed mean heart rite may reflect a card ix pacemaker coupling with cholinergic in putzern in the HRF and decrexeed mean heart rate may reflect a cardix pacema ker coupling with cholinergic inpenture modersting effects of the admin istration of axybcin during endotwemin could be a consequence of the systemic ant-influmm tory properties of axytacin.

Q 2016 Elseviar Inc.All rights reserved.
\end{abstract}

\section{Introduction}

In healthy conditions, the cardiovascular fluctuations show complex physiological homeostatic dynamics resulting from interactions

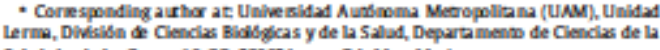
Sall, Mr de las Garzas 14 CP. 5 mos le mina, Edo Mex, Medoo.

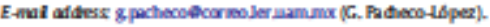

between the cardiac pacemaker cells and the aubnomic nervous sys. tem |11. Evidence in human and experimental animal models indicates that dur ing system ic inflammation (eg.endotoxem ia) the regulation of thecardiac function is manifested with both decreased heart rate fluctuations (HRF) and increased cardiac thythm regularity $[2,3]$, possibly resulting from a partial uncoupling of the cardiac pacemaker cells from the autonomic neural control [4]. Some authors have also de scribed that changes in the HRF can be used to indirectly identify the so called, cholinergic anti-inflammatory pathway (CAP) in diverse 
scenarios $15 \mathrm{l}$ and it has even been considered as a potential non-inva. sive tool to study and monitor the fetal inflammatory and anti-inflammatory responses $|6|$. On this matter, a systemic inhibition of the $\alpha 7$ nicotinic a cet ylchol ine receptor ( $\alpha 7 \mathrm{n} A \mathrm{CHR})$ induced a decrement of the HRF by eliciting an increased inflammation and a febrile response in endotowemic rats |7|. This responsesuggests a tonic role of peripheral nicotinic acetykcholine receptors for modulating heart rate dyna mics during systemic inflammation.

Notwithstanding that oxytocin has well-known plysiological funetions during labor and lactation in humans and other mammats, studies have revealed that it has immune and cardioprotective properties as well; mainly by modulaing the phasic activity of the paraympathetic nervous system $[8]$, In this regard, oxytocin possesses cardioprotective properties in ischemic conditions $|9|$, and decreases carrageenan-induced inflammation in rats |10|. Additionally, the role of signal pathways in cardioprotection have been shown to be stimulated by oxytocin receptors, which are present in both the heart and large vessels [11]. Evidence suggests that oxytocin also limits the cytokines activation caused by the bacterial cell-wall component lipopolysaccharide (LPS). possibly owing to the modulation of the CAP [12]

Further studies have reported other effects of the administration of intranasally axytocin on HRF during social mgnition experiments; where oxytocin, in addition to facilitate social behavior, decreases heart rate and increases HRF $[13,14]$. Other findings indicate that the subchronic administration of oxy bcin induces lang-lasting effects in ovariectomiad rats, including an increase in spontaneous motor activity and decreased levels of corticosterone [15].

We have recently reported linear and non-linear methods for the analysis of $\mathrm{HFF}$ duringchildbir th; acondition with was recently considered to be accompanied by a conspicuous anti-inflammatory process [16]. In the same way, we have documented that the fractal sca ling HRF analysis and sample entropy appeared as potential analytic tools that provide information regarding the homeostatic autonomic mechanisms related to inflammation [17!. In this context, the aim of the pres. ent study was to explore the effects of exogenous axytocin in HRF dynamics by applying linear and non-linear analysis as well as motor activity and peripher al tempera ture in an experimental endotoxemia model in rats. Following the findings of Gholami et al. [4]. Jankowski et al. [11] and Clodi et al [12], we hypothesized that the peripheral administration of oxytodinduring IPS-induoed endotoxemia enhances a cardiac pacemaker coupling with cholinergic influences, which is reflected in the linear and non-linear par ameters of the HRF, and reduces signs of sickness behavior such as lethargy and fever.

\section{Methods}

2.1.Animb

Adult male Dark Agouti rats (DA/HanRy, 230-250 g) were obtained from Jarvier Labs (LeGenest-Saint-kske, France) and housed in standard plastic cages with metal wire lids. Animals were maintained on a reversed 12:12 h light//ark cyde (lights off $x$ 7:00 AM) and had od libiam access to water and standard diet. Rats were allowed to acclimate to the new surroundings for at least 2 wee ks before transmitter implantation sur gery.All procedures we re followed in accordance with the animal 6 cilities of the University of Duisburg-Essen, Germany, and the experimental procedures were in accordance with the Animal Welfare Act (TierschG) - Cermany, the European Directive 2010/53 EU, and with the Nutional Institutes of Health - USA A nimal Care guidel ines These procedures were approved by the Institutional Animal Care and Use Committee (LANUV Disseldorf, Nor th Rhine-Westphdia, Cerma ry).

\section{Drugs}

Based on a previous study [18], synthetic oxytocin (3 $\mathrm{IJ} / \mathrm{ml}$, Rotexmedica GmbH, Arzneimittelwerk, Cermany) was administered at a dose of $3 \mathrm{IU} / \mathrm{kg}$ ( $6 \mathrm{mgg} / \mathrm{kg}$ ), subcutaneously (sc) in a volume of $1 \mathrm{ml}$. Lyophilized lipopolysacharide (LPS) from Echerichia coli, serotype 055.B5 (Sigma-Aldrich, Tauflirchen,Germany), was diluted with sterile saline ( $\mathrm{NaC}$ ) and administered intraperitoneally (ip) at a dose of $0.1 \mathrm{mg} / \mathrm{kg}$ in a total volume of $1 \mathrm{~mL}$ We and others have previousty shown that this LPS dose induces a rise in peripheral cytokine levels and a moderate fever response [19], as well as changes of HRF parameters $|7|$.

\subsection{Telemeter implantation surgery}

Telemetry transmitters (ETA-F20, Data Sciences International, St. Pau, Minnesota, USA) were surgically implanted for measur ing continuously the electrocardiog ram (ECG) peripheral temperature and locomotor activity. Rats were anesthe tized in an induction chamber with $5 x$ isoflurane and $2 x$ oxygen. Anesthesia was maintained by a flow of 1.5-20x isoflurane and axygen (11/min) through a mask during surgery. Thedorsal skin was cleaned and disinfected with povidone-iodine and akohol.A 2 an vertical indsion was made in the dorsa skin, and the telemetry tr ansmitter was placed sc. The biopotential transmi ther leads were tunneled under the skin with the tips guided to the right and left axillary regions. For pain relieve Carprofen $5 \mathrm{mg} / \mathrm{kg}$ was given $s c$, on the dry of surgery and the following three days. Experiments we reconducted 14 days after surgery to allow recovery $[20 \mid$.

\section{Telemetric dectrocartiogram recarding in freety moving rats}

Animats were randomly assigned to one of four different treatment groups: 1) vehicke ( $\mathrm{V}, \mathrm{n}=7) ; 2$ ) oxytocin ( $\mathrm{Ox}, 3 \mathrm{IU} / \mathrm{kg}, \mathrm{n}=8) ; 3$ ) lipopolysacchar ide (LPS, $0.1 \mathrm{mg} / \mathrm{kg} n=8$ ); 4 ) LPS + axytocin (IPS + Ox, combined administr ation of $0.1 \mathrm{mg} / \mathrm{kg}$ LPS and $31 \mathrm{l} / \mathrm{kg}$ oxytodin, $\mathrm{n}=$ 8). After injections, rats were placed in their home cage with telemetry receivers placed below the cage and connected via a data exchange matrix to a PC Baseline recordings sta rned $\approx$ 7:00 AMand the drugs administration was performed at 10;00 AM (time 0) for each group. The ECC was sampled at $2000 \mathrm{~Hz}$ using Data Sdences Internationa I hardware and Dataquest ART software. This signal was visually ins pected and reliable5-minute segments were sedected each hour $(-3 \mathrm{~h}$ to $+24 \mathrm{~h})$. All digitized signals were analyzed for ECG-ORS detection, temperature and activity assessment.

\section{Data analysis}

Raw ECG recordings were then processed using previously validated al gorithms to gener ate the R-R interval or HFr series These series were reconditioned by a filtering approach and processed as in previous studies [21 ] to exclude for ectopic beats and artifacts.

Linear and non-linear parameters were calculated for each 5-min segment of the $R-R$ interval data. The mean heart rate (mHR), as well as the root-mean-square of successive differences (RMSSD), which quantify vagally-media ted high frequency fluctuations, and the standard deviation of the R-R intervals (SDNN), used as a measure of total HRF $[22$, we re cakculated for all series. Given that previous studies have shown that a linear frequency dom ain analysis does not provide additional information beyond that obtained from a time domain anatysis in endotoxemia experiments of rodents [23], we only performed a linear analysis in the time domain.

The short-term scaling exponents $\alpha_{p} \alpha_{n(M A C) \text {, and }} \alpha_{n(S O C N)}$ fram $4 \leq n \leq 11$ beats and the long-term scal ing parameters $\alpha_{2} \alpha_{2 y}$ (macs, and $\alpha_{2 y s a v}$ from $n>11$ beats of all series were evaluated by applying detrended fluctuation analysis (DFA) and the magnitude and sign anatyses (MSA) [24]. Values of the scaling exponents $\alpha_{n}$ and $\alpha_{2}$ of 0.5 indicate white noise and the absenor of long-range correlations, a value of 1 reflects the behavior of a $1 / f$ process having persistent lang-range correlations whilst the slope of 1.5 indicates a random walk (Brownian 
noise) with a very smooth behavior wherecorrelations still exist but do not follow in a power-law form [25]

For the MSA a nalysis, finding positive cor relations in the magnitude series (ie, $\left.\alpha_{M, u c}>0.5\right)$ has been identified as reliable markers of nonlinear properties [24). The $\alpha_{1}$ cacov exponent provides information about the temporal directionality of the original series in relation to howseries" increments alternate, indicating if a positive or negative subsequent increment (decrement) is more likely to ocaur given a current increment (decrement). To assess the regularity of the R-R time series we also estimated the sample entropy (Sampin) as described by Richman 8 Moorman [26], The parameter $m$ was fixed to 2, and tolerance level $r$ was 02 .

The average actogram was calaulated from continuous timeseries of body movement fram -3 to $+24 \mathrm{~h}$ using a software package for the analysis and visualization of chronobiological activity data $[27\}$

2.5. Statistical analysis

All parameters were analyzed by wo-way-ANOVA with repeated measure sa lang time. Accordingwith the differences identified between groups, an area under curve (AUC) analysis was then applied at consecutive $2 \mathrm{~h}$ periods $(+7 \mathrm{~b}+9 \mathrm{~h})$. The AUCanalysis was performed posterior to the time reported by Mazloom et al. [7] (i.e after $t=6$ hof the drugs or vehide injections) and only dur ing dark periods (i.e. before $t=9 \mathrm{~h}$ ), with the intention of awoiding drcadian variations induced

by subsequent period of inactivity (light phase) $|20|$. However, with the goal of verifying further eflects of axytocin on LPS-induced endotaxemia, which seem to be manifested at lang-term according to previous results reported by Clodi et al [12], AUC data bars from body temper ature were graphed and a nalyzed separ ately only from +7 to $+9 \mathrm{~h}$ and $+10 \mathrm{~b}+12 \mathrm{~h}$ corresponding to dark and light periods, respectively. The AUC for each period was calculated by the trape zidal method (the AUC dat are expressed as means \pm SD). Finally, we made planned AUC comparisons between Vvs Ox V vs. LPS and LPS vs. LPS $+O \times$ groups by one-way ANOVA, followed by Fisher's LSD and Kolmogorov-Smimov post hoc tests ( 0.05 was considered as the significance level).

\section{Results}

In Fig 1 we show the estimated line $x$ parameters of HRF starting $3 \mathrm{~h}$ before to $24 \mathrm{~h}$ after treatment. The AUC of each parameter associated to the +7 to +9 h period (shaded area) was compiled; their further analysis is presented at the figure's insert A black/white bar at the bottom of each panel indicates respectively the dark and light photoperiods. Our results show tha LPS injection was assoda ted with a biphasic dynamic characterized by an early increment in the mHR (Fig. 1a) and decremented SDNN (Fig. 1b) followed by a prolanged period of tachycardia and depressed HRF.
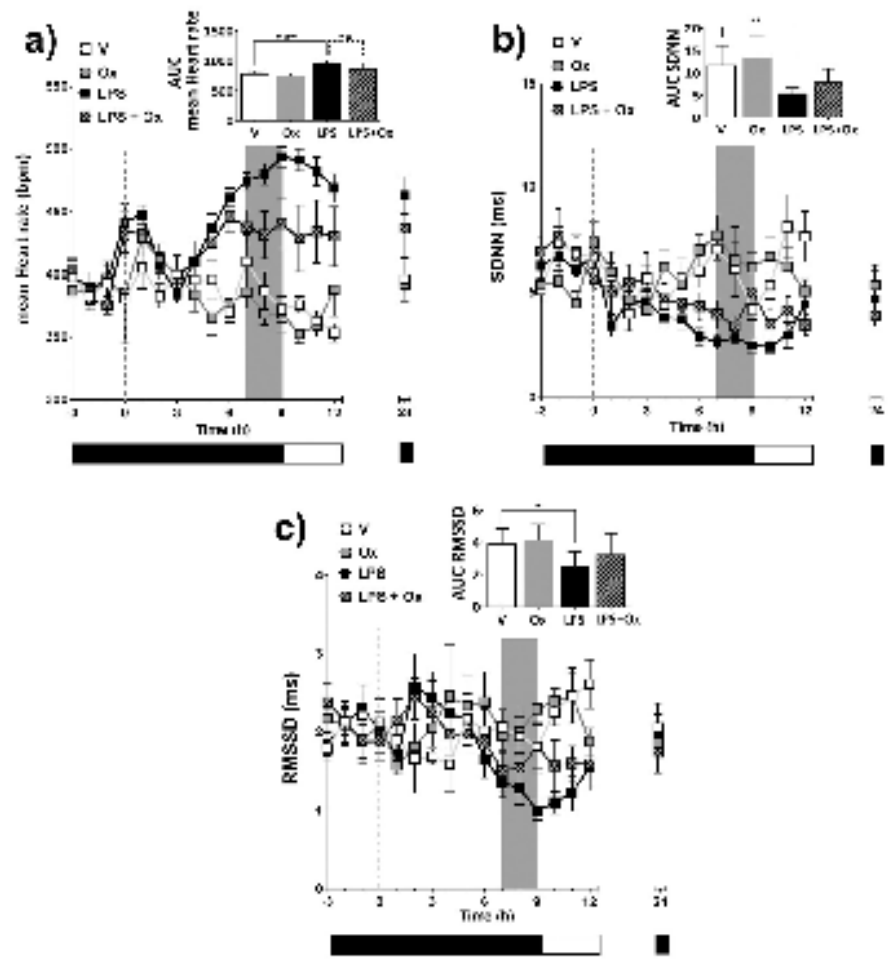

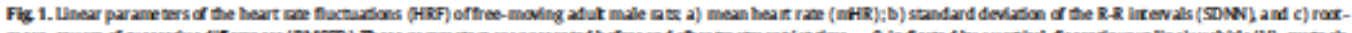
mex-

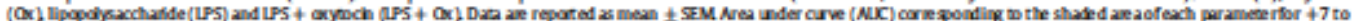

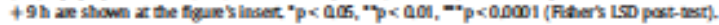


The effect of $L P S$ on mHR was statistically significant according to planned comparisons of the AUC ( $F=1928 ; p<0.0001, \mathrm{~V}$ vs LPS). A single shot administration of axytodin at a dose of $31 \mathrm{U} / \mathrm{kg}$ provoked changes in the $m H R 6 h$ post-LPS injection ( $F=19.28 ; p<0.01$, LPS vs LPS + Ox). The HRF linear indices SDNN (Fig 1b) and RMSSD (Fig.1c) showed a significant reduction ( $F=7.52 ; \mathrm{p}<0.01$ and $\mathrm{F}=$ 3.60; $\mathrm{p}<0.05$, respectively) $6 \mathrm{~h}$ post-LPS injection.

The effect of the endotoxin injection on the irregularity structure of HRF series was a ko investigated using DFA and SampEn, depicted in Fig 2. The short-term scaling exponent $\alpha_{1}$ remained decreased (Fig. 2a) from +7 to +9 h post-LPS injection according to the results of planned AUC comparisons ( $F=4.25 ; p<0.01, V$ vs LPS)

The parameter $\alpha_{\text {ncrov }}$ (Fig $2 \mathrm{~b}$ ) also presented a biphasic dynamic. From +7 to +9 h the LPS injection produced anticorrelated (lower) values in this parameter in comparison to vehicles ( $F=10.58$; $\mathrm{p}<0.0001, \mathrm{~V}$ v LPS), but in contrast the LPS injection combined with oxytocin produced a less anticorrelated (higher) values in the endotoxemic rats ( $F=10.58 ; p<0.01$, LPS vs LPS + Ox).

The non-linear exponent $\alpha_{\eta(M u c)}$ decreased significantly after the single dose of $L P S$ ( $F=1.90 ; p<0.05$, V vs LPS ) Fig. $2 c$. However, the SampEn parameter did not show changes from +7 to $+9 \mathrm{~h}$, Fig. $2 \mathrm{~d}$.
The long-term fractal scaling parameters ( $\alpha_{2}, \alpha_{20}\left(m_{4} c_{0}\right.$, and $\left.\alpha_{2} \operatorname{sac}_{0}\right)$ did not present changes as well after drugs administration and they are not reported here.

In summary, a single dose administration of exogemous oxytocin did not modify by itself the heart rate dynamics from +7 to $+9 \mathrm{~h}$ in any parameter ( $V$ vs. Ox); but in the presence of endotoxemia the oxytocin did introduce significant changes in the mHR and $\alpha_{n(s o w)}$ (LPS vs, LPS + Ox)

Fig. 3 shows representative exa mples of the linear and non-linear analysis of HRF of V, LPS, Ox, and LPS + Ox groups. The $\log -\log F(n)$ vs $n$ and $\log -\log F(n) / n$ vs, $n$ relationships providing the $\alpha_{\eta}, \alpha_{n(s)}$ (s).

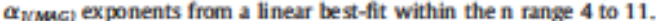
The re was linear relationship between log (fluctuation) and $\log$ (window size) in all the groups at the time analyzed, which corresponds to fractal-like structure with $1 /$ fdynamics $|25|$.

Additionally, the Fig 4 showsa signdecomposition of typicaldata for LPS and LPS + Ox groups. This figure illustrates a higher anticor related pattem in HRF during endotoxemia (LPS) in comparison to data from the LPS + Ox group.

Importandy, we also found that the drcadian rhythm of peripheral body temperature is altered by LPS, as this group of rats presented an
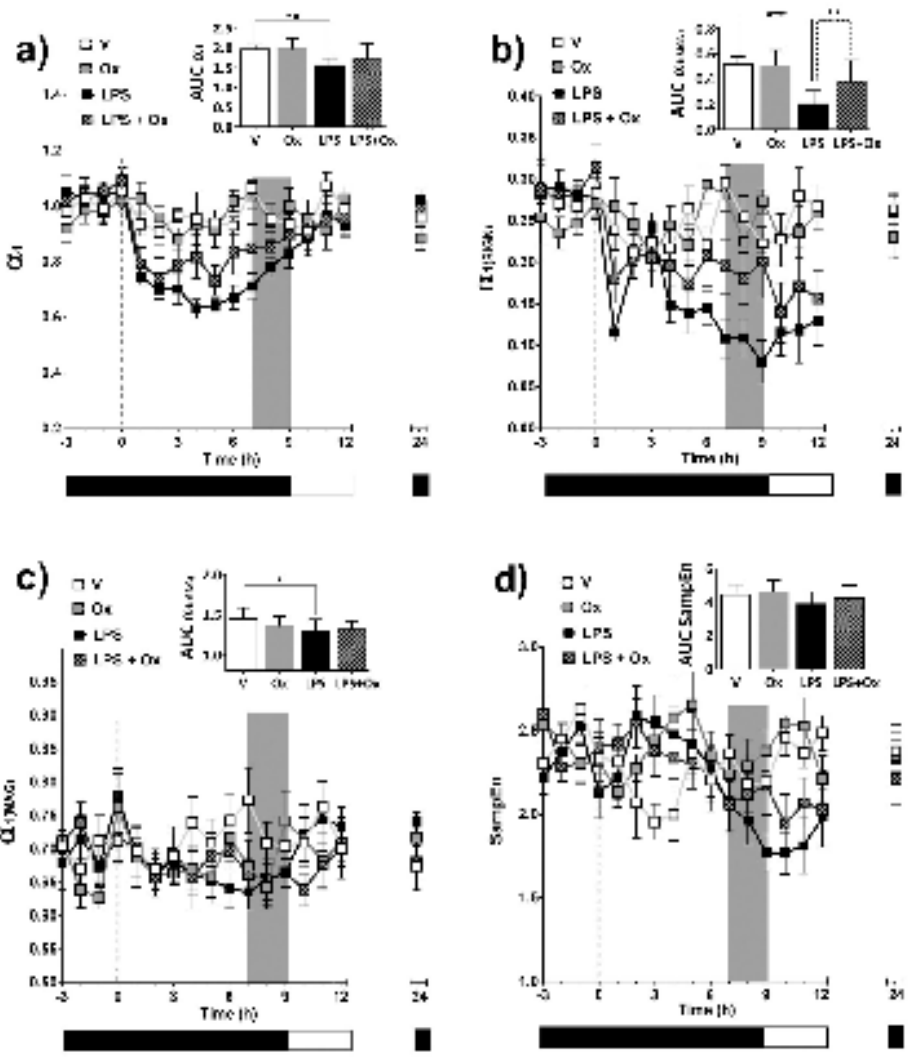

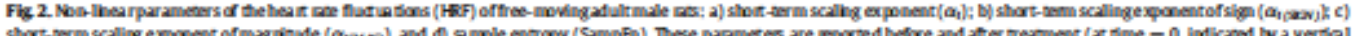

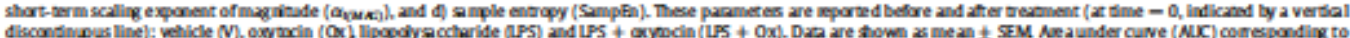

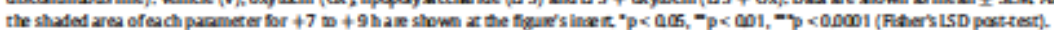


a)

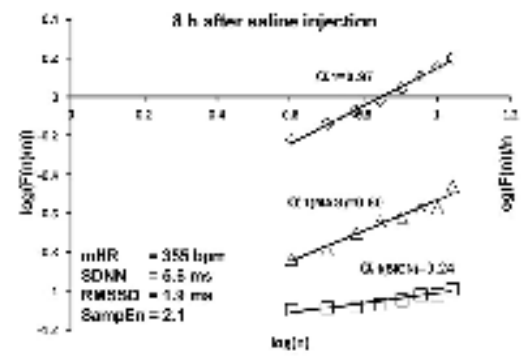

c)

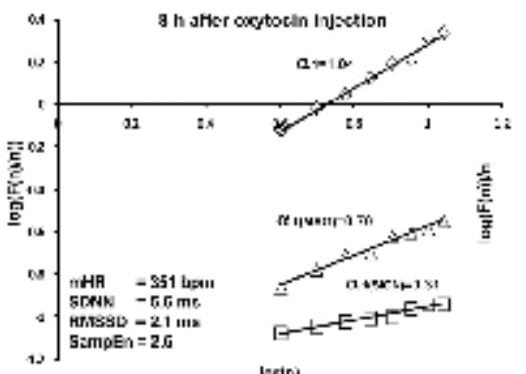

b)

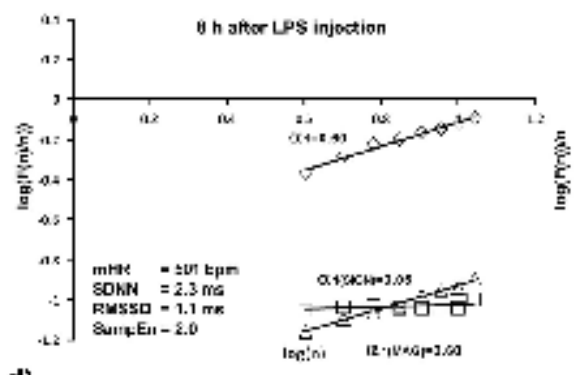

d)

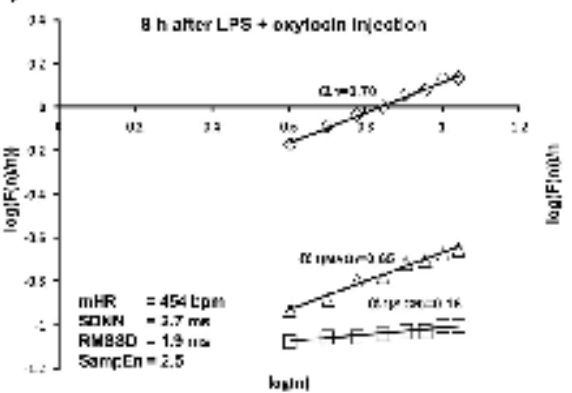

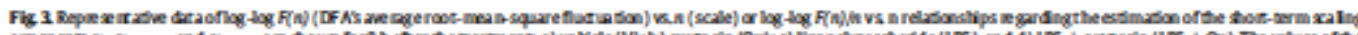

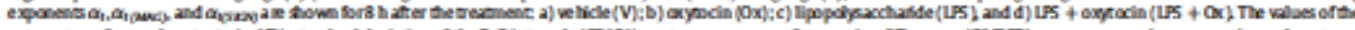

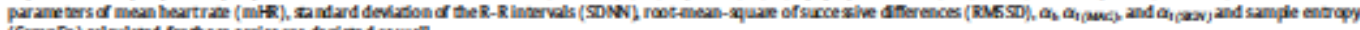

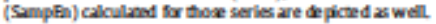

inverted dynamics in comparisan to vehicle group (Fig. 5a). Furthermore a transient hypothermia from +2 to $+4 \mathrm{~h}$ was observed in LPS-treated rats, the AUC corresponding to this period was smaller in relation to vehicle $\left(709^{\circ} \mathrm{C} \cdot \mathrm{h}\right.$ vs $722^{\circ} \mathrm{C} \cdot \mathrm{h}$ respectively, with trending level of $\mathrm{F}=282$; $\mathrm{p}=0.06$ ). Interestingly, oxytodin did not seem to have any eflect on sudh transient hypothermi2. Yet LPS administration induced a significa rt increment in body temperature from +10 to $+12 \mathrm{~h}$ after treatment
( $F=965 ; p<0.001, V$ vs. IPS), which was significantly deregulated by the afministration of axytocin ( $F=965 ; p<005$, LPS vS.LPS $+0 x$ )

Finally, we found that exogenous oxytodin tre atment reduced uPS. induced lethargy; as observed by significant changes in locomotion (Fig 5b) at $6 \mathrm{~h}$ post-IPS (V v LPS, p < Q003) and post-LPS and axytodin injection (LPS vs. LPS + Ox, p < 0.05) according to the KolmagorovSmimov non-parametric test. a)

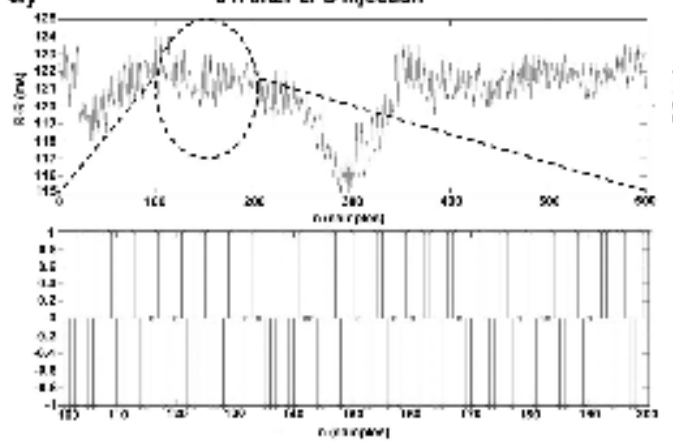

b) $8 \mathrm{~h}$ after LPS + Ok injoction
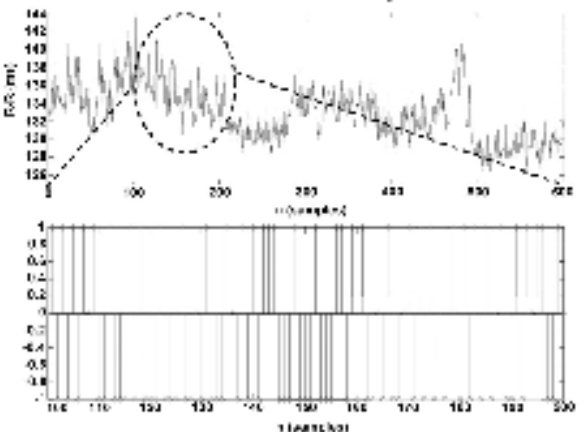

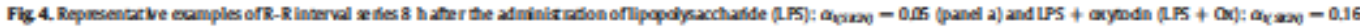

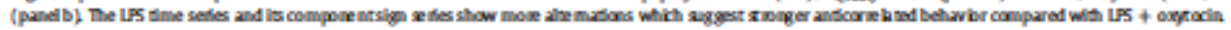


a)

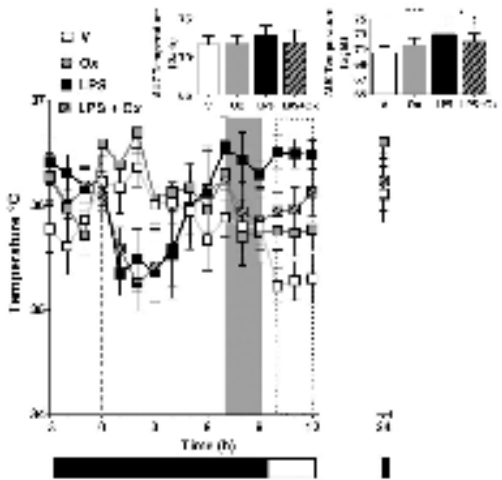

b)
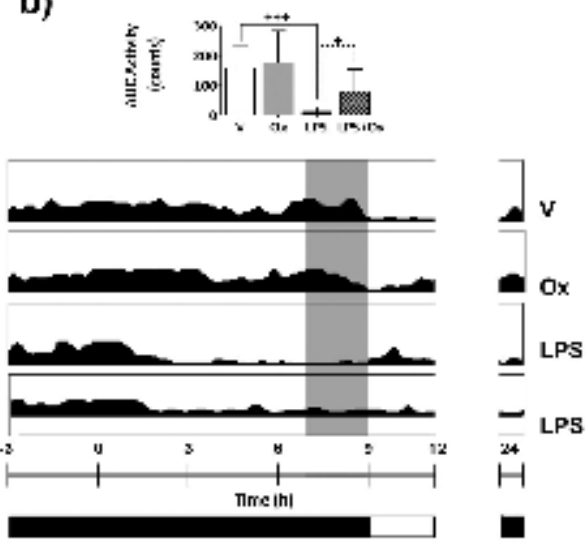

Fig 5 a) Peripheral body amper zure, and by ae rage actogam of fecly moving adt:

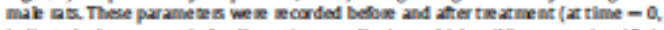
indicared by a verscal disconthaous line); velicle (V), aryroch (Ox).

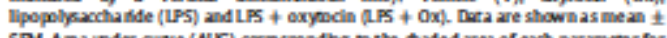
SRM Anea under cuive (NUC) corresponding w the traded area of each paramener for

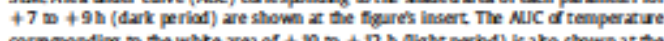

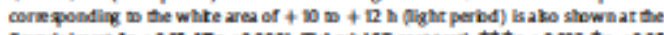

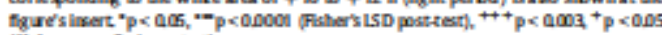
(Kolnogorv-Sininev est).

\section{Disassion}

The results of this studydemonstrate that a single exogenous dose of oxytocin does not modify by itself the HFF, temperature and body movement of axy todin-treated rats in comparison to velide ras. However, in animuls undergoing endotoxemia this hormone provokes a less anticorrelated pattern in HRF indicated by $\alpha_{7}$ (asco ( Fig $2 \mathrm{~b}$ ), decreased mHR (Fig 1a), deregulation of peripheral temperature (Fig 5a), and an increased bocomotion (Fig 5b) up to $6 \mathrm{~h}$ after the LPS injection.

A previous study showed that a single exogenous administration of oxytocin does not impact on the basal levels of corticotrophin, cor tisol. tumor necrosis fictor- $\alpha$, and other cytokines [12]. In our study, the ladk of HRF, temperature and body movement modifications after a single oxytocin administration is consistent with sudh study. However. physiologica modulation introduced by axytocin was onlyevident during endotoxemia (induced by LPS). In fact, Clodi et al [12] suggested that exagenous axytocin decreases the neuroendocrine and cytokine activation, and even activate the CAP, par ticularly during inflammation scenarios; supporting our date. Thus the significantchanges in the mHR and $\alpha_{\left.\eta_{\text {(asco }}\right)}$ identified $6 \mathrm{~h}$ after the administration of coxy bod which reveal less anticorrelated pattern in HRF and adecreased mean heart rate, suggest the occurrence of a cardiac pacemaker coupling with cholinergic influences. This consideration is in line with the fact that some authors have considered that oxytodin embraces functional effects as a cardiovascular and autonomic modulating peptide [8,28,29]; ma inly mediated by local oxytocinergic receptors at the heart $130 \mid$. Indeed. the administration of axytocin could modulate $\alpha 2$-adrenoceptor binding characteristics, thereby resulting in enhanced receptor activity [31].

Regarding the eflects of the LPS injection, the results for the linear parameters of $H R F$ ( $m H R$ and SDNN) as well as peripheral temperature between 0 to $+6 \mathrm{~h}$ are consistent with a previous report [7]. In our rat model, we confirmed that the LPS injection induced a biphasic response pattern with an initial decrease in peripher al body temperature accompanied by a prolonged period of increased $m H R$ with reduced total $H F$ from 0 to $+6 \mathrm{~h}$. Whereas this study just reported da $\mathrm{b}$ up to $6 \mathrm{~h}$ after treatment, our results also indicate that after that period the LPS e flects were still evident on the HRF. We have previously cha racterized the immunol ogical outcome of a $\mathrm{LPS}$ peri pheral a dministration at $0.1 \mathrm{mg} / \mathrm{kg}$ dose (identical dose as employed in this experiment); resulting in a substantial increment of peripheral pro-inflammatory cytokines leve $\mathrm{s}$ (tumor necrosis fuctor- $\alpha$, interleukin $1-\beta$ and interleukin 6 ) at $90 \mathrm{~min}$ after treatment [32] and central pro-inflammatory cytokines levels in the amygdala (tumor necrosis factor- $\alpha$, inter leukin $1-\beta$ ) at 150 to $200 \mathrm{~min}$ after treatment [33]. Here, we also found that in the longterm (ie +7 to $+9 \mathrm{~h}$ ) the HRF remain affected by this single dose of LPS (as indicated by lower SDNN values, Fig. 1b). This effect on the HRF may then be associated with the continuation in the long-term of elevated pro-inflammatory cy tolines levels as previously reported for shorter periods [33]. In fact, the SDNN has been associated with the peak expression of multiple cytokines by Fairchild et al [23] as it shows an inverse correlation with tumor necrosis fictor- $\alpha$ levels [34). Continuing with the interpretation of linear HRF parameters, a potential vagal withdrawal or cholinergic uncoupling is observed for the LPS group (indicated by a reduced RMSSD, Fig. 1c). The vagal function is known to play a critical role in the regulation of the inflummatory response via the CAP because the vagal modulation is inversely associated with the inflammatory process [35]. Thus, when the vagal activity is low, the inhibitory influence on inflammation gets disrupted resulting in an excess of peripheral pro-inflammatory cytokines $[36,37\}$.

Concerning the non-linear HRF parameters, we observed a signifcant alteration in the HRF scaling dynamics and non-linear properties for the LPS group. This indicates that in response to endotox in the fr actal-like structure of cardiac periods is modified. Thus, the decrement of the $\alpha_{n}$ and $\alpha_{n(M a c)}$ parameters (Fig $2 \mathrm{a}$ and Fig, $2 c$, respectively) may indicate the uncoupling of the autonomic and cardiac systems [4]

The $\alpha_{n \text { ascov }}$ short-term scaling parameter showed interesting changes, it was decremented after the LPS administration (Fig. $\mathbf{b b}, \mathrm{V}$ vs LPS). The alternations of the $R-R$ interval series can be visualized in the sign series; see example in Fig. 42. These alternations indicate a stronger anticorrelated behavior (for both the R-R interval series and the sign series) under the influence of the LPS. Tskinginto consideration that thesign of the heartbeat increments is related to the interaction between the sympathetic and the parasympathetic systems [38 ], such attemations should result from a sympathetic predominance during endobxemia (reflected as well as an increased mHR, Fig. 1a). In fact, HRF spectral dhanges found in previous studies are consis tent with a relative increase in sympathetic activity after LPS injection in adult animak [39]. Additional evidence supports that the scaling parame ter $\alpha_{\text {p(sacw) }}$ changes after the administration of an autonomic blocking drug in comparison to a placebo group [38). On the other hand, the exogenous oxytocin administration in conjunction with LPS produced a less anticorrelated pattern in the HRF during LPS-induced endotoxemia as

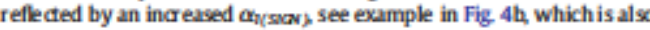
manifested by a decreased mHR, Fig. 12. The less anticorrelated pattern 
found in the LPS + Ox groups incomparison to LPS seems to be associated with an amplitude increment in the HRF owing to the administration of oxytocin.

By contrast, the linear RMSSD parameter $\mathrm{A}$ iled to reveal differences between LPS vs. LPS + Ox groups. This restriction may be related to the manifestation of small RMSSD changes by our experimental design because the parameter shows values near the resol ution established by the ECG sample frequency (ie. $\approx 0.5 \mathrm{~ms}$ ). Yet, this restriction is not appreciated with the $\alpha_{n\left(s c v_{0}\right)}$ scalingexponent, becoming a potential index to identify the cardiac cholinergic control as similar reported elsewhere [17].

Given the well characteriad "sidness behavior" induced by the LPS we discard that the bcomotor activity is the predominant factor explaining the dhanges of the HFF parameters reported here Therefore, our results may be also explained by the activa bon of the inflammatory response after the LPS administration as identifed by both a reduction of activity (Fig. 5b, V vs. LPS) and an increment of temperature (Fig. 52 , trending level of $\mathrm{F}=1.50 ; \mathrm{p}=0.07$ ). This interpretation is consis. tent with findings of studies showing that locomotion decreases following a LPS treatment in mice, thereby considering that the LPS administration may be used as a model for sickness-depression |40].

Our results for the peripheral temperature are in line with a previous study that reports the eflects of oxytocin in combination with LPS in humans $|12|$. Similarly, the eflects of axytocin on temperature during endotoxem ia seem to be manifested anly ward the end of our observation period (from +10 to $+12 \mathrm{~h}$ ). Therefore, these findings support the consideration that oxytodin might alleviate symptoms associated with systemic inflammation at long-term [41]. Noteworthy, Reid et al compared the core temper ature and the peripher al temperature a fter LPS injection in Holstein steers, which lead them to suggest that the core temper ature and the peripheral temperature do not move in synchrony after an LPS challenge, rather both follow an inverse relation $[42]$. In this sense, ourresults for temperature may have been influenced by the transmitters' location (i.e. subcutaneously implanted), consequendy more studies are still necessary to elucidate the influences of oxytocin in response to LPS-challenge on the regulation of body temperature.

Finally, locomotion was also influenced by the single dose of axytocin (Fig.5h, LPS vs LPS + Ox) that restricted the lethargic LPS-induced effects This condition may indirectly reflect the anti-inflammatory properties of oxy bcin. Indeed previous evidence suggests that a subchronic administration of oxytocin reduoes fatigue in older adults [43] and increases the effects of clonidine (an alpha 2-adrenoreceptor agonist) by reducing blood pressure and modifying the bocomotor activity in rats [44]. Although oxytocin has a half-lifeof only few minutes, the reduction in blood pressure in response to axytocin has not been observed untila bout 6 to $8 \mathrm{~h}$ after its first administrabon $\mid 44$. Thesecardiovasallar effects are coherent and timely coincident with the delayed changes introduced by oxytocin on rats' locomotion and HRF parameters during the LPS-induced endotoxemia of our study.

\subsection{Limilations}

It should acknowledge that we did not test different doses of axytocin that may modify our results. However, with the administration of a single low dose of oxytocin we were able to introduce changes in fr actal and non-linear parame ters of FRF during endotoxemia. Yet, owing to transmitter's modelused here and its actual bocation, the core temperature and blood pressure were not possible to be recorded.In fact, previous research suggests that oxytocin and LPS both decrease blood pressure in rodents $[45,46$, and lower values of HRF have 1 so been as. sociated to higher values of blood pressure $[47]$. Another indicates that LPS produces a rapidimparment of the baroreflex function [48], independently from the level of blood pressure, while oxytocin is likely acting on the baroreceptor reflex sensitivity as well $|49|$. Future work will consider applying higher doses of oxytodin as well as monitor ing the cholinergic spillovers, blood pressure and core temperature and trying other routes of administration to investigate the actual rela bonship between peripheral cytokines levels and HRF parameters.

\section{Conclusion}

During LPS-induoed endotoxemia the long-term HRF became mare anticorrelated (as indicated by lower values of $\alpha_{V\left(s_{2}\right.}$ ). In addition this endotoxemia was accompanied by: a) tachycardia, b) a lass of fractal heart rate dynamiss, c) changes in the peripheral temperature, and d) lethargic behavior. However, a concomitant single dose of peripheral oxytodin provolved a less anticorrelated pattem in the long-term HRF (as indicated by higher values of $\alpha_{\text {N(sock) }}$, restored the normal heart rate values, reduced lethargy and moder ated the LPS-induced hyperthermia. We suggest that the less anticorrela ted pattern in the HRF and decrea sed mean heart rate may result from a cardiac chol inergic autonomic coupl ing owing to both the concomitant administra bon of sys temic exogenous oxytocin during LPS-induced endotoxemia and its interaction with heart's oxytocin receptors.

\section{Conflict of interest}

The authors declare no conflict of interests.

\section{Acknomledgments}

J. Jwier Reyes-Lagos thanks the Mexican Council for Science and Technology (CONACYT) for providing scholarship (CVU/Scholarship number: 381983/253449). This work was partially funded by the Metropolitan University (UAM)- Mexico research and mobility funds to GPL, MAPC and JCE, as well as institutional funds of the University Hos. pital of Essen- Germany.

\section{References}

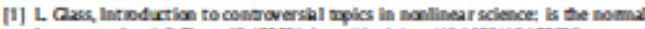

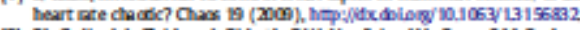

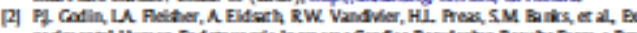

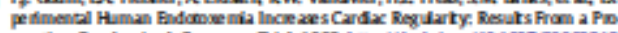

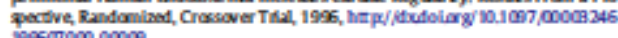
1006000000000.

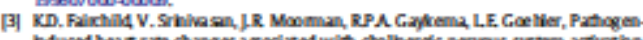

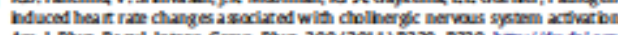

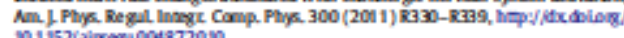

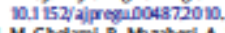

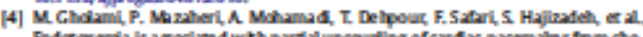

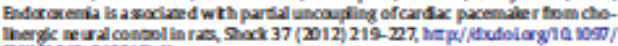

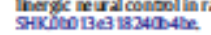

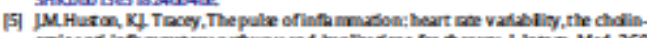

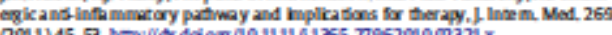

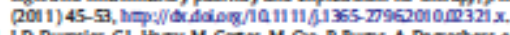

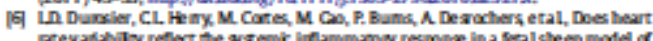

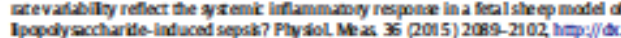

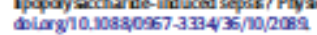

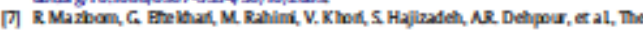

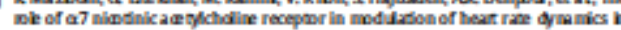

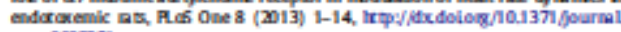
ponecos DSI.

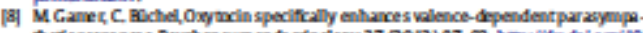

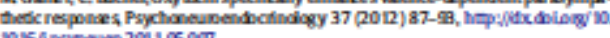
1015//posymeoen 20 i 105000 .

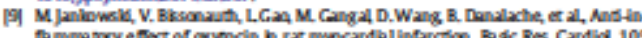

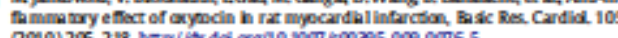

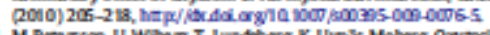

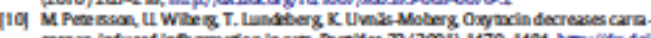

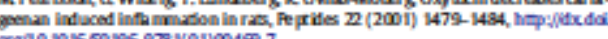

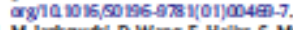

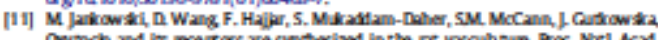

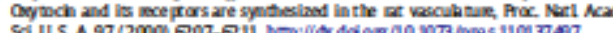

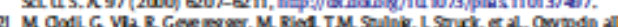

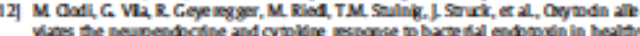

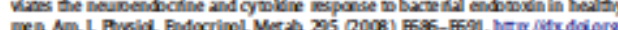

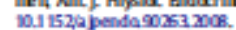




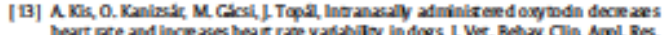

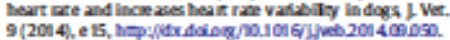

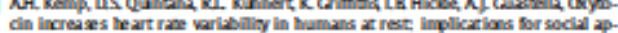

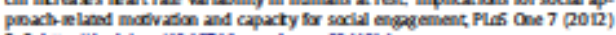

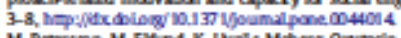

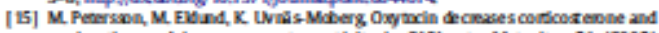

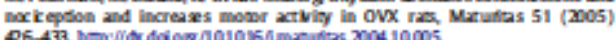

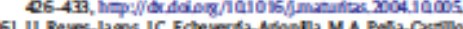

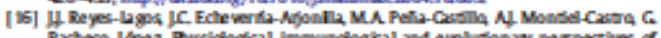

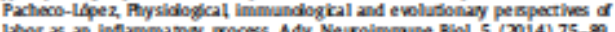

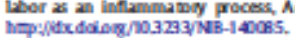

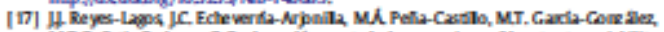

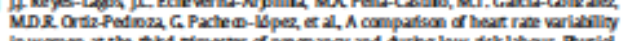

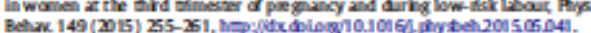

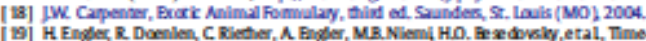

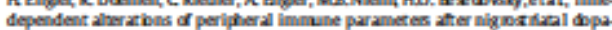

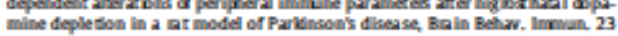

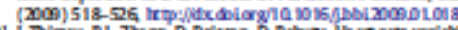

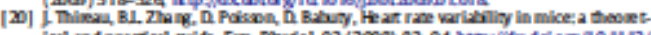

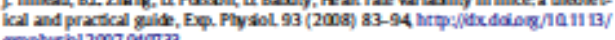

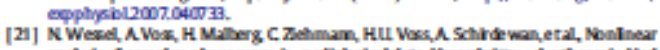

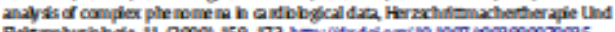

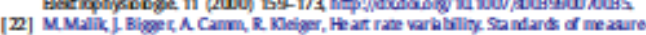

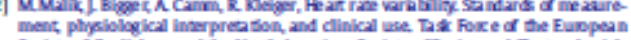

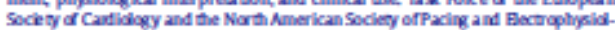

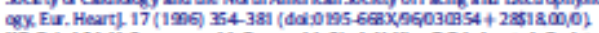

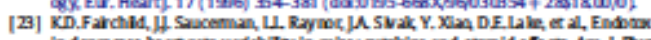

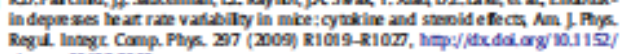
2ipreg $40132 \mathrm{mom}$.

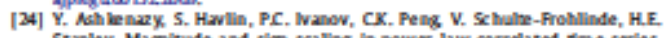
Stanley, Magitude and sly scalling in power-law correlated Ime series, S0378-437103700008- 6 .

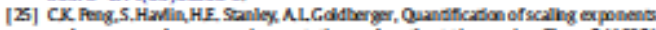

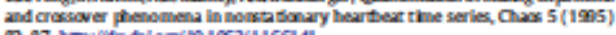

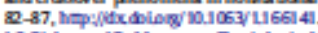

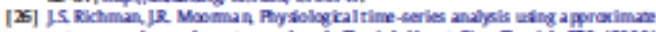

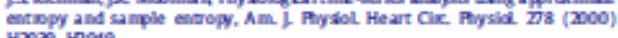

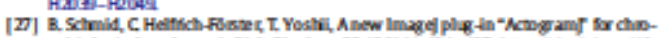

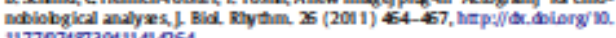
117707437304114106

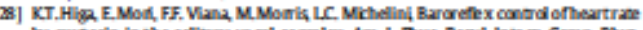

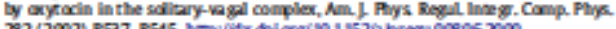

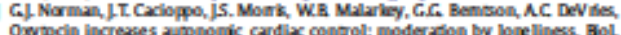

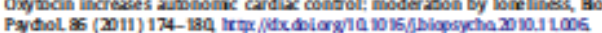

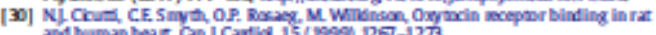

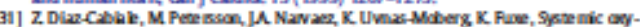

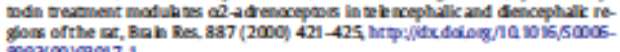

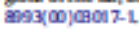

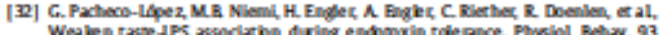

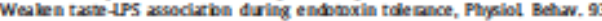

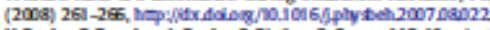

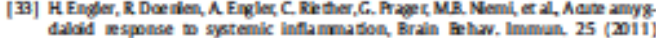

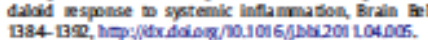

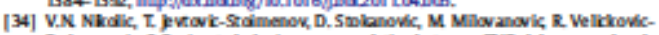

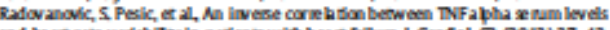

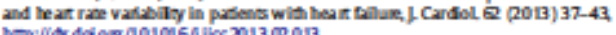

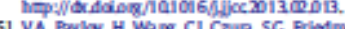

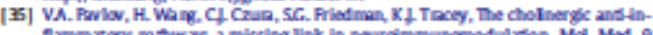

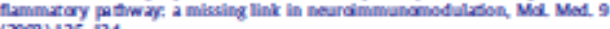

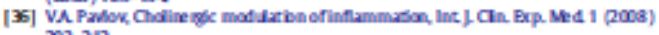

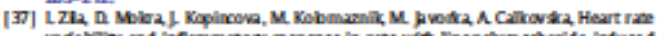

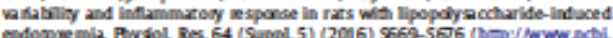

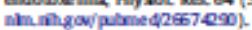

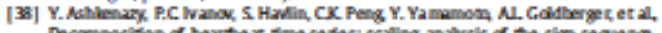
Decomposilison of hearthe $x$ time sedes: scaling andysls of the sliph sequenr.

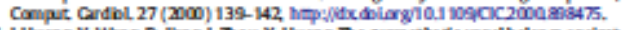

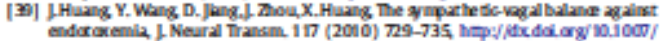
endoratemla f Neur

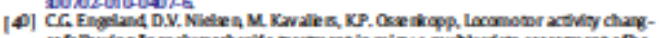

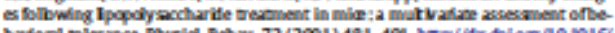

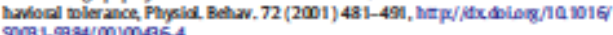

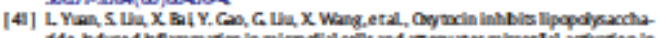

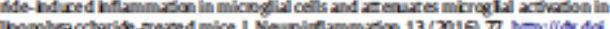
apoplyaccharis--averad mice,

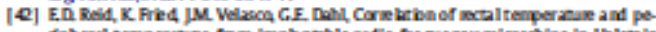

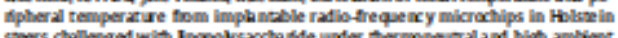

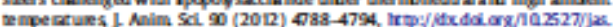
2011-005.

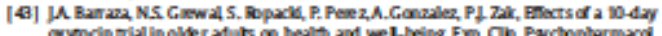

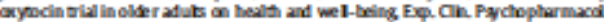

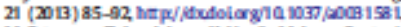

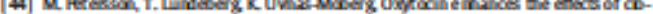

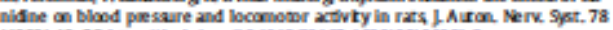

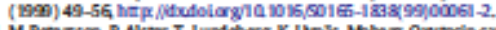

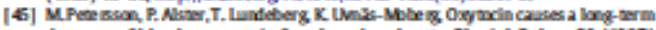

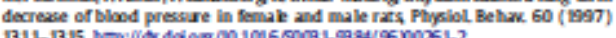

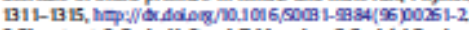

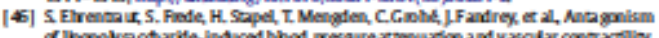

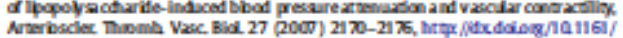
ATVBAHAIOV.14510.

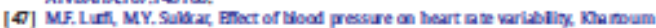
Med. 1 of (2011) $548-53$.

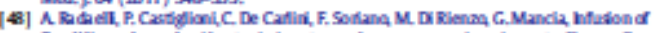

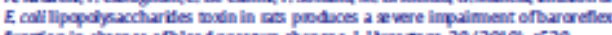

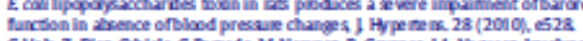

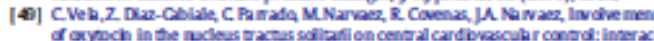

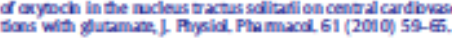




\title{
Physiological, Immunological and Evolutionary Perspectives of Labor as an Inflammatory Process
}

\author{
José Javier Reyes-Lagos ${ }^{2}$, Juan Carlos Echeverria-Ajonilla ${ }^{a}$, Miguel Ángel Peña-Castillo ${ }^{a}$, \\ Augusto J. Montiel-Castro ${ }^{\mathrm{h}, \mathrm{c}}$ and Gustavo Pacheco-Lopez, ${ }^{c, *}$ \\ "Electrical Engineering Department, Universidad Autonoma Metropolitana (UAM) Campus Iztapalapa, \\ Mexico City, Mexico \\ ${ }^{b}$ Darwin Center for Evolutionary Thinking (CEDAR), Philosophy Department, Social Sciences and Humanities \\ Division, Universidad Autónoma Metropolitana (UAM) Campus Iztapalapa, Mexico City, Mexico \\ ${ }^{\mathrm{c}}$ Health Sciences Department, Universidad Autonoma Metropolitana (UAM) Campus Lerma, Lerma, Mexico
}

\begin{abstract}
The precise mechanisms for the onset of labor at term remain unknown, yet several studies in humans reveal the role of cytokines in the initiation and maintenance of labor, showing many of the hallmarks of inflammation. Recent findings suggest a possible relationship between the activity of the autonomic nervous system (ANS) and the vagal anti-inflammatory response during labor. Furthermore, the role of vaginal microbiota is particularly important during pregnancy because vaginal dismicrobism is one of the most important mechanisms associated with preterm birth. In this review, we present evidence suggesting that a sterile anti-inflammatory response is manifested to attenuate the excessive inflammation introduced by low-risk labor at term, involving either the action of a cholinergic pathway, uterine-like myokines or the vaginal microbiome.
\end{abstract}

Keywords: Anti-inflammatory response, heart rate variability, vaginal microbiota, pregnancy, labor

\section{INTRODUCTION}

Human pregnancy and labor are physiological scenarios during which the fetal allograft must be tolerated, fed and allowed to grow. The process of labor is mounted to deliver the fetus from the woman's uterus [1]. Parturition is characterized by both cervical ripening and myometrial maturation followed by uterine contractions leading to cervical dilatation and birth [2]. Given that labor seems to be driven by pro-inflammatory cytokines, we suggest that it shows inflammation hallmarks and that the immune privileges that the fetal-placental unit enjoyed during pregnancy are suppressed at the time of labor [3].

\footnotetext{
"Cornespondence to: Dr. G.Pacheco-Lopez, UAM-Lemme, Av.de las Garras 10, Col. El Paniedn, Lemn, Edo Mexico, C.P. 52005, México. Tel: +52 728 2827002; Ext. 2014; E-mail: g.pacheco, corroo.leruammi.
}

During term and preterm labor different immunological changes are observed, including acute inflammatory features such as an increased influx of leucocytes and an elevated expression of proinflammatory cytokines that have been observed in cervical tissues and fetal membranes [4-6]. Likewise, many studies support the hypothesis that labor involves an inflammatory event [7-13], but more precisely, that human labor should be considered as a sterile inflammatory event mainly because it may be free of microbes triggering labor. According to Rock et al. [14], some sterile pro-inflammatory stimuli, like dead cells, irritant particles (including crystals, minerals and protein aggregates), trauma, immunogenic antigens and autoimmune conditions can cause an inflammatory response. An important finding was that all of such stimuli elicit this inflammation through the same cytokine mediator, interleukin-1 (IL-1) [14]. Given that

ISSN 1878-948X/14\$27.50 e 2014 - IOS Press and the wathors. All rights reserved

This article is published anline with Open Access and distributed under the terms of the Creative Commans Attribution Non-Commercial License. 
labor implies substantial muscular work involving significant physical efforts, with an important metabolic activity $[15,16]$, we hypothesize that rigorous energy regulation must then be achieved by homoeostatic physiological processes during this final stage of pregnancy where inflammation is also occurring.

Other authors have reported that an inflammatory input activates fast and subconscious antiinflammatory neural responses [17]. In fact, Huston and Tracey [18] defined a neuronal circuit acting as the anti-inflammatory reflex in which the main component is the descending branch of the vagus nerve. Centered on this model, action potentials coming from vagus nerve lead lymphocytes to release acetylcholine that inhibits the production of pro-inflammatory cytokines through $\alpha 7$ nicotinic receptors [18, 19]. This consideration then leads to propose that the observation of the activity of the vagus nerve can provide a suitable tool for measuring an anti-inflammatory reflex in various physiological contexts, thereby supporting a relationship between the activity of the autonomic nervous system (ANS) and an anti-inflammatory response [18]. A conventional noninvasive method to assess the ANS is by analyzing heart rate fluctuations (HRF) data [20] In general, linear and non-linear methods are applied to obtain measures that are used to estimate parasympathetic and sympathetic activities [20]. Additionally, some studies reinforce the consideration that the cardiovagal activity, quantified by the analysis of $\mathrm{HRF}$ data, could provide insights to understand the inmunovagal route [21].

In addition, the role of vaginal microbiota in relation to the process of labor may be particularly important because vaginal dismicrobism is one of the most important mechanisms associated with preterm birth and perinatal complication [22]. Some authors have reported that a probiotic dietary supplementation can be related to a global anti-inflammatory effect on the vaginal immunity, with potential implications in preventing preterm birth [23]. However, most of the vaginal microbiota of pregnant women has been studied during pathological situations such as bacterial vaginosis and aerobic vaginitis [24-28]. As the role of microbiota should not be limited to pathological conditions, we consider necessary to reevaluate the physiological role of vaginal microbiota during pregnancy and its relationship with inflammation.

Current research on the microbiome is exposing several dependencies of the host on microbiota for the maintenance of health, and also the crucial role that endosymbionts may play in the initiation and propagation of disease. Thus, several experimental model systems, including mice, fish, insects, squid and non-human primates, continue providing important insights about the host-microbiota homeostasis [29, 30].

Focused in the physiological process of labor at term, the purpose of this review is to address the following questions linked to labor in healthy women: Is an anti-inflammatory reflex an adaptive response to cope with the excessive inflammation occurring during labor? Could this process be assessed by the analysis of heart rate dynamics, immunological biomarkers and the characterization of vaginal microbiota? To provide some insights into these questions, first we review important issues on the energetic homeostasis during labor. Then, by presenting evidence about the increased vagal modulation during labor at term indicated by HRF data, we focus on the sterile anti-inflammatory reflex. Finally, by means of a comparative approach, we present a few evolutionary aspects of the relationship between vaginal microbiota and pregnancy.

\section{ENERGY HOMEOSTASIS DURING LABOR}

During pregnancy, the fetus requires glucose and amino acids for its growth and development, which sets the pregnant woman to a continuous state of energydemand. Studies of protein and energy metabolism demonstrate the need of regulating the usage of those nutrients [31, 32]. Fat is deposited in maternal stores throughout pregnancy, providing an energy reserve of $30000 \mathrm{kcal}$ at the end of gestation [31]. Of course this reserve is important to satisfy the fetal requirements, but possibly, also, to confront an important period of energy expenditure caused primarily by an increasing contractile activity in the myometrium during labor. In fact, the maternal heart rate during labor increases up to levels comparable to moderate or heavy exercise [33].

The molecular mechanisms involved in the uterine quiescence during gestation and the induction of labor are not completely known, though it has been demonstrated that the energetic metabolism of the uterine muscle is different between pregnancy and labor [34]. As glucose represents the primary maternal energy reservoir during the first and second stages of labor [35], if labor is prolonged and the source of glucose is limited, gluconeogenesis can be insufficient. During normal labor, the concentration of free fatty acids and ketone bodies increases, leading to the recruitment of substrates other than glucose and a relative reduction of carbohydrates $[36,37]$. Thus, labor's efforts 
rapidly decrease the availability of carbohydrates, leading the women's body to metabolize fat for obtaining energy. Consequently, the availability of amino acids in the mother's and fetus' bloodstream is reduced, while the fatty acids and ketones increase [38]. Furthermore, Scheepers et al. suggest that maternal hyperglycemia occurs during labor, leading to increments in maternal and fetal lactate production, resulting in metabolic acidosis [35].

It is well known that, during physical activity, the consumption of energy is linked to the actual duration of this activity [39]. But, given that labor can be extended for several hours (the average time of labor for a primiparous woman is about 16 to 17 hours) [40]. it becomes a high energy-demand process similar to that of mid-heavy exercise according to Sōhnchen et al. [33]. One may ask how much energy is being used during labor. For instance, if the energy expenditure for a $55 \mathrm{~kg}$ woman during moderate and heavy exercise is between $3.5-7.7 \mathrm{Kcal} / \mathrm{min}[41]$, therefore the estimate of energy consumption is $3400-7900 \mathrm{Kcal}$ for a woman during 16 to 17 hours in labor. However, there is few empirical information about energy-expenditure during labor. It has reported as low as $50-100 \mathrm{Kcal}$ per hour of active labor [42] and as high as $300-520 \mathrm{Kcal}$, Maganha and Peraçoli [43]. Why is this big variation occurring? One likely answer may be related to the differences in energy expenditure between the first and second stages of labor [44]. However, Katz et al. have reported that due to the intermittent character of uterine contractions, normal labor and delivery do not impose high energy demands on the parturient, but that a prolonged labor may result in maternal metabolic disturbances [45]. Thus, these considerations provide opportunity for the realization of future research on this phenomenon.

Other studies indicate that rather than lipids, the pregnant uterine smooth muscle uses glucose as its main nutritive metabolite, and that compared to the striated muscle, the anaerobic pathway of the glucose metabolism is more active in the myometrium [46]. Also, it has been suggested that glucose has a critical role as the principal fuel for ATP formation and both the adenylate kinase and $5^{\prime}$-nucleotidase reactions are involved in any event of glucose shortage [46]. Other studies suggest that glycogen is important because the myometrium content in pregnant rats was found to be increased just prior to parturition [47]. Findings during the latter half of pregnancy in pregnant rats showed gradual increments of insulin binding sites that peaked on the day of parturition [48]. Other findings suggested the effectiveness of insulin in the uterus of pregnant rats, showing that its sensitivity in the myometrium was similar to that observed in skeletal muscle [49]. Thus, myometrium inflammation by means of insulin resistance may be required for maintaining the flow of energy that sustains uterine contractions.

From an immunological point of view, laborcan also be considered as an inflammatory event [7-13]. From this perspective, the regulation of energy homeostasis and the immune response is crucial for an organism's survival [50]. For example, in chronic inflammatory diseases, balanced energy-rich fuel supply is largely disturbed due to the vast consumption of an activate immune system [50]. In turn, this process must be occurring during labor as well to fulfill the energy consumption of the mother and fetus. Thus, the maternal immune response and the metabolic regulation should be integrated and the proper function of each must be highly dependent on the other. According to Hotamisligil et al. this interrelation can be viewed as a central homeostatic mechanism [51]. It is well known that an immune response involves a substantial investment of energy [52-54]; therefore, immunity is dependent on a trade-off between other highly demanding energy processes [55]. Labor is a process of energy consumption where the energy-immune trade-off between mother and child is still unclear. Thereby, from this point of view, labor can be regarded as an 'energy demand reaction' caused by the activity of the immune system, the mobilization of fuel stocks (lipolysis/glucogenolysis), and the induction of insulin resistance in liver, adipose tissue and skeletal muscle with the overall purpose of allocating energy-rich fuels to the activated immune cells [50] and, clearly, also the myometrium.

An orthodox trigger inflammation is infection, with the inciting stimulus being certain molecules of the invading microbes. However, several other stimuli, including mechanical trauma, ischemia, toxins, minerals, crystals, chemicals, and antigens, also trigger inflammation in a so called sterile fashion [14]; thereby, we presume that a possible phenomenon of sterile inflammation could be labor itself. Considering that most of the signs and symptoms of inflammation are caused by changes in the local vasculature of an affected tissue [56], in case of spontaneous delivery and preterm labor, there are changes mediated by inflammation in the cervix tissue and the myometrium membranes $[3,4]$. As the immune system needs many energy-rich supplies [57], local inflammation must be supported by fuel provision from local or systemic stores. Thus, the participation of an anti-inflammatory response is vital to restrain inflammation [17] and to limit the energy demands. 
This situation then raises the question: Is it possible to identify a sterile inflammatory response during lowrisk labor at term in women?

Any answer to this question should first consider that labor becomes exacerbated by inflammatory process. In fact, pro-inflammatory cytokines such as interleukin: IL-1, IL -6, Tumor Necrosis Factor (TNF- $\alpha$ ), IL-8, IL- 16, Monocyte Chemoattractant Protein 1 (MCP -1), Macrophage Inflammatory Protein (MIP- $1 \alpha$ ), and chemokine CCL.5 are all known to be involved as responsible factors for preterm labor [58]. Furthermore, these cytokines are present in high concentrations in the amniotic fluid of patients with infection or inflammation, stimulating uterine contractility by inducing prostaglandins. As it has been demonstrated that the activation of Nuclear factor $\kappa \beta(\mathrm{NF}-\kappa \mathrm{\beta})$ in human myometrium up-regulates inhibitory progesterone isoforms [59], some studies have found that the NF- $\kappa \beta$ is a key modulator of these pathways and acts by regulating the expression of prostaglandins, chemokines and the pro-inflammatory cytokines involved in both term and preterm labor $[1,60]$. The removal of the immunosuppressive and quiescent influences of progesterone by its functional withdrawal may in fact itself be initiated by the inflammation and activation of NF- $\kappa \beta[1,61]$. Therefore, they induce premature labor and birth; yet, apparently, the anti-inflammatory cytokine IL - 10 has an important role in regulating the immune response because an increased concentration of it during preterm and labor at term in amniotic fluid has also been identified [58].

\section{A STERILE ANTI-INFLAMMATORY REFLEX DURING LABOR}

As described above, pregnancy itself involves an inflammatory process associated with increased proinflammatory cytokines $[1,4,58,60]$. In this sense, it is also known that progesterone has an immunosuppressive role which promotes the immune privileges of the fetus and regulates the levels of cytokines in the maternal-fetal interface. However, when labor is triggered, these privileges are no longer preserved, causing a sterile inflammation (dilation of cervix, effacement and uterine contractions) and producing pain [3]. Therefore, to oppose this inflammation, the anti-inflammatory cholinergic reflex, among other mechanism explained, could in principle restrain, as in other contexts, the release of pro-inflammatory cytokines [17]. In some conditions, a synergistic coactivation of sympathetic/parasympathetic systems [17] is also manifested through the release of adrenaline/noradrenaline and acetylcholine, respectively. Because pain and fight reflexes are probably manifested during labor, a sympathetic participation may also be involved. Thus, both systems may probably act to down-regulate inflammation (Fig. 1).

Considering the role of myokines [62], it is now recognized that skeletal muscles express and release myokines into the bloodstream in response to muscle contraction by physical activity. Given that muscle fibers express the myokine IL-6, some studies support the relationship between an anti-inflammatory effect of exercise and IL $-6[63,64]$ because these myokines stimulate the production of the classical anti-inflammatory cytokines IL-1ra. A direct parallel between the three major myometrial phenotypes (i.e. proliferative, synthetic, and contractile/labor) and the three phases of immunological transformation (i.e. initiation, tolerance and activation) [65] has even been reported, thus pointing to the question over what is the participation of myometrial myokines during labor? Some reports suggest that the stretch of uterine myocytes increases the IL-8 mRNA expression during the onset of labor [66]. Moreover, that the cytokines IL-1B, IL -6 and IL -8 levels are higher in maternal serum during the onset labor than those of non-labor women [67]. By making an analogy between exercise and labor, we hypothetisize that the strong uterine activity induces a sterile anti-inflammatory reflex by means of myokines production.

One of the major triggers of inflammation is infection, being certain molecules of the invading microorganisms the inciting stimuli [68-70]. In this context, because labor must be free of microbes that trigger it, and in comparison with some preterm labors triggered by bacterial infection [22], low-risk labor could be considered as a sterile inflammatory event. However, while the final inflammatory manifestation of labor should be similar between infectious and sterile triggers, the specific control of the response may be different. Thereby, each inflammatory input may activate a distinct anti-inflammatory response; in case of low-risk labor at term a sterile anti-inflammatory response. Results showed that the IL -1 pathway plays a key role in the neutrophilic inflammation to diverse sterile stimuli, including a variety of irritant particles and dead cells [14]. Interestingly, this same cytokine has been implicated in the mechanism of human parturition, because some results showed that pregnant women without labor had undetectable IL $-1 \alpha$ concentration in comparison to a labor group [71]. 


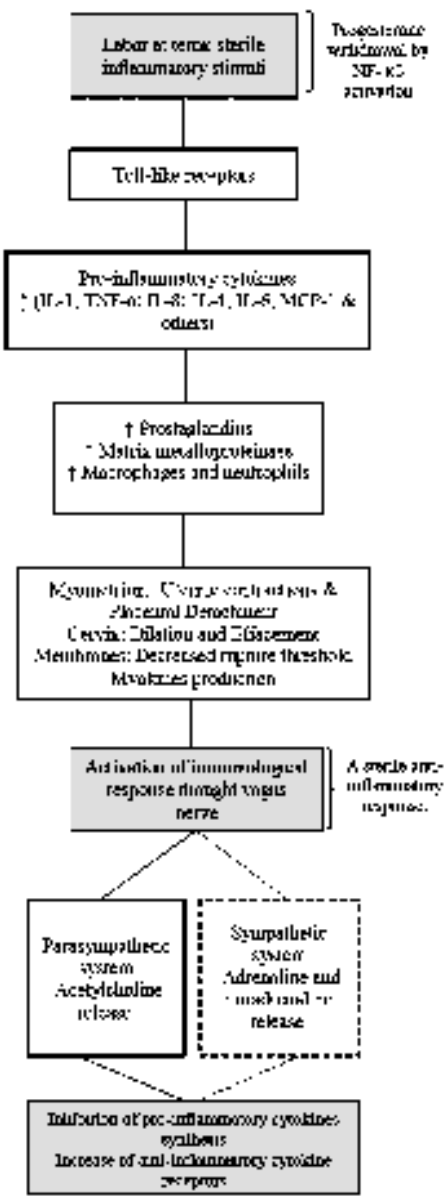

Fig. 1. Diagram of the inflammatory process as a mechanism present during labor and its possible association with a regiona anti-inflammatory sterile response. According to Traccy $\mathrm{KJ}, 2002$, this responsec sol a syarestic action by the sympathetic/parasympathetic systems is contend with inflammation. Uterine-like myokines and the vaginal microbiome may also be imvolved (see tert). (Image adapted from Peltier MR, Immunology of term and preterm labor, 2003)

INCREASED VAGAL MODULATION DURING LABOR AT TERM

A noninvasive method to assess the autonomic nervous system (ANS) is the analysis of HRF data. HRF analysis aims to separate and quantify the autonomous cardiac response in sympathetic (adrenergic) and parasympathetic (cholinergic-vagal) influences. The sympathetic and parasympathetic branches of ANS and their influences on heart rate (HR) and HRF are well understood. Sympathetic activity tends to increase HR and decrease HRF, whereas parasympathetic tends to decrease HR and increase HRF [20].

The time intervals between consecutive heart beats are measured in the electrocardiogram (ECG) from the beginning of a QRS complex to the beginning of the next QRS complex. They are conventionally named RR intervals (Fig. 2a). Thus, the HRF is defined as the variation of consecutive RR intervals. Among different mechanisms, this variation depends on the autonomic control of the heart.

A group of researchers began a series of discussions about the role of HRF analysis as an index of autonomic control, concluding that different analysis techniques of HRF provided indices associated with the autonomic control of the heart [72]. Recent studies have specifically linked the cholinergic antiinflammatory activity with changes in some of these HRF indices; thereby, considered as important parameters useful for recording the activity of such pathway [18]. In particular, given that the root mean square of the successive differences (RMSSD) is commonly used as an index of a vagal nerve mediated cardiac control, which is closely linked to respiration via the respiratory sinus arrhythmia (RSA) [73], this is one of the HRF time-domain tools that may be likely linked to the anti-inflammatory cholinergic reflex [74]. Parasympathetic activity can also be quantified by the power-spectral analysis of the HRF, providing the high frequency (HF) index. Which physiological inflammatory processes modify the RMSSD index? For instance, some atopic diseases, such as dermatitis, have been linked to changes in the autonomic modulation towards a higher parasympathetic influence. Patients with dermatitis had higher values of parasympathetic parameters (increased RMSSD) than controls. Therefore, authors have concluded that regional adjustments should be caused by anti-inflammatory cholinergic reflex relieving dermatitis symptoms [75]. Furthermore, other studies reinforce the suggestion that cardiovagal activity, quantified by the analysis of HRF, could provide insights to understand the immunovagal route [21]. Importantly, some clinical studies have also evaluated the relationship between inflammation and HRF parameters in different contexts [76-84].

In a recent study, we explored vagal modulation during labor at term assuming that an anti-inflammatory 
a)
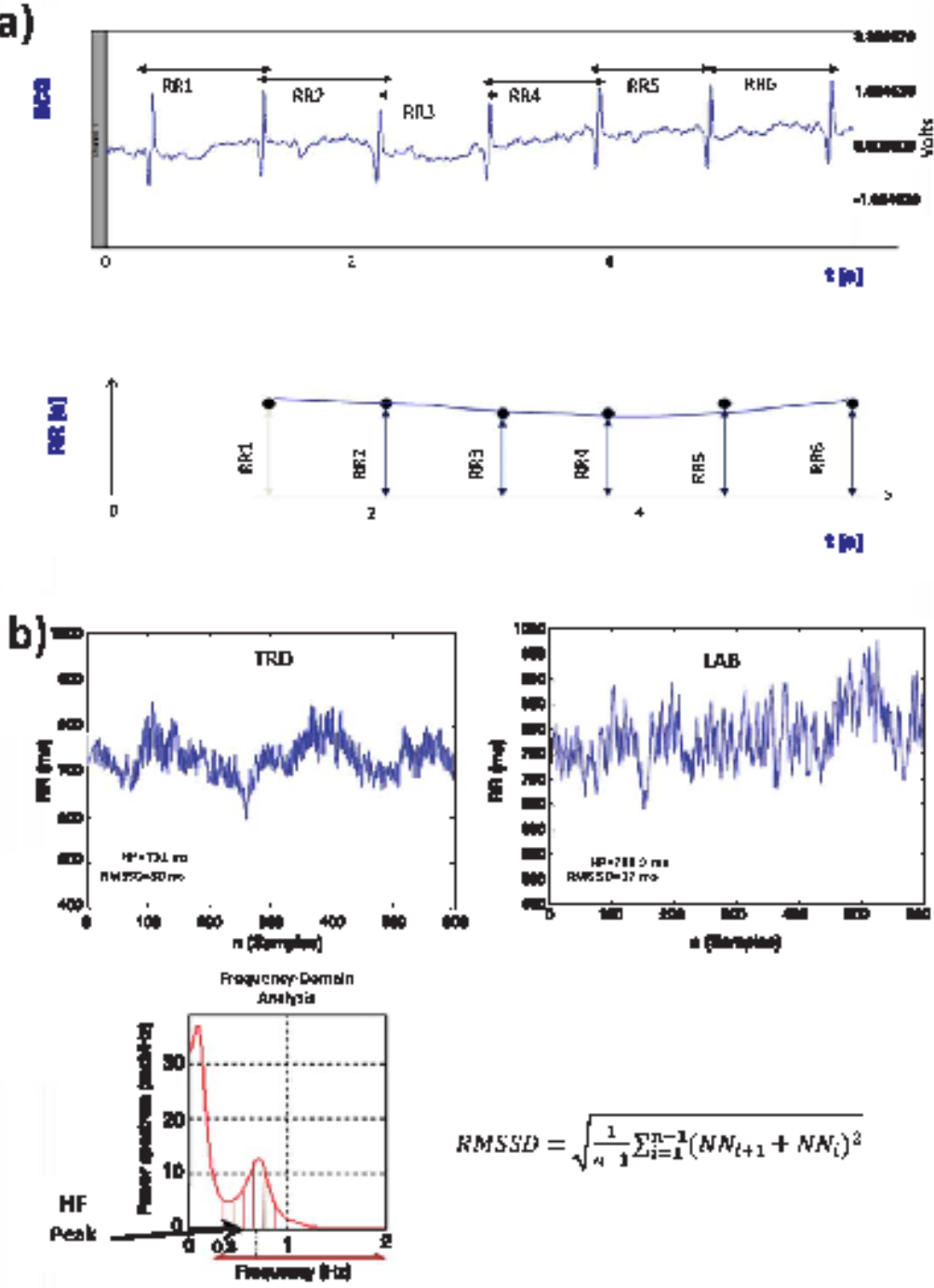

$$
R M S S D=\sqrt{\frac{1}{4-1} \sum_{i=1}^{n-1}\left(N N_{t+1}+N N_{i}\right)^{2}}
$$

Fig. 2. a) An RR interval is the elapeed time between two saccessive QRS completes of the ECG. RR intervals show the variation between consecutive heartheats. Heart rale fluctuations (HRF) measurements analyze bow these RR intervals change over time. b) Typical data of heart beat flucturtions during the last trimester of pestation prior to libor TRD (left) and during labor at term LAB (Right) segments. Values of the parameters HP and RMSSD calculated for those series are also depicted. Boetom of the figure illustrates how these parameters are obtained. 
cholinergic response was manifested during low-risk labor. Thus, once obtained informed consent, we collected at Maternal and Child Research Center, Mexico City, Mexico(CIMIGen), 10 minutes segments of electrocardiogram (ECG) from 30 women in low-risk labor at the semi-Fowler position (mean age of $26 \pm 5$ years) without any complication and with normal pregnancy outcome: mean APGAR (5 minutes) $8.9 \pm 0.7$ point, gestational age of $40 \pm 1$ weeks and birth weight of $3175 \pm 297 \mathrm{~g}$.

Women received intravenous oxytocin during early labor to improwe contractility. The ECG were recorded during periods with low uterine activity or not presenting contractions at all (LAB group), with the purpose that hemodynamic changes due to uterine contractions did not affect the HRF measurements. A second group included HRF data segments collected during the last trimester of gestation prior to labor from a different group of 30 pregnant women (TRD group) with gestational age of $35 \pm 2$ weeks.

A ECG portable device, Monica AN24, was used for data acquisition. Sampling frequency was $900 \mathrm{~Hz}$. Required segments were delineated visually by using the device's software, displaying values of maternal and fetal heart rate among ECG-derived uterine activity.

Raw maternal ECGs were then processed using previous validated algorithms to generate RR intervals or HRF series corresponding to LAB and TRD segments [85]. All series consisted of 600 samples (spanning 5 to 10 minutes duration).

Segments of both groups were analyzed to estimate the average heart period (HP), RMSSD, and HF peak index to estimate the respiration rate [86]. Previous research [87] has shown that the central frequency location of the HF peak of HRF (Fig. 2b) can be an appropriate index of respiration rate. Therefore, the HF component of HRF is a useful proxy for respiration rate when respiration is not directly measured.

RMSSD was estimated as:

$$
R M S S D=\sqrt{\frac{1}{n-1} \sum_{I=1}^{n-1}\left(N N_{l+1}+N N_{l}\right)^{2}}
$$

where $\mathrm{NN}_{\mathrm{i}}$ is the duration of the $\mathrm{i}$-th $\mathrm{NN}$ interval in the analyzed ECG, and $\mathrm{n}$ is the number of all $\mathrm{NN}$ intervals [20, 88].

We found RMSSD statistical differences $(p<0.03)$ between LAB and TRD groups $(36 \pm 14 \mathrm{~ms}$ vs. $25 \pm 13 \mathrm{~ms}$, respectively), without affecting neither HP ( $705 \pm 100 \mathrm{~ms}$ vs. $705 \pm 90 \mathrm{~ms}$, respectively), nor the
Table 1

Mean values ( \pm SD) of paramelers of HRF (HP, RMSSD and HF Peak). Gestitional age of $\mathrm{LAB}(40 \pm 1$ weeks) ve. gestitional ape of TRD $(35 \pm 2$ weeks) were statically different $(p<0.00001)$ between

\begin{tabular}{lccc}
\multicolumn{4}{c}{ LAB and TRD } \\
\hline GROUP & HP (ms) & RMSSD (ms) & HF PE.AK (Hz) \\
\hline LAB & $705 \pm 100$ & $36 \pm 14^{*}$ & $0.29 \pm 0.06$ \\
TRD & $705 \pm 90$ & $25 \pm 23$ & $0.29 \pm 0.06$
\end{tabular}

" $p<0.03$ between L.AB and TRD.

HF peak $(0.29 \pm 0.06 \mathrm{~Hz}$ vs. $0.29 \pm 0.06 \mathrm{~Hz}$, respectively); (Table 1).

These results indicate that the parasympathetic modulation of HRF was increased in the labor group (we found higher levels of RMSSD in LAB vs. TRD groups). This parameter then indicates an increased parasympathetic activity during labor that may reflect a counter-regulatory mechanism to restrain inflammation. Noteworthy, this increment did not affect the HP parameter and thus we can discard differences in the influence of ventilation between TRD and LAB groups as indicated by the HF Peak.

\section{PERINATAL MICROBIOTA}

It is now known that vaginal bacteria commensals, including Lactobacillus crispatus, $L$ jensenii, and $L$ rhamnosus, have strong associations with the vaginal epithelial cells. Vaginal bacterial commensals do not trigger cytokine secretion, but as Lactobacilli play and active role to modulate cytokine production [89], bacteria non-commensals can produce an inflammatory process. Also, this consideration is supported by the fact that recent discoveries of variation in the composition of the microbiome of healthy individuals [ $90-92]$ show the importance of identifying the processes that could possibly give rise to such variation [93], and there is a rising interest to study microbial community ecology and the healthy microbiota $[94,95]$.

Before considering pregnancy, it is necessary to review how is vaginal microbiota characterized in non-pregnant women. Studies have described the composition of the vaginal microbiota during nonpregnancy: Ravel et al. reported the results of a pyrosequencing analysis of vaginal specimens from a sample of 400 non-pregnant healthy women; they showed that the vaginal microbiota was dominated by Lactobacilli, including $L$ crispatus, $L$ iners, $L$ jensenüi and $L$ gasserii [91]. In accordance with these results, other studies support the observation that species of Lactobacillus dominate vaginal microbiota in most nomal and healthy women [96-99]. However, the 
dynamics of the community composition of vaginal microbiota are also affected by the phase of the menstrual cycle, ethnicity, and to a certain extent, sexual activity [100]. Moreover, it must be stressed that the concept of a "normal and healthy" vaginal microbiota is hard to describe without having a full understanding of its role and its effect on women's physiology According to some studies, one possible way to separate between healthy and unhealthy vaginal microbiota is based on the resulting predisposition to acquire sexually transmitted infections [98, 101].

On the other hand, further evidence indicates that the structure of the vaginal microbiota differs significantly during pregnancy, while other evidence suggests that the microbiota of pregnant women is less diverse and rich (in measured variance) throughout gestation and in proximity to the uterus. According to Aagaard et al. the richness of vaginal microbiota diversity is reduced in pregnancy, with dominance of the Lactobacillus species ( $L$ iners crispatus, jensenii and johnsonii, and the orders Lactobacillales, Clostridiales, Bacteroidales, and Actinomycetales [102]. In this study authors assume that the increased Lactobacillus dominance in the vaginal microbiota during pregnancy may be important for the first inoculum that determines neonate's upper gastrointestinal microbiota upon delivery, or for reducing the risk of ascending infection or preterm birth. In fact, these results may be linked with a remodeling of the gut microbiota over the course of pregnancy. The gut microbiota registered during the first trimester is comparable to that of normal healthy controls, but this similarity shifts substantially (in terms of phylogenetic composition and structure) over the course of pregnancy. By the third trimester an enrichment of Proteobacteria and Actinobacteria is observed in the majority of women [103]. Ottman et al. have reported that the activity and composition of the gut microbiota is affected by genetic background, age, diet, and health status of the host [104].

The possible interactions between gut and vaginal microbiota are caused by the close proximity of the vagina to the anus, exposing the vagina, cervix, and uterus to bacteria and other microorganisms, and somehow giving the intestine flora access to the reproductive tract via the rectum and perineum.

What factors lead to this unbalance or dismicrobism of vaginal microbiota? The incidence of vulvovaginal candidiasis, urinary tract infection, and bacterial vaginosis (BV), among other infections, affect vaginal microbiota [105-108]. For example, during BV the microbiota is dominated by Gardnerella vaginalis
[109] and a number of anaerobic organisms. In contrast, normal flora is dominated by various Lactobacilli producing an acid environment with $\mathrm{pH}$ in the range of 3.5 to 4.5 [110]. Bacterial vaginosis and aerobic vaginitis have been claimed as important mechanisms responsible for preterm birth and perinatal complications $[22,111]$. In addition, BV flora predisposes women to infection by the human immunodeficiency virus and sexually transmitted diseases [98]. Additionally, some authors even suggest that, given the hygienic practices of contemporary societies, an excessive use of feminine-hygiene products could cause imbalances in the vaginal microbiota which may promote infection [112].

It is also interesting to understand the mechanisms of defense used in the control of infections; vaginal defenses include: (i) mechanical barriers such as the mucus layer, hemocidin and fibronectin, (ii) host protective enzymes (e. g. lysozyme and lactoferrin), and (iii) host immune responses including the complement system and secretory immunoglobulin A (IgA), all of which are influenced by the vaginal microbiota [113-115]. Another way to sustain a healthy vaginal microbiota could be based on the oral and vaginal administration of probiotics. The application of multi-strain probiotics to improve pregnancy outcomes has already been tested in a pilot study, with some success in terms of modulating immune parameters and vaginal microbiota [23]. Such probiotic supplementation can be associated with a global anti-inflammatory effect on vaginal immunity, with potential implications for preventing preterm birth [23]. Particularly, $L$ rhamnosus GR-1 is able to up-regulate the anti-inflammatory cytokine interleukin 10 (IL-10) and the colony-stimulating factor 3 (CSF3); and, independently to down-regulate the pro-inflammatory cytokine TNF- $\alpha$ in human placental trophoblast cells [116-118]. Even the TNF- $\alpha$ has been associated with infection-mediated preterm birth [119, 120]. These studies have suggested that the administration of probiotics may help restoring and maintaining a healthy vaginal microbiota, and thus, that some probiotic strains seem to have the ability to interfere with the inflammatory pathway leading to premature delivery. Findings such as these lead us to suggest that some kind of immune modulation by the vaginal microbiota may be opposing the exacerbated inflammation process observed during labor.

Now, which is the importance of the vaginal microbiota for the newborn? At the time of birth, the newborn is exposed to maternal microbiota [121-124]. The passage through the genital tract is an essential part 
of this process because the mode of delivery alters the neonatal microbiome [121-126]. In this context, Dominguez-Bello et al. have shown that vaginallydelivered newborns acquired bacterial communities resemble their own mother's vaginal microbiota (dominated by Lactobacillus, Prevotella, or Sneathia spp.); and that caesarian section newborns harbored bacterial communities that were more similar to those found on the skin surface, dominated by Staphylococcus, Corynebacterium, and Propionibacterium spp. [121]. Other results indicate that Lactobacillus found in the maternal vagina influence the development of the neonatal immune system [127]. Maternal antibiotics during labor were associated with a decreased transmission rate of vaginal Lactobacillus flora to the neonate during birth, which may have a preventive role in the development of allergic diseases in the newborn [128]. This evidence could be supported by the findings of Reid et al., because they have found that in some cases of bacterial infections, nonspecific antibiotics are used, killing the non-pathogenic members of the microbiota as well as the pathogens and leading to a substantial delay in the restoration of a healthy microbiota [129].

\section{EVOLUTIONARY PERSPECTIVES}

As in humans, several taxa have developed associations with microbial life, affecting different aspects of their health, sociality and reproduction [e.g., insects 130, 131; aquatic organisms 132; amphibians 133; reptiles 134-136; birds 137, 138; carnivores 139, 140, primates $141,142 \mathrm{j}$. Accordingly, the vaginal microbiota may also be regarded as a symbiotic relationship. Symbioses are believed to be ancient, as they involve a long history of interdependence and natural selection involving the coevolution of microbial and host traits that reinforce the relationship [143].

Different species use a variety of behaviors which, acting also as social bonding mechanisms, may allow for the direct and indirect transmission of microbiota [144], including licking [145] and grooming [146]. For instance, crucial to regulation of mammalian development are maternal biochemicals provided to offspring through lactation [147]: an ancient adaptation arising several million years ago, with the function of protecting the product from both desiccation and colonization by microbial pathogens [148]. A study by Bailey and Coe [149] signals the importance of the mother-infant relationship. These authors found that in infant mesus monkeys, the integrity of their micro- biota suffered important modifications after separation from their mothers, suggesting that this social disruption lead to an internal environment that was more prone to infection by pathogens. Indeed, it is during suckling when infants receive specific microbe strains from their mothers [150]. A variety of milk components nourish a newborn by providing the compounds that promote growth, modulate the immune system, promote cognitive development and help establishing a nomal gastrointestinal microbiota [151]. For example, human milk contains large amounts of oligosaccharides that are not directly assimilated by infants. Instead, these oligosaccharides feed the bacteria $\boldsymbol{B}$. longum infantis, a primary link in the process of infant's nutrition that helps modulating the immune responses in the intestines and with an important role in the bioconversion of digested nutrients [152]. Some authors have suggested that, compared to that found in other primates and probably due to their beneficial microbiological properties, the significantly greater oligosaccharide concentration found in human milk could have been selected based on the particular disease ecology of humans [153].

Recent developments in metagenomic methods allow the identification of the microbial communities composition by means of DNA sequencing, without the need for specific cultures, providing important insights into within and inter-individual variation [154]. Evidence suggests that, in contrast to bacterial communities found in non-human primates and as described before, the healthy human vaginal microbiota is characteristically dominated by the presence of Lactobacillus [30]. Such findings allow asking about the selective pressures leading to the establishment of this relationship across the evolutionary history of the organisms involved. Stumpf et al. [30] have recently suggested three hypotheses explaining the comparative uniqueness of the human vaginal microbiome. Their first argument is that, given that the abundant Lactobacillus are related to estrogen levels in women of reproductive age, their presence could be related to differences in the reproductive cycles between humans and non-human primates. As the vaginal microbiota of most other nonhuman primates of reproductive age resembles that of non-reproductive human females, its presence could offer protective advantages from pathogens during the crucial periovulatory periods [30]. In this sense, comparative evidence from apes suggests that menopause is not common among chimpanzees [155], gorillas [156] or orangutans [157], and therefore, that the abundant presence of Lactobacillus and menopause could be both derived features of the human life-cycle [155, 


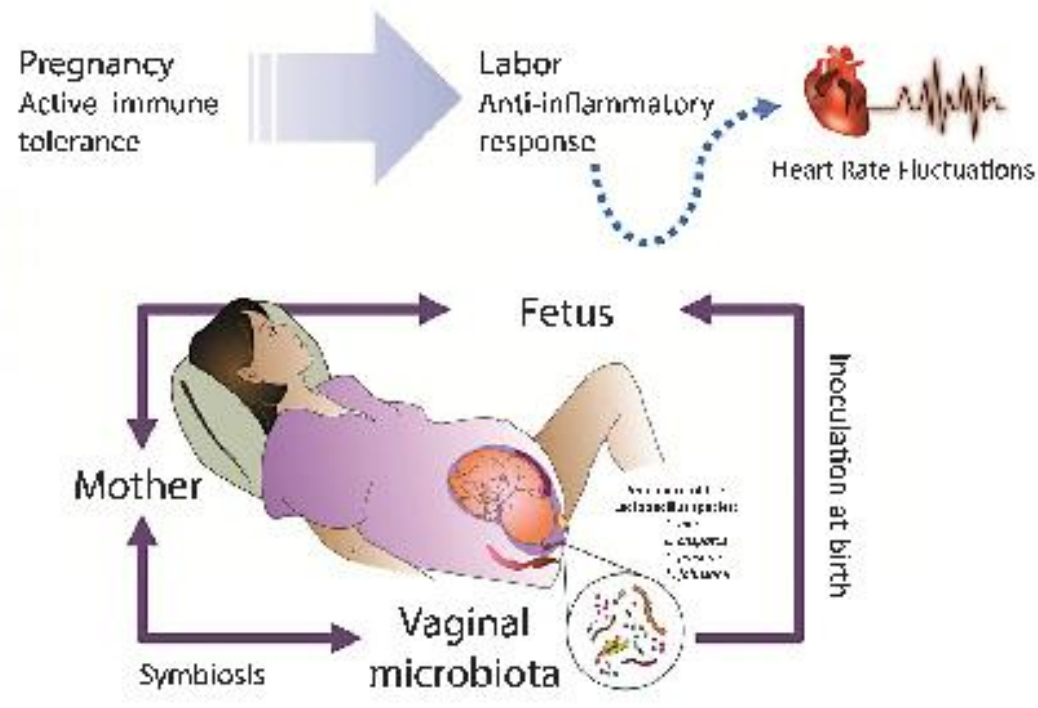

Fig. 3. Suggested interaction among mother, fetus and vaginal microbiota during laboc. A sterile anti-inflammatnry response is manifested daring low-risk labor at term, by either the action of a cholinergic puchway, dterine-like myokines or vapinal microbiome (Image adapted from [159]).

158]. The second hypothesis of Stumpf et al. is that the uniqueness of the human vaginal microbiome may be related to human's unique sexuality, i.e., the continuous female sexual receptivity increases females exposure to greater risks of infection and thus a symbiosis that could, somehow, minimize such risks would be highly advantageous and selected. Perhaps current developments involving the primate vaginal microbiome should focus research efforts on the wide variety of primate's reproductive systems and expand our knowledge on this aspect of the distinctiveness of the human primate [30]. Last but not least, by means of an "obstetric protection hypothesis", Stumpf et al. suggest that the size of the product in relation to the size of the pelvic outlet could increase the risks of infection to the mother and the fetus, and therefore that a symbiosis reducing such risks would be highly advantageous [30].

\section{CONCLUSION}

On the basis of this review, we consider lowrisk labor at term as a sterile inflammatory event where three important entities come into interplay (Fig. 3). The first is the mother, whose HRF analysis provides a non-invasive tool to disentangle the role of the anti-inflammatory vagal reflex during labor. The second entity is the vaginal microbiota, where its immunomodulation properties may be based on the modification of bacterial colonies; in particular, the family of Lactobacilli seems to play a key role in this process. The final entity is the fetus, playing an important role on the labor process; the fetal heart rate fluctuations may also represent another important marker to understand more about the antiinflammatory process during the process of labor. While this is a promising path for future research, in this review we have focused our efforts in underlying the primary role of the mother.

\section{ACKNOWLEDGMENTS}

The support of volunteer mothers and staff of CIMIGen is gratefully acknowledged. J. Javier ReyesLagos thanks the Mexican Council for Science and 
Technology (CONACyT) for providing fellowship (CVU/Fellowship number: 381983/253449).

\section{CONFLICT OF INTEREST}

Authors report no conflict of interest.

\section{REFERENCES}

[1] Golightly E, Jabbour HN, Norman JE. Endocrine immune interactions in human parturition. Mol Cell Endocrinol. 2011; 335(1): $52-59$

[2] Narwitz ER, Robinsoon JN, Challis JR. The control of labor. N Engl J Med. 1999; 341(9): 660-666.

[3] Peltier MR. Immunology of term and preterm laboc. Rep Biol End. 2003; 1(122): 1-11.

[4] Challis JR, Lockwood CJ, Myrat L, Norman JE, Strauss JF, Petrnglia F. Inflammation and pregnancy. Reprod Sci. 2009, 16(2): $206-215$.

[5] Houben ML, Nikkels PG, Van CM, Visser GH, Rovers MM, Kessel H, de Wal WJ, Schuijff L, Evers A, Kimpen J, Bont L. The association between intruaterine inflammation and spontaneous vapinal delivery at term: A cross-sectional study. Plos One. 2009; 4(8): e6572.

[6] Duhicke A, Fransson E, Centini G, Andersson E, Bystrōm B, Malmstróm A,Petraglia F, Sverremark-Bkström E, EkmanOndeberg G: Pro-inflammatory and anti-inflammatory cytokines in human preterm and term cervical ripening. J Reprod Immunol. 2010; 84(2): 176-185.

[7] Osman L, Young A, Ledingham MA., Thomson A, Jordan F, Greer LA, Norman IE Leukncyte density and pro-inflammitory cytokine expression in human fetal membranes, decidua cervir and myometrium before and daring labour at term. Mol Hum Reprod. 2003; 9(1): 41-45.

[8] Thomson N, Telfer JF, Young A, Campbell S, Stewart CJ, Cameron IT, Greer LA, Norman JE. Leukocytes infiltrate the myometrium daring human parturition: Further evidence that labour is an inflammatory process. Hum Reprod. 1999, 14(1): $229-236$.

19] Ledingham MA. Thomson AJ, Jordan F, Young A, Crawfond M, Norman IE. Cell adhesion molecule expression in the
cervix and myometrium during prepnancy and parturition. cervix and myometrium during pregna
Otsitet Gynecol. 2001; $97(2)$ : 235-242.

[10] Winkler M, Fischer DC, Ruck P, Horny HP, Kemp B, Rath W. Cytokine concentrations and expression of adhesion molecules in the lower uterine segment during parturition at term: Relation to cervical dilatation and duration of labor. Z Gehurtshille Neonatol. 1998; 202(4): 172-175.

[11] Sennstrom MB, Dkman G, Westergren-Thorsson G, Malmstrom A, Bystrom B, Endresen U, Mlambo N, Norman M, Subi B, Brauner A. Human cervical ripening, an inflammatory peocess medialed by cytokines. Mol Hum Reprod. 2000 ; 6(4), 375-381.

[12] Yuan M, Jonlan F, Mclnnes IB, Harnet MM, Norman JE Leukocytes are primed in peripheral blood for activation during term and preterm labour. Mol Hum Reprod. 2009, 15(11): $713-724$.

[13] Young A, Thomson AJ, Ledingham M, Jondan FG, LA, Nocman JE. Immunolocalization of proinflammatory cytokines in myometriumcervix, and fetal membranes during human parturition at term. Biol Reprod 2002; 66(2): 445-449.
[14] Rack KI, Latz. E, Ontiveros F, Kano H. The sterile inflammatory response. Annu Rev Immunol. 2010; 28: 321-342.

[15] Sloane E, Biology of Women, 4th ed, New York: Wiley, 2001.

[16] DeCherney AH, Pernoll ML. Current obstetric \& gynecologic diagnosis \& treatment. 10th ed. Norwalk, Conn: Appletion 8 L L ange, 1994.

[17] Tracey KJ. The Inflammatory Reflex. Nature. 2002; $420(6917): 853-859$.

[18] Huston JM, Tracey KJ. The polse of inflammation: Heart rale variability, the cholinergic anti-inflammatory pathway and implications for therapy. J Intern Med. 2011; 269(1): 45.53.

[19] Rosis-Ballina M, Olofsson PS, Ochani M, Valdes-Ferrer SI, Levine YA, Rearion C, Tusche MW, Paviov VA, Andersson U, Chama S, Mak TW, Traccy KJ. Acetykholinesynthesizing $\mathrm{T}$ cells relay neunal signals in a vaqus nerve circuit. Science. 2011;334(6052): 98-101.

[20] Task Forte of the European Society of Candiology and the North American Society of Pacing and Electrophysiology. Heart nule variability: Standards of measurement, physiological interpretation and clinical use. Euro H J. 1996; 17(3): 354-381.

[21] Tonhajperova L, Mokra D, Visnovcon Z. Vagal function indexed by respinatery sinus anthythmin and cholinergic anti-inflammatory pathway. Respir Physiol Neurobiol. 2013; 187(1): 78-81.

[22] Donati L, Di Vico A, Nucci M, Quaqliazzi L, Spagnoolo T, Labianca A, Bracaglia M, Ianniello F, Caruso A. Paradisi G. Vaginal microbial flora and oulcome of presnancy. Arch Gynecol Obestet. 2010; 281: 589-600.

[23] Vitali B, Cruciani F, Baldassarre ME, Capursi T, Spisni E, Valerii MC, Candela M, Turroni S, Brigidi P. Dietary supplementation with peobiotios during late pregnancy: Outcome on vaginal microbiota and cytnkine secretion. BMC Microbiol. 2012; 12: 236 .

[24] Goldenberg RI、Culhane JF, lams JD, Romero R. Epidemiology and caseses of preterm birth. lancet. 2008; 371: demiollo 75 .

[25] Hillier SL., Nugent RP, Fischenhach DA, Krohn MA, Gỉbs RS, Martin DH, Cotch MF, Edelman R, Pestorek JG, Rao AV, McNellis D, Regan IA, Carry JC, Klehanoff MA. Association between hacterial vaginosis and preterm delivery of alow-birth-weight infant. The vaginal infections and prematurity study group. N Eingl I Med. 1995; 333: 1737-1742.

[26] MoGreqor 1A, French II. Bacterial vaginosis in pregnancy. Obodet Gynecol Surv. 2000; 55(5 Suppl 1): 1-19.

[27] Beigi KH, Yodin MH, Cosentino L, Meyn LA, Hillier SL. Cytokines, pregnancy, and bacterial vaginosis: Comparison of levels of cervical cytnkines in pregnant and nonpregnant women with bacterial vaginosis. J Infoct Dis. 2007; 196: 1355-1360.

[28] Mattsby-Baltmer I, Platz-Christensen IJ, Hosseini N, Rosén P.II-lbeta, II-6, TNFil pha, fetal fibronectin, and endoborin in the lower genital tract of pregnant women with bacterial vaginosis. Acta Obedet Gynecol Scand. 1998; 77: $701-706$.

[29] Kostic AD, Howitt MR, Garrett WS. Exploring hostmicrobioka interactions in animal models and humass. Genes Dev. 2013; 1;27(7): 701-718.

[30] Sumpf RM, Wilson BA, Rivern A, Yildirim S, Yeoman CJ, et al. The primate vapinal microbiome: Comparative content and implications for human heakth and disease. Am J Phys Anthr. 2013; 152(S57): 119-134.

[31] King JC. Physiology of pregnancy and nutrient metabolism. Am J Clin Nutr. 2000; 71 (5 Suppl): 1218S-1225s. 
[32] Scheepers HC, de Jong PA, Essed GG, Kanhai HH. Carbobydnite solution intuke during labour just before the start of the second stage: A double-blind study on metabolic effect: and clinical outcome. BJOG. 2004; 111(12): 1382-1387.

[33] Söhnchen N, Melzer K, Tejada BM, Jastrow-Meyer N Othenin-Girand V, Irion $\mathrm{O}$, Boul nal beart nule changes during labour. Fur J Obstet Gynecol Reprod Biol. 2011; 158(2): 173-178.

[34] Laudataki T. Energy metabolism of the myometrium in proynancy and labor. Zentralbl Gynakol. 1985; 107(9): 568573.

[35] Scheepers HC, de Jong PA, Essed GG, Kanhai HH. Fetal and malemal energy metabolism daring labor in melation to the available caloric substrite. J Perinat Med. 2001; 29(6). 457-464.

[36] Kashyap ML. Carbohydrate and lipid metabolism during human labor: Free falty acids, glucose, insulin and lactic acid metabolism during normal and orytocin-indsced labor for postmaturity. Metabolism. 1976; 25: 865-871.

[37] Felig P, Lynch V. Starvation in human pregnancy; Hypolycemin, hypoinsulinemia and byperketonemia. Science. 1970; $170: 990$.

[38] Keppler AB. The use of intravenous fluids daring labor Birth. 1988; 15: 75-79.

[39] Wood C, Ng KH, Honslow D. Time - m important variable

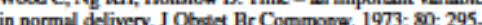
300 .

[40] Limmer D, et al. Emergency Care. 9th ed. Englewood Cliffs, New Jersey: Prentice Hall, 2000.

[41] McArdle WD, Katch FI, Kalch VL. Euercise Physiology Energy Nutrition and Human Performance, 6th ed. Baltimore, MD: Lippincott Williams \& Wilkins, 2007.

[42] Marchese T, Coughlin JH, Adams CJ. Nurse midwifery Health care for women and newborns. J Nurse Midwifery 1983; 18: 115-75.

[43] Maquana e Melo CR, Perapoli JC. Mewouring the energy spent by parturient women in fasting and in ingesting caloric replacement (Honey). Rev Lat Am Einfermagem. 2007; 1S(4): $612-617$.

[44] Banerioe B, Khew KS, Saha N, Ratnam SS. Energy cost and blood sugar level during different stapes of labour and dantion of labour in Asiatic women. J Obstet Gynaecol B Commonw. 1971; 78(10): 927-929. [45] Katz M, Kroll D, Shapiro Y, Cristal N, Meizner I. Enerzy
expenditure in normal labor. Isr J Med Sci. 1990; 26(5) 254.257.

[46] Steingrimsdoutir T, Ronquist G, Ulmoten U, Waldenstrōm A Different enerry metabolite pattern between uterine smooth muscle and striated roctus muscle in term prosnant women. Fur J Obstet Gynecol Reprod Biol. 1995; 62(2): 241-245.

[47] Chew CS, Rinand GA. Glyoogen levels in the nat myometrium at the end of prognancy and immediately postpartum. Biol Reprod. 1979, 20(5): 1111-1114.

[48] Sakamoto H, Leranth C, Macl usky NU, Saito Y, Naftolin F Insulin specific binding sites in the myometrium of pregnant nuts. Endocrinology. 1987; 120(5): 1951-1955.

[49] Fipueroa H, Marusic E, Gonzalez M, Barcos F, Yungue P. Efecto in vưso de la insulina sobre la capacidad contricti uterina inducida por oritocina. Rev Chil Obstet Genecol. 2002; 67(3): 184-189.

[S0] Strub RH, Cutolo M, Buttqereit F, Pongratz G. Energy regulation and meuroendocrine-immune control in chroni inflammatory diseases. J Intern Med. 2010,267(6): 543-560.

[51] Hotamisligil GS. Inflammation and metubolic disonders Nature. 2006; 444(7121): 860-867.
[52] Sadd BM, Schmid-Hempel P. Principles of ecological immunology. Evol Appl. 2008; 2: 113-121.

[53] Demas GE. The energetics of immunity: A neuroendocrine link between energy balance and immune function. Horm Behav. 2004; 45: 173-190.

[54] Lochmiller RI, Deerenberg C. Trade-offs in evolutionary immunology. Oikos. 2000; 88: 87-98.

[55] Paheco-Lopez G, Bermbdex-Rattoni F. Brain-immune interactions and the neunl hasis of disease-avoidant inges. tive behaviour. Philos Trans R Soc Lond B BiolSci. 201; 366(1583): 3359-3405.

[56] Majno G.Cells, Tissoves and Diveases: Principles of Ceneni Puthology. 2nd ed. Cambridge, MA: Oxford Univ. Press, 2004.

[57] Buttpereit F, Burmester GR, Bnund MD. Bicenergetic of immune functions: Fundamental and therapeutic mpects. Immunol. Today. 2000; 21: 192-199.

[58] Gotsch F, Romero R, Kuxanovic JP, Erez O, Espinona J, Kim CJ, Vaisboch E, Than NG, et al. The anti-inflammatory limb of the immune response in preterm labor, intm-amniotic infectioninflammation, and spontaneous parturition alt term: A role for interleukin-10. J Mitem Fetal Neonatal Med. 2008; $21(8)$ : 529-547.

[59] Condon JC, Hardy DR, Kovaric K, Mendelson CR. Uprequlation of the progesterone receptor (PR)-C isoform
in laboring myometrium by activation of nuclear factorkappal may contribute to the onset of labor through inhibition of PR function. Mol Endocrinol. 2006; 20(4): 764-775.

[60] Maclntyre DA, Sykes L, Teoh TG, Bennett PR. Prevention of preterm labour via the modalation of inflammatory path. ways. J Mitern Fetal Neonatal Med. 2012; 25(Suppl 1): ways. $17-20$.

[61] Stekeres-Bartho J, Wilcxynski JR, Basta P, Kalinka J. Role of progesterone and progestin therapy in threalened abortion and preterm labour. Front Biosci. 2008; 13: 1981-1990.

[62] Pedersen BK. Muscles and their myolines. JExp Biol.2011; 214(Pt 2): $337-46$.

[63] Surkie R, Ostrowski SR, Jauffred S, Febbraio M, Pedersen BK. Exercise and II-6 infusion inhibit endotoxin-induced TNF-alpha production in humans. FASEB J. 2003; 17: 844 886.

[64] Sieensberg A, Fischer CP, Keller C, Moller K, Podersen BK. IL-6 enhances plasmall-1n, II-10, and cortisol in humans Am J Physiol Endocrinol Metah. 2002; 285: E433-E437.

[65] Shynlova O, Lee YH, Srikhajon K, Lye SJ. Physiologic uterine inflammation and labor onset: Integration of endocrine and mechanical signals. Reprod Sci. 2013; 20(2): 154-167.

[66] Loudon IA, Scoranna SR. Bennett PR, Johnson MR. Mechanical stretch of human uterine smooth musxele cells increases II.-8 mRNA expression and peptide synthesis. Mol Hum Reprod. 2004; 10(12): 895-899.

[67] Hehisch G, Neumaier-Wagner PM, Huch R, von Mandach U. Mulemal senum interleukin-1 betn, -6 and -8 levels and potential determinants in pregnancy and peripartum. J Perinat Mad. 2004; 32(6): $475-490$.

[68] Motrhitov R. Origin and physiological roles of inflammation. Nalure 2008; $454: 428.435$.

[69] Akin S, Uematses S, Takeuchi O. Puthogen recognition and innate immunity. Cell. 2006; 124: 783-801.

[70] Inohan C, McDonald C, Nunez G. NOD-LRR proteins: Role in host-microbial internctions and inflammatory disease. Annu Rev Biochem. 2005; 74: 355-83.

[71] Romero R, Maroor M, Brandt F, Sepulveda W, Avila C, Cotton DB, Dinarello CA. Interleukin-1 alpha and interleukin-1 
beta in preterm and term human parturition. Am J Reprod Im in 1902 - $27(3-4): 117-123$

[72] Panti G, Mancia G, Di Rienzo M, Custiglioni P, Taylor IA, Seudinger P. Point-Counterpoint: Candiovascular variability is is not an index of autronomic control of circulation.J Appl Physiol. 2006; 101: 676-682.

[73] Bemtson GG, Lozano DI, Chen YJ. Filter properties of root mean square successive difference (RMSSD) for beart nate. Pyychophysiology. 2005; 42(2): 246-252.

[74] Thayer JF, Fischer JE. Heart rale varibility, ovemight urinary norepinephrine and $\mathrm{C}$-reactive protein: Evidence for the cholinergic anti-inflummatory pathway in heal thy human adults. J Intern Med. 2009; 265(4): 439-447.

[75] Boettger MK, Bär KJ, Dohrmann A, Müller H, Mertins L. Brockmeyer NH, Apelink MW. Increased vagal modulation in atopic demmatitis. J Dermatol Sci. 2009; 53(1) : 55-59.

[76] Godin PI, Fleisher LA, Eidkath A, Vandivier RW, Preas HI. Banks SM, Buchman TG, Suffrodini AF. Experimental human endotourmia incremes cardiac reqularity: Results from a prospective, nandomized, crossover trial. Crit Care Med. 1996; 24(7): $1117-1124$.

[77] Lohrer P, Kanuvidas MK, Lu SE, Coyle SM, Oikawa LO, Macor M, Calvano SE, Lowry SF. Voluntarily produced increases in heart nate variabifity modalate autonomic effects of endotorin indsoed systemic inflammation: An explorzlory study. Appl Psychophysiol Biofeedhack. 2010; 35(4): 303-315.

[78] Chuang HC, Hsuch TW, Chang CC, Hwang IS, Chuang KJ, Yan YH, Cheng TJ. Nickel-rogulated heart rate variability:
The roles of oridative stress and inflammation. Toxicol Appl Pharmacol. 2013; 266(2): 298-306.

[79] Alvarez SM, Kissamanis Karnides M, Coyle SM, Lu SE Macor M, Oikawa LO, Lehrer PM, Calvano SE, Lowry SF. Low-dose steroid alters in vivo endototin-indaced systemic inflammation but does not infloence autonomic dysfunction. J Endotoxin Res. 2007; 13(6): 358-368.

[\$0] Kox M, Ramaless BP, Pompe JC, van der Hoeven JG, Hoedemaekers CW, Pickkers P. Interplay between the acute inflammatory response and heart nite variability in healthy human volunteers. Shock. 2011; 36(2): 115-120.

[81] Gholami M, Munaheri P, Mohamadi A, Dehpour T, Safari F, Hajizadeh S, Moore KP, Mani AR. Endotouremia is asesociated with partial uncoupling of candiac pacemuler from cholinergic neural control in nuts. Shock. 2012; 37(2): 219. 227.

[82] Huang J, Wang Y, Jiang D, Thou J, Huang X. The sympathetic-nagl balance equinst endotoxemia. J Neural Transm 2010; 117(6): 729-735.

[83] Jan BU, Coyle SM, Macor MA, Reddell M, Calvano SF, Lowry SF. Relationship of basal heart nte variability to in vivo cylnkine responses after endotatin exposure. Shock. $2010,33(4): 363-368$.

[84] Jan BU, Coyle SM, Oikawa LO, Lu SE, Calvaso SE, Lehrer PM, Lowry SE. Influence of acute epinephrine infusion on endotoxin-induced parameters of beart nute variability: A nadomimed controlled trial. Ann Surg. 2009, 249(5): 750 756.

[85] Echeverria JC, Ortiz R, Ranirez N, Modina V, Gomzalez R. A reliable method for abdominal ECG signal processing. In: Proceedings of Computers in Candiology 1998, sep 13-16; Cleveland, OH, USA. pp. $529-532$.

[86] Tarvainen MP, Niskanen IP, Lipponen IA, Ranta-Abo PO, Karjaluinen PA. Kubios HRV - heart rale variability anal. ysis softwarc. Comput Methods Programs Biomed. 2014; 113(1): 210-220.
[87] Thayer IF, Peaskey C, Muth ER. Estimation of respiratory frequency from autoregressive spectral analysis of heart period. Biomed Sci Instrum 1996; 32: 93 -99.

[88] Malik M. Time-Domain Measurement of Heart Rate Varishility. Candiac Flectrophysioogy Rev. 1997; 1(3): 329-334.

[89] Rose WA 2nd, MoGowin C., Spagnoolo RA, Emes-Pyles TD, Popov VL., Pyles RB. Commensal bacteria modulate innate immune responses of vaginal epithelial cell mukiinnate immune responses of vaginal epithelial
layer cultures. PLoS One. 2012; 7(3). e32728.

[90] Palmer C, Bik EM, DiGiulio DB, Relman DM, Brown PO. Development of the human infant intestinal microbiota. PLoS Biol. 2007; 5(7): el77.

[91] Ravel J, Gajer P, Abdo Z, Schneider GM, Koenig SS, MoCulle SI, Karlebach S, Gorle R, Russell J, Tacket CO, Brotman RM, Davis CC, Ault K, Penalta L, Forney LJ. Vaginal microbiome of reproductive-age women. Proc Nat Acad Sci U S A. 2011; 108(Suppl 1): 4680-4687.

[92] Wu GD, Chen J, Hoffmann C, Bittinger K, Chen YY, Keilhaugh SA, Bewtn M, Kmights D, Walkers WA, Knight R, Sinha R, Gilroy E, Gupta K, Baldassano R, Nessel L, Li H, Bushman FD, Lewis JD. Linking long-term dietary patterns with gut microbial enterotypes. Science. 2011; 334(6052): 105-108.

[93] Costello EK, Stagaman K, Dethlefsen L, Bohannan BJ, Relman DA. The application of ecological theory toward an
understanding of the human microbiome. Science. 2012; 8 ; understunding of the hu

[94] Mihaljevic JR. Linking metacommunity theory and symhionts evolutionary ecology. Trends Ecol Evol. 2012; 27(6): 322.329.

[95] Prosser IL, Bohannan BJ, Curtis TP, Flis RJ, Firestone MK, Freckleton RP,Gireen Jl, Green LE, Killham K, Lennon JJ, Othom AM, Solan M, van der Gast CJ, Young JP. The role of ocoom AM, Solan M, van der Gast C, Young IP. The role of ecological theory in micr.

[96] Donders GG, Bosmans E, Dekeersmaecker A, Vereecken A, Van Bulkk B, Spitz B. Puchogenesis of abnormal vaginal hacierial flarn. Am JObstet Gynecol. 2000, 182(4): 872-878.

[97] Gapta K, Supleton AE, Hooton TM, Roberts PL, Fennell Q. Summ WE Inverse association of $\mathrm{H}_{2} \mathrm{O}_{2}$-producing women with recurrent urinary tract infections. J Infect Dis. women with recurrent 1998 ; $178(2): 446-450$.

[98] Martin HL, Richandwon BM, Nyange PM, Lavrcys L, Hillier SI, Chohan B, Mandaliya K, Ndinya-Achola JO, Bwzyo J, Kriss J. Vaginal lactobacilli, microbial florz, and risk of human immunodeficiency vinus type 1 and sexully transmitted disease acquistition. J Infect Dis. 1999; 18066): $1863-1868$

[99] Sobel JD. Is There a Prodective Role for Vaginal Flara? Curr Infect Dis Rep. 1999, 1(4): 379-383.

[100] Gajer P, Brotman RM, Bai G, Sakamoto I, Schütte UM, Zhong X, Koenig SS, Fu L, Ma ZS, Zhou X, Abdo Z, Forney IJ, Ravel J. Temporal dynamics of the human vaginal microbiokn Sci Transl Med. 2012; 4(132): 132ns2.

[101] Cherpes TL, Meyn LA, Krohn MA, Larie JG, Hillier SL. Asesciation between acquisition of herpes simplex virus type 2 in women and bacterial vaginosis. Clinlnfect Dis. $2003 ; 37(3)$ : $319-325$.

[102] Aagaard K, Riehle K, Ma J, Seguta N, Mistretta TA, Coarfa C, Raza S, Rosenbuam S, Van den Veyver I, Milosavlievic A. Gevers D, Hutienhower C, Petrosino J, Vensalovic J. A metapenomic approach to chanacterization of the vaginal microbiome signature in preqnancy. PLoS One. 2012; 7(6): e36466. 
[103] Koren O, Goodrich JK, Cullender TC, Spor A, Lautinen K. Bäckhed HK, GomznlezA, Werner IJ, Angenent IT, Knigh R, Bickthed F, Isolaun E, Salminen S, Ley RE. Hoot remod eling of the gut microbiome and metabolic changes during presnancy. Cell. 2012; 15063): 470-490.

[104] Ottman N, Smidt H, de Vos WM, Beher C. The function of cur micrubiock Who is out there and what do they do? Front Cell Infect Microbiol. 2012;2:104.

[105] Dielubanz $\mathrm{E}$, Schaeffer $\mathrm{N}$. Urinary tract infections in vomen. Mod Clin North Am. 2011; 95: 27-41.

[106] Quan M. Vaginitis: Diagnosis and management. Postgnd Med. 2010, 122: 117-127.

[107] Mili M, Gurel AB. The epidemiology, pathogenesis, and diegnosis of vulvovaginal candidosis: A mycological perspective. Crit Rev Microbiol. 2011; 37: 250-261.

[108] Hay P. Recurrent bacterial vaginosis. Curr Opin Infect Dis. $2009 ; 22: 82-86$.

[109] Menard JP, Fenollar F, Henry M, Bretelle F, Raoul D. Molecular quantification of Gandnerella vaginalis and Atopobiam vaginae loads to prodict hacterialvaginosis. Clin Infect Dis. 2008; 47(1): 33-43.

[110] Boskey ER, Telsch KM, Whaley KJ, Moench TR, Cone RA Acid production by vaginal flon in vitmo is consistent with the rate and extent of vaginal acidification. Infect Immun. 1999; 67(10): $5170-5175$.

[111] Li J, MoCarmick J, Bocking A, Reid G. Importance of vaginal microbes in reproductive health. Reprod Sci. 2012; 19(3): 235-242.

[112] Fashemi B, Delaney MI, Ondendonk AB, Fichorova RN Effects of feminine hypiene products on the vaginal mucoss biome. Microb Ecol Health Dis. 2013; 24.

[113] Witkin SS, Linhares IM, Giraldo P. Bacterial Bon of the female penital tract: Function and immune requlation. Best Pract Res Clin Otstet Gynocol. 2007; 21: 347-354.

[114] Mak P, Siwek M, Pobl J, Dubin A. Menstrual hemocidin HbBI is-146 is an acidophilic antihacterial peptide poten tiating the activity of human defensins, cathelicidin and lysazyme. Am J Reprod Immunol. 2007; 57: 81-91.

[115] Cohen MS, Black JR, Proctor RA, Sparling PF: Host defences and the vaginal mucosa A re-evaluation. Scand J Urol Nephrol Suppl. 1984; 86: 13-22.

[116] Yeganegi M, Leung CG, Martins A, Kim SO, Reid G. Challis JR, Bocking AD. Laxtrbacillus thamnosus GR-1 induced IIL-10 production in human placental tropboblas: cells imvolves activation of IAK/STAT and MAPK pathways. Reprod Sci. 2010; 17(11): 1043-1051.

[117] YeganegiM, I eung CG,Martins A, Kim SO, ReidG, Challis JR, Bocking AD. Lactobacillus hamnosus GR-1 stimulates colonystimulating factor 3 (granulocyte) (CSF3) cotput in placental trophoblast cells in a fetal sex-dependent manner Biol Reprod. 2011; 84(1): 18-25.

[118] Yeganegi M, Watson CS, Martins A, Kim SO, Reid G,

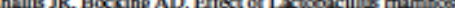
GR-1 supernatant and fetal sex on lipopolysaccharideinduced cytokine and prostaglandin-regulating enzymes in human placental trophoblast cells: Implications for treatment of bacterial vapinosis and prevention of preterm labor Am J Obstet Gynecol. 2009, 2000(5): 532el-e8.

[119] Romero R, Chairononongsa T, Kuivaniemi H, Tromp G. Bacterial vaginosis, the inflammatory response and the risit of preterm birth: $A$ role for genetic epidemiology in the prevention of preterm birth. Am J Obsiet Gynecol. 2004; 190(6): $1509-1519$.

[120] Zaga V, Fistnda-Gutierrex G, Beltran-Monitoya J, Maida Claros R. Lopez-Vancell R, Vadillo-Ortega F. Secretions of interleukin-1 beta and tumor necrosis factor alpha by whole fetal membranes depend on initial interactions of amnion or choriodecidan with lipopolysacchanides or group B streptococci. Biol Reprod. 2004; 71(4): 1296-1302.

[121] Dominquez-Bello MG, Costello EK, Contrens M, Magris M, Hidalgo G, Fierer N, Knight R. Delivery mode shapes the accuisition and strocture of the initial microbiota across multiple body habituts in newborm. Proc Natl Acad Sci U multiple body habitus in newborss.

[122] Favier CF, de Vos WM, Akkermans AD.Development of bacterial and bisdobacterial communities in feces of newborn bahies. Anaerobe. 2003; 9(5): 219-229.

[123] Mackie RI, Sghir A, Gaskins HR. Developmental microbial ecology of the neonotal gastrointestinal tract. Am J Clin Nutr. 1999, 69(5): 1035s-1045s.

[124] Grönhand MM, Lothonen OP, Ferola E. Kero P. Fecal microflora in healthy infants bom by different methods of delivery: Permanent changes in intestinal Bora aftercesarean delivery. J Pediatr Gastroenterol Nutr. 1999; 29(1): 19-25.

[125] Penders J, Thijs C, Vink C, Sielma FF, Saijders B, Kum meling I, van den Brandt PA, Stobberingh EF. Factors influencing the composition of the intestinal microbiots in early infancy. Pediatrics. 2006; 118(2): 511-521.

[126] Tumbung PJ, Hamaty M, Yatounenkn T, Cantarel BL. Duncan A, Ley RE, Sogin MI. Jones WJ, Roe BA, Affourtit JP, Epholm M, Henrissat B, Heath MC, Knipht R, Gondon II. A core gut microbiome in obese and lean twins. Nuture. 2009; 457(7228): 450-484.

[127] Siencel-Gabriel K, Gabriel I, Wicxkowski A, Pul M, Olejek A. Prenatal priming of cond blood T lymphocytes by microbiota in the matemal vagina. Am J Reprod Immunol. 2009; 61(3): 246-252.

[128] Keski-Nisula L, Kyynärïnen HR, Kärkkiïnen U, Kartukorpi J, Heinosen S, Pekkanen J. Malemal intrapartum antibiotics and decreased vertical transmission of Lactobacillus to neonates during birth. Acta Paediatr. 2013; $102(5): 450-485$.

[129] Reid G, Younes 1A. Van der Mei HC, Gloor GB, Kniph R, Busscher H. Microbiokn restonation: Nutural and supplemented recovery of human microbial communities. Nat plemented recovery of human mict

[130] Engel P, Moran NA. The gut microbiota of insects - diversity in structure and function. FEMS microbiol revs. 2013; $1-37$

[131] Cremer S, Armitage SNO, Schmid-Hempel P. Social immonity. Curr Biol. 2007; $17(16)$ : R693-R702.

[132] Verschuere L, Rombat G, Sorpeloos P, Ventraete W. Pro biotic bacteria as biological control apents in aquaculture. biotic bacteria as biological control apents in aqua

[133] Walke JR, Harris RN, Reinert L.K, Rollins-Smith L. a, Woodhams DC. Social Immunity in Amphibians: Evidence for Vertical Transmission of Innate Defenses. Biotropica. $2011 ; 2 ; 43(4): 396-400$.

[134] Werner DL, Baker EM, Gonzalez EDC, Sosa IR. Kinship recognition and grouping in hatchling green iguanas. Behav Fool Sociobiol. 1987; 21(2): $83-89$.

[135] Troyer K. Behavional acquixition of the hindgut fermenta tion sysiem by hatchling Iguana iguana. Behav Ecol and Sociobiol. 1984; 14(3): 189-193.

[136] White J, Richand M, Massot M, Meylan S. Cloacal bacterial diversity increases with multiple mates: Evidence of setul transmission in female common lizands. PLOS one. 2011; 6(7): $1-5$. [137] Kulkarmi S, Heeb P. Social and sexual behaviours aid trans--
mission of bacteria in binds. Behav Proc. 2007; 74(1): 85-92. 
[138] White J, Mirlem P, Duschin E, Muland H, Hath SA, Heeb P, et al. Sexually trancemittied bacteria affect female cloacal assemblages in a wild bind. Ecol Lett. 2010; 13(12): 1515. 1524.

[139] Albone ES, Perry, GC. Anal sac secretion of the red fox, Vulpes vulpes; volatile fatty acids and diamines: Implica. tions for a fermentation hypochesis of chemical recognition. J Chem Feol. 1976; 2: 101-111.

[140] Gorman MI. A mechanism for individual recognition by odour in Herpestes maropunctatus (Carnivora: Vivernidae). Anim Behav. 1976; 24: 141-145.

[141] Ochman H, Worobey M, Kuo C, Ndjango IN, Peeters M, Hahn BH, \& al. Evolutionary Relationdhips of Wild Hominids Recapitulated by Gut Microbial Communities. PLoS Biol. 2010; 8(11): 1-8.

[142] Nunn Cl. Primale Disease Foology in Companative and Theoretical Perspective. Am J Primatol. 2012; 74: 497-509.

[143] Lombando MP. Access to mutualistic endosymbiotic microbes: An underapprecialed benefit of group livine. Behav Fool Sociobiol. 2007; 62(4): 479-497.

[144] Montiel-Castro N, Gonzilez-Cernartes RM, BravoRuiseco G, and Pacheco-López G. The microbiolagut-brain axis: Neurobehavional correlates, health and gociality. Front Integr Neurosci. 2013; 7(70): 1-16.

[145] Mooring, MS, Blumstein DT, Stoner C. The evolution of pansite defence grooming in ungulates. Biol J Linn Soc. 2004; 81: 17.37.

[146] Dunbar RIM. Functional signifcusce of social grooming in primales. Folin Primatol. 1991; 57: 121-131.

[147] Power MI, Schullin, J. Malernal requlation of offspring development in mammals is an ancient adeptation tied to lactation. Appl Transl Gen. 2013; 2: 55-63.

[148] Oftedal Or. The evolation of milk secretion and its ancient origins. Animal. 2012; 6: 355-368.
[149] Bailey MT, Coe CL. Malernal separation disrupts the integrity of the intestinal microflon in infant resus monkys. Der Prychobiol. 35: 146-155.

[150] Brunel A, Gouet P. Intestinal microflora of the newbarn nat as related in mammary, frecal, and vaginal staphylococci strains isolated from the dam. Can J Microbiol. 1989; 35: 989-993.

[151] Tivkovic AM, German JB, Lebrilla CB, Milk DA. Human milk glycobiome and its impart on the infunt grastroinlestinal milk glycobiome and its impact on the infint 8 .
microbioke. PNAS. 2011; 108: S4653-S4658.

[152] Hinde K, German JB. Food in an evolutionary context: Insights from mother's mill. J Sci Food Agric. 2012; 92: $2219-2223$.

[153] Hinde K, Millipan L.A. Primate Milk: Proximate Mechanisms and Ultimate Perspectives. Evol Anthr. 2011; 23: 9.23.

[154] Beneun A, DeStefuno J, Gordon I. Anthropology of microbes. PNAS. 2012; 109(17): 6378-6381.

[155] Emery Thompsoon M, Jones JH, Pusey AE, Brewer-Marsden $\mathrm{S}$, Goodall J, et al. A ging and fertility patterns in wild chimpanzees provide insights into the evolution of menopause. Curr Biol. 2007; 17(24): 2150-2156.

[156] Robbins AM, Robbins MM, Genald-Steklis N, Steklis, HD. Age-related patterns of reprodactive success among female mountain gorillas. Am J Phys Anthropol. 2006; 131: 511moun.

[157] WichSA, Utami-Atmoko S, MitnSetia T, Rijksen H, Schurmann, et al. Life history of wild Sumutran onangutans (Pongo abelii). J Hum Evol. 2004; 47: 385-398.

[158] Hawkes K, Ơconnell JF, Blurton Jones NG., Alvarez H, Chamov E. Grandmothering, menopause, and the evolution of human life histories. 1998; 95: 1336-1339.

[159] Soeley R, Stephens T, Tate P. Analomy and Physiology. 7th Edition. San Financiscos McGraw-Hill, 2006 


\section{BIBLIOGRAFÍA}

[1] S. Ö. İşeri, G. Şener, B. Sağlam, N. Gedik, F. Ercan, and B. Ç. Yeğen, "Oxytocin Protects Against Sepsis-Induced Multiple Organ Damage: Role of Neutrophils," J. Surg. Res., vol. 126, no. 1, pp. 73-81, Jun. 2005.

[2] M. Petersson, U. Wiberg, T. Lundeberg, and K. Uvnäs-Moberg, "Oxytocin decreases carrageenan induced inflammation in rats," Peptides, vol. 22, no. 9, pp. 1479-1484, 2001.

[3] P. Nathanielsz, D. Giussani, and W. Wu, "Stimulation of the switch in myometrial activity from contractures to contractions in the pregnant sheep and nonhuman primate.," Equine Vet. J., vol. Supplement, no. 24, pp. 83-8, 1997.

[4] M. Thiery, W. Parewijck, and G. Martens, "Active management of premature rupture of membranes and unfavorable cervix in term and near-term pregnancy," American Journal of Obstetrics and Gynecology, vol. 158, no. 3 PART 1. pp. 679-680, 1988.

[5] S. Kota, K. Gayatri, S. Jammula, S. Kota, S. V. S. Krishna, L. Meher, and K. Modi, “Endocrinology of parturition," Indian J. Endocrinol. Metab., vol. 17, no. 1, p. 50, 2013.

[6] A. López Bernal, J. Rivera, G. N. Europe-Finner, S. Phaneuf, and G. Asbóth, "Parturition: activation of stimulatory pathways or loss of uterine quiescence?," Adv. Exp. Med. Biol., vol. 395, pp. 435-51, 1995.

[7] D. B. Garrioch, "The effect of indomethacin on spontaneous activity in the isolated human myometrium and on the response to oxytocin and prostaglandin.," Br. J. Obstet. Gynaecol., vol. 85, no. January, pp. 47-52, 1978.

[8] J. R. G. Challis, S. G. Matthews, W. Gibb, and S. J. Lye, "Endocrine and paracrine regulation of birth at term and preterm," Endocrine Reviews, vol. 21, no. 5. pp. 514550, 2000.

[9] E. R. Norwitz, J. N. Robinson, and J. R. Challis, "The Control of Labor," N. Engl. J. Med., vol. 341, no. 27, pp. 2098-2099, 1999.

[10] S. G. Matthews and J. R. G. Challis, "Regulation of the hypothalamo-pituitaryadrenocortical axis in fetal sheep," Trends in Endocrinology and Metabolism, vol. 7, no. 7. pp. 239-246, 1996.

[11] G. D. Thorburn, S. A. Hollingworth, and S. B. Hooper, "The trigger for parturition in sheep: fetal hypothalamus or placenta?," J. Dev. Physiol., vol. 15, no. 2, pp. 71-79, 1991. 
[12] R. E. Garfield, G. Saade, C. Buhimschi, I. Buhimschi, L. Shi, S. Q. Shi, and K. Chwalisz, "Control and assessment of the uterus and cervix during pregnancy and labour," in Human Reproduction Update, 1998, vol. 4, no. 5, pp. 673-695.

[13] B. M. Sanborn, "Ion channels and the control of myometrial electrical activity," Semin. Perinatol., vol. 19, no. 1, pp. 31-40, 1995.

[14] G. Weiss, "CLINICAL REVIEW 118 Endocrinology of Parturition *," J. Clin. Endocrinol. Metab., vol. 85, no. 12, pp. 4421-4425, 2000.

[15] E. Golightly, H. N. Jabbour, and J. E. Norman, "Endocrine immune interactions in human parturition," Mol. Cell. Endocrinol., vol. 335, no. 1, pp. 52-59, 2011.

[16] M. R. Peltier, "Immunology of term and preterm labor.," Reprod. Biol. Endocrinol., vol. 1, p. 122, 2003.

[17] I. Osman, A. Young, M. A. Ledingham, A. J. Thomson, F. Jordan, I. A. Greer, and J. E. Norman, "Leukocyte density and pro-inflammatory cytokine expression in human fetal membranes, decidua, cervix and myometrium before and during labour at term.," Mol. Hum. Reprod., vol. 9, no. 1, pp. 41-5, Jan. 2003.

[18] A. J. Thomson, J. F. Telfer, A. Young, S. Campbell, C. J. R. Stewart, I. T. Cameron, I. a. Greer, and J. E. Norman, "Leukocytes infiltrate the myometrium during human parturition: Further evidence that labour is an inflammatory process," Hum. Reprod., vol. 14, no. 1, pp. 229-236, 1999.

[19] M. A. Ledingham, A. J. Thomson, F. Jordan, A. Young, M. Crawford, and J. E. Norman, "Cell adhesion molecule expression in the cervix and myometrium during pregnancy and parturition.," Obstet. Gynecol., vol. 97, no. 2, pp. 235-42, Feb. 2001.

[20] M. Winkler, D. C. Fischer, P. Ruck, H. P. Horny, B. Kemp, and W. Rath, "[Cytokine concentrations and expression of adhesion molecules in the lower uterine segment during parturition at term: relation to cervical dilatation and duration of labor].," $Z$. Geburtshilfe Neonatol., vol. 202, no. 4, pp. 172-5, 1998.

[21] M. B. Sennström, G. Ekman, G. Westergren-Thorsson, A. Malmström, B. Byström, U. Endrésen, N. Mlambo, M. Norman, B. Ståbi, and A. Brauner, "Human cervical ripening, an inflammatory process mediated by cytokines.," Mol. Hum. Reprod., vol. 6, no. 4, pp. 375-81, Apr. 2000.

[22] M. Yuan, F. Jordan, I. B. McInnes, M. M. Harnett, and J. E. Norman, "Leukocytes are primed in peripheral blood for activation during term and preterm labour," Mol. Hum. Reprod., vol. 15, no. 11, pp. 713-724, Nov. 2009.

[23] A. Young, A. J. Thomson, M. Ledingham, F. Jordan, I. A. Greer, and J. E. Norman, 
"Immunolocalization of proinflammatory cytokines in myometrium, cervix, and fetal membranes during human parturition at term.," Biol. Reprod., vol. 66, no. 2, pp. 4459, Feb. 2002.

[24] E. T. Abrams and E. M. Miller, "The roles of the immune system in Women's reproduction: Evolutionary constraints and life history trade-offs," Am. J. Phys. Anthropol., vol. 146, no. S53, pp. 134-154, 2011.

[25] T. R. Mosmann and S. Sad, "The expanding universe of T-cell subsets: Th1, Th2 and more," Immunology Today, vol. 17, no. 3. pp. 138-146, 1996.

[26] R. Inés Barañao, "Inmunología del embarazo," Invest Clin, vol. 52, no. 522, pp. 175194, 2011.

[27] T. G. Wegmann, H. Lin, L. Guilbert, and T. R. Mosmann, "Bidirectional cytokine interactions in the maternal-fetal relationship: is successful pregnancy a TH2 phenomenon?," Immunol. Today, vol. 14, no. 7, pp. 353-356, 1993.

[28] R. Mattsson, R. Holmdahl, A. Scheynius, F. Bernadotte, A. Mattsson, and P. H. Van der Meide, "Placental MHC class I antigen expression is induced in mice following in vivo treatment with recombinant interferon-gamma.," J. Reprod. Immunol., vol. 19, no. 2, pp. 115-29, Feb. 1991.

[29] B. U. Tezabwala, P. M. Johnson, and R. C. Rees, "Inhibition of pregnancy viability in mice following IL-2 administration.," Immunology, vol. 67, no. 1, pp. 115-9, 1989.

[30] G. Chaouat, A. Assal Meliani, J. Martal, R. Raghupathy, J. F. Elliott, J. Elliot, T. Mosmann, and T. G. Wegmann, "IL-10 prevents naturally occurring fetal loss in the $\mathrm{CBA} \times \mathrm{DBA} / 2$ mating combination, and local defect in IL-10 production in this abortion-prone combination is corrected by in vivo injection of IFN-tau.," J. Immunol., vol. 154, no. 9, pp. 4261-8, May 1995.

[31] N. Gomez-Lopez, D. StLouis, M. A. Lehr, E. N. Sanchez-Rodriguez, and M. ArenasHernandez, "Immune cells in term and preterm labor.," Cell. Mol. Immunol., vol. 11, no. 6, pp. 571-81, 2014.

[32] L. Sykes, D. a. MacIntyre, X. J. Yap, S. Ponnampalam, T. G. Teoh, and P. R. Bennett, "Changes in the Th1:Th2 cytokine bias in pregnancy and the effects of the antiinflammatory cyclopentenone prostaglandin 15-deoxy-?? 12,14- prostaglandin J 2," Mediators Inflamm., vol. 2012, 2012.

[33] A. H. DeCherney, L. Nathan, T. M. Goodwin, and N. Laufer, "Current obstetric \& gynecologic diagnosis \& treatment," Sex. Transm. Dis., p. 701, 2012.

[34] J. C. King, "Physiology of pregnancy and nutrient metabolism," Am. J. Clin. Nutr., vol. 
71, no. 5 SUPPL., pp. 1218-1225, 2000.

[35] H. C. J. Scheepers, P. a De Jong, G. G. M. Essed, and H. H. H. Kanhai, "Fetal and maternal energy metabolism during labor in," New York, vol. 29, pp. 457-464, 2001.

[36] N. Söhnchen, K. Melzer, B. M. De Tejada, N. Jastrow-Meyer, V. Othenin-Girard, O. Irion, M. Boulvain, and B. Kayser, "Maternal heart rate changes during labour," Eur. J. Obstet. Gynecol. Reprod. Biol., vol. 158, no. 2, pp. 173-178, 2011.

[37] T. Laudański, "Energy metabolism of the myometrium in pregnancy and labor," Zentralblatt fur Gynakologie, vol. 107, no. 9. pp. 568-573, 1985.

[38] M. L. Kashyap, R. Sivasamboo, S. P. Sothy, J. S. Cheah, and P. S. Gartside, "Carbohydrate and lipid metabolism during human labor: free fatty acids, glucose, insulin, and lactic acid metabolism during normal and oxytocin-induced labor for postmaturity.," Metabolism., vol. 25, no. 8, pp. 865-75, Aug. 1976.

[39] P. Felig and V. Lynch, "[Starvation in human pregnancy: hypoglycemia, hypoinsulinemia, and hyperketonemia].," Science, vol. 170, no. 3961, pp. 990-2, Nov. 1970.

[40] A. B. Keppler, "The Use of Intravenous Fluids During Labor," Birth, vol. 15, no. 2, pp. 75-79, Jun. 1988.

[41] C. Wood, K. Hing Ng, D. Hounslow, and H. Benning, "TIME-AN IMPORTANT VARIABLE IN NORMAL DELIVERY," BJOG An Int. J. Obstet. Gynaecol., vol. 80, no. 4, pp. 295-300, Apr. 1973.

[42] D. Limmer, M. F. O’Keefe, H. Grant, B. Murray, and J. D. Bergeron, Emergency Care With Pearson Etext. Pearson College Div, 2015.

[43] K. V. McArdle WD, Katch KI, Exercise Physiology: Nutrition, Energy, and Human Performance. 2009.

[44] T. Marchese, M. K. Barger, and L. L. Paine, "Primary care for women revisited Nurse-midwifery management of common health problems," J. Nurse. Midwifery., vol. 41, no. 2, pp. 80-82, 1996.

[45] Melo C; Peraçoli J, "Mensuração da energia despendida no jejum e no aporte calórico (mel) em parturientes," Rev. Latino-am Enferm., vol. 15, no. 4, pp. 612-617, 2007.

[46] B. Banerjee, K. S. Khew, N. Saha, and S. S. Ratnam, "Energy Cost and Blood Sugar Level During Different Stages of Labour and Duration of Labour in Asiatic Women," BJOG An Int. J. Obstet. Gynaecol., vol. 78, no. 10, pp. 927-929, 1971.

[47] M. Katz, D. Kroll, Y. Shapiro, N. Cristal, and I. Meizner, "Energy expenditure in normal labor.," Isr. J. Med. Sci., vol. 26, no. 5, pp. 254-7, May 1990. 
[48] T. Steingrímsdóttir, G. Ronquist, U. Ulmsten, and A. Waldenström, "Different energy metabolite pattern between uterine smooth muscle and striated rectus muscle in term pregnant women.," Eur. J. Obstet. Gynecol. Reprod. Biol., vol. 62, no. 2, pp. 241-5, Oct. 1995.

[49] C. S. Chew and G. A. Rinard, "Glycogen levels in the rat myometrium at the end of pregnancy and immediately postpartum.," Biol. Reprod., vol. 20, no. 5, pp. 1111-4, Jun. 1979.

[50] H. SAKAMOTO, C. LERANTH, N. J. MACLUSKY, Y. SAITO, and F. NAFTOLIN, "Insulin Specific Binding Sites in the Myometrium of Pregnant Rats*," Endocrinology, vol. 120, no. 5, pp. 1951-1955, May 1987.

[51] H. Figueroa D., E. T. Marusic B., M. González N., F. Barcos M., and P. Yungue V., "Efecto in Vitro De La Insulina Sobre La Capacidad Contractil Uterina Inducida Por Oxitocina," Rev. Chil. Obstet. Ginecol., vol. 67, no. 3, pp. 184-189, 2002.

[52] E. Hyun, R. Ramachandran, M. D. Hollenberg, and N. Vergnolle, "Mechanisms behind the anti-inflammatory actions of insulin.," Crit. Rev. Immunol., vol. 31, no. 4, pp. 307-40, 2011.

[53] R. H. Straub, M. Cutolo, F. Buttgereit, and G. Pongratz, "Energy regulation and neuroendocrine-immune control in chronic inflammatory diseases," J. Intern. Med., vol. 267, no. 6, pp. 543-560, 2010.

[54] G. S. Hotamisligil, "Inflammation and metabolic disorders 1," Nature, vol. 444, no. 1476-4687 (Electronic), pp. 860-867, 2006.

[55] B. M. Sadd and P. Schmid-Hempel, "Principles of ecological immunology.," Evol. Appl., vol. 2, no. 1, pp. 113-21, Feb. 2009.

[56] G. E. Demas, "The energetics of immunity: A neuroendocrine link between energy balance and immune function," Hormones and Behavior, vol. 45, no. 3. pp. 173-180, 2004.

[57] R. L. Lochmiller and C. Deerenberg, "Trade-offs in evolutionary immunology: just what is the cost of immunity?," Oikos, vol. 88, no. 1, pp. 87-98, Jan. 2000.

[58] G. Pacheco-Lopez and F. Bermudez-Rattoni, "Brain-immune interactions and the neural basis of disease-avoidant ingestive behaviour," Philos. Trans. R. Soc. B Biol. Sci., vol. 366, no. 1583, pp. 3389-3405, 2011.

[59] F. Buttgereit, G. R. Burmester, and M. D. Brand, "Bioenergetics of immune functions: fundamental and therapeutic aspects.," Immunol. Today, vol. 21, no. 4, pp. 192-9, Apr. 2000. 
[60] K. J. Tracey, "The inflammatory reflex," Nature, vol. 420, no. 6917, pp. 853-859, 2002.

[61] M. Rosas-Ballina and K. J. Tracey, "Cholinergic control of inflammation.," J. Intern. Med., vol. 265, no. 6, pp. 663-79, Jun. 2009.

[62] H.-R. Berthoud and W. L. Neuhuber, "Functional and chemical anatomy of the afferent vagal system," Auton. Neurosci., vol. 85, no. 1-3, pp. 1-17, Dec. 2000.

[63] L. E. Goehler, R. P. . Gaykema, S. E. Hammack, S. F. Maier, and L. R. Watkins, "Interleukin-1 induces c-Fos immunoreactivity in primary afferent neurons of the vagus nerve," Brain Res., vol. 804, no. 2, pp. 306-310, Sep. 1998.

[64] L. E. Goehler, J. K. Relton, D. Dripps, R. Kiechle, N. Tartaglia, S. F. Maier, and L. R. Watkins, "Vagal paraganglia bind biotinylated interleukin-1 receptor antagonist: a possible mechanism for immune-to-brain communication.," Brain Res. Bull., vol. 43, no. 3, pp. 357-64, 1997.

[65] J. E. Blalock, "The immune system as the sixth sense," in Journal of Internal Medicine, 2005, vol. 257, no. 2, pp. 126-138.

[66] K. J. Tracey, "The inflammatory reflex.," Nature, vol. 420, no. 6917, pp. 853-859, 2002.

[67] P. Holzer, "Role of visceral afferent neurons in mucosal inflammation and defense," Current Opinion in Pharmacology, vol. 7, no. 6. pp. 563-569, 2007.

[68] J. R. Challis, C. J. Lockwood, L. Myatt, J. E. Norman, J. F. Strauss, and F. Petraglia, "Inflammation and pregnancy.," Reprod. Sci., vol. 16, no. 2, pp. 206-215, 2009.

[69] F. Gotsch, R. Romero, J. P. Kusanovic, O. Erez, J. Espinoza, C. J. Kim, E. Vaisbuch, N. G. Than, S. Mazaki-Tovi, T. Chaiworapongsa, M. Mazor, B. H. Yoon, S. Edwin, R. Gomez, P. Mittal, S. S. Hassan, and S. Sharma, "The anti-inflammatory limb of the immune response in preterm labor, intra-amniotic infection/inflammation, and spontaneous parturition at term: a role for interleukin-10.," J. Matern. Fetal. Neonatal Med., vol. 21, no. 8, pp. 529-547, 2008.

[70] L. Sykes, D. A. Maclntyre, X. J. Yap, T. G. Teoh, and P. R. Bennett, "The Th1:Th2 dichotomy of pregnancy and preterm labour," Mediators Inflamm., vol. 2012, 2012.

[71] Y. Sato, H. Hotta, H. Nakayama, and H. Suzuki, "Sympathetic and parasympathetic regulation of the uterine blood flow and contraction in the rat.," J. Auton. Nerv. Syst., vol. 59, no. 3, pp. 151-8, Jul. 1996.

[72] B. K. Pedersen, "Muscles and their myokines.," J. Exp. Biol., vol. 214, no. Pt 2, pp. 337-346, 2011. 
[73] R. Starkie, S. R. Ostrowski, S. Jauffred, M. Febbraio, and B. K. Pedersen, "Exercise and IL-6 infusion inhibit endotoxin-induced TNF-\&amp;alpha; production in humans," FASEB J., vol. 17, no. 8, pp. 884-6, Mar. 2003.

[74] A. Steensberg, C. P. Fischer, C. Keller, K. Møller, and B. K. Pedersen, "IL-6 enhances plasma IL-1ra, IL-10, and cortisol in humans," Am. J. Physiol. - Endocrinol. Metab., vol. 285, no. 2, pp. E433-E437, Aug. 2003.

[75] O. Shynlova, Y.-H. Lee, K. Srikhajon, and S. J. Lye, "Physiologic Uterine Inflammation and Labor Onset: Integration of Endocrine and Mechanical Signals," Reprod. Sci., vol. 20, no. 2, pp. 154-167, Feb. 2013.

[76] J. A. Z. Loudon, S. R. Sooranna, P. R. Bennett, and M. R. Johnson, "Mechanical stretch of human uterine smooth muscle cells increases IL-8 mRNA expression and peptide synthesis.," Mol. Hum. Reprod., vol. 10, no. 12, pp. 895-899, 2004.

[77] G. Hebisch, P. M. Neumaier-Wagner, R. Huch, and U. Von Mandach, "Maternal serum interleukin-1 ??, -6 and -8 levels and potential determinants in pregnancy and peripartum,” J. Perinat. Med., vol. 32, no. 6, pp. 475-480, 2004.

[78] R. Medzhitov, "Origin and physiological roles of inflammation," Nature, vol. 454, no. 7203, pp. 428-435, Jul. 2008.

[79] S. Akira, S. Uematsu, and O. Takeuchi, "Pathogen Recognition and Innate Immunity," Cell, vol. 124, no. 4, pp. 783-801, Feb. 2006.

[80] N. Inohara, M. Chamaillard, C. McDonald, and G. Nuñez, "NOD-LRR PROTEINS: Role in Host-Microbial Interactions and Inflammatory Disease," Annu. Rev. Biochem., vol. 74, no. 1, pp. 355-383, Jun. 2005.

[81] L. Donati, A. Di Vico, M. Nucci, L. Quagliozzi, T. Spagnuolo, A. Labianca, M. Bracaglia, F. lanniello, A. Caruso, and G. Paradisi, "Vaginal microbial flora and outcome of pregnancy," Arch. Gynecol. Obstet., vol. 281, no. 4, pp. 589-600, 2010.

[82] K. L. Rock, E. Latz, F. Ontiveros, and H. Kono, "The sterile inflammatory response.," Annu. Rev. Immunol., vol. 28, pp. 321-342, 2010.

[83] R. Romero, M. Mazor, F. Brandt, W. Sepulveda, C. Avila, D. B. Cotton, and C. A. Dinarello, "Interleukin-1 alpha and interleukin-1 beta in preterm and term human parturition," Am J Reprod Immunol, vol. 27, no. 3-4, pp. 117-123, 1992.

[84] M. Mobini, M. Mortazavi, S. Nadi, M. Zare-Bidaki, S. Pourtalebi, and M. K. Arababadi, "Significant roles played by interleukin-10 in outcome of pregnancy.," Iran. J. Basic Med. Sci., vol. 19, no. 2, pp. 119-24, Feb. 2016.

[85] J. J. Reyes-Lagos, J. C. Echeverría-Arjonilla, M. Á. Peña-Castillo, A. J. Montiel- 
Castro, and G. Pacheco-López, "Physiological , Immunological and Evolutionary Perspectives of Labor as an Inflammatory Process," Adv. Neuroimmune Biol., vol. 5, no. 2, pp. 75-89, 2014.

[86] M. Malik, J. Bigger, A. Camm, and R. Kleiger, "Heart rate variability. Standards of measurement, physiological interpretation, and clinical use. Task Force of the European Society of Cardiology and the North American Society of Pacing and Electrophysiology.," Eur. Heart J., vol. 17, pp. 354-381, 1996.

[87] G. Parati, G. Mancia, M. Di Rienzo, and P. Castiglioni, "Point:Counterpoint: Cardiovascular variability is/is not an index of autonomic control of circulation," $J$. Appl. Physiol., vol. 101, no. 2, pp. 676-682, Apr. 2006.

[88] J. M. Huston and K. J. Tracey, "The pulse of inflammation: Heart rate variability, the cholinergic anti-inflammatory pathway and implications for therapy," J. Intern. Med., vol. 269, no. 1, pp. 45-53, 2011.

[89] G. G. Berntson, D. L. Lozano, and Y.-J. Chen, "Filter properties of root mean square successive difference (RMSSD) for heart rate," Psychophysiology, vol. 42, no. 2, pp. 246-252, Mar. 2005.

[90] J. F. Thayer and J. E. Fischer, "Heart rate variability, overnight urinary norepinephrine and C-reactive protein: Evidence for the cholinergic anti-inflammatory pathway in healthy human adults," J. Intern. Med., vol. 265, no. 4, pp. 439-447, 2009.

[91] M. K. Boettger, K. J. Bär, A. Dohrmann, H. Müller, L. Mertins, N. H. Brockmeyer, and M. W. Agelink, "Increased vagal modulation in atopic dermatitis," J. Dermatol. Sci., vol. 53, no. 1, pp. 55-59, 2009.

[92] I. Tonhajzerova, D. Mokra, and Z. Visnovcova, "Vagal function indexed by respiratory sinus arrhythmia and cholinergic anti-inflammatory pathway," Respir. Physiol. Neurobiol., vol. 187, no. 1, pp. 78-81, Jun. 2013.

[93] R. P. Sloan, H. McCreath, K. J. Tracey, S. Sidney, K. Liu, and T. Seeman, "RR interval variability is inversely related to inflammatory markers: the CARDIA study.," Mol. Med., vol. 13, no. 3-4, pp. 178-84, 2007.

[94] T. Intzilakis, G. Hartmann, M. R. Mouridsen, J. Eugen-Olsen, P. Kumarathurai, S. Madsbad, T. P. Almdal, S. B. Haugaard, and A. Sajadieh, "Soluble urokinase plasminogen activator receptor, C-reactive protein and triglyceride are associated with heart rate variability in non-diabetic Danes," Eur. J. Clin. Invest., vol. 43, no. 5, pp. 457-468, 2013.

[95] H.-C. Chuang, T.-W. Hsueh, C.-C. Chang, J.-S. Hwang, K.-J. Chuang, Y.-H. Yan, and 
T.-J. Cheng, "Nickel-Regulated Heart Rate Variability: The Roles of Oxidative Stress and Inflammation.," Toxicol. Appl. Pharmacol., vol. 266, no. 2, pp. 298-306, 2013.

[96] J. Huang, Y. Wang, D. Jiang, J. Zhou, and X. Huang, "The sympathetic-vagal balance against endotoxemia," J. Neural Transm., vol. 117, no. 6, pp. 729-735, 2010.

[97] P. J. Godin, L. A. Fleisher, A. Eidsath, R. W. Vandivier, H. L. Preas, S. M. Banks, T. G. Buchman, and A. F. Suffredini, "Experimental human endotoxemia increases cardiac regularity: results from a prospective, randomized, crossover trial.," 1996.

[98] K. D. Fairchild, J. J. Saucerman, L. L. Raynor, J. a Sivak, Y. Xiao, D. E. Lake, and J. R. Moorman, "Endotoxin depresses heart rate variability in mice: cytokine and steroid effects.," Am. J. Physiol. Regul. Integr. Comp. Physiol., vol. 297, no. 4, pp. R1019R1027, 2009.

[99] M. Gholami, P. Mazaheri, A. Mohamadi, T. Dehpour, F. Safari, S. Hajizadeh, K. P. Moore, and A. R. Mani, "Endotoxemia is Associated With Partial Uncoupling of Cardiac Pacemaker From Cholinergic Neural Control in Rats," Shock, vol. 37, no. 2, pp. 219-227, 2012.

[100] K. D. Fairchild, V. Srinivasan, J. R. Moorman, R. P. a Gaykema, and L. E. Goehler, "Pathogen-induced heart rate changes associated with cholinergic nervous system activation.," Am. J. Physiol. Regul. Integr. Comp. Physiol., vol. 300, no. 2, pp. R330R339, 2011.

[101] R. Mazloom, G. Eftekhari, M. Rahimi, V. Khori, S. Hajizadeh, A. R. Dehpour, and A. $\mathrm{R}$. Mani, "The role of $\alpha 7$ nicotinic acetylcholine receptor in modulation of heart rate dynamics in endotoxemic rats," PLoS One, vol. 8, no. 12, pp. 1-14, 2013.

[102] P. Lehrer, M. K. Karavidas, S. E. Lu, S. M. Coyle, L. O. Oikawa, M. MacOr, S. E. Calvano, and S. F. Lowry, "Voluntarily produced increases in heart rate variability modulate autonomic effects of endotoxin induced systemic inflammation: An exploratory study," Appl. Psychophysiol. Biofeedback, vol. 35, no. 4, pp. 303-315, 2010.

[103] B. U. Jan, S. M. Coyle, L. O. Oikawa, S.-E. Lu, S. E. Calvano, P. M. Lehrer, and S. F. Lowry, "Influence of acute epinephrine infusion on endotoxin-induced parameters of heart rate variability: a randomized controlled trial.," Ann. Surg., vol. 249, no. 5, pp. 750-756, 2009.

[104] B. U. Jan, S. M. Coyle, M. a Macor, M. Reddell, S. E. Calvano, and S. F. Lowry, "Relationship of basal heart rate variability to in vivo cytokine responses after endotoxin exposure.," Shock, vol. 33, no. 4, pp. 363-368, 2010. 
[105] M. Kox, J. C. Pompe, J. G. van der Hoeven, C. W. Hoedemaekers, and P. Pickkers, "Influence of different breathing patterns on heart rate variability indices and reproducibility during experimental endotoxaemia in human subjects.," Clin. Sci. (Lond)., vol. 121, no. 5, pp. 215-222, 2011.

[106] W. J. Kop, P. K. Stein, R. P. Tracy, J. I. Barzilay, R. Schulz, and J. S. Gottdiener, "Autonomic Nervous System Dysfunction and Inflammation Contribute to the Increased Cardiovascular Mortality Risk Associated With Depression," Psychosom. Med., vol. 72, no. 7, pp. 626-635, Sep. 2010.

[107] A. Celik, F. Koc, H. Kadi, K. Ceyhan, and U. Erkorkmaz, "Inflammation is related to unbalanced cardiac autonomic functions in hypertension: an observational study," Anadolu Kardiyoloji Dergisi/The Anatolian Journal of Cardiology, vol. 56. pp. 233240, 2012.

[108] G. J. Norman, J. T. Cacioppo, J. S. Morris, W. B. Malarkey, G. G. Berntson, and a. C. DeVries, "Oxytocin increases autonomic cardiac control: Moderation by Ioneliness," Biol. Psychol., vol. 86, no. 3, pp. 174-180, 2011.

[109] K. T. Higa, E. Mori, F. F. Viana, M. Morris, and L. C. Michelini, "Baroreflex control of heart rate by oxytocin in the solitary-vagal complex.," Am. J. Physiol. Regul. Integr. Comp. Physiol., vol. 282, no. 2, pp. R537-R545, 2002.

[110] A. H. Kemp, D. S. Quintana, R. L. Kuhnert, K. Griffiths, I. B. Hickie, and A. J. Guastella, "Oxytocin Increases Heart Rate Variability in Humans at Rest: Implications for Social Approach-Related Motivation and Capacity for Social Engagement," PLOS One, vol. 7, no. 8, pp. 3-8, 2012.

[111] J. C. Condon, D. B. Hardy, K. Kovaric, and C. R. Mendelson, "Up-Regulation of the Progesterone Receptor (PR)-C Isoform in Laboring Myometrium by Activation of Nuclear Factor-kB May Contribute to the Onset of Labor through Inhibition of PR Function," Mol. Endocrinol., vol. 20, no. 4, pp. 764-775, Apr. 2006.

[112] D. A. MacIntyre, L. Sykes, T. G. Teoh, and P. R. Bennett, "Prevention of preterm labour via the modulation of inflammatory pathways," J. Matern. Neonatal Med., vol. 25, no. sup1, pp. 17-20, Apr. 2012.

[113] M. Clodi, G. Vila, R. Geyeregger, M. Riedl, T. M. Stulnig, J. Struck, T. a Luger, and A. Luger, "Oxytocin alleviates the neuroendocrine and cytokine response to bacterial endotoxin in healthy men.," Am. J. Physiol. Endocrinol. Metab., vol. 295, no. 3, pp. E686-E691, 2008.

[114] J. W. Drover and R. F. Casper, "Initiation of parturition in humans," Canadian Medical 
Association Journal, vol. 128, no. 4. pp. 387-392, 1983.

[115] M. Kox, B. P. Ramakers, J. C. Pompe, J. G. van der Hoeven, C. W. Hoedemaekers, and P. Pickkers, "Interplay between the acute inflammatory response and heart rate variability in healthy human volunteers.," Shock, vol. 36, no. 2, pp. 115-120, 2011.

[116] J. J. Reyes-Lagos, J. C. Echeverría-Arjonilla, M. Á. Peña-Castillo, M. T. GarcíaGonzález, M. D. R. Ortiz-Pedroza, G. Pacheco-López, C. Vargas-García, S. CamalUgarte, and R. González-Camarena, "A comparison of heart rate variability in women at the third trimester of pregnancy and during low-risk labour," Physiol. Behav., vol. 149, pp. 255-261, 2015.

[117] L. Garzoni, C. Faure, and M. G. Frasch, "Fetal cholinergic anti-inflammatory pathway and necrotizing enterocolitis: the brain-gut connection begins in utero.," Front. Integr. Neurosci., vol. 7, no. August, p. 57, 2013.

[118] Y. Ashkenazy, S. Havlin, P. C. Ivanov, C. K. Peng, V. Schulte-Frohlinde, and H. E. Stanley, "Magnitude and sign scaling in power-law correlated time series," Phys. A Stat. Mech. its Appl., vol. 323, pp. 19-41, 2003.

[119] J. W. Kantelhardt, Y. Ashkenazy, P. C. Ivanov, A. Bunde, S. Havlin, T. Penzel, J. H. Peter, and H. E. Stanley, "Characterization of sleep stages by correlations in the magnitude and sign of heartbeat increments," Phys. Rev. E. Stat. Nonlin. Soft Matter Phys., vol. 65, no. 5, p. 6, 2002.

[120] D. T. Schmitt, P. K. Stein, and P. C. Ivanov, "Stratification pattern of static and scaleinvariant dynamic measures of heartbeat fluctuations across sleep stages in young and elderly," IEEE Trans. Biomed. Eng., vol. 56, no. 5, pp. 1564-1573, 2009.

[121] P. C. Ivanov, Y. Ashkenazy, J. W. Kantelhardt, and H. E. Stanley, "Quantifying heartbeat dynamics by magnitude and sign correlations," Unsolved Probl. Noise Fluctuations, vol. 665, pp. 383-391, 2003.

[122] D. T. Schmitt and P. C. Ivanov, "Fractal scale-invariant and nonlinear properties of cardiac dynamics remain stable with advanced age: a new mechanistic picture of cardiac control in healthy elderly.," Am. J. Physiol. Regul. Integr. Comp. Physiol., vol. 293, no. 5, pp. R1923-R1937, 2007.

[123] Y. Ashkenazy, P. C. Ivanov, S. Havlin, C. K. Peng, Y. Yamamoto, a L. Goldberger, and H. E. Stanley, "Decomposition of heartbeat time series: scaling analysis of the sign sequence.," Comput. Cardiol., vol. 27, pp. 139-142, 2000.

[124] S. Copeland, H. S. Warren, S. F. Lowry, S. E. Calvano, D. Remick, and Inflammation and the Host Response to Injury Investigators, "Acute Inflammatory Response to 
Endotoxin in Mice and Humans," Clin. Vaccine Immunol., vol. 12, no. 1, pp. 60-67, Jan. 2005.

[125] W. H. Rowan, M. J. Campen, L. B. Wichers, and W. P. Watkinson, "Heart rate variability in rodents: Uses and caveats in toxicological studies," Cardiovasc. Toxicol., vol. 7, no. 1, pp. 28-51, 2007.

[126] M. Jankowski, V. Bissonauth, L. Gao, M. Gangal, D. Wang, B. Danalache, Y. Wang, E. Stoyanova, G. Cloutier, G. Blaise, and J. Gutkowska, “Anti-inflammatory effect of oxytocin in rat myocardial infarction," Basic Res. Cardiol., vol. 105, no. 2, pp. 205218, 2010.

[127] R. Romero, M. Mazor, Y. K. Wu, M. Sirtori, E. Oyarzun, M. D. Mitchell, and J. C. Hobbins, "Infection in the pathogenesis of preterm labor.," Semin. Perinatol., vol. 12, no. 4, pp. 262-79, Oct. 1988.

[128] N. Kaga, Y. Katsuki, M. Obata, and Y. Shibutani, "Repeated administration of lowdose lipopolysaccharide induces preterm delivery in mice: A model for human preterm parturition and for assessment of the therapeutic ability of drugs against preterm delivery," Am. J. Obstet. Gynecol., vol. 174, no. 2, pp. 754-759, 1996.

[129] R. Lim, C. J. Morwood, G. Barker, and M. Lappas, "Effect of silibinin in reducing inflammatory pathways in in vitro and in vivo models of infection-induced preterm birth.," PLoS One, vol. 9, no. 3, p. e92505, 2014.

[130] U. Klöckner, U. Rueckschloss, C. Grossmann, S. Matzat, K. Schumann, H. Ebelt, U. Müller-Werdan, H. Loppnow, K. Werdan, and M. Gekle, "Inhibition of cardiac pacemaker channel hHCN2 depends on intercalation of lipopolysaccharide into channel-containing membrane microdomains.," J. Physiol., vol. 592, no. Pt 6, pp. 1199-211, 2014.

[131] WHO (World Health Organization), "Health in 2015: from MDGs, Millennium Development Goals to SDGs, Sustainable Development Goals.," World Heal. Organ., p. 204, 2015.

[132] R. Lozano, M. Naghavi, K. Foreman, S. Lim, and Shibuya, "Global and regional mortality from 235 causes of death for 20 age groups in 1990 and 2010: a systematic analysis for the Global Burden of Disease Study 2010.," Lancet, vol. 380, no. 9859, pp. 2095-128, 2012.

[133] L. A. Villanueva Egan, A. K. Contreras Gutiérrez, M. Pichardo Cuevas, and J. Rosales Lucio, "Perfil epidemiológico del parto prematuro," Ginecologia y Obstetricia de Mexico, vol. 76, no. 9. pp. 542-548, 2008. 
[134] J. Pan and W. J. Tompkins, "A real-time QRS detection algorithm.," IEEE Trans. Biomed. Eng., vol. 32, no. 3, pp. 230-236, 1985.

[135] N. Wessel, A. Voss, H. Malberg, C. Ziehmann, H. U. Voss, A. Schirdewan, U. Meyerfeldt, and J. Kurths, "Nonlinear analysis of complex phenomena in cardiological data," Herzschrittmachertherapie und Elektrophysiologie, vol. 11, no. 3. pp. 159-173, 2000.

[136] J. Sztajzel, "Heart rate variability: A noninvasive electrocardiographic method to measure the autonomic nervous system," Swiss Medical Weekly, vol. 134, no. 3536. pp. 514-522, 2004.

[137] J. McNames and M. Aboy, "Reliability and accuracy of heart rate variability metrics versus ECG segment duration," Med. Biol. Eng. Comput., vol. 44, no. 9, pp. 747-756, 2006.

[138] J. E. Mietus, C. K. Peng, I. Henry, R. L. Goldsmith, and A. L. Goldberger, "The pNNx files: re-examining a widely used heart rate variability measure," Heart, vol. 88, no. 4, pp. 378-380, 2002.

[139] N. Wessel, A. Voss, H. Malberg, C. Ziehmann, H. U. Voss, A. Schirdewan, U. Meyerfeldt, and J. Kurths, "Nonlinear analysis of complex phenomena in cardiological data," Herzschrittmachertherapie und Elektrophysiologie, vol. 11, no. September, pp. 159-173, 2000.

[140] J. Gallo, J. Farbriaz, and D. Alvarez, "Análisis espectral de la variabilidad de la frecuencia cardíaca," IATREIA, vol. 12, pp. 61-71, 1999.

[141] J. Widdicombe and L. Y. Lee, "Airway reflexes, autonomic function, and cardiovascular responses.," Environ. Health Perspect., vol. 109 Suppl, no. August, pp. 579-584, 2001.

[142] a Zaza and F. Lombardi, "Autonomic indexes based on the analysis of heart rate variability: a view from the sinus node.," Cardiovasc. Res., vol. 50, no. 3, pp. 434442, 2001.

[143] S. Vandeput, Heart rate variability: linear and nonlinear analysis with applications in human physiology, no. October. University Dissertation, 2010.

[144] M. Kuwahara, K. Yayou, K. Ishii, S. Hashimoto, H. Tsubone, and S. Sugano, "Power spectral analysis of heart rate variability as a new method for assessing autonomic activity in the rat," J. Electrocardiol., vol. 27, no. 4, pp. 333-337, 1994.

[145] D. L. Eckberg, "Sympathovagal balance a critical appraisal," Circulation, vol. 96, no. 9, pp. 3224-3232, 1997. 
[146] P. Cilliers, "Understanding Complex Systems," in Handbook of Systems and Complexity in Health, 2013, pp. 27-38.

[147] M. Mitchell, Complexity: A Guided Tour. Proceedings of the Seventh International Conference on Language Resources and Evaluation (LREC'10), 2009.

[148] A. L. Goldberger, L. a N. Amaral, J. M. Hausdorff, P. C. Ivanov, C.-K. Peng, and H. E. Stanley, "Fractal dynamics in physiology: alterations with disease and aging.," Proc. Natl. Acad. Sci. U. S. A., vol. 99 Suppl 1, pp. 2466-2472, 2002.

[149] J. G. Contreras, "La variación del ritmo cardiaco," Cinvestav, no. Enero-Marzo, pp. 24-27, 2007.

[150] L. Glass, "Introduction to controversial topics in nonlinear science: Is the normal heart rate chaotic?," Chaos, vol. 19, no. 2, 2009.

[151] A. L. Goldberger, "Non-linear dynamics for clinicians: Chaos theory, fractals, and complexity at the bedside," Lancet, vol. 347, no. 9011. pp. 1312-1314, 1996.

[152] B. B. Mandelbrot, "Mandelbrot - Fractal Geometry - What Is It.pdf," Proceedings Of The Royal Society Of London A Mathematical And Physical Sciences, vol. 423, no. 1864. p. 3, 1989.

[153] K. Hu, P. C. Ivanov, Z. Chen, P. Carpena, and H. E. Stanley, "Effect of trends on detrended fluctuation analysis.," Phys. Rev. E. Stat. Nonlin. Soft Matter Phys., vol. 64, no. 1 Pt 1, p. 11114, 2001.

[154] a Eke, P. Herman, L. Kocsis, and L. R. Kozak, "Fractal characterization of complexity in temporal physiological signals.," Physiol. Meas., vol. 23, no. 1, pp. R1-R38, 2002.

[155] J. B. Bassingthwaighte and G. M. Raymond, "Evaluation of the dispersional analysis method for fractal time series," Ann. Biomed. Eng., vol. 23, no. 4, pp. 491-505, 1995.

[156] H. V Huikuri, T. H. Mäkikallio, C. K. Peng, a L. Goldberger, U. Hintze, and M. Møller, "Fractal correlation properties of R-R interval dynamics and mortality in patients with depressed left ventricular function after an acute myocardial infarction.," Circulation, vol. 101, no. 1, pp. 47-53, 2000.

[157] C. K. Peng, S. Havlin, H. E. Stanley, and A. L. Goldberger, "Quantification of scaling exponents and crossover phenomena in nonstationary heartbeat time series.," Chaos, vol. 5, no. 1, pp. 82-7, 1995.

[158] M. A. Peña, J. C. Echeverría, M. T. García, and R. González-Camarena, "Applying fractal analysis to short sets of heart rate variability data," Med. Biol. Eng. Comput., vol. 47, no. 7, pp. 709-717, 2009.

[159] H. V Huikuri, J. S. Perkiömäki, R. Maestri, and G. D. Pinna, "Clinical impact of 
evaluation of cardiovascular control by novel methods of heart rate dynamics.," Philos. Trans. A. Math. Phys. Eng. Sci., vol. 367, no. 1892, pp. 1223-38, 2009.

[160] K. K. L. Ho, G. B. Moody, C.-K. Peng, J. E. Mietus, M. G. Larson, D. Levy, and A. L. Goldberger, "Predicting survival in heart failure case and control subjects by use of fully automated methods for deriving nonlinear and conventional indices of heart rate dynamics," Circulation, vol. 96, no. 3, pp. 842-848, 1997.

[161] K. Saermark, M. Moeller, U. Hintze, H. Moelgaard, P. E. B. Thomsen, H. Huikuri, T. Makikiallio, J. Levitan, and M. Lewkowicz, "Comparison of recent methods of analyzing heart rate variability," Fractals-Complex Geom. Patterns Scaling Nat. Soc., vol. 8, no. 4, pp. 315-322, 2000.

[162] G. Krstacic, G. Parati, D. Gamberger, P. Castiglioni, A. Krstacic, and R. Steiner, "Heart rate variability and nonlinear dynamic analysis in patients with stress-induced cardiomyopathy," Med. Biol. Eng. Comput., vol. 50, no. 10, pp. 1037-1046, 2012.

[163] T. H. Mäkikallio, S. Høiber, L. Køber, C. Torp-Pedersen, C. K. Peng, A. L. Goldberger, and $\mathrm{H}$. V Huikuri, "Fractal analysis of heart rate dynamics as a predictor of mortality in patients with depressed left ventricular function after acute myocardial infarction. TRACE Investigators. TRAndolapril Cardiac Evaluation.," Am. J. Cardiol., vol. 83, no. 6, pp. 836-9, Mar. 1999.

[164] M. P. Tulppo, A. M. Kiviniemi, A. J. Hautala, M. Kallio, T. Seppänen, T. H. Mäkikallio, and H. V. Heikki, "Physiological background of the loss of fractal heart rate dynamics," Circulation, vol. 112, no. 3, pp. 314-319, 2005.

[165] J. S. Richman and J. R. Moorman, "Physiological time-series analysis using approximate entropy and sample entropy.," Am. J. Physiol. Heart Circ. Physiol., vol. 278, no. 6, pp. H2039-H2049, 2000.

[166] C. Li, D.-K. Tang, D.-A. Zheng, G.-H. Ding, C.-S. Poon, and G.-Q. Wu, "Comparison of nonlinear indices in analyses of heart rate variability.," Conf. Proc. IEEE Eng. Med. Biol. Soc., vol. 2008, pp. 2145-8, 2008.

[167] A. Travaglini, C. Lamberti, J. DeBie, and M. Ferri, "Respiratory signal derived from eight-lead ECG," Comput. Cardiol. 1998, pp. 65-68, 1998.

[168] G. B. Moody and R. G. Mark, "Derivation of respiratory signals from multi-lead ECGs," Comput. Cardiol., vol. 12, no. August, pp. 113-116, 1985.

[169] N. Cesarovic, P. Jirkof, A. Rettich, and M. Arras, "Implantation of radiotelemetry transmitters yielding data on ECG, heart rate, core body temperature and activity in free-moving laboratory mice.," J. Vis. Exp., no. 57, Nov. 2011. 
[170] N. Cesarovic, F. Nicholls, A. Rettich, P. Kronen, M. Hässig, P. Jirkof, and M. Arras, "Isoflurane and sevoflurane provide equally effective anaesthesia in laboratory mice," Lab. Anim., vol. 44, no. 4, pp. 329-336, Oct. 2010.

[171] V. Gross and F. C. Luft, "Exercising Restraint in Measuring Blood Pressure in Conscious Mice," Hypertension, vol. 41, no. 4, pp. 879-881, Apr. 2003.

[172] K. Kramer, S. A. van Acker, H. P. Voss, J. A. Grimbergen, W. J. van der Vijgh, and A. Bast, "Use of telemetry to record electrocardiogram and heart rate in freely moving mice.," J. Pharmacol. Toxicol. Methods, vol. 30, no. 4, pp. 209-15, Dec. 1993.

[173] K. Kramer and L. B. Kinter, "Evaluation and applications of radiotelemetry in small laboratory animals," Physiol. Genomics, vol. 13, no. 3, pp. 197-205, May 2003.

[174] J. Thireau, B. L. Zhang, D. Poisson, and D. Babuty, "Heart rate variability in mice: a theoretical and practical guide.," Exp. Physiol., vol. 93, no. 1, pp. 83-94, 2008.

[175] J. Miller, K. Ty-Torredes, M. Schindel, C. Harman, and A. Baschat, "796: Non-invasive detection of significant uterine activity," Am. J. Obstet. Gynecol., vol. 199, no. 6, p. S225, Dec. 2008.

[176] BIO-RAD, "Bio-Plex Multiplex Immunoassays | Aplicaciones y tecnologías | Bio-Rad." [Online]. Available: http://www.bio-rad.com/es-mx/applications-technologies/bioplex-multiplex-immunoassays. [Accessed: 17-Apr-2017].

[177] F. T. Pérez-Durillo, "Síndrome metabólico. asociación entre glp--1 y factores de riesgo cardiovascular," Universidad de Jaén, 2016.

[178] L. D. Durosier, C. L. Herry, M. Cortes, M. Cao, P. Burns, A. Desrochers, G. Fecteau, A. J. E. Seely, and M. G. Frasch, "Does heart rate variability reflect the systemic inflammatory response in a fetal sheep model of lipopolysaccharide-induced sepsis?," Physiol. Meas., vol. 36, no. 10, pp. 2089-2102, 2015.

[179] M. Gamer and C. Büchel, "Oxytocin specifically enhances valence-dependent parasympathetic responses," Psychoneuroendocrinology, vol. 37, no. 1, pp. 87-93, 2012.

[180] M. Jankowski, D. Wang, F. Hajjar, S. Mukaddam-Daher, S. M. McCann, and J. Gutkowska, "Oxytocin and its receptors are synthesized in the rat vasculature," Proc Natl Acad Sci U S A, vol. 97, no. 11, pp. 6207-6211, 2000.

[181] A. Kis, O. Kanizsár, M. Gácsi, and J. Topál, "Intranasally administered oxytocin decreases heart rate and increases heart rate variability in dogs," J. Vet. Behav. Clin. Appl. Res., vol. 9, no. 6, p. e15, 2014.

[182] A. H. Kemp, D. S. Quintana, R.-L. Kuhnert, K. Griffiths, I. B. Hickie, and A. J. 
Guastella, "Oxytocin Increases Heart Rate Variability in Humans at Rest: Implications for Social Approach-Related Motivation and Capacity for Social Engagement," PLoS One, vol. 7, no. 8, p. e44014, Aug. 2012.

[183] M. Petersson, M. Eklund, and K. Uvnäs-Moberg, "Oxytocin decreases corticosterone and nociception and increases motor activity in OVX rats," Maturitas, vol. 51, no. 4, pp. 426-433, 2005.

[184] J. W. Carpenter, Exotic animal formulary, 3rd ed. St. Louis ( MO): Saunders, 2004.

[185] H. Engler, R. Doenlen, C. Riether, A. Engler, M. B. Niemi, H. O. Besedovsky, A. del Rey, G. Pacheco-López, J. Feldon, and M. Schedlowski, “Time-dependent alterations of peripheral immune parameters after nigrostriatal dopamine depletion in a rat model of Parkinson's disease," Brain. Behav. Immun., vol. 23, no. 4, pp. 518-526, 2009.

[186] B. Schmid, C. Helfrich-Förster, and T. Yoshii, “A New ImageJ Plug-in 'ActogramJ' for Chronobiological Analyses.," J. Biol. Rhythms, vol. 26, pp. 464-467, 2011.

[187] N. J. Cicutti, C. E. Smyth, O. P. Rosaeg, and M. Wilkinson, "Oxytocin receptor binding in rat and human heart," Can J Cardiol, vol. 15, no. 11, pp. 1267-1273, 1999.

[188] Z. Diaz-Cabiale, M. Petersson, J. A. Narvaez, K. Uvnas-Moberg, and K. Fuxe, "Systemic oxytocin treatment modulates $\alpha 2$-adrenoceptors in telencephalic and diencephalic regions of the rat," Brain Res., vol. 887, no. 2, pp. 421-425, 2000.

[189] G. Pacheco-Lopez, M. B. Niemi, H. Engler, A. Engler, C. Riether, R. Doenlen, E. Espinosa, R. Oberbeck, and M. Schedlowski, "Weaken taste-LPS association during endotoxin tolerance," Physiol. Behav., vol. 93, no. 1-2, pp. 261-266, 2008.

[190] H. Engler, R. Doenlen, A. Engler, C. Riether, G. Prager, M. B. Niemi, G. PachecoLópez, U. Krügel, and M. Schedlowski, "Acute amygdaloid response to systemic inflammation," Brain. Behav. Immun., vol. 25, no. 7, pp. 1384-1392, 2011.

[191] V. N. Nikolic, T. Jevtovic-Stoimenov, D. Stokanovic, M. Milovanovic, R. VelickovicRadovanovic, S. Pesic, M. Stoiljkovic, G. Pesic, S. Ilic, M. Deljanin-Ilic, D. Marinkovic, N. Stefanovic, and S. M. Jankovic, "An inverse correlation between TNF alpha serum levels and heart rate variability in patients with heart failure," J. Cardiol., vol. 62, no. 1, pp. 37-43, 2013.

[192] V. A. Pavlov, H. Wang, C. J. Czura, S. G. Friedman, and K. J. Tracey, "The Cholinergic Anti-inflammatory Pathway: A Missing Link in Neuroimmunomodulation," Mol. Med., vol. 9, no. 5-8, pp. 125-134, 2003.

[193] V. A. Pavlov, "Cholinergic modulation of inflammation.," Int. J. Clin. Exp. Med., vol. 1, no. 3, pp. 203-212, 2008. 
[194] I. Zila, D. Mokra, J. Kopincova, M. Kolomaznik, M. Javorka, and A. Calkovska, "Heart rate variability and inflammatory response in rats with lipopolysaccharide-induced endotoxemia," Physiol Res, vol. 64 Suppl 5, pp. S669-76, 2016.

[195] C. G. Engeland, D. V Nielsen, M. Kavaliers, and K. P. Ossenkopp, "Locomotor activity changes following lipopolysaccharide treatment in mice: a multivariate assessment of behavioral tolerance.," Physiol. Behav., vol. 72, no. 4, pp. 481-91, 2001.

[196] L. Yuan, S. Liu, X. Bai, Y. Gao, G. Liu, X. Wang, D. Liu, T. Li, A. Hao, and Z. Wang, "Oxytocin inhibits lipopolysaccharide-induced inflammation in microglial cells and attenuates microglial activation in lipopolysaccharide-treated mice," $J$. Neuroinflammation, vol. 13, no. 1, p. 77, 2016.

[197] E. D. Reid, K. Fried, J. M. Velasco, and G. E. Dahl, "Correlation of rectal temperature and peripheral temperature from implantable radio-frequency microchips in holstein steers challenged with lipopolysaccharide under thermoneutral and high ambient temperatures," J. Anim. Sci., vol. 90, no. 13, pp. 4788-4794, 2012.

[198] J. a Barraza, N. S. Grewal, S. Ropacki, P. Perez, A. Gonzalez, and P. J. Zak, "Effects of a 10-day oxytocin trial in older adults on health and well-being.," Exp. Clin. Psychopharmacol., vol. 21, no. 2, pp. 85-92, 2013.

[199] M. Petersson, T. Lundeberg, and K. Uvnäs-Moberg, "Oxytocin enhances the effects of clonidine on blood pressure and locomotor activity in rats," J. Auton. Nerv. Syst., vol. 78, no. 1, pp. 49-56, 1999.

[200] K. Takayama, K. Yuhki, K. Ono, T. Fujino, A. Hara, T. Yamada, S. Kuriyama, H. Karibe, Y. Okada, O. Takahata, T. Taniguchi, T. lijima, H. Iwasaki, S. Narumiya, and F. Ushikubi, "Thromboxane A2 and prostaglandin F2 $\alpha$ mediate inflammatory tachycardia," Nat. Med., vol. 11, no. 5, pp. 562-566, 2005.

[201] T. Oka, K. Oka, T. Kobayashi, Y. Sugimoto, A. Ichikawa, F. Ushikubi, S. Narumiya, and C. B. Saper, "Characteristics of thermoregulatory and febrile responses in mice deficient in prostaglandin EP1 and EP3 receptors," J Physiol, vol. 551, pp. 945-954, 2003.

[202] N. T. Mowery, J. A. Morris, J. M. Jenkins, A. Ozdas, and P. R. Norris, "Core temperature variation is associated with heart rate variability independent of cardiac index: A study of 278 trauma patients," J. Crit. Care, vol. 26, no. 5, 2011.

[203] M. Petersson, P. Alster, T. Lundeberg, and K. Uvnäs-Moberg, "Oxytocin causes a long-term decrease of blood pressure in female and male rats," Physiol. Behav., vol. 60, no. 5, pp. 1311-1315, 1997. 
[204] S. Ehrentraut, S. Frede, H. Stapel, T. Mengden, C. Grohé, J. Fandrey, R. Meyer, and G. Baumgarten, "Antagonism of lipopolysaccharide-induced blood pressure attenuation and vascular contractility," Arterioscler. Thromb. Vasc. Biol., vol. 27, no. 10, pp. 2170-2176, 2007.

[205] M. F. Lutfi and M. Y. Sukkar, "Effect of blood pressure on heart rate variability," Khartoum Med. J., vol. 4, no. 1, pp. 548-553, 2011.

[206] A. Radaelli, P. Castiglioni, C. De Carlini, F. Soriano, M. Di Rienzo, and G. Mancia, "Infusion of e. coli lipopolysaccharides toxin in rats produces a severe impairment of baroreflex function in absence of blood pressure changes," J. Hypertens., vol. 28, p. e528, 2010.

[207] C. Vela, Z. Diaz-Cabiale, C. Parrado, M. Narvaez, R. Covenas, and J. A. Narvaez, "Involvement of oxytocin in the nucleus tractus solitarii on central cardiovascular control: Interactions with glutamate," J. Physiol. Pharmacol., vol. 61, no. 1, pp. 5965, 2010.

[208] J. F. Thayer, A. Loerbroks, and E. M. Sternberg, "Inflammation and cardiorespiratory control: The role of the vagus nerve," Respir. Physiol. Neurobiol., vol. 178, no. 3, pp. 387-394, 2011.

[209] Y. H. Hsieh, F. J. Jacono, and T. E. Dick, "Cardio-respiratory coupling is negligible in a rodent septic-model," FASEB J., vol. 26, 2012.

[210] M. Faghihi, A. M. Alizadeh, V. Khori, M. Latifpour, and S. Khodayari, "The role of nitric oxide, reactive oxygen species, and protein kinase $C$ in oxytocin-induced cardioprotection in ischemic rat heart," Peptides, vol. 37, no. 2, pp. 314-319, 2012.

[211] I. Silva and G. B. Moody, "An Open-source Toolbox for Analysing and Processing PhysioNet Databases in MATLAB and Octave," J. Open Res. Softw., vol. 2, no. 1, p. e27, 2014.

[212] H. Gonçalves, T. Henriques-Coelho, J. Bernardes, A. P. Rocha, A. Nogueira, and A. Leite-Moreira, "Linear and nonlinear heart-rate analysis in a rat model of acute anoxia," Physiol. Meas., vol. 29, no. 9, pp. 1133-1143, Sep. 2008.

[213] D. L. Eckberg and M. J. Eckberg, "Human sinus node responses to repetitive, ramped carotid baroreceptor stimuli.," Am. J. Physiol., vol. 242, no. 4, pp. H638-44, 1982.

[214] C. Pequeux, C. Breton, M.-T. Hagelstein, V. Geenen, and J.-J. Legros, "Oxytocin receptor pattern of expression in primary lung cancer and in normal human lung.," Lung Cancer, vol. 50, no. 2, pp. 177-188, 2005.

[215] M. L. Ogletree, "Pharmacology of prostaglandins in the pulmonary microcirculation.," 
Ann. N. Y. Acad. Sci., vol. 384, pp. 191-206, 1982.

[216] M. Zen, A. Ghirardello, L. laccarino, M. Tonon, C. Campana, S. Arienti, M. Rampudda, M. Canova, and A. Doria, "Hormones, immune response, and pregnancy in healthy women and SLE patients," Swiss Medical Weekly, vol. 140, no. 13-14. pp. 187-201, 2010.

[217] J. E. Acosta-Terriquez, M. A. Ramos-Martinez, L. M. Zamora-Aguilar, and J. MurilloLlanes, "Prevalence of urinary tract infection in hospitalized patients with preterm labor. [Spanish] TT - Prevalencia de infeccion de vias urinarias en pacientes hospitalizadas con amenaza de parto pretermino.," Ginecol. Obstet. Mex., vol. 82, no. 11, pp. 737-743, 2014.

[218] D. R. Velez, S. J. Fortunato, N. Morgan, T. L. Edwards, S. J. Lombardi, S. M. Williams, and R. Menon, "Patterns of cytokine profiles differ with pregnancy outcome and ethnicity," Hum. Reprod., vol. 23, no. 8, pp. 1902-1909, 2008.

[219] P. C. Greig, A. P. Murtha, C. J. Jimmerson, W. N. Herbert, B. Roitman-Johnson, and J. Allen, "Maternal serum interleukin- 6 during pregnancy and during term and preterm labor.," Obstet. Gynecol., vol. 90, no. 3, pp. 465-9, 1997.

[220] D. R. Velez, R. Menon, P. Thorsen, L. Jiang, H. Simhan, N. Morgan, S. J. Fortunato, and S. M. Williams, "Ethnic differences in interleukin 6 (IL-6) and IL6 receptor genes in spontaneous preterm birth and effects on amniotic fluid protein levels," Ann. Hum. Genet., vol. 71, no. 5, pp. 586-600, 2007.

[221] J. E. Thaxton and S. Sharma, "Interleukin-10: A Multi-Faceted Agent of Pregnancy," American Journal of Reproductive Immunology, vol. 63, no. 6. pp. 482-491, 2010.

[222] R. Druckmann and M. A. Druckmann, "Progesterone and the immunology of pregnancy," in Journal of Steroid Biochemistry and Molecular Biology, 2005, vol. 97, no. 5, pp. 389-396.

[223] P. Kumar and N. Magon, "Hormones in pregnancy," Niger Med J, vol. 53, no. 4, pp. 179-183, 2012.

[224] R. Sabat, "IL-10 family of cytokines," Cytokine Growth Factor Rev., vol. 21, no. 5, pp. 315-324, 2010.

[225] W. Ouyang, S. Rutz, N. K. Crellin, P. A. Valdez, and S. G. Hymowitz, "Regulation and Functions of the IL-10 Family of Cytokines in Inflammation and Disease," Annu. Rev. Immunol, vol. 29, pp. 71-109, 2011.

[226] WMA, "Declaration of Helsinki.," 1974.

[227] IOM, Weight Gain During Pregnancy: Reexamining the Guidelines, no. May. 2009. 
[228] Secretaría de Salud, "Norma Oficial Mexicana NOM-007-SSA2-1993, Atención de la mujer durante el embarazo, parto y puerperio y del recién nacido. Criterios y procedimientos para la prestación del servicio," D. Of. la Fed., pp. 1-22, 1995.

[229] United Nations Children's Fund and World Health Organization, Low Birthweight: Country, regional and global estimates. 2004.

[230] J. B. S. Garcia, A. M. Issy, and R. K. Sakata, "Citocinas e anestesia," Rev. Bras. Anestesiol., vol. 52, no. 1, pp. 86-100, Feb. 2002.

[231] R. Robles, R. Varela, S. Jurado, and F. Paez, "The Mexican version of the Beck Anxiety Inventory: Psychometric properties. [Spanish]. [References]," Rev. Mex. Psicol., vol. 18, no. 2, p. 218, 2001.

[232] T. Liukkonen, P. Räsänen, J. Jokelainen, M. Leinonen, M. R. Järvelin, V. B. MeyerRochow, and M. Timonen, "The association between anxiety and C-reactive protein (CRP) levels: Results from the Northern Finland 1966 Birth Cohort Study," Eur. Psychiatry, vol. 26, no. 6, pp. 363-369, 2011.

[233] C. Pitsavos, D. B. Panagiotakos, C. Papageorgiou, E. Tsetsekou, C. Soldatos, and C. Stefanadis, "Anxiety in relation to inflammation and coagulation markers, among healthy adults: The ATTICA Study," Atherosclerosis, vol. 185, no. 2, pp. 320-326, 2006.

[234] S. Vassiliadis, a Ranella, L. Papadimitriou, a Makrygiannakis, and I. Athanassakis, "Serum levels of pro- and anti-inflammatory cytokines in non-pregnant women, during pregnancy, labour and abortion.," Mediators Inflamm., vol. 7, no. 2, pp. 69-72, 1998.

[235] J. Z. Bakdash and L. R. Marusich, "Repeated Measures Correlation.," Front. Psychol., vol. 8, p. 456, 2017.

[236] M. M. Mukaka, "Statistics corner: A guide to appropriate use of correlation coefficient in medical research," Malawi Med. J., vol. 24, no. 3, pp. 69-71, 2012.

[237] J. Choi, P. S. C. Leung, C. Bowlus, and M. E. Gershwin, "IL-35 and Autoimmunity: a Comprehensive Perspective," Clin. Rev. Allergy Immunol., vol. 49, no. 3, pp. 327332, Dec. 2015.

[238] A. Zdanov, "Structural analysis of cytokines comprising the IL-10 family," Cytokine Growth Factor Rev., vol. 21, no. 5, pp. 325-330, Oct. 2010.

[239] U. R. Markert, Immunology of pregnancy. Karger, 2005.

[240] D. J. Gough, N. L. Messina, L. Hii, J. A. Gould, K. Sabapathy, A. P. S. Robertson, J. A. Trapani, D. E. Levy, P. J. Hertzog, C. J. P. Clarke, and R. W. Johnstone, "Functional Crosstalk between Type I and II Interferon through the Regulated 
Expression of STAT1," PLoS Biol., vol. 8, no. 4, p. e1000361, Apr. 2010.

[241] P. C. Arck, "Stress and pregnancy loss: role of immune mediators, hormones and neurotransmitters.," Am. J. Reprod. Immunol., vol. 46, no. 2, pp. 117-23, 2001.

[242] D. W. Sadowsky, M. J. Novy, S. S. Witkin, and M. G. Gravett, "Dexamethasone or interleukin-10 blocks interleukin-1 $1 \beta$-induced uterine contractions in pregnant rhesus monkeys," Am. J. Obstet. Gynecol., vol. 188, no. 1, pp. 252-263, 2003.

[243] S. P. Rajagopal, J. L. Hutchinson, D. A. Dorward, A. G. Rossi, and J. E. Norman, "Crosstalk between monocytes and myometrial smooth muscle in culture generates synergistic pro-inflammatory cytokine production and enhances myocyte contraction , with effects opposed by progesterone," vol. 21, no. 8, pp. 672-686, 2015.

[244] S. Astle, D. M. Slater, and S. Thornton, "The involvement of progesterone in the onset of human labour.," Eur. J. Obstet. Gynecol. Reprod. Biol., vol. 108, no. 2, pp. 17781, Jun. 2003.

[245] B. C. Choi, K. Polgar, L. Xiao, and J. a Hill, "Progesterone inhibits in-vitro embryotoxic Th1 cytokine production to trophoblast in women with recurrent pregnancy loss.," Hum. Reprod., vol. 15 Suppl 1, pp. 46-59, 2000.

[246] H. Fickenscher, S. Hor, H. Kupers, A. Knappe, S. Wittmann, and H. Sticht, "The interleukin-10 family of cytokines," Trends in Immunology, vol. 23, no. 2. pp. 89-96, 2002.

[247] S. Saito, A. Nakashima, T. Shima, and M. Ito, "Th1/Th2/Th17 and Regulatory T-Cell Paradigm in Pregnancy," American Journal of Reproductive Immunology, vol. 63, no. 6. pp. 601-610, 2010.

[248] J. Apuzzio, Y. Chan, A. Al-Khan, N. Illsley, P.-L. Kim, and S. Vonhaggen, "Secondtrimester amniotic fluid interleukin-10 concentration predicts preterm delivery.," J. Matern. neonatal Med., vol. 15, no. 5, pp. 313-7, 2004.

[249] G. L. Veith and G. E. Rice, "Interferon gamma expression during human pregnancy and in association with labour," Gynecol. Obstet. Invest., vol. 48, no. 3, pp. 163-167, 1999.

[250] N. Hanna, L. Bonifacio, P. Reddy, I. Hanna, B. Weinberger, S. Murphy, D. Laskin, and S. Sharma, "IFN-gamma-Mediated Inhibition of COX-2 Expression in the Placenta from Term and Preterm Labor Pregnancies," Am. J. Reprod. Immunol., vol. 51, no. 4, pp. 311-318, Apr. 2004.

[251] A. R. Fuchs, F. Fuchs, P. Husslein, and M. S. Soloff, "Oxytocin receptors in the human uterus during pregnancy and parturition.," Am. J. Obstet. Gynecol., vol. 150, no. 6, 
pp. 734-41, 1984.

[252] M. do Carmo Leal, A. P. Esteves Pereira, R. M. Soares Madeira Domingues, M. M. Theme Filha, M. A. Bastos Dias, M. Nakamura-Pereira, M. H. Bastos, and S. Granado Nogueira da Gama, "Obstetric interventions during labor and childbirth in Brazilian low-risk women ," Cad.Sa\{ú\}de P\{ú\}blica, vol. 30 Sup:S1-. p. , 2014.

[253] J. L. Neal, J. M. Lamp, N. K. Lowe, S. L. Gillespie, L. T. Sinnott, and D. O. McCarthy, "Differences in inflammatory markers between nulliparous women admitted to hospitals in preactive vs active labor," Am. J. Obstet. Gynecol., vol. 212, no. 1, p. 68e1-68e8, 2015.

[254] E. J. Bridges, S. Womble, M. Wallace, and J. McCartney, "Hemodynamic monitoring in high-risk obstetrics patients, I. Expected hemodynamic changes in pregnancy.," Crit. Care Nurse, vol. 23, no. 4, pp. 53-62, 2003.

[255] Q. Fu and B. D. Levine, "Autonomic circulatory control during pregnancy in humans," Semin. Reprod. Med., vol. 27, no. 4, pp. 330-337, 2009.

[256] T. M. Cooper, P. S. McKinley, T. E. Seeman, T.-H. Choo, S. Lee, and R. P. Sloan, "Heart rate variability predicts levels of inflammatory markers: Evidence for the vagal anti-inflammatory pathway," Brain. Behav. Immun., vol. 49, no. December, pp. 94$100,2015$.

[257] C. D. Kuo, G. Y. Chen, M. J. Yang, H. M. Lo, and Y. S. Tsai, "Biphasic changes in autonomic nervous activity during pregnancy.," Br. J. Anaesth., vol. 84, no. 3, pp. 323-329, 2000.

[258] Task Force, "Heart rate variability. Standards of measurement, physiological interpretation, and clinical use. Task Force of The European Society of Cardiology and the North American Society for Pacing and Electrophysiology," Eur Hear. J., vol. 17, no. 3, pp. 354-381, 1996.

[259] M. J. Burgueño, J. L. García-Bastos, and J. M. González-Buitrago, "Las curvas ROC en la evaluación de las pruebas diagnósticas," Med. Clin. (Barc)., vol. 104, no. 17, pp. 661-670, 1995.

[260] J. J. Reyes, M. a Peña, J. C. Echeverría, M. T. García, M. R. Ortiz, C. Vargas, and R. González-Camarena, "Short-term heart rate dynamics of women during labor.," Conf. Proc. IEEE Eng. Med. Biol. Soc., vol. 2011, pp. 1929-32, 2011.

[261] P. Cunningham and S. J. Delany, "k-Nearest Neighbour Classifiers," Mult. Classif. Syst., vol. 34, no. APRIL 2007, pp. 1-17, 2007.

[262] C. Prahm, K. Eckstein, M. Ortiz-Catalan, G. Dorffner, E. Kaniusas, and O. C. 
Aszmann, "Combining two open source tools for neural computation (BioPatRec and Netlab) improves movement classification for prosthetic control," BMC Res. Notes, vol. 9, no. 1, p. 429, 2016.

[263] J. Castillo, K. Cortez, A. Wong, and P. Villalpando, "Analisis de correlacion canonica (ACC) e investigacion cientifica (Canonical correlation analysis and scientific research)," Innovaciones de Negocios, vol. 4, no. 2, pp. 405-422, 2007.

[264] B. G. Tabachnick and L. S. Fidell, "Tabachnick, Fidell_2001.pdf," Using Multivariate Statistics. p. 1008, 2001.

[265] M. a Peña, J. C. Echeverría, M. T. García, M. R. Ortiz, a Martínez, C. Vargas-Garcia, and R. González-Camarena, "Short-term heart rate dynamics of pregnant women.," Auton. Neurosci., vol. 159, no. 1-2, pp. 117-122, 2011.

[266] R. Karasik, N. Sapir, Y. Ashkenazy, P. C. Ivanov, I. Dvir, P. Lavie, and S. Havlin, "Correlation differences in heartbeat fluctuations during rest and exercise," Phys. Rev. E - Stat. Nonlinear, Soft Matter Phys., vol. 66, no. 6, pp. 6-9, 2002.

[267] J. J. Collins, C. E. Lin, H. R. Berthoud, and R. E. Papka, "Vagal afferents from the uterus and cervix provide direct connections to the brainstem," Cell Tissue Res., vol. 295, no. 1, pp. 43-54, 1999.

[268] V. A. Holmes, J. M. W. Wallace, W. S. Gilmore, P. McFaul, and H. D. Alexander, "Plasma levels of the immunomodulatory cytokine interleukin-10 during normal human pregnancy: A longitudinal study," Cytokine, vol. 21, no. 6, pp. 265-269, 2003.

[269] N. Suzuki, J. Sugawara, Y. Kimura, S. Nagase, K. Okamura, and N. Yaegashi, "Assessment of maternal heart-rate variability during labor using wavelet-based power spectral analysis," Gynecol. Obstet. Invest., vol. 74, no. 1, pp. 35-40, 2012.

[270] M. A. M. D. Q. Carreira, A. B. Nogueira, F. M. Pena, M. G. Kiuchi, R. C. Rodrigues, R. D. R. Rodrigues, J. P. S. De Matos, and J. R. Lugon, "Heart Rate Variability Correlates to Functional Aerobic Impairment in Hemodialysis Patients.," Arq. Bras. Cardiol., pp. 493-501, 2015.

[271] K. L. Thornburg, S. L. Jacobson, G. D. Giraud, and M. J. Morton, "Hemodynamic changes in pregnancy.," Semin. Perinatol., vol. 24, no. 1, pp. 11-14, 2000.

[272] M. Malik, "Time-Domain Measurement of Heart Rate Variability," Card. Electrophysiol. Rev., vol. 1, no. 3, pp. 329-334, 1997.

[273] J. A. Lothian, "Do not disturb: the importance of privacy in labor.," J. Perinat. Educ., vol. 13, no. 3, pp. 4-6, 2004.

[274] M. R. Putnam, L. E. Rice, R. P. Wettemann, K. S. Lusby, and B. Pratt, "Clenbuterol 
(planipart(trade mark)) for the postponement of parturition in cattle.," Theriogenology, vol. 24, no. 4, pp. 385-93, 1985.

[275] C. Nagel, L. Trenk, C. Aurich, N. Ille, M. Pichler, M. Drillich, W. Pohl, and J. Aurich, "Sympathoadrenal balance and physiological stress response in cattle at spontaneous and PGF2??-induced calving," Theriogenology, vol. 85, no. 5, pp. 979 985, 2016.

[276] J. J. Reyes-Lagos, "Uso de clasificadores en la dinámica de las fluctuaciones de la frecuencia cardiaca materna durante el trabajo de parto," Congr. Nac. Ing. Biomédica, vol. 1, pp. 48-51, 2012.

[277] M. Østensen, F. Förger, J. L. Nelson, A. Schuhmacher, and G. Hebisch, "Pregnancy in patients with rheumatic disease: anti- inflammatory cytokines increase in pregnancy and decrease post partum," Ann Rheum Dis, vol. 64, pp. 839-844, 2005.

[278] C. Eidenschenk, S. Rutz, O. Liesenfeld, and W. Ouyang, "Role of IL-22 in microbial host defense," Current Topics in Microbiology and Immunology, vol. 380. pp. 213236, 2014.

[279] D. Medenwald, C. A. Swenne, H. Loppnow, J. A. Kors, D. Pietzner, D. Tiller, J. Thiery, S. Nuding, K. H. Greiser, J. Haerting, K. Werdan, and A. Kluttig, "Prognostic relevance of the interaction between short-term, metronome-paced heart rate variability, and inflammation: Results from the population-based CARLA cohort study," Europace, vol. 19, no. 1, pp. 110-118, 2017.

[280] A. Haarala, M. Kähönen, C. Eklund, J. Jylhävä, T. Koskinen, L. Taittonen, R. Huupponen, T. Lehtimäki, J. Viikari, O. T. Raitakari, and M. Hurme, "Heart rate variability is independently associated with C-reactive protein but not with Serum amyloid A. The Cardiovascular Risk in Young Finns Study," Eur. J. Clin. Invest., vol. 41, no. 9, pp. 951-957, 2011.

[281] T. G. Buchman, "The community of the self.," Nature, vol. 420, no. 6912, pp. 246251, 2002.

[282] L. Chen and Y. Hao, "Feature Extraction and Classification of EHG between Pregnancy and Labour Group Using Hilbert-Huang Transform and Extreme Learning Machine," Comput. Math. Methods Med., vol. 2017, pp. 1-9, 2017. 
ASOCIACIÓN DE UNA RESPUESTA

INFLAMATORIA CON LA DINÁMIC

DE LAS FLUCTUACIONES DE LA

FRECUENCIA CARDIACA DURANTE

EL TRABAJO DE PARTO A

TÉRMINO Y DE BAJO RIESGO

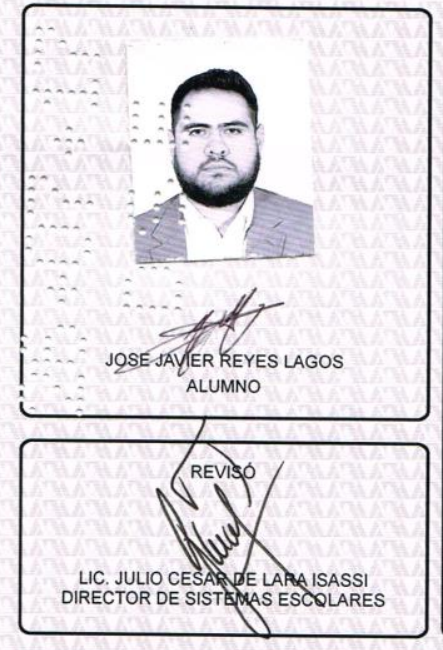

Bajo la Presidencia del primero y con carácter de Secretaria la última, se reunieron a la presentación de la Disertación pública cuya denominación aparece al margen, para la obtención del grado de:

DOCTOR EN CIENCIAS (INGENIERIA BIOMEDICA)

DE: JOSE JAVIER REYES LAGOS

$y$ de acuerdo con el artículo 78 fracción IV del Reglamento de Estudios Superiores de la Universidad Autónoma Metropolitana, los miembros del jurado resolvieron:

\section{Aprobar}

Acto continuo, el presidente del jurado comunicó al interesado el resultado de la evaluación $y$, en caso aprobatorio, le fue tomada la protesta.
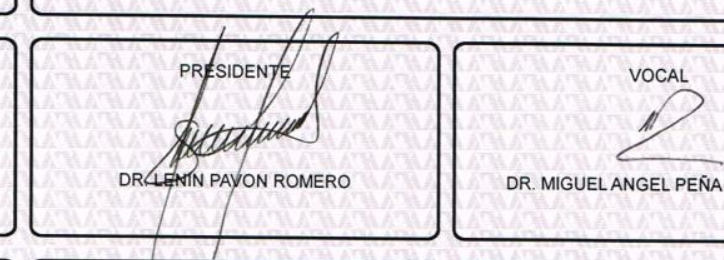

DR. MIGUEL ANGEL PENA CASTILLO

DR. JOSE GILBERTO CORDOBA HERRERA

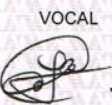

DRA. CLAUDIA LERMA GONZALEZ

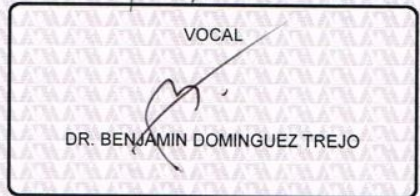

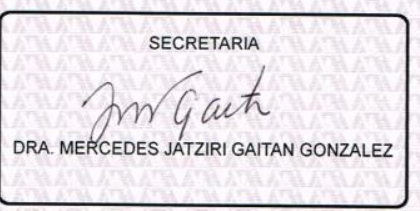

